\title{
The Implications of the ASEAN Free Trade Area (AFTA) on Agricultural Trade (A Recursive Dynamic General Equilibrium Analysis)
}

\author{
Dissertation \\ zur Erlangung des Doktorgrades \\ der Fakultaet fuer Agrarwissenschaften \\ der Georg-August-Universitaet Goettingen \\ vorgelegt von \\ Dedi Budiman Hakim \\ Geboren in Sumedang (Indonesien)
}

Gefordert von dem Deutschen Akademischen Austauschdienst

Institut für Agrarökonomie

Georg-August-Universität

Göttingen Germany 
D7

1. Referent:

Prof. Dr. S. Tangermann

2. Korreferent:

Prof. Dr. A. Haufler

Tag der mündlichen Prüfung: 21. Februar 2002 


\section{Acknowledgement}

I would like to take this opportunity to express my gratitude to my supervisor, Prof. Dr. S. Tangermann for his guidance, dedication and support, which enabled me to complete my dissertation. My appreciation also goes to Prof. Dr. A. Haufler for his comments and criticisms during the completion of this study.

I am very indebted especially to Dr. M. Banse for his invaluable advice, help and suggestions during my research preparation, computer programming, and final completion of my dissertation. Warm and conducive academic and social environment in the Institute for Agricultural Economics Georg-August-University has certainly contributed to the accomplishment of my study in Goettingen. I would like to thank Keneuoe Thinyane and Joshua Woodbeck for the English editing of this work.

My sincere thanks are extended to the Deutscher Akademischer Austauschdienst (German Academic Exchange Service, DAAD) for their financial support that made it possible for me to attain a $\mathrm{PhD}$ degree in Germany and enabled my family to have a staying permit during my study at the Georg-August-University Goettingen. I also thank the Indonesian government, particularly Bogor Agricultural University, for providing me with more than five years leave. Furthermore, this work is dedicated to my beloved wife Vitti Sawitry, my son Ramadhan Pratama Budiman and my daughter Raudha Salsabila Hakim, for their patience, understanding and sacrifice. I always received endless love and very strong, continual encouragement. They have been the motivational force in my life. Greatest thanks I express to my mother, Nurjanah Wahju, and my parents in law, Titi Sumaryati and Moedjiono, for their endless prayers and continual supports. Above all I thank God (Allah), Almighty for his mercy and everything given to me and my family. 


\section{Table of Content}

Chapter

Title

Page

Acknowledgement

Table of Content

List of Tables

List of Figures

List of Appendices

Abbreviations

\section{i}

ii

iv

vi

vii

ix

I

Introduction

ASEAN Economy and AFTA Agreement 5

II

2. 1 .

The Patterns of Economic Growth and Development

2. 2.

ASEAN Free Trade Area (AFTA) Agreement 13

2. 3.

APEC Liberalisation

2. 4.

ASEAN Economy and Trade Flow

2. 5 .

Export Destinations and Import Sources

2. 5.1

Export Destinations

2. 5.2 .

Import Sources

The Structure of Multicountry and Multisector Model for ASEAN

3. 1 .

Free Trade Area (AFTA)

3. 2.

A Basic General Equilibrium Model

Advantages and Disadvantages of CGE-Model 41

3. 3.

Calibration Procedure

3. 4.

The Production Structure of the Model

3. 4. 1.

Production Structure

3. 4. 2.

Value Added and Composite Intermediate Products

3. 4. 2. 1.

Primary Input Demand

3. 4. 2. 2.

Demand for Intermediates

3. 5.

Foreign Trade and Product Differentiation

3. 5.1 .

Demand for Domestic and Imported Goods

3. 5.2.

Bilateral Trade

3. 6.

Regional Income and Expenditure

3. 7.

Demand Structure

3. 7.1 .

Private Demand

3. 7.2.

Public Demand

3. 8 .

Investment

General Equilibrium Conditions 
Discussion of Scenario Analysis Results 82

5. 1 .

Definition of the Baseline Scenario

5. 2

Results of the Baseline Scenario

5. 3

AFTA and APEC Trade Liberalisation Scenario

5. 3.1

Results from AFTA and APEC Scenarios

119

5. 3.2

Factor Allocation

143

5. 4

Effects on Trade Creation and Diversion

150

5.5

Sensitivity Analysis

159

VI

Conclusions and Implications

163

References

173

Appendices

186 


\section{List of Tables}

No Title

Page

2. $1 \quad$ Selected Basic Indicators of ASEAN Countries 7

2. 2 Sectoral Value Added Share of GDP (\%) 7

2. 3 Sectoral Share of Employed Labour Force (\%) 8

2. 4 Regional Free Trade Arrangement - Share of World Trade, 1998

2. 5 ASEAN Trade with Major Trading Partners (US\$ million) 10

2. 6 Economic Activity by Region (US\$ 10 billion), 1995

2. 7 Sectoral Shares of GDP, 1995 (\%) 26

2. 8 Shares of Individual Sector in the Total Export Value, 1995 (\%) 27

2. 9 Shares of Individual Sector in the Total Import Value, 1995 (\%) 29

2. 10 Net Trade Balance Position (US\$ billion) 30

2. 11 Destinations of ASEAN Export, 1995 (Percent of Total Value of Exports) 31

2. 12 Sources of ASEAN Imports, 1995 (Percent of Total Value of Imports) 33

3. 1 Equations for a CGE Model of an Open Economy 40

$\begin{array}{lll}\text { 4. } 1 & \text { Sectoral Aggregation } & 75\end{array}$

$\begin{array}{lll}4.2 & \text { Country (Region) Aggregation } & 76\end{array}$

$\begin{array}{lll}\text { 4. } 3 & \text { Income Elasticities } & 78\end{array}$

4. 4 Substitution and Transformation Elasticities $\quad 79$

5. 1 Assumption on Exogenous Growth Rates 83

5. 2 Possible Outcomes of the Millennium Round 84

5. 3 Weighted Aggregate Import Tariff Levels, 1995 (\%) 85

5. 4 Indonesia's Import Tariff Rates, $1995(\%)$

5. 5 Malaysia’s Import Tariff Rates, $1995(\%)$

5. 6 The Philippine’s Import Tariff Rates, 1995 (\%) 90

5. 7 Singapore's Import Tariff Rates, $1995(\%) \quad 91$

5. 8 Thailand's Import Tariff Rates, 1995 (\%) 92

5. 9 Average Rates of Export Tax, $1995(\%) \quad 93$

5. 10 Output Tax Rates, 1995 (\%) 94

5. 11 Production of Selected Agricultural Products (000 MT) 106

5. 12 Average Annual Output Changes, Relative to the Baseline Scenario (\%) 131

5. 13 Average Annual Changes in the Sectoral Export, Relative to the Baseline 133 Scenario (\%)

5. 14 Average Annual Changes in the Sectoral Imports, Relative to the Baseline 135 Scenario (\%)

5. 15 Average Import Shares of Unprocessed Agricultural Products 141 under the Baseline Scenario (\%)

5. 16 Average Import Shares of Processed Agricultural Products 141 under the Baseline Scenario (\%)

5. 17 Average Import Shares of Non-agricultural Products 141

5. 18 Average Import Shares of Unprocessed Agricultural Products (\%) 142

5. 19 Average Import Shares of Processed Agricultural Products (\%) 142

5. 20 Average Import Shares of Non-agricultural Products (\%) 142

5. 21 Average Changes in Aggregate Production, Export and Import under the 143

5. 22 Indonesia. Average Annual Changes of Demand for Primary Factors - 146 Relative to the Baseline (\%) 
5. 23 Malaysia. Average Annual Changes of Demand for Primary Factors

Relative to the Baseline Scenario (\%)

5. 24 The Philippines. Average Annual Changes of Demand for Primary Factor

Relative to the Baseline Scenario (\%)

5. 25 Singapore. Average Annual Changes of Demand for Primary Factor -

Relative to the Baseline Scenario (\%)

5. 26 Thailand. Average Annual Changes of Demand for Primary Factor -

Relative to the Baseline Scenario (\%)

5. 27 Indonesia. Average Annual Import Changes Relative to the Baseline Scenario (US\$ million)

5. 28 Malaysia. Average Annual Import Changes Relative to the Baseline Scenario (US\$ million)

5. 29 Philippines. Average Annual Import Changes Relative to the Baseline Scenario (US\$ million)

5. 30 Singapore. Average Annual Import Changes Relative to the Baseline Scenario (US\$ million)

5. 31 Thailand. Average Annual Import Changes Relative to the Baseline 158 Scenario (US\$ million)

5. 32 Average Changes in Aggregate Production, Export and Import with High Armington Elasticities 


\section{List of Figures}

No Title

Page

3.1 Flow Chart Outlining Calibration Procedures and Model Use in 44 Typical Applied General Equilibrium Model

3.2 Nested Production Structure $\quad 48$

3.3 Nested Foreign Trade Structure 53

$\begin{array}{lll}4.1 & \text { Path of Technological Change } & 71\end{array}$

5.1 A Path of Border Tariff Reduction under Post and Next WTO Negotiation 96

5.2 The Development of Regional GDP (1995=100) 98

5.3 The Development of Regional Export $(1995=100) \quad 100$

5.4 The Development of Regional Import (1995=100) 101

5.5 The Development of Investment (1995=100) 101

5.6 The Development of Real Exchange Rates (1995=100) 102

5.7 The Development of Real Wages (1995=100) 104

5.8 The Development of Production and Factor Demand in the Processed Meat 116 Sector in Malaysia $(1995=100)$

$5.9 \quad$ A Path of Import Tariff Reduction under AFTA Scenario 118

5.10 A Path of Import Tariff Reduction under APEC Scenario 119

5.11 The Impact of Different Regional Economic Integration on Real GDP 122 Relative to the Baseline Scenario (\%)

5.12 The Impact of Different Regional Economic Integration on Total Export 125 Relative to the Baseline Scenario (\%)

5.13 The Impact of Different Regional Economic Integration on Total Import 126 Relative to the Baseline Scenario (\%)

5.14 The Impact of Different Economic Integration on Investment Relative to 126 Baseline Scenario (\%)

5.15 The Impact of Different Regional Economic Integration on Real Exchange 127 Rate Relative to the Baseline Scenario (\%) 


\section{List of Appendices}

No

Table 5.1

Table 5.2

Table 5.3

Table 5.4

Table 5.5

Table 5.6

Table 5.7

Table 5.8

Table 5.9

Table 5.10

Table 5.11

Figure 2.1

Figure 2.2

Figure 2.3

Figure 2.4

Figure 2.5

Figure 2.6

Figure 2.7

Figure 2.8

Figure 2.9

Figure 2.10

Figure 2.11

Figure 2.12

Figure 2.13

Figure 2.14

Figure 2.15

Figure 2.16

Figure 2.17

Figure 2.18

Figure 2.19

Figure 2.20

Figure 2.21

Figure 2.22

Figure 5.1
Title

Page

Weighted Average Post Uruguay Import Tariff Levels (\%)

187

Indonesia. Average Annual Import Changes under the AFTA

188

Scenario Relative to the Baseline Scenario (US\$ million)

Malaysia. Average Annual Import Changes under the AFTA

189

Scenario Relative to the Baseline Scenario (US\$ million)

Philippines. Average Annual Import Changes under the AFTA

190

Scenario Relative to the Baseline Scenario (US\$ million)

Singapore. Average Annual Import Changes under the AFTA

191

Scenario Relative to the Baseline Scenario (US\$ million)

Thailand. Average Annual Import Changes under the AFTA

192

Scenario Relative to the Baseline Scenario (US\$ million)

Indonesia. Average Annual Import Changes under the APEC

Scenario Relative to the Baseline Scenario (US\$ million)

Malaysia. Average Annual Import Changes under the APEC

Scenario Relative to the Baseline Scenario (US\$ million)

Philippines. Average Annual Import Changes under the APEC

Scenario Relative to the Baseline Scenario (US\$ million)

Singapore. Average Annual Import Changes under the APEC

Scenario Relative to the Baseline Scenario (US\$ million)

Thailand. Average Annual Import Changes under the APEC

Scenario Relative to the Baseline Scenario (US\$ million)

194

195

196

197

Destination of Rice Export (\%)

198

Destination of Cereal Export (\%)

198

Destination of Oil Seds Export (\%)

199

Destination of Other Crops Export (\%) 199

Destination of Livestock Export (\%) 200

Destination of Processed Meat Export (\%) 200

Destination of Processed Milk Export (\%) 201

Destination of Vegetable Oil Export (\%) 201

Destination of Processed Other Crop Export (\%) 202

Destination of Sugar Export (\%) 202

Destination of Beverages and Tobacco Export (\%) 203

Sources of Rice Import (\%) 203

Sources of Cereal Import (\%) 204

Sources of Oil Seeds Import (\%) 204

Sources of Other Crop Import (\%) 205

Sources of Livestock Import (\%) 205

Sources of Processed Other Crop Import (\%) 206

Sources of Processed Meat Import (\%) 206

Sources of Processed Milk Import (\%) 207

Sources of Vegetable Oil Import (\%) 207

Sources of Sugar Import (\%) 208

Sources of Beverage and Tobacco Import (\%) 208

The Development of Rice Production (1995=100) 209 
Figure 5.2

Figure 5.3

Figure 5.4

Figure 5.5

Figure 5.6

Figure 5.7

Figure 5.8

Figure 5.9

Figure 5.10

Figure 5.11

Figure 5.12

Figure 5.13

Figure 5.14

Figure 5.15

Figure 5.16

Figure 5.17

Figure 5.18

Figure 5.19

Figure 5.20

Figure 5.21

Figure 5.22

Figure 5.23

Figure 5.24

Figure 5.25

Figure 5.26

Figure 5.27

Figure 5.28

Figure 5.29

Figure 5.30

Figure 5.31

Figure 5.32

Figure 5.33

Figure 5.34

Figure 5.35
The Development of Cereal Production (1995=100)

The Development of Oil Seeds Production $(1995=100)$

The Development of Other Crop Production (1995=100)

The Development of Livestock Production (1995=100)

The Development of Processed Other Crop Production (1995=100)

The Development of Processed Meat Production (1995=100)

The Development of Processed Milk Production $(1995=100)$

The Development of Vegetable Oil Production (1995=100)

The Development of Sugar Production (1995=100)

The Development of Beverage and Tobacco Production (1995=100)

The Development of Rice Export (1995=100)

The Development of Cereal Export $(1995=100)$

The Development of Oil Seeds Export $(1995=100)$

215

The Development of Other Crop Export (1995=100)

216

The Development of Livestock Export (1995=100)

216

The Development of Processed Other Crop Export (1995=100) 217

The Development of Processed Meat Export $(1995=100)$

The Development of Processed Milk Export $(1995=100) \quad 218$

The Development of Vegetable Oil Export $(1995=100)$

The Development of Sugar Export (1995=100) 219

The Development of Beverage and Tobacco Export (1995=100) 219

The Development of Rice Import $(1995=100) \quad 220$

The Development of Cereal Import $(1995=100) \quad 220$

The Development of Oil Seeds Import $(1995=100)$

The Development of Other Crop Import $(1995=100)$

The Development of Livestock Import $(1995=100)$

The Development of Processed Other Crop Import (1995=100) 222

The Development of Processed Meat Import (1995=100) 223

The Development of Processed Milk Import (1995=100) 223

The Development of Vegetable Oil Import $(1995=100)$

The Development of Sugar Import (1995=100) 224

The Development of Beverage and Tobacco Import (1995=100) 225

The Development of Land Rent (1995=100) 225

The Development of Capital Rent (1995=100) 226 


\section{Abbreviations}

ACCSQ

AEM

AFTA

AMAD

APEC

ASEAN

ATCEG

avg.

BULOG

CAPs

CD

CEFTA

CEPT

CER

CES

CET

CET

CGE

COCAF

CRTS

CUSTA

EFTA

EU

EUR

EVSL

FAO

FDI

FTA

GAMS

GATT

GDP

GE

GTAP

IAPs

IDN

IMF

ITWG

JPN

LES

LoI

MAPA

MERCOSUR

MFA

MOP

MPSGE

MYS
ASEAN Consultative Committee for Standards and Quality ASEAN Economic Ministers

ASEAN Free Trade Area

Agricultural Market Access Database

Asia Pacific Economic Co-operation

Association of Southeast Asian Nations

Agricultural Technical Cooperation Experts’ Group

Average

National Logistics Agency/Badan Usaha Logistik

Collective Action Plans

Cobb Douglas

Central European Free Trade Agreement

Common Effective Preferential Tariff

Close Economic Relation

Constant Elasticity of Substitution

Constant Elasticity of Transformation

Common External Tariff

Computable General Equilibrium

Committee on Food, Agriculture and Forestry

Constant Return to Scale

Canada-United States Free Trade Agreement

European Free Trade Association

European Union

European Union

Early Voluntary Sector Liberalisation

Food and Agricultural Organisation

Foreign Direct Investment

Free Trade Area

General Algebraic Modelling System

General Agreement on Tariffs and Trade

Gross Domestic Product

General Equilibrium

Global Trade Analysis Project

Individual Action Plans

Indonesia

International Monetary Fund

Interim Technical Working Group

Japan

Linear Expenditure System

Letter of Intent

Manila Action Plan

Common Market of the Southern Cone

Multi Fibre Arrangement

Margin of Preference

Mathematical Programming System for General Equilibrium

Analysis

Malaysia 
NAFTA

NIC

NTBs

OECD

PDR

PHL

ROW

SGP

THA

USA
North American Free Trade Area

Newly Industrialised Country

Non Tariff Barriers

Organisation for Economic Co-operation and Development People Democratic Republic

The Philippines

Rest of the World

Singapore

Thailand

United States of America 


\section{Chapter I}

\section{Introduction}

In the late $20^{\text {th }}$ century, the world witnessed the increasing establishment of regional economic integration pursued by not only developed countries but also by developing countries. In fact, the emergence of regional integration agreements (RIAs) especially in developing countries has taken place several years ago. However, compared to the regionalism that emerged in the 1960s, the objective or motivation behind the recent RIA is different in some respects. The current RIAs tend to put emphasis on the outwardlooking policy and replace the policy of import substitution, which was inward looking. Additionally, developing countries move towards with developed countries to pursue an agreement on trade as a case of NAFTA (Mexico - USA), and APEC which were proposed by several countries in ASIA PACIFIC Rim. ${ }^{1}$

A successful history of the integration of Europe (the European Union) and the challenge of North American Free Trade Area have forced countries in ASEAN region to re-evaluate their past co-operation and strengthen their own co-operative arrangements. This is because both developments may certainly affect the economic structure (trade) of the ASEAN countries. In addition for two decades, United States and Europe remained a major trading partner of ASEAN countries. Driven by the emerging markets in several regions such as China and Southeast Asia, intra-regional trade among ASEAN has been profound. The flow of intra-regional investment has also complemented the growth of intra-regional trade on reinforcing the inter-dependence of ASEAN economies. The increase in foreign direct investment in this region reflects the improved economic environment as a result of the past and current government policies towards foreign investors. More important, in response to the open world economy, economic deregulation and trade liberalisation provide a solid foundation for the success of regional co-operation. In 1992 the ASEAN nations reviewed their past and current trade agreement and agreed to move to a deeper economic cooperation by establishing the so-called ASEAN Free Trade Area (AFTA).

\footnotetext{
${ }^{1}$ With the diverse nature of the economies, cultures and political systems prevent the efforts at integration. Therefore, the formation of integration like European style is inappropriate in this region (JOSLING, 1993). For example, some developing countries would argue for the shake of protection of infant industry and due to the past economic system, China and Vietnam would ask for special treatment (YOUNG, 1993).
} 
The establishment of AFTA, however, raised criticisms and concerns due to the fact that intra- trade among ASEAN countries remains relatively low, ranging from $18 \%$ to $22 \%$ of total ASEAN trade, similarity in factor endowments, and wide income disparity ${ }^{2}$. Besides problems in domestic politics still exist. Therefore, not surprisingly, AFTA is still in its infancy in terms of its economic impact to the members (OECD, 1995). For example, compared with tariff reductions applied by OECD countries, the tariff reduction proposed by AFTA is still higher than those in developed countries, thereby raising a question, whether AFTA tariff elimination would boost intra AFTA trade. The East Asian market, especially Japan becomes a major target of ASEAN products and also trade with other trading partners improves remarkably. Trade with its major ASEAN trading partners (Japan, USA and EU) contributes nearly 50 \% to total ASEAN trade. The 1992 agreement also excluded agricultural products from tariff reduction. Therefore, the effectiveness of the establishment of AFTA is widely questionable (see DE MELO, PANAGRYA and RODRIK, 1993).

In response to these criticisms especially in the context of excluding agricultural products in the AFTA agreement, the members revised the initial agreement and included unprocessed agricultural products. They also agreed upon a time schedule to liberalise this sector. For instance, the import tariff for rice that is regarded as a highly sensitive product will be $20 \%$ in 2010. All products that are included into a normal track reduction will have $0-5 \%$ of import tariff in 2003. Little is known about the impact of AFTA on trade in agricultural products. Most studies focusing on AFTA issues analysed the impact of AFTA on a very aggregated product basis. In addition, these studies applied either a partial equilibrium analysis or a static general equilibrium model. As a result these studies neglected an impact of tariff reduction, for example on productions of other products, exports and imports. Therefore, since a full implementation of the AFTA tariff reduction will come in effect in 2010, study concentrating on this issue is highly recommended.

Using a recursive dynamic multi-region general equilibrium model, this study includes disaggregated agricultural products; i.e. rice, cereals, oil seeds, livestock, other crops,

\footnotetext{
${ }^{2}$ In December 1995, Vietnam was accepted to become a member of Asean and is automatically required to liberalise her markets as proposed on AFTA agreement with the exception that at least all agricultural products which are temporarily excluded should be included at the beginning of 2000 and in the end of 2006. Other South East Asian countries such as Cambodia, Laos and Myanmar are being considered to be a member of ASEAN, leading to an increasingly wide income disparity among ASEAN members.
} 
vegetable oils, processed meat, processed milk, processed other crop, sugar, as well as beverage and tobacco products. The widely used GTAP database is applied in this study. And a standard GTAP model is applied however with some modifications at some places. The inclusion of beverages and tobacco in this study is due to the fact that these products especially in Indonesia, Malaysia and Singapore are regarded as a religiously unacceptable consumer good. Hence, a separate disaggregation is required. Beside agricultural products, non-agricultural sectors are also included such as textile and clothing, mining and mineral products, manufacturing and services. The choice of the commodities or sector reflects the importance of these sectors in ASEAN economics and also maintains a manageable size of model.

The structure of this study is as follows. Chapter 2 describes the ASEAN economics and the AFTA agreement. A remarkable economic growth experienced by ASEAN economies was due to outward policies where the ASEAN member countries considerably liberalise their trade regimes. An industrial transformation has also taken place with a decline in agricultural contribution to national GDP. The following chapter describes the process of AFTA agreement and how agricultural products are treated. ASEAN trade flows are also included to identify the likely impact of AFTA trade liberalisation.

Since this study applies a general equilibrium analysis, the outline of this model including interaction among sectors and economic agents, a discussion of the strengths and weaknesses of the CGE model and the process of calibration is presented in Chapter 3. Detailed model specifications of the multi region general equilibrium model developed in this study are also described in this Chapter. First of all the Chapter 3 begins with the behaviour of producers (producing sectors) and consumers of final demand (private and public households). A treatment of exported goods, imported goods and domestic goods is also provided by assuming imperfect substitutability between exported and domestic goods; and between imported and domestic goods. In addition modeling demand for imported goods from different import sources is also discussed in this chapter. This issue is important since a country in question imports goods from different exporting countries. Chapter 4 discusses the development of a recursive dynamic CGE model. As mentioned earlier this study uses the GTAP database. The description of the GTAP database, the aggregation of products and regions, and the selection of elasticities are provided in this Chapter 
The results of the simulation scenarios are presented and discussed in detail in Chapter 5. Three scenarios are made to represent the commitment of ASEAN members to liberalise their trade regimes under WTO and next WTO Round (Doha Round), APEC and AFTA agreement. In this regard, a simulation focusing on the impact of the Doha Round is very important. This is because most WTO members have been committed to reducing further trade barriers in forms of import tariff, export subsidy and output subsidy under the WTO auspices. At present, no studies have been done to examine this issue at the ASEAN level and at the level of much disaggregated products. However, before proceeding to the discussion of the results, this chapter begins with the description of bilateral import tariff level between ASEAN members and the simulation scenarios implemented in this study. To what extent the AFTA and the APEC agreements have impacts on the so-called trade creation and trade diversion effects are discussed in details in this chapter. This chapter ends with the sensitivity analysis by altering the values of Armington substitution elasticities. Conclusions and its implication will be discussed in Chapter VI. It is important to elaborate what a kind of policies can be carried out by government in response to ongoing trade liberalisation in the ASEAN region. 


\section{Chapter II}

\section{ASEAN Economy and AFTA Agreement}

\section{1. The Patterns of Economic Growth and Development}

The Association of Southeast Asian Nations (ASEAN) was established in 1967. The members of the ASEAN include old members (Indonesia, Malaysia, the Philippines, Singapore and Thailand) and new members (Brunei, Vietnam, Cambodia, Laos and Myanmar). Since the mid-1980s, most ASEAN countries have recorded a significant rate of economic growth. As a result, the term of Newly Industrialised Countries (NICs) especially attributed to Singapore, reflects the success of this country in pursuing economic development. Many also predicted that other ASEAN countries such as Malaysia and Thailand would follow Singapore's economic performances. Even, the other ASEAN countries such as Indonesia and Vietnam would be the second NICs ${ }^{3}$. This remarkable GDP growth with the exception of Brunei was due to the primarily outward-oriented and market-driven economic development policies over the past few decades (CHIRATHIVAT, 1996) and (MUN-HENG, 1996). However, as a result of the monetary crisis hitting this region, in 1997/98 the ASEAN member countries experienced a declining rate of GDP growth as shown in the Table 2.1. Most members with the exception of ASEAN countries in transition such as Lao PDR and Myanmar had a negative GDP growth. However their economic recovery has begun since 1999 despite the zero GDP growth experienced by Indonesia.

In addition, macroeconomic policies such as inflation management and monetary liberalisation also play an important role in making ASEAN as an attractive region for the promotion and expansion of trade and investment. Supporting this view, since the late 1970s the ASEAN region has been one of the most attractive investment destination in the developing world. ASEAN countries have substantially liberalised their international trade and investment regimes by lowering trade barriers and lifting restrictions on foreign investment. Therefore, it is not surprising that foreign direct investment (FDI) plays an

\footnotetext{
${ }^{3}$ Recently, most ASEAN countries particularly Indonesia, Thailand and Malaysia experienced a remarkable monetary crisis in which their exchange rate relative to US \$ depreciated very considerably. For example, from a pre-crisis level of around Rp. 2,430 per US\$ in early July 1997, the rupiah weakened to reach a low of just under Rp. 17,000 in June 1998. This is equal to a loss of about $85 \%$ of the rupiah's value (SABIRIN, 1999). Japan and South Korea also experienced a similar problem. Due to this crisis, it is expected that their economic growth will be slow and it takes approximately 2 years to recover.
} 
important role in the process of economic development in this region. Japan and East Asian Newly Industrialised Countries (NICs) are the main sources of investments and their share on total foreign investment in this region has increased substantially (ATHUKORALA and MENON, 1996). Indonesia, Malaysia and Thailand hence become a main destination of FDI due to attractive conditions offered.

The dramatic progress in economic development is parallel with the changes in the economic structure. The structural changes in ASEAN economies are mirrored by a substantial decrease in the share of agricultural sector to total GDP (Table 2.2). A decline in agricultural share is prominent in the ASEAN countries, indicating the degree of a process of industrialisation. On a country by a country basis, Indonesia and Thailand have shown a dramatic change in which the contribution of the agricultural sector to the total GDP is considerably low. Despite the decrease in the contribution of the agricultural sector to total GDP, the role of this sector is still important in terms of generating national income, providing job opportunities especially in rural areas and more importantly supporting the industries.

With an abundance in natural resources and relatively similar geography as well as climatic environment, countries in this region with the exception of Singapore and Brunei support the cultivation of a number of tropical crops and agricultural products, including rice, cassava, vegetable oils especially palm oils, sugar, spices, tropical hardwoods, and rubber (DEROSA, 1995). Related to the importance of the agricultural sector in their economy, Table 2.3 presents relatively high proportion of the population who are employed in this sector. Monetary crisis hitting this region had a direct impact on labour movement as indicated by a high proportion of agricultural labour in 1998. In the same year there was a declining share of the population who was engaged in other sectors. 
Table 2.1 Selected Basic Indicators of ASEAN Countries

\begin{tabular}{lccccccc}
\hline Countries & \multicolumn{2}{c}{$\begin{array}{c}\text { GDP1) } \\
\text { Growth, } \%\end{array}$} & $\begin{array}{c}\text { Per-capita2) } \\
\text { GDP }\end{array}$ & $\begin{array}{c}\text { Inflation } \\
\text { 2) } \\
\text { Rate, } \%\end{array}$ & $\begin{array}{c}\text { Pop1) } \\
(\mathrm{m})\end{array}$ & $\begin{array}{c}\text { Population1) } \\
\text { Growth, \% }\end{array}$ \\
& 1997 & 1998 & 1999 & 2000 & $1997-99$ & 1999 & 1999 \\
\hline Indonesia & 5 & -13 & 0 & $\$ 723$ & 3.77 & 307.0 & 2 \\
Malaysia & 7 & -7 & 6 & $\$ 4,016$ & 1.56 & 23.71 & 2 \\
Philippines & 5 & -1 & 3 & $\$ 990$ & 4.40 & 74.26 & 2 \\
Singapore & 8 & 0 & 5 & $\$ 25,864$ & 1.35 & 3.95 & 2 \\
Thailand & -2 & -10 & 4 & $\$ 1,968$ & 1.56 & 60.25 & 1 \\
$\begin{array}{l}\text { ASEAN Transitional Countries } \\
\text { Myanmar }\end{array}$ & 6 & 5 & $\mathrm{Na}$ & $\$ 155$ & 3.40 & 45.03 & 1 \\
Laos & 7 & 4 & 7 & $\$ 315$ & 23.16 & 5.10 & 2 \\
\hline
\end{tabular}

na : not available

Source : 1) World Development Indicators Database

2) ASEAN Secretariat

Table 2.2 Sectoral Value Added Share of GDP (\%) ${ }^{4}$

\begin{tabular}{|c|c|c|c|c|c|c|c|c|c|}
\hline \multirow[t]{2}{*}{ Countries } & \multicolumn{3}{|c|}{ Agriculture } & \multicolumn{3}{|c|}{ Industry } & \multicolumn{3}{|c|}{ Services } \\
\hline & 1997 & 1998 & 1999 & 1997 & 1998 & 1999 & 1997 & 1998 & 1999 \\
\hline Indonesia & 16 & 18 & 19 & 44 & 45 & 43 & 40 & 38 & 37 \\
\hline Malaysia & 11 & 13 & 11 & 45 & 44 & 46 & 44 & 43 & 43 \\
\hline Philippines & 19 & 17 & 18 & 32 & 31 & 30 & 49 & 51 & 52 \\
\hline Singapore & & & & 35 & 35 & 36 & 65 & 65 & 64 \\
\hline Thailand & 11 & 12 & 10 & 38 & 39 & 40 & 50 & 49 & 50 \\
\hline \multicolumn{10}{|c|}{ ASEAN Transitional Countries } \\
\hline Myanmar & 59 & 59 & 60 & 10 & 10 & 9 & 30 & 30 & 11 \\
\hline Vietnam & 53 & 53 & na & 21 & 22 & na & 26 & 25 & na \\
\hline
\end{tabular}

na: not available

Source: World Development Indicators Database.

\footnotetext{
${ }^{4}$ The economic crisis hitting some ASEAN economies caused the reduction of value added share in nonagricultural sectors. By contrast agricultural value added share increased. The crisis led to the expensive imported capital goods and intermediate inputs. As agricultural sector does not depend largely on the imported capital and intermediate inputs, ASEAN countries, especially Indonesia experienced a positive growth of GDP on agricultural sector. Even exported agricultural sectors, such palm oil, cacao, and coffee benefited from this crisis. As a result, labours were reported to migrate to this sector. As presented in Table 3 agricultural share of employed labour force in Indonesia (1998) is higher than that in 1997 where in this year the monetary crisis started occurring.
} 
Table 2.3 Sectoral Share of Employed Labour Force (\%)

\begin{tabular}{|c|c|c|c|c|c|c|c|c|c|}
\hline \multirow[t]{2}{*}{ Countries } & \multicolumn{3}{|c|}{ Agriculture } & \multicolumn{3}{|c|}{ Manufacturing1) } & \multicolumn{3}{|c|}{ Others } \\
\hline & 1997 & 1998 & 1999 & 1997 & 1998 & 1999 & 1997 & 1998 & 1999 \\
\hline Indonesia & 41 & 45 & 43 & 14 & 12 & 14 & 45 & 43 & 43 \\
\hline Malaysia & 17 & 19 & 18 & 25 & 22 & 23 & 60 & 59 & 59 \\
\hline Philippines & 41 & 40 & 39 & 10 & 10 & 10 & 49 & 50 & 51 \\
\hline Singapore & & & & 23 & 22 & 21 & 77 & 78 & 79 \\
\hline Thailand & 50 & 51 & 48 & 13 & 13 & 14 & 37 & 36 & 38 \\
\hline \multicolumn{10}{|c|}{ ASEAN Transitional Countries } \\
\hline Myanmar & 63 & na & na & 9 & na & na & 28 & na & na \\
\hline Vietnam & 69 & na & na & 9 & na & na & 22 & na & na \\
\hline
\end{tabular}

1) Including Mining

na: not available

Source: Asian Development Database

In the context of global economy, ASEAN's share to global trade is very low (1.3 percent), but higher than MERCOSUR's share (0.3 percent). The share of important regional trade arrangements in global trade is provided in Table 2.4. The size of ASEAN economies relative to the global economy can be seen from a small share of ASEAN trade in global trade. This number is much smaller if Singapore is excluded from the ASEAN exports. According to the World Bank (2001), the world share of Indonesia, Malaysia and Thailand in 2000 rose due to the high proportion of hi-tech in these countries' exports and an extraordinary surge in world demand for such equipment in that year. The increase in the export of high-tech equipment resulted from government policy efforts to promote high tech industries. However, such policies make countries more vulnerable to sharp cyclical changes in world markets for these products. 
Table 2.4 Regional Free Trade Arrangement - Share of World Trade, 1998 (\%)

\begin{tabular}{lc}
\hline Regional Trade Arrangement & Share to Global \\
& Trade \\
\hline European Union (EU) & 22.8 \\
Euro-Mediterranean (EUROMED) & 2.3 \\
North American Free Trade Area (NAFTA) & 7.9 \\
South America's Common Market (MERCOSUR) & 0.3 \\
Free Trade Area of the Americas (FTAA) & $2.6^{*}$ \\
ASEAN Free Trade Area (AFTA) & 1.3 \\
Australian-New Zealand & 0.1 \\
Asian Pacific Economic Co-operation (APEC) & $23.7^{*}$ \\
\hline Total & 61.0 \\
\hline Note:* Excluding subregionals & \\
Source: BERGSTEN (2001) &
\end{tabular}

The importance of the USA, EU and Japan for the ASEAN economies is presented in Table 2.5 that shows the values of ASEAN exports and imports in the period of 19961999. ASEAN trade with these countries is reported to have increased every year with the exception of the period of 1997. The consequence of the monetary crisis hitting hard the ASEAN region induced the contraction of the ASEAN economy. This in turn contributed to the decline in the ASEAN exports and imports. Within the period of 1996-1999 the average ASEAN exports and imports to and from the USA, EU and Japan accounted for around $60 \%$ and $62 \%$ of total ASEAN export and import, respectively. However, the imports from EU have dropped considerably. For instance, in 1997 the ASEAN imported from EU accounting for around $19.5 \%$ and declining to $15.5 \%$ of total ASEAN import values in 1999. Despite the implementation of the AFTA trade liberalisation, the trade with those countries remains very important. Consequently, the volume of intra-regional trade among the ASEAN economies still remains very low. 
Table 2.5 ASEAN Trade with Major Trading Partners (US\$ million)

\begin{tabular}{|c|c|c|c|c|c|c|c|c|}
\hline & \multicolumn{4}{|c|}{ Export } & \multicolumn{4}{|c|}{ Import } \\
\hline & 1996 & 1997 & 1998 & 1999 & 1996 & 1997 & 1998 & 1999 \\
\hline $\begin{array}{l}\text { DIALOGUE } \\
\text { PARTNERS }\end{array}$ & 192,883 & 192,385 & 178,380 & 200,520 & 228,731 & 229,650 & 162,017 & 167,675 \\
\hline USA & 59,516 & 70,030 & 64,620 & 70,003 & 53,001 & 61,695 & 50,942 & 45,962 \\
\hline Japan & 43,150 & 42,009 & 34,717 & 37,629 & 73,310 & 71,264 & 46,694 & 51,244 \\
\hline EU & 46,926 & 46,087 & 46,144 & 55,651 & 57,381 & 51,010 & 33,256 & 34,470 \\
\hline Australia & 6,106 & 6,418 & 7,120 & 7,854 & 8,689 & 7,964 & 5,702 & 6,081 \\
\hline Canada & 1,988 & 1,882 & 2,315 & 2,248 & 2,446 & 2,568 & 1,767 & 2,078 \\
\hline New Zealand & 813 & 774 & 757 & 892 & 1,151 & 1,297 & 864 & 750 \\
\hline $\begin{array}{l}\text { Republic of } \\
\text { Korea }\end{array}$ & 9,447 & 10,668 & 7,813 & 10,878 & 13,294 & 14,857 & 9,267 & 12,110 \\
\hline PR. China & 18,045 & 9,168 & 9,203 & 9,564 & 14,574 & 13,483 & 11,212 & 12,184 \\
\hline India & 3,723 & 4,473 & 5,218 & 5,577 & 2,844 & 4,396 & 1,750 & 2,082 \\
\hline Russia & 3,169 & 876 & 473 & 224 & 2,041 & 1,116 & 563 & 714 \\
\hline Others & 55,317 & 65,866 & 69,436 & 66,181 & 66,241 & 61,870 & 45,871 & 55,034 \\
\hline $\begin{array}{l}\text { Total Extra } \\
\text { ASEAN Trade }\end{array}$ & 248,200 & 258,251 & 247,816 & 266,701 & 294,972 & 291,520 & 207,888 & 222,709 \\
\hline
\end{tabular}

Note: Trade figures cover only Brunei Darussalam, Indonesia, Malaysia, Philippines, Singapore and Thailand

Source: ASEAN Secretariat 
Using a method of the Trend and Cycles Decomposition (TCD), (DIAO, ROE and SOMWARU, 2001) examines the cyclical trend of agricultural trade in ASEAN region. Total ASEAN agricultural trade declined in the mid 1970s and throughout 1980s. This decline was parallel with the decrease in extra-agricultural trade in this region. In addition, growth in intra agricultural trade decreased more rapidly. These growth patterns likely reflect the inwardoriented policies such as import substitution policy pursued during this period. A study focussing on agricultural pricing policies in Asia, (KRUGER, SCHIFF and VALDÉS, 1991) found an overvaluation of the real exchange rate. This policy leads to hampering the exportation of agricultural products due to a loss of comparative advantages in the world markets. Similarly, the same patterns are also found in the case of agricultural import. Imposing high trade barriers, either tariff or non-tariff barriers, to support domestic production resulted in negative growth of agricultural import. In addition, trade policies that were biased against regional trade contributed to the decreased intra trade. For example, high priority was given to imports of capital and intermediate goods that were largely supplied by the industrialised countries. This resulted from the adoption of import substitution policies together with the problems of balance of payments in some ASEAN member countries (WONG, 1980).

As ASEAN economies started liberalising their import barriers in 1980s, they experienced a high growth of export and import of agricultural products. However, a growth of extraagricultural trade was more rapid than intra-trade. In this period ASEAN economies experienced a higher economic growth compared to other countries and other regions. Gradually reduced trade barriers together with macroeconomic stabilisation resulted in an increase in export and import. For instance Indonesia continued to deregulate in a pragmatic and gradual manner. But the financial crisis emerging in the mid 1997 led to a recession in this region. When looking at both figures, the path of intra and extra agricultural trade declines since 1997. Supporting these findings, it suggests that during this period and also in following years trade with non-members will remain very important despite the commitment to reducing import barriers based on the AFTA scheme. 
The statutionary and administrative measures are also determining factors in the flow of goods. These measures are not only used in developed countries but also in developing countries in order to promote and even to prohibit trade as a procedure to achieve political economy objectives (DEROSA, 1995). In the context of ASEAN trade, most governments in this region with the exception of Singapore and Brunei have been interventionist and protectionist due to economic and political reasons. Other instruments of protection such as fiscal charges, advance sales tax, restrictive licensing, quotas, foreign-exchange restrictions, state trading monopolies and prohibitions still exist in ASEAN as means of protecting their economies 5 .

Singapore has for a long time been reducing her trade barriers as proven by the low, even zero tariff levels except the frequency of NTBs on cereals. This is due to the fact that Singapore embarked on a program of unilateral trade liberalisation since 1969 and that Singapore is too small to afford the luxury of protectionism ${ }^{6}$. The high level of non-tariff barriers on cereals is provided to protect rice farmers in this country from imported rice. Despite the role of agricultural products is not significant, apart from rice concerns, there are still many who rely on swine and poultry industries ${ }^{7}$.

Beside relatively high non-tariff barriers on cereals, there are also trade barriers imposed to mineral fuels and transportation equipment. Following Singapore, the Malaysian market seems to be open, reflected by moderate tariff levels ranging from $2.1 \%$ (non-tariff barriers frequency) to 17.6 \% (mean tariff charges). By contrast, Indonesia and Thailand apply extensively non-tariff barriers to primary commodities particularly cereals and vegetable oils as well as oil seeds, and at high average frequency ratios. In the case of Indonesia and

\footnotetext{
${ }^{5}$ ASEAN countries have been active in the multilateral negotiation in relation to reducing their trade barriers such as tariffs and non-tariff barriers (NTBs). Within the framework of the Uruguay Round, ASEAN countries have been bound to bring down their tariff barriers. More importantly, due to the increasing pressure of international and domestic groups to the activity of a state-owned marketing agency (BULOG) in Indonesia, the monopoly right of this agency to import rice and wheat is abolished. As a result, private companies can apply to import such commodities.

${ }^{6}$ The proposal of a formation of customs unions in the ASEAN region was firmly rejected by the Singaporean government because if accepted, this country had to impose higher levels of trade barriers against non-ASEAN members as a consequence of establishing customs union against third countries.

${ }^{7}$ See DEROSA (1995).
} 
Thailand, the high imposition of a high frequency of non-tariff barriers is to protect rice farmers and thus a reason to stabilise farmers` income and of food security ${ }^{8}$.

\section{2. ASEAN Free Trade Area (AFTA) Agreement}

Regarding the economic progress of ASEAN economic co-operation, NAYA and IMADA (1992) perceived three major phases of its co-operation. The first stage is the period from 1967 (the ASEAN establishment) to the first summit in 1976. In this period, ASEAN members tried to lay down a fundamental foundation for future co-operation. In the beginning of its establishment, political objectives became a major consideration. Therefore, it is not surprising that the idea of deep economic co-operation did not appear. The second phase, which took place between 1976 and the announcement of AFTA formation became a period of consolidation and preparation for better co-operation. As mentioned earlier, the agenda of economic institutions such as ASEAN PTA and three industrial co-operation agreements were a great outcome despite a low degree of success. The ASEAN PTA signed in 1977, ten years after the Bali Concord, has produced little impacts on boosting intra-ASEAN trade. The little success of ASEAN PTA may refer to the relatively low margin preference ranging from 10 percent in the beginning of PTA to 40 percent later on. Ten years later in 1987, members reviewed their trade policy and tried to make significant changes so as to make ASEAN PTA work effectively. The decisions included:

- Exclusion lists to be reduced to no more than 10 percent of the number of traded items and/or 50 percent of the value of intra-ASEAN trade;

- Inclusion of excluded product list with minimum margin of preference (MOP) of $25 \%$;

- Deepening the tariff reductions of those existing PTA items to 50 per cent on an abroad concession of 5 per cent per year or product-by-product concessions;

- Immediate restraint of non-tariff barriers (NTBs), accompanied by negotiation for a curtailment of such NTBs; and

- Reduction of ASEAN content level to 35 per cent ${ }^{9}$.

\footnotetext{
${ }^{8}$ With large supports from the government such as agricultural credit, higher import tariffs, the development of water irrigation, domestic price policy like a floor price policy, training and extension, Indonesia in 1984 achieved self sufficiency on rice. This achievement became a turning point in Indonesian agricultural policy because in 1970s Indonesian was reputed as the largest rice importer.

${ }^{9}$ CHIRATHIVA (1996).
} 
However, these decisions had no effect on enhancing intra-ASEAN trade. This was due to a lack of a political will from the ASEAN governments to make ASEAN PTA more workable. This was reflected by the slow progress of tariff reduction and the hesitation of the government to bring the items into the inclusion list. The slow progress of tariff reduction was due to concerns over unfavourable implications if the members liberalise quickly their domestic markets which still had high border tariff rates at that time. The last phase, from 1992 to 2006 -the period of AFTA implementation- will be a critical period, whether all ASEAN members are fully committed to implementing the AFTA agreement.

In response to a slow progress of the ASEAN economic co-operation and the formation of the European single market and the North American Free Trade Area (AFTA), ASEAN countries in January 1992 signed an agreement to establish ASEAN Free Trade Area (AFTA) which came into effect at the beginning of 1993 and was planned to be implemented by 2008. The full implementation of the AFTA agreement began in 1995 and the final implementation is accelerated from 2008 to 2003. Under the ASEAN PTA, no reciprocal rule was made and only the nominating country granted margin preferences. By contrast, under the AFTA plan a reciprocal rule is made in a sense that goods and their tariff reduction schedules under the CEPT scheme apply for all ASEAN members. Therefore, the AFTA plan seems across-theboard and more promising than the ASEAN PTA. Strong commitments of the ASEAN member countries to succeeding this effort are seen from the inclusion of as many products as possible into the fast track programme.

The establishment of AFTA will provide and create an integrated market of 330 million people with a combined GDP of US\$293 billion, growing at $7 \%$ a year (1992). More importantly, it will provide an attractive environment in order to attract foreign investment. Therefore, through reducing trade barriers among ASEAN countries, industries have a great opportunity to expand their capacities in order to engage on this remarkably potential market.

TAN (1996) identified fundamental factors stimulating the need of creating the AFTA. These factors include: (1) the emergence and consolidation of economic blocs particularly in the Europe and America in which developed countries become protectionist; (2) within the 
Southeast Asian region in which market driven trade policy dominates the decision of the government in this region by the adoption of trade/economic liberalisation and the strategy of attracting FDI; and (3) the increasing competitive environment coming from outside. In addition to these factors, AKRASANEE and STIFEL (1992) recognised that the introduction of international production network which lowers the production cost through the technological advances was one of other considerations facing ASEAN industries to lower their cost of production and to become more competitive.

According to the 1995 protocol of the establishment of AFTA, the members agreed to reduce trade barriers such as tariff and non-tariff barriers (quota and quantitative restrictions) through the forming of the Common Effective Preferential Tariff Scheme (CEPT). The goal of the Scheme is to reduce tariffs for all manufactured goods to $0-5 \%$ by the year 2003. The design of the CEPT scheme covers almost all products and thus provides comprehensive product coverage than previous attempts at liberalisation that put emphasise on product-by-product approach (ARIFF, 1994). And the establishment of the CEPT leads to the harmonisation of tariffs among ASEAN members, but the level of tariffs against non-ASEAN countries remains unchanged. At the ASEAN Summit in January 1992, 15 product groups were designated to be on the CEPT Scheme for accelerated tariff reductions. The original CEPT consisted of 41,147 tariff lines, which accounted for about 88 percent of the tariff lines. These were subject to a schedule of tariff reduction to bring them to a range $0-5 \%$ by the year 2003. Some 3,321 tariff lines were temporarily excluded (i.e. in the Temporary Exclusion List) while another 523 tariff lines were permanently excluded from tariff reduction (i.e. in the General Exception List). The only processed agricultural product included in the original CEPT is vegetable oil ${ }^{10}$.

Due to the economic changes especially during 1993-1994, represented by the agreement among ASIA-PACIFIC countries to enhance their economic co-operation by implementing Bogor memorandum ${ }^{11}$, ASEAN members reviewed their trade policy. According to the

\footnotetext{
${ }^{10}$ The inclusion of vegetable oils (palm oil) into the CEPT group is not surprising due to the fact that Indonesia and Malaysia are large palm oil producers.

${ }^{11}$ According to the APEC Economic Leaders' Declaration on November 15, 1994, the APEC leaders agreed to enhance trade and investment in this region and have set up the final period of implementation. The final period of implementation varies depending on the stage of development. APEC developed countries are required to eliminate their trade barriers no later than the year 2010 and for APEC developing countries no later than 2020.
} 
Fourth AFTA Council and the $25^{\text {th }}$ ASEAN Economic Ministers (AEM) meeting, members agreed to speed up the AFTA implementation through the introduction of two programmes of tariff reduction under CEPT Scheme: The Fast Track Programme and the Normal Track Programme (ASEAN Secretariat).

1. The Fast Track Programmes means that (a) tariffs above $20 \%$ will be reduced to $0-5 \%$ within 10 years (i.e., by 1 January 2003). Members committed to implement this programme are Indonesia, Malaysia, Philippines, Singapore and Thailand, and (b) tariffs at $20 \%$ and below will be reduced to $0-5 \%$ within 7 years (i.e., by 1 January 2000). Indonesia, Malaysia, Philippines and Singapore were committed to implement this programme.

2. The Normal Track Programme indicates that (a) tariffs above $20 \%$ will be reduced in two stages: (1) to 20\% within 5 to 8 years (by 1 January 2001) and (2) subsequently, to $0-5 \%$ in 7 years according to an agreed schedule ending on 1 January 2008). In this programme, Indonesia, Malaysia, Philippines and Thailand started implementing the normal track of tariff cut. And (b) tariffs of $20 \%$ and below will be reduced to $0-5 \%$ within 10 years (i.e., by 1 January 2003). Those countries agreed to implement these programmes, beginning 1 January 1994 as the starting time with the exception of Brunei, due to administrative requirement, which indicated June 1994 as the starting time for the implementation of the normal track programme of tariff reduction above $20 \%$.

Considering agricultural products, the 1992 CEPT agreement excluded unprocessed agricultural products from the CEPT Scheme. The exclusion of unprocessed agricultural products from agreement raised strong criticism. NADAL DE SIMONE (1995) insisted that the exclusion of agricultural raw material/unprocessed products from the CEPT would affect intra-regional trade negatively, as it reduced economic complementary and interdependency. In addition, JOSLING (1997) strongly argued that intra ASEAN trade could expand if the agricultural sectors were to be fully incorporated in the liberalisation plans. In response to such criticism, the $26^{\text {Th }}$ ASEAN Economic Ministers (AEM) Meeting in September 1994 decided to include unprocessed agricultural products into the CEPT Scheme. Unprocessed agricultural products are categorised into three major lists: (a) Immediate Inclusion List, (b) Temporary Exclusion List (TEL) and (c) Sensitivity List. All products included in the 
Sensitivity List will have a special arrangement as a transitional period by 1 January 2010. On the other side all products have to be liberalised into the CEPT Scheme. These categorisations which have occurred as well in the case of the Central European Free Trade Agreement/CEFTA (TWESTEN and TANGERMANN, 1998) reflect the time frame of tariff reductions.

Tariff reduction for unprocessed products in the Immediate Inclusion List has begun since 1st January 1996 and by 2003 the process of tariff reduction for these product categories will have been completed. The final import tariff levels for these products will be 0-5 \%. .To support and speed up the accomplishment of tariff reduction, member states are required to eliminate quantitative restrictions (QRs) and other non-tariff barriers (NTBs) on this product category ${ }^{12}$. This applies for products that are included in the Temporary Exclusion List with the exception of the tariff reduction taking place since 1st January 1997. Products in the Immediate Inclusion List and Temporary Exclusion Lists represent more than 87\% of the tariff lines, composing 1760 tariff lines. As mentioned earlier, by 2003 these products will be in the CEPT Scheme. The members also recognised that the number of products included in the Sensitive List should be minimised and at the same time expanding the Inclusion List as much as possible. Indonesia and Malaysia were concerned about opening up their markets to unprocessed agricultural products. It is feared that the inclusion of sensitive products in the CEPT will affect millions of farmers and that if the protection of unprocessed agricultural products in this list is lifted immediately, this will lead to unemployment of resources and social disruption (AFTA Reader Vol. 4 September 1996). Even products such as rice, wheat flour, sugar and cloves will be put into a more permanent sensitive list ${ }^{13}$ However, the tariff reductions which will be arranged specially will be more preferential than the Uruguay Round commitment.

\footnotetext{
12 The members have agreed to eliminate non-tariff barriers (NTBs) no latter than 2003. To comply with this goal, the Interim Technical Working Group (ITWG) on CEPT for AFTA was established. Its progress is directly reported to ASEAN Senior Economic Officials. In order to accelerate the elimination of the NTBs, this working group co-operates with the ASEAN Consultative Committee for Standards and Quality (ACCSQ). Several measures have been identified as major NTBs that affect intra-regional trade: custom surcharges, technical measures and product characteristic requirement, and monopolistic measures (AFTA Secretariat). The elimination of NTBs for sensitive products will be completed by 2010. For new members the final elimination of these barriers is extended for some years.

${ }^{13}$ Far Eastern Economic Review 1995(51), p.60.
} 
The inclusion of sensitive products such as agricultural products into market liberalisation, e.g., free trade area (FTA) leads to important implications in terms of national trade policy. With regard to this, JOSLING (1995) identified such implications: (1) FTA members will have to modify their agricultural policies to accommodate free trade intra-bloc trade. (2) FTA members will also change their third countries trade policies over time, and (3) domestic policies in FTA members are likely to change even when they do not conflict with intra-bloc trade. In addition as he added, the inclusion of agriculture in FTA is also supported by several reasons: (1) wide access to importer markets, (2) different food costs which would lead to distorting trade, investment and wage comparability, and (3) international competitiveness.

Despite the fact that unprocessed agricultural products have been incorporated into the CEPT, there is, however, no attempt to co-ordinate agricultural policies among the members. Agricultural policies are still their domestic agenda. To enhance the ASEAN economic cooperation, the ASEAN Committee on Food, Agriculture and Forestry (COFAF) has been established. One of its aims was, however, far away from a policy co-ordination, but only to set up a food security reserve (MÜLLER, 1995, JOSLING et al, 1998).

\section{3. APEC Trade Liberalisation}

Despite the commitment of the ASEAN member countries to reducing trade barriers in order to enhance trade in the ASEAN region, the ASEAN member countries are also actively involved in promoting open trade and practical economic cooperation among Asia-Pacific economies (APEC). Apart from a need to enhance trade in this region, the establishment of APEC was due to uncertainty in the outcome of the Uruguay Round (FERIDHANUSETYAWAN, 1998). This cooperation was founded in 1989 and the members include ASEAN member countries (Brunei Darussalam, Malaysia, Indonesia, Philippines, Singapore, Thailand and Viet Nam), Australia, Canada, Chile, China Hong Kong, China, Japan, Korea, Mexico, New Zealand, Papua New Guinea, Peru, Russia, and Chinese Taipei. The current price GDP for APEC economies for year 2000 was US\$ 17,921 billion and APEC's percentage of global trade for the year 2000 was around $47 \%$. In addition, APEC members account for $42 \%$ of the world's population. Trade within the APEC members accounts approximately for $40 \%$ of the global trade (1998). In addition, around $70 \%$ of 
APEC export destination and import sources are intra-regional. A considerable rate of this APEC intra-trade is not due to the APEC institution but the APEC economies have been pursuing trade openness. YOUNG and HUFF (1997) stressed that countries in this region are dynamic, export-oriented economies.

The unique nature of the APEC is that it seems to apply the concept of 'open regionalism'. This implies that any reductions of trade barriers it achieves for its members are extended to non-member countries. The WTO mechanism of the most-favoured-nation (MFN) is more likely to be adapted due to its familiar and readily available vehicle (RAE, CHATTERJEE and SHAKUR, 1999).

The members reached a monumental agreement which set the long term goals of free and open trade and investment following the APEC leaders meeting in Bogor (1994). APEC industrialised countries are required to reduce trade barriers by 2010 and 2020 for APEC developing countries. Several attempts have been carried out to implement the Bogor Agreement. The meeting in Manila (1996) provided a clear step by setting the Manila Action Plan for APEC (MAPA) which contains Individual Action Plans (IAPs) and Collective Action Plans (CAPs). In addition, the Manila Action Plan (MAPA) also includes the abolition of non-tariff measures, deregulation, standard harmonisation, governmental procurement, intervention in case of trade frictions, and trade liberalisation measures (TAKATA, 1998). Different from the AFTA agreement, the process of trade liberalisation is voluntary and concerted unilateral actions undertaken by individual APEC members based on its own plans, priorities and the levels of developments in each APEC member (FERYDHANUSETYWAN, 1998).

Due to a slow progress of trade liberalisation under the Individual Action Plan (IAPs), the members introduced the so-called Early Voluntary Sectoral Liberalisation (EVSL). This EVSL was a part of the CAPs. Besides the EVSL implements the outcome of the Osaka Action Agenda (1995) which states that APEC members will identify industries in which the progressive reduction of tariffs may have positive effects on trade and economic growth in the Asia Pacific region. According to the outcomes of the Vancouver meeting (1997) 15 sectors 
were selected with 9 sectors given a high priority ${ }^{14}$. The selection of the nine sectors was mainly based on the exporter's interest and they included at least one sector of exporter's interest of each APEC member country (YARNAZAWA, 1999).

Similar to the ASEAN case, there is no concerted action on the harmonisation of agricultural trade policies among APEC member countries. However, in response to the importance of work on agricultural technical cooperation, the Agricultural Technical Cooperation Experts’ Group (ATCEG) was established whose objective is o enhance agriculture's contribution to the region's economic growth and social well-being. Its scope extended to areas incorporating (a) food and agriculture-related research and development; (b) trade and other matters; and (c) food and agriculture-related environmental issues (APEC Secretariat).

As mentioned earlier the establishment of the APEC was formalised in 1989 with the goal of promoting multilateral trade reform and facilitating regional trade. Initially, the concept or idea of making the region more opened to trade was proposed by the Japanese economist Kyoshi Kojiyama in 1964. By that time, the formation of APEC was not formally developed or institutionalised. This is due to the fact that (1) GATT has successfully created an open trading regime and (2) unlike the EU case, APEC members are characterised with a diverse nature of the economies, cultures and political system (YOUNG and HUFF, 1997). However, the members realised that the GATT faced difficulties in sustaining multilateral trade liberalisation. The disillusionment of members over the GATT resulted in accelerating the formation of a free trade zone in the region. The debatable issue behind the establishment of APEC was what kind of regionalism was pursued in the region and whether a reciprocal policy suited to the region. The concept of open regionalism raised considerable attention especially to those who observe the process of a formation of APEC (see COYLE and WANG (1998), WANG and COYLE (2002), and YOUNG and HUFF (1997). Open regionalism requires that trade barrier reduction conducted by the members apply as well for nonmembers. Such an approach as WANG and COYLE (2002) acknowledged, will promote economic benefits for both economies (member and non-member economies) and furthermore

\footnotetext{
${ }^{14}$ These sectors include chemicals, energy, environmental goods and services, fish, forest products, gems and jewellery, medical equipment and instruments, toys, and telecommunications products and systems. The other six sectors are oilseeds and oilseeds products, food, fertiliser, autos, natural and synthetic rubber and civil air craft.
} 
will create conducive atmosphere for accelerating the process of global free trade. Like AFTA, it seems that APEC will be a "stepping stone" to wider trade liberalisation. This rationale is understandable as the USA approaches most of economies in the American continent to establish the so-called Free Trade Area on Americas (FTAA), since then.

As mentioned above APEC trade liberalisation should be opened to all economies whether they are members or not. DRYSDALE (1988) proposed APEC should be based on nondiscriminatory basis. He then argued remarkable economic growth in the region was largely attributed to the open trade policy pursued by APEC economies. In addition economies in Western Pacific has been liberalising their foreign trade unilaterally. Such policy had a great impact on trade and investment in the region. However, other members argued that trade liberalisation apply only for member and for non-members who agree to reciprocal liberalisation measures (WANG and COYLE, 2002). With reciprocal basis, free riders who will possibly exploit the APEC can be avoided. Unconditional trade liberalisation will also provide some APEC members disincentive to pursue further trade and investment barrier reduction. If it is the case the members might even stay back from further trade liberalisation.

The Bogor Declaration in 1994 became a starting point for the members to put a stepping stone for future economic co-operation, especially in terms of enhancing and promoting trade and investment in the region. The members decided to liberalise their trade regimes and investment by 2010 for the developed countries and 2020 for developing countries ${ }^{15}$. Despite financial crisis has beset some APEC members, specifically some of Asian economies in 1997 and 1998 it is predicted economic growth in the region in near future will continue to occur at above the world average. If all members met the Bogor declaration, then the growth will substantially take place (CHAN and NUGENT, 1998) ${ }^{16}$.

\footnotetext{
${ }^{15}$ Tariff liberalisation as admitted is only a small part of the overall liberalisation. In response to wider and broader economic cooperation several measures have been conducted to speed up the process of trade and investment liberalisation in the region. Measures include improvement of customs clearance procedure, the creation of a business person's smart card, APEC investment agreements, development cooperation, procedure of facilitating technology transfer, cooperation in infrastructure, and harmonisation of product standard.

${ }^{16}$ Countries that experienced hard financial crisis such as South Korea, Thailand and Indonesia are reported to grow with the rate close to that before crisis. For instance, Indonesian GDP grows by 4 percent in 2003. Economic recovery in South Korea and Thailand has even been faster than that in Indonesia. This fast economic recovery provides strong economic fundament for further trade growth. This also proves that East Asian region is one of very dynamic region in the world.
} 
To implement the Bogor declaration several state heads and ministerial meeting have been conducted. This ambitious plan of reducing trade barriers and investment impediment requires members' commitment. Due to enormous differences in terms of factor endowment and economic development among the members agreements on how the members reduce their trade barriers and investment impediment can be only facilitated through intensive and regular meetings. The first meeting to spell out the Bogor declaration was the Osaka summit in 1995. One of the important outcomes of the summit was that trade liberalisation within APEC should be based on a MFN basis. The Osaka action agenda put emphasis on (GOSPER, et al (1996) in OKTAVIANI (2000)): (1) a procedure by which members will proceed with trade and investment liberalisation, (2) the general principles which guide the process, and (3) detailed plans on collective actions including its objectives and guidelines and on common policy concepts as well as joint activities. As a way of liberalising trade and investment in the region the members also agreed to eliminate their trade barriers. For instance, the Chinese government announced to reduce not only import tariffs but also quota licensing and import control measures for industrial and agricultural products.

The second meeting held in Manila in1996 laid concreted trade liberalisation plans by which the members agreed to take plans (known as Manila Individual Action Plans). These plans are composed of Individual Action Plans, Collective Action Plans and other joint activities (OKTAVIANI, 2000). Following these actions the members were required to submit their detailed liberalisation plans to be updated at each successive ministerial meeting. Individual plans also need approval from other members to assure comparability among the members. It is important to take a note here that like other sectors, agricultural sector was also included and called for comprehensive treatment. However, the inclusion of agricultural products in the plans raised objections from Northeast Asian members. To accommodate such differences among the members regarding the treatment of agricultural products, the members adopted the principle of "flexibility". This principle gave the members opportunities to delay agricultural liberalisation (SCOLLAY and GILBERT, 2000). But the members also acknowledged all sectors are ultimately included in the liberalisation process. 
The Vancouver meeting in 1997 announced more concreted trade liberalisation plans. These plans were known as Early Voluntary Sector Liberalisation (ESVL) ${ }^{17}$. Products to be reduced their import tariffs were classified into two tiers; the first tier such as forestry and fisheries and the second tiers, such as processed food. As reported, Japan and South Korea were reluctant to proceed further with the trade liberalisation in these sectors. Other APEC members also faced difficulties in terms of reducing trade barriers within a short period. One of the reasons why these economies stood firmly not to liberalise their agricultural, forestry and fisheries sectors earlier was their import tariffs on these sectors were relatively high (SCOLLAY and GILBERT, 2000). On the contrary, APEC exporting economies such as the United States, Australia and New Zealand insisted all sectors should be treated equally. This implies that to accelerate trade liberalisation and to boost trade in the region, the liberalisation should apply for all sectors.

\section{4. ASEAN Economy and Trade Flow}

This section highlights the economic performance of ASEAN countries based on the GTAP 4 data set $^{18}$. Comparing GDP and trade between regions, it is clearly seen that European Union dominates the world economy that accounts for around 30 percent for the global GDP and 39 percent for traded commodities, respectively. Other major ASEAN trading partners: Japan and USA were reported to contribute 18 and 25 percent to the global GDP and 9 and 13 percent to the globally traded commodities, respectively. On the contrary, ASEAN as a community accounted only for 2 percent and 6 percent to the world GDP and world trade, respectively. Based on individual country comparison Indonesia and Thailand were reported to contribute relatively higher shares than the rest of ASEAN countries. The level of GDP in the ASEAN countries was closely related to the size of the countries as indicated by the size of

\footnotetext{
${ }^{17}$ The proposal of the EVSL has been widely criticised due to the fact that product liberalization is not parallel with the WTO process of liberalisation. The WTO is committed to liberalising all sectors not product-byproduct. With a wider product coverage the liberalisation will bring about more benefits to the members. OKLEY (1999) argued that product-by-product liberalisation may have a poorer effect than use of the global and sector-wide approaches.

${ }^{18}$ The classification of commodities and the aggregation of countries or regions follows the objective of this study that examines the likely impact of the establishment of AFTA on the production and agricultural trade in the ASEAN region. Trade data are mainly based on the Global Trade Analysis Project (GTAP) database version 4. This database is developed by the consortium of the GTAP at the Purdue University. The detailed information about which commodities and regions are grouped into new commodities and countries or regions presented in this chapter is discussed later in the Chapter 3.
} 
the population. However, focusing on the commodities globally traded, Singapore and Malaysia were reported to trade more commodities compared to other ASEAN members. Their shares to the world commodity trade are 2.2 percent and 1.5 percent.

The strong reliance of ASEAN economies with the exception of Singapore on agriculture yet dominates their economic development as reflected by the relatively high share of agricultural sector to the total GDP (see Table 2.7). For instance, the contributions of its sector to the GDP for Philippines, Indonesia, Thailand and Malaysia are 27 percent, 25 percent, 16 percent and 15 percent, respectively. Singapore has the lowest share of agricultural sector to the national GDP. A varied range of agricultural share can be regarded as an indication of different degree of industrialisation among ASEAN members despite the fact that rapid development of ASEAN members has taken place during the past two decades. Comparing among other regions before financial crisis hitting this region, the AEAN economic growth is even reported to be the highest. Focusing on Philippines' and Indonesia's case, agricultural-based sectors consistently play an important role that provides not only job opportunities for agricultural labour but also intermediate inputs for downstream industries. 
Table 2.6 Economic Activity by Region (US\$ 10 billion), 1995

\begin{tabular}{lrccc}
\hline & GDP & GDP(\%) & Trade1) & Trade (\%) \\
\hline Indonesia & 19.7 & 0.8 & 5.9 & 1.0 \\
Malaysia & 7.0 & 0.3 & 9.3 & 1.5 \\
Philippines & 5.8 & 0.2 & 2.8 & 0.4 \\
Singapore & 5.9 & 0.2 & 13.4 & 2.2 \\
Thailand & 15.0 & 0.6 & 7.5 & 1.2 \\
ASEAN & $\mathbf{5 3 . 4}$ & $\mathbf{2 . 1}$ & $\mathbf{3 8 . 9}$ & $\mathbf{6 . 3}$ \\
European & 766.2 & 29.6 & 241.2 & 38.8 \\
Union & & & & \\
Japan & 469.5 & 18.1 & 54.3 & 8.7 \\
USA & 658.8 & 25.4 & 79.7 & 12.8 \\
ROW & 644.8 & 24.9 & 206.9 & 33.3 \\
\hline
\end{tabular}

1) Refers to imports.

Source: GTAP Database Version 4

Examining individual agricultural sectors more closely, Table 2.8 illustrates the wide difference of their shares to the national GDP. Given the importance of the rice sector as staple food, the contribution of this sector together with processed agricultural products to the agricultural GDP has been significant. For instance, the shares of the rice sector in the national GDP except for Singapore range from 3 percent (Thailand) to 6 percent (Indonesia). Due to the importance of the rice sector in the ASEAN economies, this sector is excluded from the tariff reduction programme and put in the sensitivity list. The members have agreed to postpone the negotiation on this sector. Vegetable and crops are reported to have a relatively higher contribution to the national GDP compared to sugar and cereal. The importance of livestock sector in the ASEAN economies, particularly in Indonesia and Philippines also exists as shown by their relatively higher shares. 
Table 2.7 Sectoral Shares of GDP, 1995 (\%)

\begin{tabular}{lccccc}
\hline & Indonesia & Malaysia & Philippines & Singapore & Thailand \\
\hline Rice & 5.6 & 4.4 & 5.0 & 0.0 & 3.3 \\
Cereal & 0.5 & 0.0 & 0.1 & 0.0 & 0.4 \\
Livestock & 1.1 & 0.0 & 1.7 & 0.0 & 0.2 \\
Oil seeds & 1.2 & 0.8 & 1.0 & 0.2 & 0.2 \\
Crops & 4.1 & 3.8 & 7.5 & 0.4 & 1.9 \\
$\begin{array}{l}\text { Vegetable oil } \\
\text { Processed other }\end{array}$ & 0.7 & 0.6 & 0.0 & 0.5 & 0.1 \\
crop & 2.2 & 0.6 & 5.5 & 0.5 & 2.9 \\
$\begin{array}{l}\text { Processed meat } \\
\text { Processed milk }\end{array}$ & 0.3 & 0.3 & 1.3 & 0.2 & 0.7 \\
$\begin{array}{l}\text { Sugar } \\
\text { Beverage and }\end{array}$ & 0.0 & 0.1 & 0.3 & 0.1 & 0.2 \\
tobacco & 1.6 & 4.3 & 8.3 & 0.8 & 5.3 \\
$\begin{array}{l}\text { Total agric. } \\
\text { sector }\end{array}$ & $\mathbf{2 4 . 7}$ & $\mathbf{1 5 . 4}$ & $\mathbf{2 6 . 9}$ & $\mathbf{3 . 3}$ & $\mathbf{1 5 . 7}$ \\
$\begin{array}{l}\text { Mining and } \\
\text { mineral products }\end{array}$ & 10.4 & 9.6 & 0.9 & 7.7 & 3.3 \\
$\begin{array}{l}\text { Textiles } \\
\text { Manufacturing }\end{array}$ & 15.6 & 28.6 & 9.1 & 30.7 & 32.9 \\
$\begin{array}{l}\text { Total } \\
\text { manufacture }\end{array}$ & $\mathbf{2 8 . 1}$ & $\mathbf{3 9 . 6}$ & $\mathbf{1 1 . 6}$ & $\mathbf{3 9 . 3}$ & $\mathbf{4 0 . 6}$ \\
Service & $\mathbf{4 7 . 3}$ & $\mathbf{4 5 . 0}$ & $\mathbf{5 6 . 5}$ & $\mathbf{5 7 . 8}$ & $\mathbf{4 3 . 7}$ \\
\hline
\end{tabular}

Source: GTAP Database Version 4

As the share of agricultural export in total export declines, manufacturing export begins to dominate ASEAN exports. Nevertheless, agricultural sectors are still regarded as a source of foreign earning as shown by relatively high shares of rice export in the total export with the exception of the case in Singapore. Their shares range from 10 percent (Philippines) to 23 percent (Thailand) (see Table 2.8). These numbers express the importance of the agricultural sector in the ASEAN economy. On the sub-sector basis processed agricultural products, vegetable oil and processed other crops are important export products. As one of the world's rice exporting countries, Thailand rice export accounts for 6 percent of total export. A lower share of agricultural export in Indonesia compared to the share in Thailand is due to the dominating role of exports of the mining sector, mainly oil sector as seen from the relatively higher share of this sector in the total sector (24 percent). 
The composition of export of non-agricultural products differs between the members. For instance, 80 percent of the value of exports generated in Malaysia stems from the exports of manufacture. In comparison, the export of this product category in Philippines and Thailand account for 54 percent. On an individual basis, Indonesia, Malaysia and Singapore have been reported to export mining products more than textile. On the other side, textile export in the Philippines and Thailand account for a relatively larger share of the total export value compared to the exports of mining products. Comparing between Indonesia and Thailand in terms of export value, Indonesia relies largely on mining products, while in Thailand exports of agricultural products especially processed agricultural products play a dominant role in its export structure.

Table 2.8 Shares of Individual Sector in the Total Export Value, 1995 (\%)

\begin{tabular}{lccccc}
\hline & Indonesia & Malaysia & Philippines & Singapore & Thailand \\
\hline Rice & 0.1 & 0.0 & 0.0 & 0.0 & 5.8 \\
Cereal & 0.1 & 0.1 & 0.3 & 0.0 & 1.7 \\
Livestock & 0.0 & 0.0 & 0.0 & 0.0 & 0.1 \\
Oil seeds & 2.0 & 4.5 & 3.1 & 0.2 & 0.0 \\
Other Crops & 0.5 & 0.4 & 0.3 & 0.1 & 0.4 \\
$\begin{array}{l}\text { Vegetable oil } \\
\text { Processed other }\end{array}$ & 0.0 & 0.0 & 0.1 & 0.0 & 0.0 \\
crops & 3.1 & 1.3 & 3.3 & 0.8 & 7.6 \\
$\begin{array}{l}\text { Processed meat } \\
\text { Processed milk }\end{array}$ & 0.7 & 1.8 & 0.1 & 0.2 & 1.4 \\
$\begin{array}{l}\text { Sugar } \\
\text { Beverage and }\end{array}$ & 0.0 & 0.1 & 0.0 & 0.0 & 0.1 \\
tobacco & 0.9 & 2.3 & 2.5 & 0.8 & 5.6 \\
Total agric. & $\mathbf{1 3 . 5}$ & $\mathbf{1 0 . 5}$ & $\mathbf{9 . 9}$ & $\mathbf{2 . 9}$ & $\mathbf{2 2 . 7}$ \\
$\begin{array}{l}\text { Sector } \\
\text { Mining and }\end{array}$ & 24.2 & 6.2 & 2.9 & 5.0 & 2.2 \\
$\begin{array}{l}\text { mineral products } \\
\text { Textiles }\end{array}$ & 12.0 & 3.1 & 7.5 & 1.3 & 8.6 \\
$\begin{array}{l}\text { Manufacturing } \\
\text { Total }\end{array}$ & 38.6 & 70.1 & 43.8 & 64.1 & 42.9 \\
manufacturing & $\mathbf{7 4 . 8}$ & $\mathbf{7 9 . 3}$ & $\mathbf{5 4 . 2}$ & $\mathbf{7 0 . 4}$ & $\mathbf{5 3 . 7}$ \\
Service & $\mathbf{1 1 . 6 6}$ & $\mathbf{1 0 . 2 0}$ & $\mathbf{3 5 . 9 5}$ & $\mathbf{2 6 . 7 6}$ & $\mathbf{2 3 . 5 4}$ \\
\hline
\end{tabular}

Source: GTAP Database Version 4.

On the import side, most ASEAN members experience relatively low import share on agricultural products that range from 5 percent (Singapore) to 11 percent (Philippines) (see 
Table 2.9). Examining the continuous and enormous effort, committed by the members to achieve self-sufficiency in food products, this finding is not surprising. For instance, the Food and Agriculture Organisation (FAO) in 1984 recognised and awarded the Indonesian government for its achievement in attaining rice self-sufficiency. Before 1984 Indonesia was well known as one of the major rice importers. Mobilising resources with various programmes such as intensification, land diversification and land rehabilitation have resulted in the remarkable increase in rice production.

Focusing on individual sectors, the share of sugar imports in Singapore and Indonesia are the highest compared to other agricultural products that accounts for around $1.5 \%$ and $2.8 \%$, respectively. On the other side, processed other crops import in Thailand and the Philippines remains high, accounting for around $2 \%$. Table 2.9 also suggests the importance of rice sector in the Indonesian economy as shown by the relatively high import share. This is largely due to the increase in the demand for rice that is driven mostly by the increasing size of the population. It is estimated that Indonesian import on rice will continually rise due to the recent Letter of Intent (LoI) between the Indonesian government and the International Monetary Fund (IMF). Under this agreement, both parties have established a framework of reforms for an IMF-loan to Indonesia in series of agreements in late 1997 and early 1998. The reforms will affect the Indonesian import structure since they eliminate the import monopoly power of the Indonesia's National Logistics Agency (BULOG) as well as subsidies for wheat, wheat flour, sugar and garlic. More important, other measures included the reduction of tariffs on all food items to a maximum of a 5 percent level, the de-regulation on trade across districts and the provincial boundaries within the economy and the removal of formal and non-formal barriers to investments in palm oil plantations. Recently the IMF rejected the plan, proposed by the government to impose a 30 percent import duty on rice in time of scarcity and 65 percent in harvest time as a means of protecting rice farmers. According to the LoI, the Indonesian government is allowed to impose import tariffs on rice by 25 percent import duty in scarcity time and 35 percent in harvest time ${ }^{19}$.

\footnotetext{
${ }^{19}$ Asia Times, November 22, 2001.
} 
Table 2.9 Shares of Individual Sector in the Total Import Value, 1995 (\%)

\begin{tabular}{lccccc}
\hline & Indonesia & Malaysia & Philippines & Singapore & Thailand \\
\hline Rice & 1.7 & 0.4 & 0.4 & 0.1 & 0.0 \\
Cereal & 0.5 & 0.4 & 0.4 & 0.1 & 0.0 \\
Livestock & 1.4 & 1.7 & 1.7 & 0.0 & 0.4 \\
Oil seeds & 0.3 & 0.2 & 0.2 & 0.4 & 0.1 \\
Other Crops & 0.4 & 0.3 & 0.3 & 0.4 & 0.7 \\
Vegetable oil & 0.5 & 0.3 & 0.2 & 0.1 & 0.1 \\
Processed other & 1.3 & 1.0 & 2.1 & 1.3 & 2.0 \\
crops & & & & & \\
Processed meat & 0.2 & 0.4 & 0.5 & 0.3 & 0.1 \\
Processed milk & 0.5 & 0.9 & 2.0 & 0.3 & 0.7 \\
Sugar & 2.8 & 1.5 & 1.1 & 1.5 & 1.1 \\
Beverage and & 0.2 & 0.3 & 1.7 & 0.8 & 0.4 \\
tobacco & & & & & \\
Total agric. & $\mathbf{9 . 7}$ & $\mathbf{7 . 2}$ & $\mathbf{1 0 . 5}$ & $\mathbf{5 . 2}$ & $\mathbf{5 . 6}$ \\
$\begin{array}{l}\text { Sector } \\
\text { Mining and }\end{array}$ & 7.2 & 2.6 & 7.9 & 8.0 & 6.6 \\
mineral products & & & & & \\
Textiles and & 4.5 & 2.5 & 4.5 & 2.6 & 2.3 \\
clothing & & & & & \\
Manufacturing & 63.5 & 77.1 & 62.4 & 72.5 & 69.7 \\
$\begin{array}{l}\text { Total } \\
\text { manufacturing }\end{array}$ & $\mathbf{7 5 . 1}$ & $\mathbf{8 2 . 2}$ & $\mathbf{7 4 . 8}$ & $\mathbf{8 3 . 0}$ & $\mathbf{7 8 . 6}$ \\
Service & $\mathbf{1 5 . 2}$ & $\mathbf{1 0 . 6}$ & $\mathbf{1 4 . 8}$ & $\mathbf{1 1 . 8}$ & $\mathbf{1 5 . 8}$ \\
\hline Source: GTAP Data & & & & &
\end{tabular}

Source: GTAP Database Version 4

Table 2.10 summarises the net trade balance position in 1995. In general, Indonesia, Malaysia and Thailand can be categorised as net food exporters. On the other side, Singapore and Philippines are net importers. However, taking a closer look at the individual basis, a significant difference within the members is apparent. All of the ASEAN countries import more cereal and sugar than export. Recalling the definition of sector used in this study it is understandable that the members have to cover domestic demand for such products, specifically cereals with the import. This is due to the fact that wheat does not grow well in this region. As a result, the members import cereal (wheat) mostly from Australia and the USA (see Appendix Figure 2.17).

Table 2.10 also outlines that the rice sector in Thailand dominates its export earnings. Examining more closely the agricultural net trade balance position, around $\$ 4.3$ billions has 
been generated solely from the export of rice products. Meanwhile net trade for processed agricultural products accounts for $\$ 3.7$ billion. A similar pattern of net trade balance is also found in the case of Indonesia and Malaysia. They are also net exporters for vegetable oil and crop products. In addition, as one of the world's major exporter of vegetable oil, especially export of palm oil and its derivatives, the Malaysian net trade balance for such products is larger than for other agricultural products such as processed agricultural products. Due to high comparative advantage in the vegetable oil production, it is not surprising that all members have agreed to include vegetable oil into the first CEPT programme.

Table 2.10 Net Trade Balance Position (US\$ billion) 1995

\begin{tabular}{lccccc}
\hline & Indonesia & Malaysia & Philippines & Singapore & Thailand \\
\hline Rice & -0.85 & -0.32 & -0.19 & -0.17 & 4.28 \\
Cereal & -0.75 & -1.42 & -0.75 & -0.05 & -0.32 \\
Crops & 2.28 & 0.44 & 0.20 & -0.89 & 3.06 \\
Vegetable oil & 0.96 & 3.28 & 0.72 & -0.25 & -0.08 \\
Oil seeds & -0.24 & -0.21 & -0.06 & -0.09 & -0.08 \\
Livestock & 0.07 & 0.11 & -0.07 & -0.39 & -0.38 \\
Sugar & -0.23 & -0.28 & -0.08 & -0.12 & 1.22 \\
Processed crop & 1.02 & 0.11 & -0.03 & -0.71 & 3.72 \\
Processed meat & 0.25 & 0.99 & -0.18 & -0.10 & 0.92 \\
Processed milk & -0.24 & -0.64 & -0.86 & -0.32 & -0.61 \\
Beverage and & -0.04 & -0.16 & -0.69 & -0.12 & -0.25 \\
tobacco & & & & & \\
Total agric. & $\mathbf{2 . 2 3}$ & $\mathbf{1 . 9}$ & $\mathbf{- 1 . 9 9}$ & $-\mathbf{3 . 2 1}$ & $\mathbf{1 1 . 4 8}$ \\
sector & & & & & \\
Mining and & 9.34 & 2.56 & -2.71 & -4.05 & -4.58 \\
mineral products & & & & & \\
Textiles & 4.18 & 0.23 & 0.03 & -1.75 & 4.21 \\
Manufacturing & -12.78 & -12.10 & -15.85 & -12.81 & -33.97 \\
Total \\
manufacture
\end{tabular}

Source: GTAP Database Version 4.

\section{5. Export Destinations and Import Sources}

\section{5. 1. Export Destinations}

Table 2.11 summarises the destinations of ASEAN exports. Individual ASEAN member exports to other ASEAN members, ranges from 12 \% (Indonesia) to $25 \%$ (Malaysia) with the 
exception of exports from Malaysia to Singapore and Singapore to Malaysia. Exports to the individual ASEAN member account for less than $10 \%$, even in some cases only $1 \%$. This figure suggests that ASEAN important trading partners together with ROW are their most important destinations of export. The position of Singapore as the entrepot point for ASEAN commodities is obviously apparent. Singapore becomes a second ASEAN export destination. For example, exports of Malaysian goods and services to Singapore make up $19 \%$ of its total value of export, more than to the European Union and Japan. Surprisingly, Singapore exports to Malaysia account for $11 \%$, which is equal to the exports to Japan. This figure provides the insights of the likely impact of the AFTA trade liberalisation through the reduction and removal border tariff rates with the ASEAN member countries.

Table 2.11 Destinations of ASEAN Export, 1995 (Percent of Total Value of Exports)

\begin{tabular}{lccccc}
\hline & & \multicolumn{3}{c}{ Importing Countries } & \\
& Indonesia & Malaysia & Philippines & Singapore & Thailand \\
\hline Indonesia & & 1.0 & 1.0 & 2.0 & 1.7 \\
Malaysia & 1.9 & & 1.9 & 1.3 & 2.5 \\
Philippines & 1.3 & 0.9 & & 1.6 & 0.8 \\
Singapore & 7.0 & 19.4 & 4.5 & & 8.6 \\
Thailand & 1.4 & 3.6 & 2.5 & 4.0 & \\
ASEAN & 11.6 & 24.9 & 9.9 & 18.9 & 13.6 \\
European Union & 16.8 & 14.6 & 21.1 & 14.0 & 16.9 \\
Japan & 26.4 & 13.8 & 18.4 & 11.2 & 20.3 \\
USA & 14.8 & 21.0 & 11.2 & 18.9 & 18.1 \\
ROW & 30.4 & 25.8 & 20.3 & 37.0 & 31.1 \\
\hline
\end{tabular}

Source: GTAP Database Version 4.

Appendices Figures 2.1-2.11 present the destination of exports of an individual ASEAN country for agricultural products. Starting from export destination of rice products, the export destination of rice products was rest of the world (ROW) that accounted for 70 percent (Thailand) and 90 percent (both Indonesia and Singapore). Based on Appendix Figure 2.1, it appears that the ASEAN market for rice is very small as reflected by the small shares of rice products exported by either Singapore or Thailand to this region. Nevertheless from the ASEAN point of view, Thailand is the major rice supplier especially for Indonesia whereby the Thailand's export share to Indonesia accounts for more than 10 percent of its total rice export. 
Different from the patterns of export destination of rice products, the members see this region as an important market for their cereal. For example, Indonesia exports mostly to Malaysia and in the same time Singapore became a major Malaysian export destination of this product. In addition, Indonesia was an important destination of Philippine cereal export that accounted for almost 90 percent of its total cereal export. Export to non-ASEAAN members was also reported in the case of Singapore and Thailand. The rest of the world was reported to be a major Singapore export destination of cereal products.

ASEAN export destinations of crop, oil seeds and livestock are depicted in Appendix Figures 2.3-2.5. Appendix Figure 2.3 reveals that despite the importance of ROW as a main ASEAN export destination for crop, ASEAN members, particularly Indonesia and Malaysia consider other members as their export destination for this commodity. For instance, Indonesian export share to Malaysia is close to 20 percent. Well over 60 percent of Malaysian exports of this product are even destined for the Singapore market.

In the context of oil seeds trade, large shares of exports to ASEAN members are reported, especially in the case of Indonesia, Malaysia and Thailand. In average, their exports to other ASEAN countries account for around $30 \%$ of their total value of oil seeds export. With regard to the ASEAN export destination for livestock, it is reported that Malaysia's export to Singapore accounts for almost 90 percent of its total value of livestock export. By contrast, most of Philippine livestock exports are destined to non-ASEAN countries specifically Japan and ROW.

In connection with the exports of processed agricultural products: processed crop and processed meat, Japan and ROW are major ASEAN export destination. However, concerning exports of processed milk, Indonesia, Malaysia and Philippine still consider the ASEAN to be an important market for their export. Malaysian export to Singapore and Indonesian export to Malaysia as well as Philippine export to Singapore account for $70 \%, 60 \%$ and $30 \%$, respectively. 


\section{5. 2. Import Sources}

Having discussed the destinations of the ASEAN export, this section will be devoted to elaborating the sources of the ASEAN imports. Since the scenarios implemented in this study are largely based on the reduction or removal of import tariff rates, therefore the patterns of bilateral trade or imports are important to identify. Sources of the ASEAN import reveal basically the same patterns as the export one, as can be seen in Table 2.12 below. Again the non-ASEAN market is important for the ASEAN economies. For example, ROW and Japan remain the major ASEAN sources of import that account approximately for $30 \%$ and $20 \%$, respectively. On the other side, shares of imports from the ASEAN economies to individual members vary from $9 \%$ (Indonesia) to $22 \%$ (Malaysia and Singapore). Similar with what has been mentioned in the context of export destinations, Singapore remains the entrepot point for other ASEAN economies. Almost $80 \%$ of Malaysian imports from the ASEAN members stem from Singapore.

Table 2.12 Sources of ASEAN Imports, 1995 (Percent of Total Value of Imports)

\begin{tabular}{lrrrrc}
\hline & \multicolumn{5}{c}{ Importing Countries } \\
& Indonesia & Malaysia & Philippines & Singapore & Thailand \\
\hline Indonesia & & 1.4 & 1.8 & 3.0 & 1.0 \\
Malaysia & 1.8 & & 2.2 & 13.1 & 3.8 \\
Philippines & 0.5 & 0.6 & & 0.9 & 0.8 \\
Singapore & 5.1 & 17.9 & 5.6 & & 5.9 \\
Thailand & 1.9 & 2.3 & 1.6 & 4.6 & \\
ASEAN & $\mathbf{9 . 3}$ & $\mathbf{2 2 . 2}$ & $\mathbf{1 1 . 1}$ & $\mathbf{2 1 . 7}$ & $\mathbf{1 1 . 5}$ \\
European & 24.4 & 17.8 & 16.6 & 14.0 & 21.2 \\
Union & & & & & \\
Japan & 20.8 & 22.2 & 21.0 & 20.1 & 27.4 \\
USA & 8.0 & 13.3 & 17.8 & 14.3 & 11.7 \\
ROW & 37.5 & 24.5 & 33.4 & 29.9 & 28.3 \\
\hline SOUn
\end{tabular}

Source : GTAP Database Version 4.

Appendices Figures 2.12-2.22 show the patterns of sources of the ASEAN imports. Sources of the imports of unprocessed agricultural commodities, such as rice, cereal, oil seeds, crop and livestock are first discussed. ASEAN member states are reported to have imported rice mostly from Thailand. Even rice imported from this country in Singapore, Malaysia and Philippines account for a larger proportion of their total value of import. On the other hand, 
ROW is a major source of import for Indonesia that accounted for more than 60 percent of Indonesia rice import (Appendix Figure 2.12) ${ }^{20}$. Based on this figure, it can be expected that reducing import tariff rates for rice will lead to increasing rice imports in the ASEAN members. Concerning other unprocessed agricultural commodities, all ASEAN nations import these products mainly from the USA and ROW. For instance, over 80 percent of Philippine cereal import was imported from the USA. In addition, ROW remains a major source of imports for Indonesia, Malaysia and Singapore. The reliance of ASEAN members on nonASEAN members as a major source of cereal is because of a natural constraint where wheat cannot grow well in the tropical climate. Similar patterns also apply for imports of oil seeds and crops, although in a case of livestock and crop imports in Singapore, this country imports from Malaysia that amounts to $80 \%$ and $20 \%$ of its total value of imports.

Appendix Figures 2.17 - 2.22 show sources of imports of processed agricultural products: vegetable oil; processed crop; processed meat; processed milk; sugar; and beverage and tobacco products. Compared to sources of import of unprocessed agricultural products, relatively different patterns exist. Despite the fact that non-ASEAN regions are considered a major source of ASEAN import, ASEAN members demand these products from ASEAN markets itself. For example, Malaysia is a major ASEAN source of vegetable oil import. Singapore even imported it from Malaysia, accounting for more than 90 percent of its total import. The importance of ASEAN members as a major source of vegetable oil import has been predicted during the process of forming the ASEAN Free Trade Area (AFTA) agreement. As to the AFTA Plan, the initial AFTA agreement included only vegetable oil into the tariff reduction scheme for the category of agricultural products. This was due to the fact that Indonesia and Malaysia are the world major producers of vegetable oil (crude palm oil).

A high reliance of ASEAN economies on non-ASEAN economies is evident in terms of import of processed milk. With the exception of Singapore, all ASEAN economies import processed milk from ROW, EU and USA, respectively. For this reason, the implementation of the AFTA trade liberalisation would have no impacts on trade on this commodity. Despite the

\footnotetext{
${ }^{20}$ Beside Thailand, Vietnam is a major rice export due to the government intervention to increase rice production by establishing an“ export zone area”, providing a high quality of seed and determining a floor price.
} 
fact that Singapore was reported to have imported dairy products from Malaysia, AFTA would have a small effect, since the level of import tariffs for Singapore has been very low and even zero for some cases. Different from the patterns of imports of processed milk, the important of Thailand for the ASEAN sugar import is illustrated in Appendix Figure 25. The figure shows that for example the Indonesian and Philippine market on sugar are highly dependent on the supply from Thailand. This is quite similar with the case of rice imports. This figure also suggests the importance of Thailand as a major sugar producing country, at least in the context of ASEAN trade.

In terms of import sources of non-agricultural products, a considerable difference of sources of import patterns is that non-ASEAN member countries are the only sources of imports of nonagricultural commodities. This supports the international trade theory that trade between developed countries and developing countries is largely inter-industry. This is due to the difference in factor endowments and technological processes (LEWIS, ROBINSON and THIERFELDER, 2001). The developed countries provide capital goods and services for developing countries. Japan has become a major source of manufacturing imports for ASEAN countries. Given the shortage of intermediate and capital goods necessary for product manufacturing, the ASEAN nations import such goods from Japan for manufacturing. In contrast, the ASEAN nations rely largely on the imports of service from the European Union. The only ASEAN member country that exports manufacturing products to the ASEAN nation is Singapore. However, trade pattern does not reflect the production capacity of this country, but merely highlights the vital position of this country as an entrepot country for other ASEAN member countries. 


\section{Chapter III}

\section{The Structure of Multicountry and Multisector Model for ASEAN Free Trade Area (AFTA)}

\section{1. A Basic General Equilibrium Model}

It has been a long tradition that economists employ General Equilibrium (GE) to analyse the complexity of economy to overcome some weaknesses of partial equilibrium models. ADELMAN and ROBINSON (1978) have initially pioneered the use of a model of applied general equilibrium in developing countries. Since then, many models of applied general equilibrium have been developed by linking countries and regional models. In response to increasing needs of general equilibrium analysis, several institutions have developed CGE models that are publicly accessible: for instance: Monash University (Australia) with the ORANI model and Purdue University (USA) with the Global Trade Analysis Project (GTAP) model and database. The later is now widely used by researchers around the world, especially those who are focusing on changes in trade policies and any related issues. This database is regularly up-dated in accordance with latest bilateral trade data and also improved in terms of a number of commodities and regions.

Today the world witnesses a growing number of regional economic integration, pursued not only by developed countries but also by developing countries as a means of stimulating economic growth and facilitating structural adjustment (INNWON, 1995). This increasing regional economic integration pursued contributes to the increasing use of a computable general equilibrium model in order to investigate the implications of such economic integration on welfare, production and trade. Multilateral agreement under the auspices of the GATT/WTO and such agreement concerning the reduction of carbon dioxide emission, for instance the Kyoto Protocol contribute to the increasing application of CGE models.

CGE models are developed to represent economic interaction among actors and sectors in the whole economy. By introducing a change in policy instrument for example reduced import tariff rates in the model, the model will move to a new economic equilibrium. Thus 
researchers can now estimate the deviation of results being examined relative to the values in benchmark equilibrium. In other words, CGE models work by simulating the interaction of various economic actors (consumers, producers, and government) across markets. Optimising behaviour of individual economic actors is a fundamental assumption of CGE models. This behaviour is described in equations explaining various first-order conditions for profit and utility maximisation.

Following ROBINSON (1989) there are four components underlying a CGE model. First of all, the specification of economic actors is being examined and analysed. In a simple CGE model, there are usually two economic actors, such as consumers and producers. However, in a large CGE model, other institutions particularly government and rest of the world are incorporated in the model. Including other regions in the model is also common in order to identify the repercussion effects of, for instance, changes in trade policies in other regions on the economy of the region in question. Secondly, the assumption behind the behaviour of institutions mentioned above should be clearly specified. For producers, maximising profits subject to technological constraints is usually assumed. Likewise, consumers are assumed to maximise their utility with respect to income constraints. Thirdly, prices play a very important role in guiding agents to make decisions. In a Walrasian model, prices are the only signals that agents need to know. And fourthly, modellers should specify "the rules of the game” according to which agents interact. Under the assumption of perfect market competition, each agent is a price taker and prices are flexible. However, under the monopolistic market, the decision of the agent on supply is based on information about the demand function of the demander by equalising its marginal cost to its marginal revenue.

Robinson (1989) added other important issues related to building a CGE model are a numeraire and the Walras' law. In the CGE analysis absolute price levels will be not determined. The model is concerned only with relative prices. This reflects the well-known fact that if all prices for example increase in the same proportion but relative prices are unchanged, the real relationship in the economy is then unaltered. This specification is related to the assumption of homogeneity of degree zero for supply and demand functions. The choice of numeraire is a matter of convenience, thus any price can be arbitrarily set to 1 . The 
numeraire good is therefore the good the price of which is set to 1 and changes in all other prices are determined relative to the numeraire good.

In the general equilibrium analysis, the equality of demands and supplies across all product and factor markets must always hold. This implies that the sum of the excess demands across markets must be zero. This proposition is known as Walras' Law. This law states that with $m$ economic agents and $n$ markets, if all economic agents satisfy their budget constraints and $n-1$ markets are in equilibrium, with the quantity demanded equal to the quantity supplied, then the $n$th market will be automatically in equilibrium.

Table 3.1 provides a set of equations. For sake of simplicity, foreign markets are represented by only one foreign market. The economy produces also a single commodity $X$. This commodity is produced not only using primary factors (capital and labour) but also intermediate input. This is represented by equation (1). Equations (11) and (12) are demand functions for primary factors (capital and labour). The number of factors demanded depends on rental rate of capital, labour wage, output price and composite price. As mentioned before domestic producing sector faces two types of market: domestic and export markets. Therefore, commodity $X$ is transformed into an export commodity $E$ and domestic-marketed commodity D. Commonly, a Constant Elasticity of Transformation (CET) function is employed to transform commodities into export and domestic markets. The price of the transformed commodity is represented by equation (26). In multi-region CGE models, a two level CET function is often used. First, a first level of CET function transforms domestic-marketed commodity and export commodity. In the second level, a CET function is used to transform export commodity into different export destinations.

Household, government and producing sectors demand composite goods that are supplied by domestic producers and foreign markets (imported goods). Equation (3) determines how to aggregate both commodities. Its composite price is provided in equation (25). Researchers often assume imperfect substitution between domestic and imported goods. The Armington assumption has been commonly applied using a Constant Elasticity of Substitution (CES) function to represent this imperfect substitution. Similar with the export transformation 
function (CET), a two level CES function is commonly used. HERTEL, IANCHOVICHINA and MCDONALD (1997) discuss different procedures to deal with the use of Armington function. In applying this function, researches may choose to track differentiated import to the users or aggregated imports to users. The latter however is more demanding in terms of different values of Armington elasticties and mathematical equations.

Equations (2) and (3) describe a transformation of commodities into domestic and foreign markets and an aggregation of domestic and imported commodities into composite products. By maintaining assumptions of profit maximisation for producers and of cost minimisation for domestic consumers (household, government and producing sectors), a level of desired import and export ratios are given by equations (4) and (5) that is a function of import price, export price and domestic price. These prices are derived using cost dual functions of equation (3) and (2).

The most important elements underlying the development of general equilibrium analysis are (a) system constraints and (b) accounting identities. In this small open economy model, demands for goods and primary factors are subject to the availability of these goods and factors as seen in equations (13) - (15). Accounting identities or zero profit conditions guarantee the same values between demands and expenditures; and outputs and inputs as presented by equations (31) - (35). 


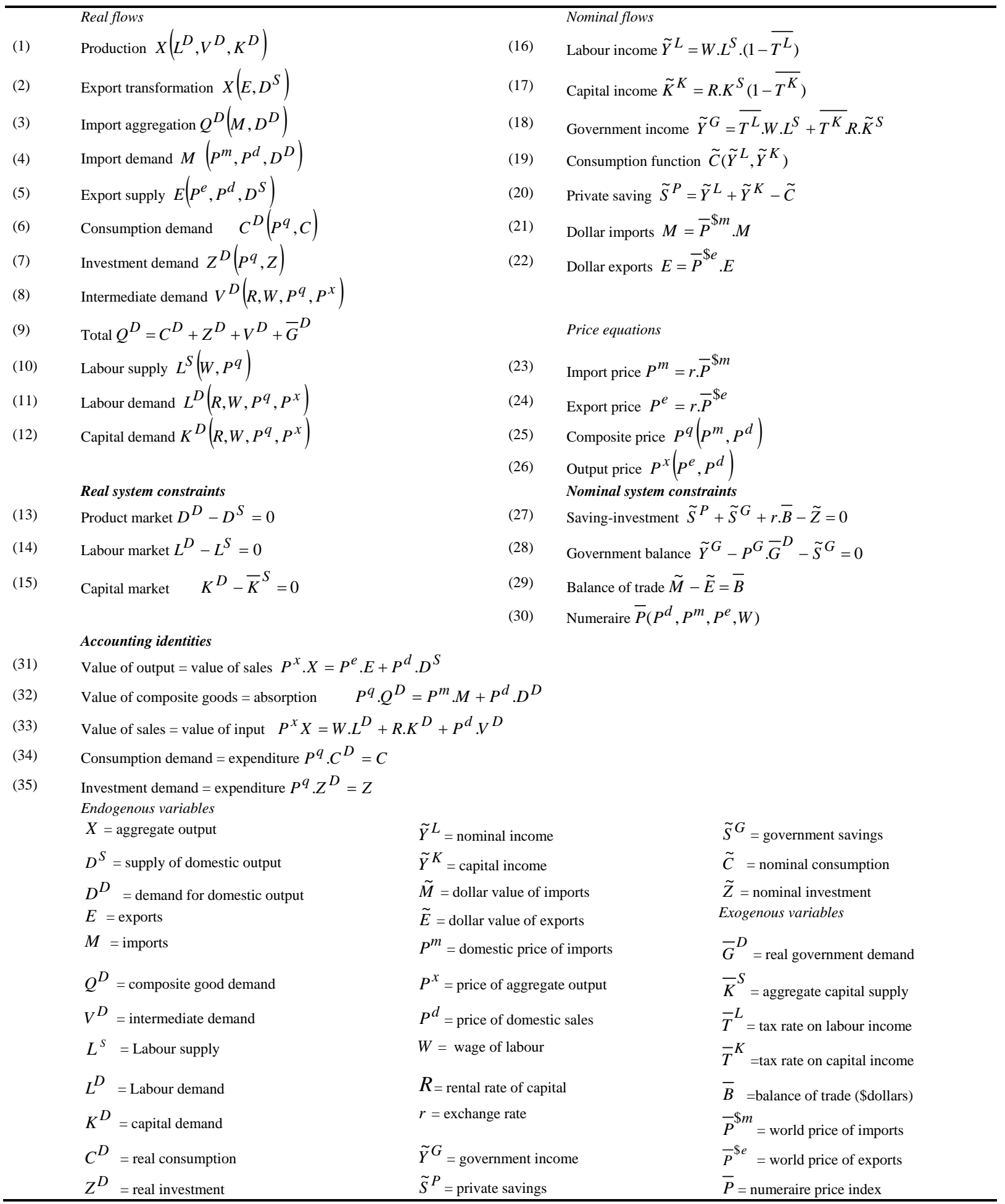

Notes: Variables with a tilde denote nominal magnitudes. Variables with a bar are exogenous. The superscripts d, $\mathrm{m}$, e, $\mathrm{x}$, and q refer to the domestic good, imports, exports, output, and the composite good, respectively (D, M, E, X, and Q). The superscripts D and S refer to demand and supply. The superscripts L and $\mathrm{K}$ refers to labour and capital. Superscripts $\mathrm{P}$ and $\mathrm{G}$ refer to private and government.

Source: ROBINSON (1989) 


\section{2. Advantages and Disadvantages of CGE-Model}

Regarding the extensive uses of the computable general equilibrium (CGE) model, researchers are concerned with the capability of such a method in representing the real world. Therefore, this section summarises the advantages and disadvantages of the CGE analysis. Exploring both natures of such models will provide a meaningful guidance in interpreting results of this model.

Advantages of the CGE model include:

- The formulation of developing a CGE framework requires an explicit and complete specification of both supply and demand sides in all markets: output and input markets (ROBINSON, 1989). And all economic actors behave to optimise their goals (minimising costs for producers and maximising utilities for consumers). In other words, the CGE models have a solid microeconomic foundation that can guide to interpret results of simulations or a counterfactual analysis.

- Due to the ensured internal consistency of the model, researchers can use the model for policy evaluation with many implications (INNWON, 1995).

- As a result of incorporating various markets in the model, the model can capture the impact of counterfactual analysis not only in the sector in question but also in either downstream or upstream sectors. This depends on the commodities or sectors being examined in the models (see RAE, CHATTERJEE and SHAKUR, 1999). In other words, the CGE model permits taking into account interactions throughout the economy in a consistent manner.

- This ability of capturing desegregated commodities and private households provides researchers with wide opportunities to examine for example structural aspects in developing countries, corresponding to market distortions and failures where developing countries experience these phenomena (INNWON, 1995).

- Many aspects of economic analysis such as the impact of government policies on national welfare (gain or loss), terms of trade, and income distributions / poverty can be examined in the same time when using a general equilibrium model. 
Despite some advantages or strengths of a general equilibrium model described above, some criticisms also turn up which limit these strengths of such a model.

- Econometricians criticise a lack of significance of results from the general equilibrium model. It is very common to have a test of the fitness of econometric models. Based on the significance of the parameters being estimated, researchers may suggest policy implications. However as GUNNING and KEYZER (1985) suggested a full system econometric estimation of parameters is almost impossible. This is because of two reasons: (a) identification problems and (b) lack of data. On the other side, CGE models rely highly upon the calibration procedure where most parameters such as elasticities are derived from literature sources. However, one has to be careful to values of elasticities from various sources. This is because the number of sectors and also the year of publication are different from the sectors being analysed. Relating to this issue, HERTEL, IANCHOVICHINA and MCDONALD (1997) emphasised that empirical estimations of such elasticities, particularly Armington elasticities, present several challenges: (a) different definitions of sectors (narrowly and widely defined sectors), (b) regional aggregation as well as product aggregation and (c) the appropriate time frame for econometric estimation. In connection with this weakness, JORGENSON (1984) has incorporated values of elasticity parameters based on econometric estimation. In addition, BANSE (1997) calibrated a consumer demand function using an AIDS demand function by imposing the restrictions of demand theory such as homogeneity, adding up and symmetry.

- Currently dynamic CGE models are widely applied to examine the impact of various issues of changes in trade policies. However, in the context of this kind of model, BORGES (1986) in INNGWON (1995) indicated a problem in areas of inter-temporal issues and expectations. Recursive dynamic CGE models are lacks of future expectations facing economic actors in the models. Researchers then assume a myopic expectation where the economic actors determine their decision based on previous information.

- The complexity of models that incorporate, for instance several sectors, institutions and regions in a case of multi-region CGE models may cause difficulties in interpreting results, and difficulties to represent detailed policy measures. 


\section{3. Calibration Procedure}

As has been discussed earlier, one of the weaknesses of general equilibrium analysis is a lack of significant parameters being estimated. GE modellers often apply a procedure of calibration and "guess-estimation" of parameters instead of estimating the parameters (INGWON, 1995). Values of elasticities are key parameters to be determined outside of the model. CGE modellers rely mostly on the availability of published parameter estimates. However, before proceeding to the discussion of the calibration process, it is important to have a look at the concept of calibration (MANSUR and WHALLEY, 1984). This process describes as the common procedure to 'calibrate' the model to a base year observation. The 'calibration' reflects the ability of the model to reproduce base year data as a model solution. According to this explanation, GE modellers are required to reproduce economic equilibrium (benchmark equilibrium) on the basis of year to be selected. The selection of a year is often very critical due to the data availability and the objective of research (ex ante and ex post analysis). In connection with problems concerning ex ante and ex post estimations, GRENNWAY (1983) provides discussions of these issues.

Following SHOVEN and WHALLEY (1984) the flow chart of the calibration procedure is provided in Figure 3.1. The first step of a calibration procedure is to collect basic data for economy for a single year or an average of years. Major data required to be assembled include production, resources, trade flows, government policies depending on issues to be analysed, for instance government revenues from import tariff, household taxes and output taxes, household income and expenditure, national income and expenditure and any related data.

As depicted in Figure 3.1, the next step is to develop a benchmark equilibrium data set. In this process, a mutual consistency of constructed data set becomes very important due to the fact that most of data collected are supplied from different sources and years of publications. The term of a benchmark equilibrium data set always refers to the development of a matrix containing balances for all commodities and budget constraints for all agents, called Social Accounting Matrix (SAM) (GUNNING and KEYZER, 1995). Referring to the construction of the SAM, three conditions that need to be satisfied are (a) demands equal supplies for all commodities, (b) zero profit condition in all industries (producing sectors). This condition 
reflects the assumption of constant return to scale that allows industries not to have profits.

And (c) Demand for all commodities facing economic agents (private and public households) satisfies their budget constraints (WHALLEY, 1985).

Figure 3.1 Flow Chart Outlining Calibration Procedures and Model Use in Typical Applied General Equilibrium Model

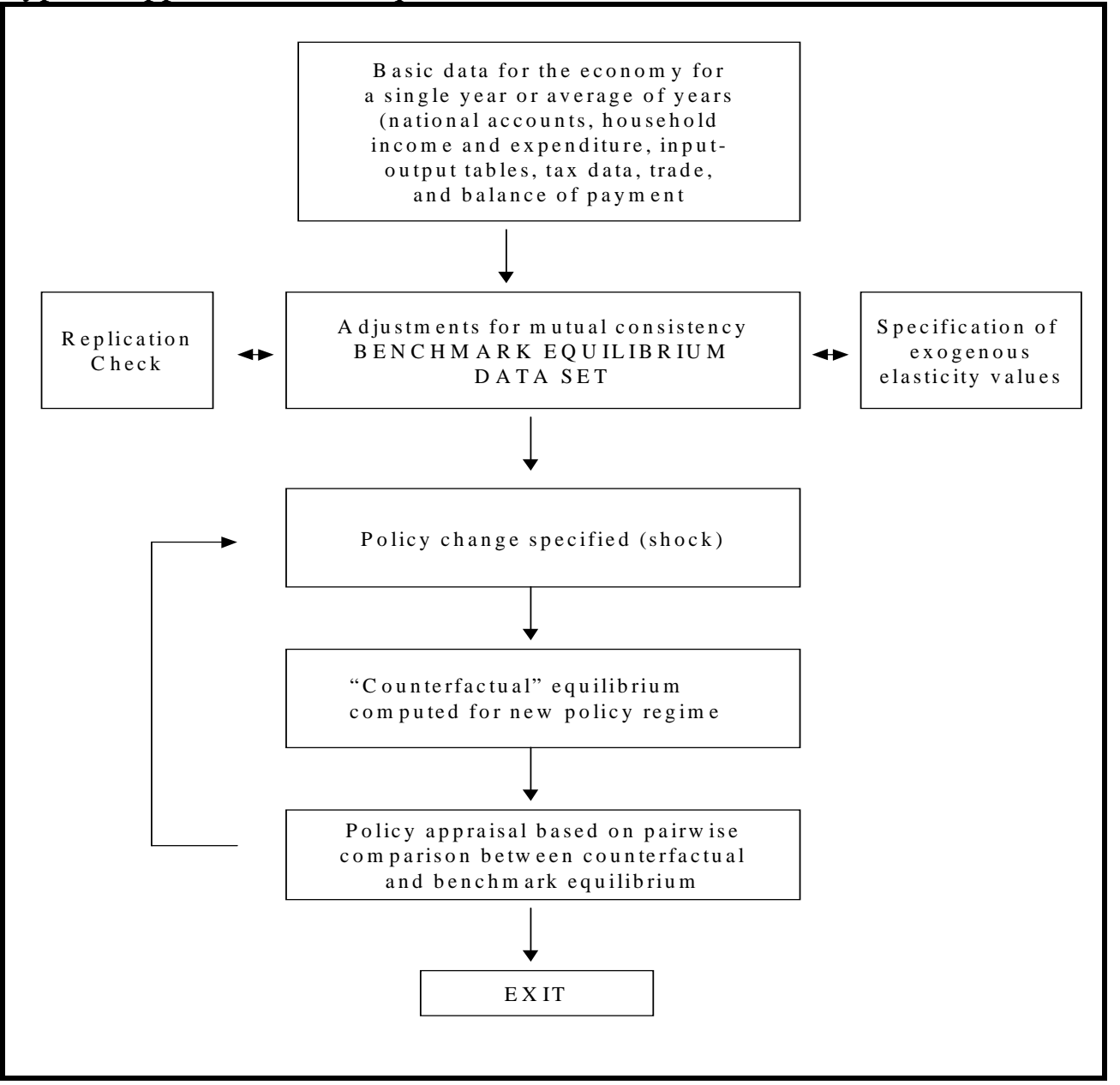

Source: SHOVEN and WHALLEY (1992), p 104.

In addition, the chosen number of commodities and agents depend very much on the objective of any study. This choice of classification of commodities and agents seems to be one of the most decisive steps. However, the manageable size of models should be taken into consideration. For a more and further discussion on the development of SAMs, see PYATT and ROUND (1985). 
Having constructed the SAM, a replication check is to be made in order to reproduce a consistent benchmark equilibrium data set. In doing so, modellers are required to specify functional forms, for instance: production functions for producing sectors and demand functions for private and public households. The choice of functional forms is related to the selection of corresponding elasticities. Cobb-Douglas and Constant Elasticity Substitution (CES) functions become common functional forms be used in modelling production and demand functions. This is due to the simplicity of these functions. The choice of functional forms has an implication on parameters used in the calibration process. The parameters are more or less identical with elasticities (MANSUR and WHALLEY, 1984). For example, if the CES function is chosen, values of substitution elasticities between primary factors should be supplied. Likewise, if a Lineal Expenditure System (LES) is used to represent demand function, values of income (expenditure) elasticities on individual commodities being examined in models are required. These elasticities are augmented by either a literature search or an econometric estimation. Using chosen functional forms, selected values of elasticities and assuming all the equations describing the equilibrium in the system (model) are met in the benchmark period, the next process is to replicate the observed flow values incorporated in the social accounting matrix (SAM). If this process produces new data that are identical with the observed data in the SAM, the calibration process ends.

As the model has been calibrated to the benchmark equilibrium data set, modellers now can introduce policy changes (shocks) in the model. The kind of policy changes introduced into the model depends on the objective of research. In examining for example the impact of trade liberalisation pursued by nation(s), a reduction or removal of border tariffs is often made. However in the complicated situation, modellers may introduce several policy changes into model in order to examine the impact of a reduction or an abolition of trade barriers. By introducing a shock into the model, the new equilibrium or the counterfactual equilibrium can be calculated. As a result, the impact of policy changes can be computed by comparing the counterfactual and the benchmark equilibria. The interpretation of results is then made based on a comparison between both equilibria. The impact of further policy changes can be also observed by introducing scenarios. 


\section{4. The Production Sector of the Model}

In this study, a custom-built CGE developed by RUTHERFORD (1998) ${ }^{21}$ will be used. The structure of this model is similar with the standard Global Trade Analysis Project (GTAP) model with some differences in some parts, particularly the specification of investment behaviour. In applying this model into the ASEAN countries, some modifications have been made. For instance, the Linear Expenditure System (LES) function for household demand is adopted replacing a Cobb-Douglas function. With the adoption of the LES functional form, it relaxes the assumption that income elasticity in the Cobb-Douglas function is unitary. In the standard GTAP model ${ }^{22}$ the Constant Difference in Elasticities (CDE) that was initially developed by HANOCH (1978) is chosen to represent a private demand function. It is acknowledged that the CDE allows for a richer representation on income effects in the demand system $^{23}$. However, due to the use of the system of a mathematical programming system for general equilibrium analysis (MPSGE) which operates as a subsystem within GAMS (General Algebraic Modelling System), modellers face a restricted choice to apply flexible demand system. Only the Cobb-Douglas (CD), the Constant Elasticity of Substitution (CES) functions and the LES can be used in the MPSGE system.

This section describes the model used in this study, focusing firstly on the production structure, secondly on demand structure (private household, public household and investment). The other sections present the Armington specification to model bilateral trade, the introduction of transportation cost, and finally the macroeconomic closure. The choice of a closure, prescribing which variables are endogenous and exogenous in a general equilibrium analysis plays an important role. In this model, balance of trade is assumed to be exogenous. Looking at the equation (30) the selection of which a price is selected to be numeraire is

21 This custom built CGE under GAMS/MPSGE is publicly accessible for user on the URL (http:// http://robles.Colorado.EDU/ tomruth/gtapingams/html/gtapgams.html). In addition, MPSGE compared with other system provides a compact, non-algebraic representation of the model that is less tedious. This compactness results in fewer opportunities for mistakes and will save much time for writing and programming the model. Despite these advantages, the disadvantages of MPSGE are not only non-transparent for the readers but also very restrictive for specifying the consumer preferences.

${ }^{22}$ The standard GTAP model is implemented using the GEMPACK software. See PEARSON (1997) Implementing GTAP using the GEMPACK software in HERTEL (1997) Global Trade Analysis. Modelling and Applications. Cambridge University Press.

${ }^{23}$ BANSE (1999) has experimented using three kinds of demand system to represent consumer preferences (the Cobb-Douglass function, the Linear Expenditure System (LES) and the Almost Ideal Demand System (AIDS)). 
important. For example, if the domestic price Pd is defined as numeraire, $r$ (in equation 27) corresponds to the real exchange rate (ROBINSON, 1989). This description is related to the static model. Later the specification of a recursive-dynamic model will be introduced.

The essential characteristics underlying the specification of applied general equilibrium models are related to the assumptions of economic agents: firms, private household (consumers) and the public sector (government). Firms' demand for input factor and intermediate input, private household's demand for final products and government demand for public goods are then specified.

\section{4. 1. Production Structure}

As typical in most computable general equilibrium models, the model developed in this study assume that firms employ production technology under constant return to scale (CRTS) with the cost minimisation from the use of primary input factors. In this model, four different types of primary input factors will be used in the production function, and these are skilled labour, unskilled labour, capital and land. Labour as specified in most CGE models is mobile between production sectors, but not internationally. Capital is immobile not only between production sectors but also internationally. Due to the capital immobility, the capital rate of return is different from one sector to other sectors. Beside labour and capital, agricultural land as primary input factor is of importance to include in the model.

The firms' decision-making process over the utilisation of primary input factor and intermediate factors is modelled as a hierarchically nested system of constant-return-to-scale production function. The detailed explanation of the use of a nested function is examined in KELLER (1976). To visualise the technology tree of production structure, Figure 3.2 represents the composition of input factor and intermediate factors, which finally form the output $Q_{i}, i$ for producing sectors. The inputs required to produce the output $Q_{i}$ consist of a fixed proportion of value added, $Q V_{i}$ which are composed from the primary factors of production: land, labour and capital; and composite intermediate inputs, $Q A_{i}^{I D}$. Firms also purchase composite intermediate inputs, some of which are produced domestically, $Q D_{i}^{I D}$ and 
some of which are imported, $Q M_{i}^{I D}$. The firms employ the CES functional form to compose both goods. The value of $Q V_{i}$ depends on the CES function of land, skilled labour, unskilled labour, and capital. In the case of the foreign intermediate inputs, these inputs must be supplied from particular exporters, $Q X S_{i s r}, s$ represents trading countries and $r$ for region in question.

Figure 3.2 Nested Production Structure

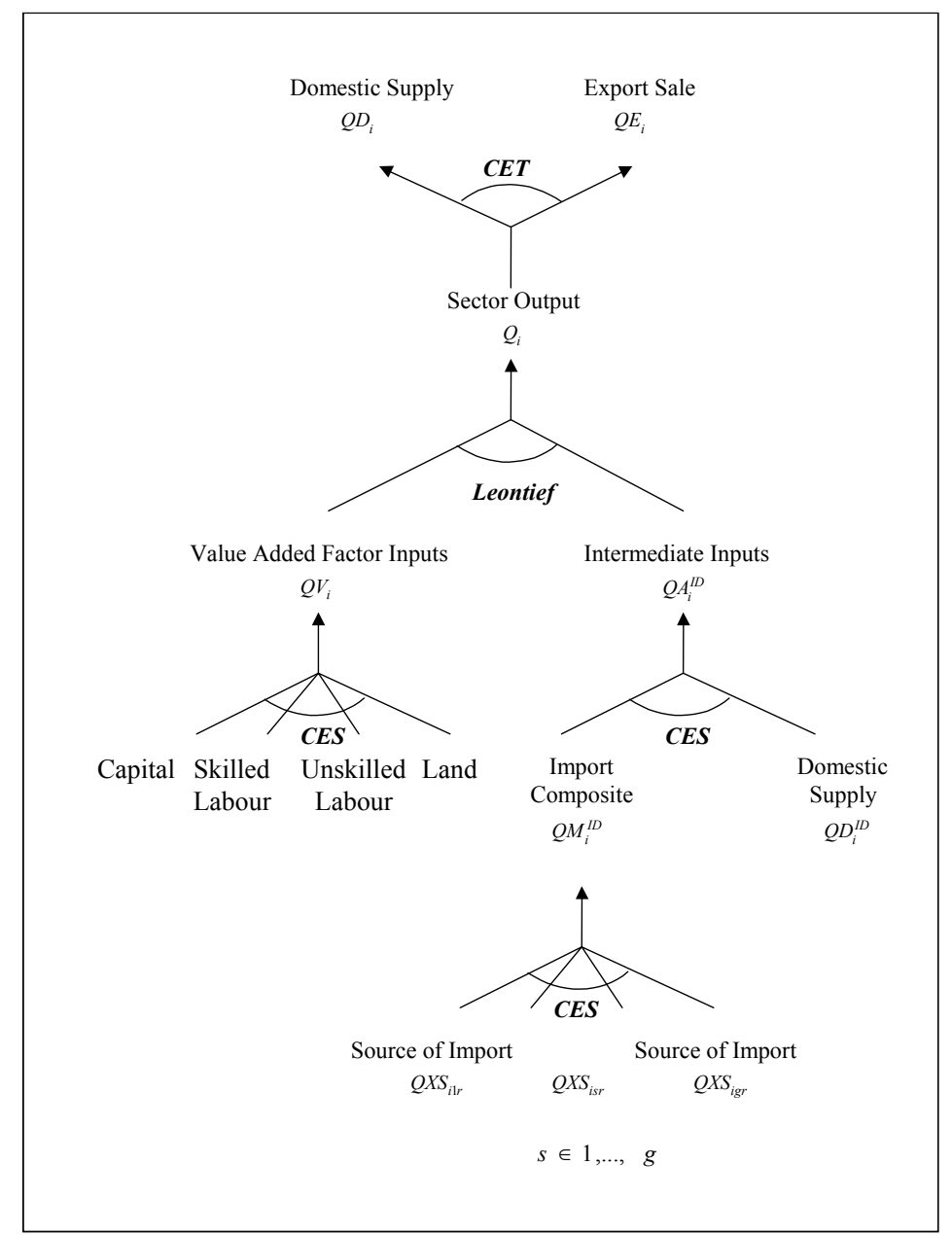

Source: Adapted from HERTEL and TSIGAS (1997)

\section{4. 2. Value Added and Composite Intermediate Products}

The first stage of firms' decision is to determine the mechanism of using or combining input factors (capital, labour; skilled and unskilled labour, and agricultural land) and composite 
intermediate products. As seen in Figure 3.2 the Leontief assumption is used to derive the demand on the intermediate inputs. Therefore the demand for intermediate inputs is not responsive to relative prices.

\section{4. 2. 1. Primary Input Demand}

Concerning the type of production functions applied for this analysis, a neo-classical production function is chosen to allow smooth substitution among factor inputs and the degree of substitutability is described by the elasticities of substitution. To describe the technology used by the firms assuming constant returns of scale, constant elasticity of substitution (CES) production function is employed which takes this general form:

$$
Q_{i}=A_{i}\left[\sum_{f} \delta_{f i} F_{f i}^{-\rho v_{i}}\right]^{-1 / \rho v_{i}}
$$

where $A_{i}$ and the $\delta_{f, i}$ s are positive parameters with $\sum \delta_{f i}=1$ and $\rho v_{i}$ is a parameter whose value is greater or less than -1 but not equal to zero ${ }^{24} \cdot F_{f, i}$, is level of primary factor $f$ demanded in producing goods $i$. The coefficient $A_{i}$ can be used as a scale parameters showing the input-augmenting parameter. $\delta_{f i}$ is a share parameter. The corresponding elasticity of substitution is $\sigma v_{i}=1 /\left(1+\rho v_{i}\right)$. The application of CES function to derive demand for primary input factors is due to its ability to capture the interaction between primary input factors reflected by the degree of substitutability.

In order to simplify the derivation of the demand function for primary input factors, only two input factors, say labour and capital, are used in the production process, its functional form will be:

$$
Q_{i}=A_{i}\left[\delta_{i} L_{i}^{\frac{\left(\sigma v_{i}-1\right)}{\sigma v_{i}}}+\left(1-\delta_{i}\right) K_{i}^{\frac{\left(\sigma v_{i}-1\right)}{\sigma v_{i}}}\right]^{\frac{\sigma v_{i}}{\sigma v_{i}-1}}
$$

\footnotetext{
${ }^{24}$ The CES functional form has a unique nature. As $\rho v_{i}$ approaches zero, then the CES function approaches a Cobb-Douglas form. If $\rho v_{i}$ is equal to 1 , this function will be a linear functional form.
} 
To derive demand function for input factors such as labour (unskilled and skilled labour) and capital $^{25}$, one should take the first order condition of the production function for a cost minimisation purpose. This can be undertaken by minimising labour cost $w . L$ with $w$ a wage rate and cost of capital $r . K$ with $r$ as capital rent, given product, $Q_{i}$, subject to the CES production function. Using a Lagrange multiplier, a first order derivation leads to the following equation:

$$
\frac{L_{i}}{K_{i}}=\left(\frac{\delta_{i}}{\left(1-\delta_{i}\right)}\right)^{\sigma v_{i}}\left(\frac{r}{w}\right)^{\sigma v_{i}}
$$

Substituting (3.3) into the CES production function (3.2) yields the demand function for both input factors:

(a) A factor demand for labour

$$
L_{i}=A_{i}^{-1} Q_{i}\left[\delta_{i}+\left(1-\delta_{i}\right)\left[\frac{\delta_{i} r}{\left(1-\delta_{i}\right) w}\right]^{\left(1-\sigma v_{i}\right)}\right]^{\frac{\sigma v_{i}}{\left(1-\sigma v_{i}\right)}} \text { and }
$$

(b) A factor demand for capital

$$
K_{i}=A_{i}^{-1} Q_{i}\left[\delta_{i}\left[\frac{\left(1-\delta_{i}\right) w}{\delta_{i} r}\right]^{\left(1-\sigma v_{i}\right)}+\left(1-\delta_{i}\right)\right]^{\frac{\sigma v_{i}}{\left(1-\sigma v_{i}\right)}}
$$

However, under the assumption of constant return to scale, the unique relation between the quantity of a good supplied and its price cannot be derived for profit-maximising producers. This is because multiplying input with a constant will lead to the same proportion of output and also the same proportion of profit. Because of its nature, the problem is now how the equilibrium can be solved with the assumption of constant return to scale ${ }^{26}$. With profit

\footnotetext{
${ }^{25}$ The inclusion of these primary input factors into the production function particularly in relation to international trade model poses a significant implication. As DERVIS, DE MELO and ROBINSON (1982:31) noted that :” ...it is now generally accepted that the Heckscher-Ohlin theory can be broadly validated if production factors are defined carefully and further desegregated to distinguish, in particular, between skilled and unskilled labour and between capital and natural resources".

${ }^{26}$ DINWIDDY and TEAL (1988) provided an algebraic calculation to solve the problem of constant return to scale. Despite the use of Cobb-Douglass production function, the similar results are also revealed for any linearly homogenous production functions such as a Constant Elasticity of Substitution (CES) function.
} 
maximising assumption, the level of output cannot be similarly found because the rate of change of profit with respect to changes in output is not a function of output $Q_{i}$ but only of prices of primary input factors. But it leads to the unit cost function. Thus the value of output must be the same with the value of input or production cost. By dividing the value of output and input by the output $\left(P_{i} / Q_{i}\right.$ and $\left.w \cdot L_{i} / Q_{i}+r K_{i} / Q_{i}\right)$ leads to the situation where the price per unit of $Q_{i}$ is equal to the sum of payments of two factors demanded per unit of $Q_{i}$

produced. This clearly indicates that with the assumption of constant returns to scale, the zero profit condition holds as DINWIDDY and TEAL (1988) added that a firm with zero profit can be in equilibrium and this equilibrium is compatible with any one of the set of possible output levels. More fundamentally, the assumption of zero profit condition underlies the construction of Social Accounting Matrix as an essential data source, concerning the building of a computable general equilibrium (CGE) model. Consequently, the CGE model has also to hold this rule.

\section{4. 2. 2. Demand for Intermediates}

As described earlier, beside primary input factors producers also demand intermediate goods. By definition, intermediate inputs are a unique commodity produced by industries, which can be used as input in other industries. An important assumption concerning the demand for intermediate goods is that all inputs are required in fixed proportion to output. The demand functions for intermediate goods in the model are therefore defined as follows:

$$
Q A_{i}^{I D}=\sum_{j} a_{i j} Q_{j}
$$

where $Q A_{i}^{I D}$ is the quantity of intermediate input provided by industry $i$; $Q_{j}$ is the output of the sector $\mathrm{j}$ and $a_{i j}$ is a fixed proportion representing the technological coefficient. In other words, this coefficient represents the quantity of intermediate input required to produce per unit of final product in industry $i$. As obviously seen the demand for intermediate goods is independent of the price. As a result, the volume of intermediate goods used in the production 
process of industry i depends only on the technological coefficient $a_{i j}$ and the level of output, $Q_{j}$

\section{5. Foreign Trade and Product Differentiation}

\section{5. 1. Demand for Domestic and Imported Goods}

In common with other empirically based international-trade models, it is assumed that imported and domestically produced goods in the same industry are imperfect substitutes. Hence, products are differentiated based on the country of origin. This is often referred to the Armington assumption (ARMINGTON, 1969). For example, palm oil-based products from Thailand are then considered quantitatively different from Indonesia or Malaysia. The Armington specification is a well-known procedure and commonly applied in developing empirical general equilibrium trade models. In applying this assumption one might take a benefit as WHALLEY (1985:39) stated:

"..it allows empirical estimates of trade elasticities to be incorporated into the approach as the major determinants of the strength of the terms-of-trade effects"

However, referring to the frequently used Armington assumption in the modelling of imperfect substitution between domestic goods and imported goods, one should take into account its limitation in certain situations, especially in cases of where a country has a small initial import share. As MORKRE and TARR (1995) stated:

"..in response to a change in trade policy (such as tariff or quota reductions) in a given sector, resource movement and the welfare impact will be extremely muted in sectors with a small initial import share. .....With the same elasticity of substitution, if a sector has a significant initial share, the same relative price reduction will result in a large increase in imports. The Armington assumption suggests that there would be dramatically less resource movement (and consequently less welfare impact) in the case of a small initial import share". 
Figure 3.3. Nested Foreign Trade Structure

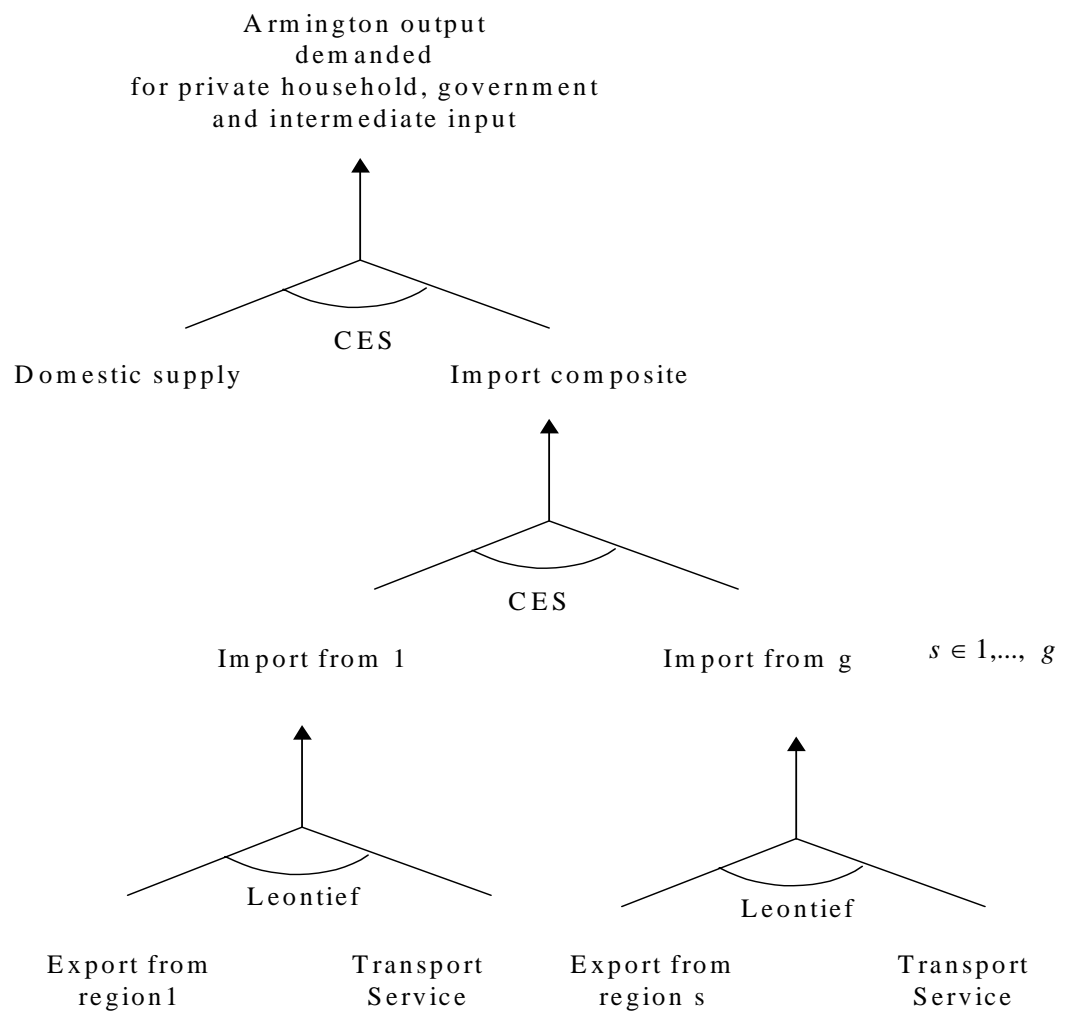

Source: Adapted from KEPPLER and SPRINGER (2000)

Concerning the treatment of import sources by agents, the modellers may choose two alternative Armington specifications, namely: differentiated imports to the users and aggregated import to the users. The former refers to the situation where each user differentiates sources of imports. The application of this specification leads to very demanding data requirements. And in the latter specification, all agents specifically: the private consumer, the government and the investor will face the same price for composite imported commodities. This means that the economy uses only one Armington specification for each good in each region. In this study the compromised procedure is chosen. Disaggregate imports are sourced at border, but composite imports are tracked to the individual agents (see HERTEL, et. al., 
1997b). As pointed in Figure 3.3, Armington composite output consisting of domestic output and import composite is demanded individually by private sector, public sector and firms for intermediate input uses. As a consequence of applying this compromised mechanism, each user of Armington composite output therefore will face different prices. For example, prices facing the private sector, public sector and firms are $P C_{i}, P G_{i}$ and $P I D_{i}$, respectively.

In applied general equilibrium models, the CES functional form is frequently used to accommodate the industry's decision on the substitutability between imported and domestic goods. Let $Q A_{i}^{A}$ be an Armington good. In the words, there are three Armington composite goods. One is for a private sector demand, one is for a public sector demand and one is for intermediate uses. This Armington goods is composed of import composite, $Q M_{i}^{A}$ and domestically produced goods, $Q D_{i}$. The specification takes the following form:

$$
Q A_{i}^{A}=\omega_{i}^{A}\left[\delta_{i}^{A} Q D_{i}^{\frac{\left(\sigma m_{i}-1\right)}{\sigma m_{i}}}+\left(1-\delta_{i}^{A}\right) Q M_{i}^{A \frac{\left(\sigma m_{i}-1\right)}{\sigma m_{i}}}\right]^{\frac{\sigma m_{i}}{\left(\sigma m_{i}-1\right)}}, A \text { for }\{C, G, I D\}
$$

where $\omega_{i}^{A}$ is a constant. $\delta_{i}^{A}$ is the share parameter and $\sigma m_{i}$ is the sector-specific elasticity of substitution and the same value for three markets. C, G and ID refer to household, government and industry demands, respectively. In order to find the optimal combination of both types of composite goods, the consumers minimise (3. 8) subject to the level of $Q A_{i}^{A}$. In other words, this optimisation is to find a ratio $Q M_{i}^{A} / Q D_{i}$ so that the marginal rate of substitution equals to the ratio of the price of the domestically produced composite goods to the price imported composite goods. This equilibrium indicates that the producers already reached an optimal or efficient solution with regard to perfect market competition.

$$
P D_{i} Q D_{i}+P M_{i} Q M_{i}^{A}
$$

where $P D_{i}$ is the price of domestically produced goods and $P M_{i}$ is the price of imported composite goods that yields the optimal mix of both goods:

$$
\frac{Q M_{i}^{A}}{Q D_{i}}=\left(\frac{\left(1-\delta_{i}^{A}\right)}{\delta_{i}^{A}}\right)^{\sigma m_{1}}\left(\frac{P D_{i}}{P M_{i}}\right)^{\sigma m_{1}}
$$

This equation suggests that the level of foreign composite goods demanded is dependent on the relative price of both goods. The lower the import price, the more the import composite 
goods is demanded. The selection of the value of the elasticity of substitution plays an important role in determining such a demand. If a very high $\sigma m_{i}$ is selected, the responsiveness of $Q M_{i}^{A} / Q D_{i}$ will be big, vice versa. In the extreme case in which the elasticity of substitution equal zero (0), the ratio of $Q M_{i}^{A} / Q D_{i}$ would be fixed and be back to the fixed-coefficients where relative price changes cannot directly influence the demand for imports. Another consequence of using equation (12) is that since the price of domestically produced composite goods increases relative to imported composite goods, the producers will substitute away from domestically produced composite goods in favour of imported composite goods $s^{27}$.

Having described the production structure used in the model, this section will discuss the foreign trade and product differentiation. First, it focuses on distinguishing the domestic sale and export sale. As presented in Figure 3.2, firms have to decide how the outputs are sold on domestic or foreign markets. In the context of the optimisation procedure, producers make an optimal allocation of the total supply $Q_{i}$ between domestically sold goods $Q D_{i}$ and exported goods $Q E_{i}{ }^{28}$. To incorporate this relation, the Constant Elasticity of Transformation (CET) function is employed. The CET production possibility frontier for both sectors, domestically sold goods and exported goods, indicates the degree of flexibility between the sectors. In addition, it features the important product differentiation between two markets (MORKRE and TARR, 1995). Given the value of the output :

$$
P D_{i} Q D_{i}+P X_{i} Q E_{i}=P_{i}^{*} Q_{i}
$$

where $P_{i}^{*}$ is the producer price, the CET specification is as follows:

$$
Q_{i}=\mathrm{A}_{i}\left[\omega_{i} Q D_{i}^{\left(\sigma e_{i}-1\right) / \sigma e_{i}}+\left(1-\omega_{i}\right) Q E_{i}^{\left(\sigma e_{i}-1\right) / \sigma \sigma_{i}}\right]^{\sigma e_{i} /\left(\sigma \sigma_{i}-1\right)}
$$

where $\mathrm{A}_{i}$ is a constant, $\omega_{i}$ is the share parameter and $\sigma e_{i}$ is the sector specific elasticity of transformation between $Q D_{i}$ and $Q E_{i}$. To determine the optimal allocation, the producers

\footnotetext{
${ }^{27}$ see DERVIS, DE MELO and ROBINSON (1982) and THIELE and WIEBELT (1993).

${ }^{28}$ It should be borne in mind that the level of $\left(Q E_{i}\right)$ is a sum of export goods to specific trading region $\mathrm{s}$ $\left(Q X S_{i r s}\right)$.
} 
maximise (3.10) subject to (3.11) that yields:

$$
\frac{Q E_{i}}{Q D_{i}}=\left[\frac{\left(1-\omega_{i}\right)}{\omega_{i}}\right]^{\sigma e_{i}}\left[\frac{P X_{i}}{P D_{i}}\right]^{\sigma e_{i}}
$$

This equation (3.12) relates industry's supply of exports to domestic sales and to the domestic price ratio of export and domestic sales. Since the level of export and domestic sale is highly determined by the price ratio, the changes in the relative price would affect the level of transformation. In other words, if no relative commodity price changes, then industry is indifferent between producing export goods or domestic sales goods. Due to an inverse relation between export goods and domestic goods, an increase in the price of export goods will induce industry to produce more export goods in favour of domestic goods. The selection of the value of transformation elasticity also has a crucial role because the strength of the transformation effect is governed by the value of this elasticity $\left(\sigma e_{i}\right)$. The higher the elasticity selected, the larger the change in $Q E_{i} / Q D_{i}$ despite the fact a change in $P X_{i} / P D_{i}$ is relatively small (THIELE and WIEBELT, 1993).

\section{5. 2. Bilateral Trade ${ }^{29}$}

As mentioned earlier, the Armington output is distinguished by several agents: producing sectors that demand intermediate inputs, private household and government. Following the structure of foreign trade (Figure 3.3), the model then has to determine the demand for the import aggregate. Under a bilateral commodity flow, imports are distinguished based on country of origin. Using a CES functional form, the demand for aggregated imported goods from all other countries is modelled. Let $Q X S_{i s r}$ denote imports of goods $i$ by country $r$, from country s. The import composite is therefore specified as follows (RUTHERFORD; 1998 and BURNIAUX et. al., 1992):

$$
Q M_{i r}^{A}=\left[\sum \psi_{i r s} Q X S_{i r s}\left(\sigma i m_{2}-1\right) / \sigma i m_{2}\right]^{\sigma i m_{2} /\left(\sigma i m_{2}-1\right)}
$$

\footnotetext{
${ }^{29}$ In this sub-section, two notations referring to regions are used. $\mathrm{r}$ describes country or region in question, while $\mathrm{s}$ refers to trading partners.
} 
where $\psi_{\text {isr }}$ is the distribution parameter and $\sigma i m_{2}$ is the bilateral trade elasticity of substitution. Another issue related to the bilateral trade is the presence of international transportation service. In the database, the value of transport service is associated with bilateral trade flows from the exporting countries/regions to the importing countries/regions. In other words, the transportation cost is inherent with the values of commodities shipped into country destinations. It is assumed that transportation costs are proportional to the level of bilateral trade between trading countries (s and $r$ ). Thus the transport cost for good $i$ from region $r$ to destination $s, Q T R D_{i r s}$ is defined as follows:

$$
Q T R D_{\text {irs }}=\chi_{\text {irs }} Q X S_{\text {irs }}
$$

where $\chi_{(i, s, r)}$ is a constant fraction or a technical coefficient. The aggregate of transport costs is defined by a Cobb-Douglas aggregate of international transport inputs supplied by different regions $Q T R_{i r}{ }^{30}$ :

$$
\sum_{i} \sum_{r} \sum_{s} Q T R D_{i r s}=\prod_{i r} Q T R_{i r}^{\theta_{i r}^{T}}
$$

For the determination of the price of import composite $P M_{i r}$ the presence of import tariff rates imposed in region $r$, export taxes in region $s$ and international transport service are then considered. Since the export taxes are imposed in region $s$, the collected income from export taxes then accrues in region $s$, not region $r$. Hence, the import price in region $r$ is equal to the export price gross of export tax in trading region $s$, international transport cost and bilateral import tariff rates imposed in the importing region $r$.

$$
P M_{i r}=\sum_{s} \varpi_{i s r}\left[P X_{i s}\left(1+t \chi_{i s r}\right)+\chi_{i s r} P T\right]\left(1+t m_{i s r}\right)
$$

where $\varpi_{i s r}$ is the share parameter, indicating the value of total import from region $\mathrm{s}$ in the total import composite. $P X_{i s}$ indicates the export price in region $s$ while $P T$ represents the price of international transport service. As summarised in Figure 3.3, the export composite

\footnotetext{
${ }^{30}$ Modelling international transport service is to intermediate between the supply of and demand for international transport service. These services are provided using a Cobb-Douglass production function that demands services exports from each country or region (HERTEL and TSIGAS, 1977). Because the demand for inputs uses a CobbDouglas functional form, it implies that there is a unitary elasticity substitution between inputs (services exports).
} 
constitutes the export from region $s$ and international transport service. $t x_{i s r}$ and $t m_{i s r}$ are export tax rates and bilateral import tariff rates, respectively.

\section{6. Regional Income and Expenditure}

Factor earnings. In each region, there is a representative agent, endowing with primary factors such as capital, agricultural land, skilled labour and unskilled labour. These consumers generate their income through the utilisation of such factors in the producing sectors or factor earnings.

$$
F_{-} E A R N=\sum_{i} \sum_{f} P F_{f} F_{f, i}
$$

In addition, the representative agent also generates income from the collection of tax revenues. Because in the GTAP data set, there are several tax definitions, source of tax revenues are then identified.

Factor tax revenue. As the first category, the model is capable of including taxes on the sales of the primary input factors to the firms.

$$
F_{-} \operatorname{Re} v=\sum_{i} t f_{i} P F_{f} F_{f, i}
$$

where $F_{-} \operatorname{Re} v$ is a sum of factor tax revenue. $t f_{i}$ is a specific tax rate of primary inputs in sector i. $P F_{f}$ refers to the price of primary input factors which can be broken down into $w_{U L}$ and $w_{S L}$, that is wage rates for unskilled and skilled labour, $r$ is the capital rent, and $l$ is land rent. $F_{f, i}$ is a level of primary input factors demanded in sector $i$.

Indirect tax or production tax. The second category is the output taxes or production taxes (indirect tax) $Y_{-} \operatorname{Re} v$. It is important to take note that the deduction of production tax is specified on a gross basis that leads to a decrease in the producer revenue.

$$
Y_{-} \operatorname{Re} v=\sum_{i} t y_{i}\left(P D_{i} Q D_{i}+P X_{i} Q E_{i}\right)
$$


where $Y_{-} \operatorname{Re} v$ is a sum of production tax revenue. $t y_{i}$ is an indirect tax rate in sector $i$. $P D_{i} Q D_{i}$ and $P X_{i} Q E_{i}$ is values of domestic sale and export sale of sector $i$. In the case of negative production taxes, the government intervenes to the market on this commodity by a subsidy. This type of government intervention might increase the government expenditure representing a public expenditure.

Taxes on final demand. This includes taxes on intermediate inputs, consumption taxes (taxes on consumer goods) and public taxes (taxes on goods demanded by the government).

$$
C_{-} \operatorname{Re} v=\sum_{i} t i_{i} P I D_{i} Q A_{i}^{I D}+\sum_{i} t c_{i} P C_{i} Q A_{i}^{C}+\sum_{i} t g_{i} P G_{i} Q A_{i}^{G}
$$

where $C_{-} \operatorname{Re} v$ is a sum of collected tax revenues on final demand goods, $t i_{i}$ is a tax rate on intermediate goods, $t c_{i}$ is a tax rate on consumer goods and $t g_{i}$ is a tax rate on goods demanded by the government. $P I D_{i} \quad P C_{i}$, and $P G_{i}$ are prices of composite goods in region $r$ facing the firms, private household and government, respectively. $Q A_{i}^{C}, Q A_{i}^{G}$ and $Q A_{i}^{I D}$ are consumer goods, public goods and intermediate goods, respectively.

Export taxes. The volume of exports is subject to the export tax rate $\left(t x_{\text {irs }}\right)$ if positive or the export subsidy rate if negative.

$$
T E X_{r}=\sum t x_{i r s} P X_{i r} Q X S_{i r s}
$$

$P X_{i r}$ is an export price for exported goods $Q X S_{\text {irs }}$ from region $r$ in question to region or trading partner $s$.

Import taxes. The last tax category, which is a main subject of this model, is that government levies a common tariff on all imports from other ASEAN countries and the rest of the world (ROW). According to the AFTA plan, import products within ASEAN members are subject to AFTA tariff reduction procedures. The calculation of import tax revenues is complex. This is due to the fact that import values in the region $r$ consist of export taxes imposed in trading regions, and costs of international service. 
$M_{-} \operatorname{Re} v_{r}=\sum t m_{i s r}\left(P X_{i s} Q X S_{i s r}\left(1+t X_{i s r}\right)+P T * Q T R D_{i s r}\right)$

where $M_{-} \operatorname{Re} v_{r}$ is a sum of import tariff revenues, $t m_{\text {isr }}$ is an import tariff rate on good $i$ from the exporting region $s$ to the importing region $r$. $t x_{i s r}$ is an export tax rate in the exporting country/region s. PT is the international transport price and $Q T R D_{\text {isr }}$ represents a transport service for goods $i$ from region $s$ to region $r$.

Current Account Balance, CA. The current account balance is defined as the difference between values of total export and total import. Levels of a current account balance and of investment have not been specified in detail. The net capital inflow in region $r$, CA, it is defined as the difference between the total import values and the total export values (KRUGMAN and OBSTFELD, 2000). If $C A$ is positive, it indicates that the region $r$ experiences a current account deficit. The net capital inflow is then allocated to the representative agent (the regional household). The current account in each region is determined exogenously. By assuming that this current account is set to be exogenous, the real exchange rate will vary to adjust the balance trade equilibrium. One might determine to set this account to be endogenous. If doing so, the interpretation of welfare becomes difficult since foreign exchange will change over time. Changes in the real exchange rate will maintain the base period current account position (REINERT and ROLAND-HOLST, 1997). Relating to this closure MAECHLER and ROLAND-HOLST (1997) added that “ if trade balance were fixed being equal to the level of foreign saving, all adjustment would necessarily be mediated by the real exchange rate, since increased import demands which follow trade liberalisation must be financed by increased exports".

$$
\overline{C A}=\sum_{i} P M_{i} Q M_{i}-P X_{i} Q E_{i}
$$

Due to the nature of a multi-region CGE model, the sum of the country's current balances is equal to zero, $\sum_{r} \overline{C A}=0$. To comply with the general consistency, the current balance in each country or region is then calculated from the regional income-expenditure identity. This procedure also applies on a regional base for the case of primary factor markets (RUTHERFORD, 1998). 
Having described the sources of regional income, the representative agent then allocates this income into private demand, public demand and investment.

\section{7. Demand Structure}

In each region there is a representative agent that determines final demand in the region. This consumer is endowed with primary factors, tax revenue, and exogenous net transfer from other regions (net capital inflows). This regional income is then allocated to private demand, public demand and investment.

\section{7. 1. Private Demand ${ }^{31}$}

Having described the sources of the regional income, the representative agent first decides to allocate a fraction of the regional income to the demand for private sectors. Suppose that income available for the representative agent to finance the expenditure on the private demand is $Y D$. In other words, this income is available for the consumption of a bundle of consumer goods. In this model a private household demand for a bundle of consumer goods is given by applying the Stone-Geary Linear Expenditure System (LES). The Application of Linear Expenditure System (LES) has been chosen for some reasons. As acknowledged by BURNIAUX et. al. (1992), the selection of the appropriate functional form for the utility function is problematic. To support this argument, HUFF et al. (1997) explored the weaknesses of other functional forms, which are usually used in the GE analysis. The CobbDouglas utility function and CES are a homothetic function which implies that average household budget shares spent on various commodities are constant or independent of household total expenditure or income. This specification, however, contradicts the wellknown Engel law in which the budget share of certain commodities (e.g. food) declines along with the increased household expenditure. Beside a Cobb-Douglass specification assumes uncompensated own-price elasticities equal to unity and zero cross price elasticities whereas a

\footnotetext{
${ }^{31}$ The limitation of a single representative household is that the model cannot identify the impact of changes in trade policies such the reduction of trade barriers on the welfare of different types of households: rural and urban households. To overcome the disadvantage of this GTAP database, a separate estimation of a demand analysis for different income household groups using national household surveys can be undertaken by adjusting a number of commodities between commodities from the GTAP database and the demand model. Hence, changes in, for example consumer prices in the CGE model are then introduced into the demand model. However, such procedure is beyond this study.
} 
Constant Elasticity Substitution imposes also the unit income elasticity restriction and a constant elasticity of substitution for all types of goods. To conform to theoretical conditions, the use of a full demand system such as Almost Ideal Demand System of DEATON and MUELLBAUER (1980) would be highly recommendable. However, due to the highly demanding data requirement for all goods (and also all countries), the Stone-Geary Linear Expenditure System (LES) is then chosen. The LES relaxes the unit income elasticity assumption.

The LES utility function is specified as follows ${ }^{32}$ :

$$
U=\sum_{i=1}^{n} \beta_{i} \ln \left(Q A_{i}^{C}-\theta_{i}\right)
$$

where $n$ is the number of consumption goods, $\beta_{i}$ is the marginal budget share of consumption goods $i$, determining the allocation of supernumerary income, that is, expenditure above that required for purchasing the subsistence consumption, $Q A_{i}^{C}$ is the quantity consumed of goods $\mathrm{i}$ and $\theta_{i}$ denotes "subsistence" consumption of goods $i$. For each $i, \sum_{i=1}^{n} \beta_{i}=1,0<\beta_{i}<1$, and $\left(Q A_{i}^{C}-\theta_{i}\right)>0$.

The consumption of goods is constrained by their limited income available, so the demand function is derived by maximising the LES utility function subject to the income constraints, yielding:

$$
Q A_{i}^{C}=\theta_{i}+\frac{\beta_{i}}{P C_{i}}\left[Y D-\sum_{j} P C_{j} \theta_{j}\right]
$$

Equation (3.24) shows that each quantity demanded is a function of household income, YD and of all prices (its price $P C_{i}$ and the prices of all other consumer goods). Following DERVIS, DE MELO and ROBINSON (1982), given exogenously average budget shares $a_{i}$

\footnotetext{
${ }^{32}$ For a detailed description of LES , see TAYLOR (1979), HARRISON and KIMBELL (1985), and PHLIPS (1983)
} 
and expenditure elasticities $\varepsilon_{i}$, the marginal budget shares are specified as follows:

$$
\beta_{i}=\varepsilon_{i} a_{i}
$$

In order to hold the Engel aggregation condition, the sum of marginal budget shares must be one. Given the Frisch parameter ${ }^{33}$, measuring the elasticity of the marginal utility of income with respect to income, the supernumerary income can be then determined, using this following formula:

$$
\phi=\frac{-Y D}{Y D-S}, \text { where } S=\sum_{j} P C_{j} \theta_{j}
$$

To complete the LES specification, the last parameter to be determined is the subsistence consumption $\left(\theta_{i}\right)$. Given the values of average budget shares, marginal budget shares and Frisch parameter, the value of the subsistence consumption is given by the following equation:

$$
\theta_{i}=\left(\frac{Y D}{P C_{i}}\right)\left(a_{i}+\frac{\beta_{i}}{\phi}\right)
$$

\section{7. 2. Public Demand}

Different from the demand structure for private household (consumers), the level of government demand is assumed to be exogenously fixed. The implication of this closure is that the production of public goods is fully financed by the collection of government income from private household, production and trade (export taxes/subsidies and import taxes/subsidies). In the model, the level of taxes (export taxes/subsidies and import taxes/subsidies) is fixed allowing real government saving is endogenous ${ }^{34}$. The allocation of the public expenditure on the final demand is based on the Cobb-Douglas functional form. Despite the exogeneity of public demand, the government demand for composite goods is responsive to the changes in the relative prices.

$$
G=\prod_{i} Q A_{i}^{G \xi_{i}} \text {, where } \sum \xi_{i}=1
$$

$Q A_{i}^{G}$ is composite goods $i$ demanded by the government. It is important to emphasise here

\footnotetext{
33 This parameter was introduced by FRISCH (1959) which was called money flexibility. Both FRISCH (1959) and TAYLOR (1979) proposed a value of -2 for the Frisch parameter. This value applies for consumer goods. ${ }^{34}$ In the database, the level of government saving is zero.
} 
that this is similar with demand for intermediate inputs and for consumer goods. The composite goods are composed of domestic goods and imported goods. As presented in Figure 3.3 composite imports consist of imports from different trading partner, using the CES functional form.

\section{8. Investment ${ }^{35}$}

In the GTAP database, the capital goods is indicated by the domestic output of sector CGD. Hence, the regional investment is defined here as the sum of capital goods, $Q D_{c g d}{ }^{36}$.

$$
I N V=\sum_{c g d} P D_{c g d} Q D_{c g d}
$$

where INV is the regional investment. Since investment also equals regional saving $\mathrm{SAVE}^{37}$, and its level depends entirely on a fixed fraction of the regional income or a marginal propensity to save, the relation between investment and the regional saving is therefore specified as follows:

$$
I N V=\sum_{c g d} P D_{c g d} Q D_{c g d}=S A V E
$$

Because the level of investment depends largely on the level of saving, saving plays an important role in the equilibrium. The model provides a mechanism that marginal propensity to save will vary to adjust to assure that the level of investment must be equal to the level of saving. This saving-driven closure corresponds to the "neoclassical" macroeconomic closure. As a result of choosing this closure the household sector alone cannot be used properly to estimate changes in welfare (REINERT and ROLAND-HOLST, 1997).

35 In the original custom-built GTAPinGAMS (Rutherford, 1998), investment is assumed to be exogenous. However, in this study investment becomes endogenous. This is done by changing the negative notation of investment to the positive notation. This in effect make investment a demanded good (GILBERT, 2001, personal communication). The endogeneity of investment is certainly important in terms of modelling the (recursive) dynamic CGE model. This is because capital stock in the current year is dependent on the investment in the previous year

${ }^{36}$ Within the dataset investment inputs flow to the cgd sector, and demand for cgd sectoral output appears as the sole non-zero in the $I_{i}$ vector for each region (RUTHERFORD, 1998). CGD refers to saving good and sector cgd must appear as a distinct sector in any aggregation.

${ }^{37}$ SAVE includes foreign saving or net foreign capital inflows, that is, $\overline{C A}$ 


\section{9. General Equilibrium Conditions}

The economy is in full equilibrium if all commodity and factor markets clear and the balance of the government budget hold. For commodity and factor markets, equilibrium means that the demand for all commodities and factors equals supply. In most AGE literature, equilibrium exists where excess demand for all commodities and factors is equal to zero.

\section{- Domestic Output}

Domestic output is entirely absorbed for the private consumer demand, intermediate inputs, public sector demand, plus domestic investment demand. The equilibrium of this output in each country is written as follows:

$$
Q D_{i}=Q D_{i}^{C}+Q_{i}^{G}+Q D_{i}^{I D}+I_{i}
$$

- Import

As described in the sub chapter of Bilateral Trade, aggregate import on goods $i$ is defined by the Armington aggregation across imports from different source of import or countries of source. Therefore, the volume of imported goods must be equal to the use of imports: imported intermediate goods, imported consumer goods and imported public goods that are algebraically specified as follows:

$$
Q M_{i}^{A}=Q M_{i}^{C}+Q M_{i}^{G}+Q M_{i}^{I D}
$$

- Export

The supply of exports must be equal to the sum of bilateral import demands including the transport cost:

$$
Q E_{i}=\sum_{s} Q X S_{i r s}+Q T R_{i}
$$

- Primary Input

The demand for input factors in each sector equals the primary factor endowment by private consumers.

$$
\sum_{i} F_{f i}=F S_{f}
$$


$F S_{f}$ is the supply of primary input factors: capital, skilled labour, unskilled labour and agricultural land. The assumption of full employment has an important economic implication as well as a calculation procedure (WHALLEY, 1985) in determining a full equilibrium. Due to the assumed zero excess demand for labour, any changes in demand for labour must be in line with changes in labour supply. In this relation, wages will adjust to equate demand and supply of labour. Under the competitive market, labours are paid based on their value of marginal product. 


\section{Chapter IV}

\section{The Extended CGE Model for ASEAN Free Trade Area (AFTA)}

\section{1. Dynamic AFTA Model ${ }^{38}$}

The model described in the Chapter 3 does not take into account of the impact of time preference on the model results. In other words, the model focuses solely on the certain time (static approach. Such static CGE models only take into account inter-sectoral resource shifts, and hence cannot consider inter-temporal resource allocation through investment and consumption/saving decision. It should be stated that investment or capital accumulation is the most important source of growth. Effects of trade reforms on investment and, hence on growth are ignored by a static CGE model.

By incorporating time preference into a model that is commonly termed as a dynamic or intertemporal general equilibrium model, the model is then able to have great potential for analysing economic problems that involve trade-offs across time. With the application of an inter-temporal approach into the model, the model framework therefore combines the strengths of the two modelling issues (static and dynamic general equilibrium analysis) (MALAKELLIS, 1993). The reason for employing the dynamic CGE approach in this study is due to the fact that the benefit of establishing regional integration either in the form of a customs union or free trade area (FTA) agreement cannot be judged solely on the basis of a single period analysis, but should be investigated based on a long term view. During the process of economic integration, the structural adjustments especially those facing producers might, take place either based on backward information such as the influence of investment on the capital formation or on forward information such as for example future capital rate of return. With regard to the long-term effect of economic integration, BALASSA (1961) referred to "dynamic effects" and MOLLE (1990) referred to "restructuring effects". This is because economic agents will react to the new situation and adapt the structure of production, consumption and the economy on the whole. Supporting the argument of the importance of

\footnotetext{
${ }^{38}$ The recursive-dynamic model used in this study is quite similar to BANSE (1997).
} 
building a dynamic model, especially in the context of trade liberalisation, one might take a closer look at what BALDWIN (1989) insisted that the dynamic benefits of trade liberalisation are many times the benefits generated from static models.

Ideally, modelling a dynamic general equilibrium analysis should refer to the fact that behaviour of consumers and producers are derived from inter-temporal optimisation. It could be undertaken if both consumers and producers are assumed to have a perfect foresight. The meaning of a perfect foresight refers to the situation in which for given values of the exogenous variables, the agent (consumers and producers) can completely predict the future path or direction of variables (BETTENDORF, 1994). Following RUTHERFORD (1998), the finite horizon or infinite horizon of the model plays an important role in predicting the future equilibrium.

In this study, however, the recursive sequence equilibrium approach is used. The term "recursive" refers to the situation in which the current equilibria depend solely on the past or previous equilibria. FULLERTON; KING; SOVEN and WHALLEY (1981) in BALLARD et. al. (1985) initially pioneered the use of this approach in the CGE modelling. In this approach, economic agent is endowed with the myopic expectation. It means that the current decision of the economic agent is derived from the information of the past in the formation of expectations.

The most frequently used information is that the economic agents (consumers) are endowed with capital, which is determined by the level of investment and provides the link between different static equilibria (BETTENDORF, 1994).

\section{2. Accumulated Capital Stocks}

In the dynamic process, the level of capital stocks becomes a very crucial factor. This is because in the static model, capital is assumed to be fixed. Letting the dynamic process enter into the model, the demand and supply of capital will change fundamentally. In the other word, relaxing the assumption of exogeneity of capital stock will have an important implication for the income and resource allocation effects of trade (FRANCOIS, 
MCDONALD and NORDSTRÖM, 1997). In addition, the process of capital accumulation is modelled sequentially (sequential approach). In this regard, the level of capital stock between periods will be updated.

The level of future capital stocks $(t+1)$ which are available for the process of production in the period $t+1$ is identical to the depreciated level of capital stock inherited from the previous period and the investment, taking place between period $t$ and $t+1$. Referring to this relationship, it is then assumed that the length of the gestation lag for all sectors is one period. The capital accumulation equation is specified as follows: ${ }^{39}$

$$
K_{t}=(1-\delta) K_{t-1}+I_{t-1}
$$

Where $\delta$ is the constant rate of economic depreciation, $\mathrm{K}$ is the aggregate capital stock and I is the level of investment in the previous period. Because the current level of capital stocks depends closely not only on the past period of capital stocks (t-1) but also on the previous periods ( $t-2, t-3$ and $t-n)$, thus the equation above can be deduced in to general equation, including previous periods (BEGHIN, 1996):

$$
\begin{aligned}
& K_{t}=(1-\delta)\left[(1-\delta) K_{t-2}+I_{t-2}\right]+I_{t-1} \\
& K_{t}=(1-\delta)^{n} K_{t-n}+\sum_{j=1}^{n}(1-\delta)^{j-1} I_{t-j}
\end{aligned}
$$

As has mentioned earlier, the modified custom-built-multi-region model (RUTHERFORD, 1998 ) is used. However, extending into a recursive model, further modification is made, especially in the context of a dynamic calibration. The original model does not include regional capital stocks ${ }^{40}$. As a result, the equation (4.1) can be arranged by exploiting the unit

\footnotetext{
${ }^{39}$ In this model, investment is modelled only as economy-wide aggregate (i.e. not sector specific). Within any period, capital is then fully mobile among sectors. However, in the sector-specific capital assumption, each producing sector would demand capital according to for example, expected profitability (DERVIS, DE MELO and ROBINSON, 1982) or difference in capital demanded and optimal capital stock in each producing sector (BANSE, 1997).

40 GTAPinGAMS uses capital earnings data from the social accounting matrix in the static model.
} 
price convention and using capital earning, $K S E_{t}$ represents physical capital services instead of the capital stock (SPRINGER, 1998, and SCOLLAY and GILBERT, 1999a). The initial gross return rate on capital, $\mathrm{rO}_{0}$ can be calculated using the following equation:

$$
r 0_{0}=K E_{0} / K_{0}
$$

where zero indicates the benchmark value, $K E_{0}$ is the regional capital earning in the benchmark equilibrium and $K_{0}$ stands for regional capital stock in the benchmark equilibrium. Regional capital stocks are collected from DIMARANAN (1998). Using the gross return rate on capital as a scale factor, the physical units of capital services can now be calculated as follows:

$$
K E_{, t+1}=(1-\text { depr }) K E_{, t}+I_{, t} * r O_{0}
$$

where depr represents a regional depreciation rate. In each period, the value of regional capital services has to be updated.

\section{3. Technological Change}

As implicitly seen in the static model, the technological change in the production technology, which increases the production in economic sectors, plays a limited role. In other words, the model assumes a given level of technology which remains constant. However, the role of the technological efficiency in the dynamic model plays a very important factor due to the fact that research elaboration to find a new technology to increase the level of productivity in each sector, particularly in the agricultural sector may take place. Incorporating the change in the level of technology in the model requires the introduction of a new parameter, called "a parameter of technological change augment" which is sector-specific and exogenously determined. In modelling the technological change, it is assumed that the capital/labour ratio is held constant with a constant wage/interest rate ratio (Hicksian neutral technology). As a consequence, the production growth due to technological changes, which maintains the constant capital/labour ratio follows a particular path as indicated in the Figure 4.1.

To implement the assumed annual increase in the technological change, the selected values of the total factor productivity (TFP) are then used. Recall the production function employed in 
this study (equation 3.1).

$$
Q_{i}=A\left[\sum \delta_{i} F_{f i}^{-\rho}\right]^{-1 / \rho v_{i}}
$$

where $A$ indicates the parameter of input augment technology. With the constant return to scale and homogeneous of degree 1 production, multiplying the input factor with a constant $A$ will result in the additional increase of the output by $A$ as well. Therefore, in the recursive dynamic model, the assumed TFP growth rates in each region replace the parameter of input augment technology.

Figure 4.1. Path of Technological Change

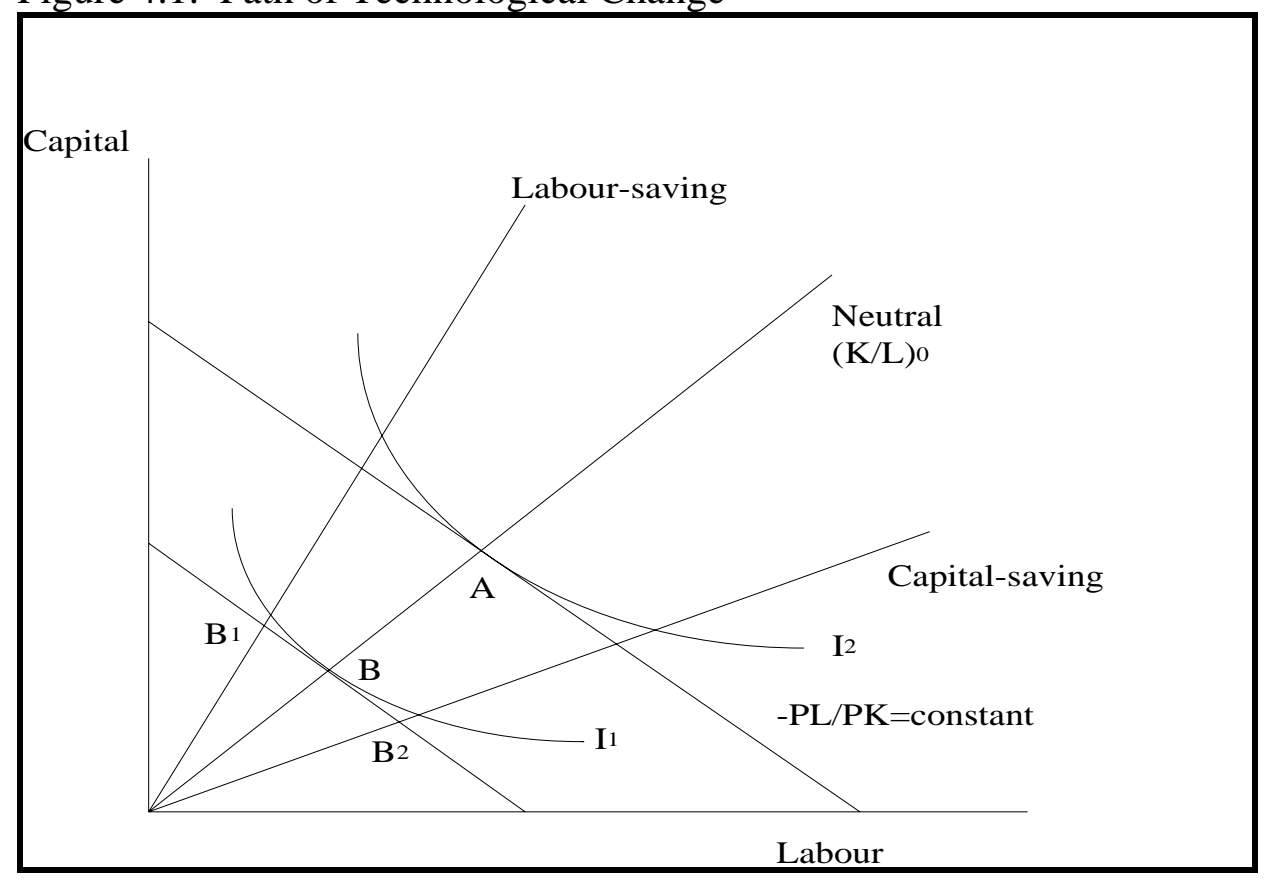

Source: SADOULET and JANVRY (1995).

\section{4. Labour Supply}

As mentioned in the section on the model development, labour supply is exogenously predetermined. In the context of dynamic modelling, the availability of labour force becomes endogenous as a result of labour supply adjustment. The labour supply in the period $t+1$ follows the equations below:

$$
\begin{aligned}
& L_{U L(t+1)}=\left(1+\hat{G}_{U L}\right) L_{U L(t)} \\
& L_{S L(t+1)}=\left(1+\hat{G}_{S L}\right) L_{S L(t)}
\end{aligned}
$$


where $L_{U L}$ and $L_{S L}$ are unskilled and skilled labour supply respectively, and $\hat{G}_{U L}$ and $\hat{G}_{S L}$ are a natural growth of unskilled and skilled labour force.

\section{5. The GTAP Database ${ }^{41}$}

As has been mentioned earlier, this study uses the GTAP database. Many CGE modellers who examine wide-ranging economic issues such as environmental issues, regional integration and multilateral trading negotiation (GATT/WTO) have used this database extensively ${ }^{42}$. The database used for this study is the GTAP-4 database, which covers 45 regions and 50 sectors. This database consists of detailed bilateral trade, transport and protection data characterising economic linkages among regions, and is inked together with individual country input-output data bases which account for inter-sectoral linkages.

The GTAP was developed in 1992 in response to an increasing need to access to cheap data cost for those conducting quantitative analyses on international economic issues ${ }^{43}$. The development of the GTAP database can be traced from the history of the data construction. The GTAP version 1 was built completely based on the SALTER project, supplied by the Australian Industry Commission that undertook this study during the 1980`s and early 90`s. Updating bilateral trade data and additional product and region coverage was undertaken for the release of the versions 2 and 3 (37 commodities, 30 regions and three production factors). For the GTAP version 4, the GTAP consortium has completely replaced the entire original SALTER database. As mentioned above, the GTAP version 4 contains 45 regions that is three times of the GTAP version one database. The members of the GTAP network supply all bilateral trade data in the GTAP version 4.

In relation to the protection data, this version of the GTAP database has three main components. The UNCTAD TRAINS database is the main source of tariff information. The second component is related to the support and protection data for agriculture. Similar with the

\footnotetext{
${ }^{41}$ HERTEL in MCDOUGALL, R.A., A. ELBEHRI, and T.P. TRUONG (1998). Global Trade, Assistance, and Protection: The GTAP 4 Data Base. Center for Global Trade Analysis. Purdue University. In the time of writing this dissertation, the last GTAP data base (version 5 based on the 1997 bilateral trade) is publicly available since 2001

42 The GTAP office provides publicly a list of studies, using the GTAP model and database (see http://www.agecon.purdue.edu/gtap/apps/)

${ }^{43}$ HERTEL (1998) in MCDOUGALL, R.A., A. ELBEHRI, and T.P. TRUONG (1998).
} 
protection data in the version one, market price support and subsidy information were adapted from the OECD`s Producer Subsidy Equivalent (PSE) database. For non-OECD countries, the procedure of indirect estimates has developed using the GTAP version three as a main source $^{44}$. The third component deals with the non-agricultural, non-tariff barriers.

Another improved feature of the GTAP version 4 is the treatment of primary factors. This version has split labour payments into unskilled and skilled labour components for each commodity in each region. The split of the labour categories broadens the scope of the analysis, particularly for those investigating the impact of changes in trade policy; for instance on the labour movement or migration. In addition, the latest version includes natural resource endowment, for example; agricultural land, fisheries, fossil fuels and mining ${ }^{45}$. In comparison, the versions 1-3 of the GTAP database contain only one type of natural resource endowment, which is agricultural land.

The objective of this study is to investigate the impact of the AFTA agreement on agricultural trade on the individual ASEAN countries. Therefore it is important to look closely at the concept of import protection data in the GTAP database. All import protection data is derived based on average MFN tariff rates at the tariff line level (source from the World Bank), which are aggregated up to the GTAP concordance using trade weights. This technique implies that a given region will have different bilateral tariff levels, which capture the differences in import composition by country. In the agricultural sectors, efforts have been made to capture the impact of non-tariff barriers by using tariff equivalents, but the data is somewhat sketchy for non-OECD countries. Agricultural output subsidies are based on producer subsidy equivalent calculations from the OECD and USDA (SCOLLAY and GILBERT, 1999a).

\section{6. Aggregation Strategy}

In the current version of GTAP database ASEAN countries are only represented by Indonesia, Malaysia, the Philippines, Thailand, Singapore and Vietnam. Ideally, this study should include all current ASEAN members, both old and new members. However, with the inclusion of

\footnotetext{
${ }^{44}$ ACAR and MC DOUGALL (1998) inn MCDOUGALL, R.A., A. ELBEHRI, and T.P. TRUONG (1998).

${ }^{45}$ HERTEL and TSIGAS (1998) in MCDOUGALL, R.A., A. ELBEHRI, and T.P. TRUONG (1998).
} 
Vietnam into the model, one is required to carefully accommodate the characteristics of Vietnam's economy as a country in transition. Therefore, some adjustments should be carefully undertaken to accommodate firms' decision to allocate their production factor and of how a level of price is determined. Due to the assumption upheld in this study in which firms operate in the competitive market, this study then excludes Vietnam. As mentioned earlier, ASEAN countries' trade depends highly on Japan, USA and European Union (EU). As the most important ASEAN trading partners, these regions are explicitly included into the model.

Likewise, the 50 GTAP commodities are aggregated into rice, grain, crops, oil seed, sugar, livestock, meat products, dairy products, crop products, beverages and tobacco products, mining and mineral products, clothing and textiles, manufactured products and services. The detailed sectoral aggregations are presented in Table 4.1. The choice of such commodities is due their relative importance in the ASEAN economies and the size of current trade restrictions especially rice, beverages and tobacco products, processed meat and processed milk. In addition, this study attempts to incorporate products into the early voluntary sectoral liberalisation (EVSL) under the APEC scenario. Those products include oil seeds, mining and mineral products and manufactured products. In addition, the manageable size of the model is a part of the consideration.

One may consider the impact of aggregation on the results. Since the GTAP data base version 4 consists of 45 regions/countries, 50 commodities/sectors and five production factors, two kinds of effects may exist. As GELHAR and FRANDSEN (1998) noted, models with high levels of aggregation would tend to predict large efficiency gains. On the other side, models with more disaggregate levels would tend to predict larger terms-of-trade effects. 
Table 4.1 Sectoral Aggregation

\begin{tabular}{|c|c|}
\hline Sector & Aggregated commodities \\
\hline Rice & Paddy rice, processed rice. \\
\hline Cereal & Wheat, grain (other than rice and grain). \\
\hline Other crops & $\begin{array}{l}\text { Vegetable fruit and nuts, sugar cane and beet, plant-based fibres and } \\
\text { crops n.e.c.. }\end{array}$ \\
\hline Vegetable oils & Vegetable oils. \\
\hline Oil seeds & Oil seeds \\
\hline Sugar & Sugar. \\
\hline Livestock & $\begin{array}{l}\text { Bovine cattle- sheep and goats - horse, animal products n.e.c., raw } \\
\text { milk, wool and fish. }\end{array}$ \\
\hline Processed meat & Bovine cattle meat products, meat products n.e.c. \\
\hline Processed milk & Dairy products \\
\hline $\begin{array}{l}\text { Processed other } \\
\text { crops }\end{array}$ & Other food products \\
\hline $\begin{array}{l}\text { Beverages and } \\
\text { tobacco }\end{array}$ & Beverages and tobacco \\
\hline $\begin{array}{l}\text { Mining and } \\
\text { mineral products }\end{array}$ & Coal, oil, natural gas, other minerals, petroleum and coal products \\
\hline Textiles & Textiles, wearing apparel, leather goods. \\
\hline Manufactures & $\begin{array}{l}\text { Lumber and woods, forestry, pulp and paper, chemicals rubber and } \\
\text { plastics, non-metallic mineral products, primary ferrous metals, non- } \\
\text { ferrous metals, fabricated metal products, primary ferrous products, } \\
\text { motor vehicles, other transport equipment, electronic equipment, } \\
\text { machinery and equipment, other manufacturing products. }\end{array}$ \\
\hline Services & $\begin{array}{l}\text { Electricity, gas manufacturing and distribution, water, construction, } \\
\text { trade and transport, other services (private), other services (public), } \\
\text { dwellings }\end{array}$ \\
\hline
\end{tabular}

Source: GTAP database (version 4). 
Table 4.2 Country (Region) Aggregation

\begin{tabular}{ll}
\hline \multicolumn{1}{c}{ Country/region } & \multicolumn{1}{c}{ Aggregated countries/regions } \\
\hline $\begin{array}{c}\text { ASEAN countries } \\
\text { Indonesia }\end{array}$ & Indonesia \\
Malaysia & Malaysia \\
Philippines & Philippines \\
Singapore & Singapore \\
Thailand & Thailand \\
Major ASEAN & \\
trading partners & \\
European Union & United Kingdom, Germany, Sweden, Finland, Rest of EU \\
Japan & Japan \\
USA & USA \\
Rest of world & \\
ROW & Australia, New Zealand, Republic of Korea, Vietnam, China, \\
& Hong Kong, Taiwan, India, Sri Langka, Rest of South Asia, \\
& Canada, Mexico, Central America and Caribbean, Venezuela, \\
& Columbia, Rest of Andean Pact, Argentina, Brazil, Chile, \\
& Uruguay, Rest of South America, European Free Trade Area \\
& (AFTA), Central European Associates, Former Soviet Union, \\
& Turkey, Rest of Middle East, Morocco, Rest of North Africa, \\
& South Africa, Rest of South Africa, Rest of Sub-Saharan Africa, \\
& Rest of world \\
\hline Source: GTAP database (version 4)
\end{tabular}

Source: GTAP database (version 4)

\section{7. Elasticitiy Assumptions}

Looking at the model specified in the section of Model Development, it is very obviously clear that there are a number of behavioural parameters to be numerically specified. The specifications of these parameters are among the most important procedure in CGE modelling, either adapting from the empirical evidences (literature surveys) or estimating them econometrically. Based on the specified models, there are three categories of elasticities: (a) income elasticities for estimating the Linear Expenditure System (LES) function, (b) substitution elasticities between production factors, domestic-import sources and import sources, and (c) transformation elasticities for domestic and export products. Most of numerical elasticities (income elasticities and substitution elasticities) are adapted from MCDOUGALL, DIMARANAN and HERTEL (1998) ${ }^{46}$. Looking at the values of income

\footnotetext{
${ }^{46}$ MCDOUGALL, DIMARANAN and HERTEL (1998) in MCDOUGALL, ELBEHRI and TRUONG. Global Trade, Assistance, and Protection: The GTAP 4 Data Base. Center for Global Trade Analysis. Purdue University. The source of substitution elasticities for the GTAP model are mainly based on the SALTER model.
} 
elasticities in Table 4.3, it is very important to bear in mind that adjustment has been made in order to conform to the nature of estimation of the LES function, in which weighted average income elasticities must be equal to unity ${ }^{47}$.

Table 4.4 reports the values imposed on key parameters, specifically substitution and transformation parameters. Despite the fact that the specification of the parameters is guided by the literature reviews, simplifying assumptions have been undertaken. First, this model assumes identical values for both CES elasticties and CET elasticities in all regions, production and international trade (Armington assumptions). In spite of the unrealistic nature of these assumptions, literature review provides little guidance on country-specific values for these parameters (BURNIAUX, et al. 1992) ${ }^{48}$.

\footnotetext{
${ }^{47}$ The procedure used to satisfy the adding up rule see TAYLOR (1979)

${ }^{48}$ BURNIAUX, MARTIN, NICOLETTI and MARTINS (1992). Green. A Multi-sector, multi region dynamic general equilibrium model for quantifying the costs of curbing CO2 Emission: A Technical Manual. Economic Department. Working Papers no. 116. Organisation for Economic Co-operation and Development. Paris. Due to the use of aggregated imports to the users, all agents specifically: private consumer, government and investor will face the same price for composite imported commodities. This means that the economy uses only one Armington specification for each good in each region. In this study the compromised procedure is then chosen by disaggregating sources of import at the border and individual agent determines the demand for such composite imported goods and domestically produced goods (see HERTEL, et. al., 1997b).
} 
Table 4.3 Income Elasticities

\begin{tabular}{lccccccccc}
\hline \multicolumn{1}{c}{ Products } & Indonesia & Malaysia & Philippines & Singapore & Thailand & EU & Japan & USA & ROW \\
\hline Rice & 0.970 & 0.510 & 0.918 & 0.580 & 0.929 & 0.171 & 0.200 & 0.151 & 0.222 \\
Grain & 0.174 & 0.201 & 0.213 & 0.100 & 0.133 & 0.100 & 0.100 & 0.100 & 0.138 \\
Crops & 0.100 & 0.100 & 0.100 & 0.100 & 0.100 & 0.100 & 0.100 & 0.100 & 0.100 \\
Oil seeds & 0.100 & 0.100 & 0.100 & 0.100 & 0.100 & 0.100 & 0.100 & 0.100 & 0.100 \\
Livestock & 0.778 & 0.992 & 1.109 & 0.576 & 0.949 & 0.713 & 0.928 & 0.674 & 0.618 \\
Sugar & 0.970 & 0.740 & 0.920 & 0.580 & 0.930 & 0.170 & 0.750 & 0.150 & 0.560 \\
Vegetable Oil & 0.970 & 0.740 & 0.920 & 0.580 & 0.930 & 0.170 & 0.750 & 0.150 & 0.560 \\
Proc. Meat & 0.860 & 0.360 & 0.660 & 0.560 & 0.400 & 0.330 & 0.700 & 0.130 & 0.470 \\
Proc. Milk & 1.340 & 0.380 & 0.500 & 0.400 & 0.540 & 0.100 & 0.500 & 0.100 & 0.350 \\
Proc. Crops & 0.970 & 0.740 & 0.850 & 0.580 & 0.870 & 0.170 & 0.750 & 0.150 & 0.700 \\
Beverages and & 0.830 & 0.830 & 0.830 & 0.830 & 0.830 & 0.900 & 0.890 & 0.890 & 0.900 \\
Tobacco & & & & & & & & & \\
Mining and & 1.230 & 1.230 & 1.230 & 1.230 & 1.230 & 1.130 & 1.120 & 1.090 & 1.140 \\
Mineral Products & & & & & & & & & \\
Textiles & 0.960 & 0.960 & 0.960 & 0.960 & 0.960 & 0.960 & 0.960 & 0.960 & 0.960 \\
Manufacturing & 1.115 & 1.067 & 1.115 & 1.020 & 1.120 & 1.069 & 1.062 & 1.036 & 1.286 \\
Services & 1.227 & 1.227 & 1.220 & 1.201 & 1.050 & 1.130 & 1.090 & 1.086 & 1.220 \\
\hline Source: Calcula & & & & & & & & &
\end{tabular}

Source: Calculated based on data from The GTAP Version 4 
Table 4.4 Substitution and Transformation Elasticities

\begin{tabular}{lcccc}
\hline & sigma_va $^{1)}$ & sigma_1 $^{2)}$ & sigma_2 & sigma_3 \\
\hline Rice & 0.34 & 2.20 & 4.40 & 1.25 \\
Cereal & 0.24 & 2.20 & 4.40 & 1.25 \\
Other crops & 0.24 & 2.20 & 4.40 & 1.25 \\
Vegetable oils & 0.24 & 2.20 & 4.40 & 1.25 \\
Oil seeds & 0.24 & 2.20 & 4.40 & 1.25 \\
Sugar & 1.12 & 2.20 & 4.40 & 1.25 \\
Livestock & 0.24 & 2.80 & 5.60 & 1.25 \\
Procc. Meat & 1.12 & 2.40 & 4.40 & 2.00 \\
Procc. Milk & 1.12 & 2.40 & 4.40 & 2.00 \\
Procc. Crops & 1.12 & 2.40 & 4.40 & 2.00 \\
Beverages and & 1.12 & 3.10 & 6.20 & 2.00 \\
tobacco & & & & \\
Mining and & 1.16 & 2.80 & 4.75 & 2.00 \\
Mineral & & & & \\
Products & & & 6.60 & 2.00 \\
Textiles & 1.26 & 4.40 & 5.75 & 2.00 \\
Manufacturing & 1.26 & 5.20 & 3.90 & 0.50 \\
Services & 1.68 & 1.90 &
\end{tabular}

1) Value-added substitution elasticity

2) Domestic-import substitution elasticity

3) Sourcing of import substitution elasticity

4) Domestic-export transformation elasticity

Source: 1), 2) and 3) Calculated from GTAP database (version 4)

4) adapted ROBINSON, EL-SAID and SAN (1998)

In contrast, the modellers are mostly recommended to choose region-specific estimates, especially estimates of the top nest substitution elasticity. This is because as BROWN (1987) in HERTEL, IANCHOVICHINA and MCDONALD (1997) indicated that the magnitude of terms of trade effects is largely determined by the value of such elasticities. The less the elasticity is specified in the region that changes tariff, the smaller the effects will be. However, there is no common standard to determine the appropriate values of substitution elasticities. To estimate econometrically, these elasticities face several constraints: (1) a product definition, (2) regional aggregation and (3) the appropriate time frame for economic estimation. Due to these constraints, an alternative solution is to conduct systematic sensitivity analysis on these elasticities and other parameters (HERTEL, IANCHOVICHINA and MCDONALD, 1997). This proposed procedure has been widely and extensively used to assess the behaviour of models

The use of elasticities presented in Table 4.4 follows the nested production function (Figure 3.2) and nested foreign trade structure (Figure 3.3). The firms combine the primary factors (capital, skilled labour, unskilled labour and agricultural land) using the CES functional form with the value of substitution elasticity (sigma_va). It is 
acknowledged that the assumption of similar values of substitution elasticity between factors is unrealistic. In the other words, one of the limitations of this study is the assumed value added substitution elasticity. One may argue that the elasticity of substitution between capital and unskilled labour would be higher than between capital and skilled labour. For example machinery can easily replace unskilled labour while skilled labour can manage machinery. It is suggested that to reduce or remedy this limitation, a two-level CES production function in which first capital and unskilled labour is aggregated using a higher value of substitution elasticity be used. Second, skilled labour and a new aggregation of capital and unskilled labour enter into the main production function (LAYARD and WALTERS, 1978). Due to a lack of information about values of substitution elasticities between both primary factors, this procedure was not used here.

\section{8. Post Uruguay Tariff Estimates}

Despite the fact that the main objective of this study is to examine the impact of ASEAN trade liberalisation under the CEPT commitment, trade measures under the multilateral agreement such as the results of the last Uruguay Round as well as the possible outcome of the Millennium Round should be taken into consideration. This is because ASEAN members have been actively involved in this round and have committed to reducing their trade barriers. This market thereby provides more accesses for products from other parties. The developing countries are required to reduce their border tariff by 24 percent in 19952004 and 36 percent for developed countries (1995-2000). With respect to the domestic support, both developing countries and developed countries decrease their domestic support by 13 percent and 20 percent, respectively. Related to export subsidies, the same reduction rates as the reduction of tariff rates apply

As outlined in the simulation scenarios, the baseline scenario incorporates the impact of the Uruguay Round and possible impact of next WTO round (Millennium Round) on agricultural trade in ASEAN region and its major trading partners. The first concern is to determine post-Uruguay round tariff levels that will be used for another tariff reduction following the Millennium Round. Post-UR tariff levels are obtained from FRANCOIS and STRUTT (1999). Their estimates were based on post-Uruguay Round rate information from version 3 of the GTAP data set and the GATT/WTO Integrated Database (IDB). The most important nature of the post Uruguay Round tariff rates is that the level of border 
tariffs for agricultural products remains unchanged compared to the 1995 tariff levels. In other words, no further tariff reductions are needed to move from the benchmark GTAP version 4 to the post-Uruguay Round levels. This is due to the fact that the 1995 GTAP data set was developed during the high world prices. As a result, it leads to very low protections being reported in this database, especially for agricultural sectors. On the other side, the level of WTO tariff levels was based on the period where world prices were low (late 1980s), leading to high protection levels. Following these facts and also reports by INGCO (1996) that at some places there was "dirty" tariffication in agriculture, there was no need to further reduce border protection in the 1995 GTAP data base in this sector in connection with the estimation of post-Uruguay Round (HERTEL, 2000). In the context of a "dirty” tariffication process, countries very often inflated the price differences between domestic and international levels. It applies particularly in the case of sensitive products, such as: agricultural products. Therefore, this process will allow a government to set higher tariff levels than ever existed between 1986 and1988 ${ }^{49}$. With this large tariff difference between pre-Uruguay tariff levels and the 1995 tariff levels, the assumption of no change from 1995 agricultural tariff levels is quite sensible (HERTEL and MARTIN, 1999).

49 see INGCO (1995). Agricultural Trade Liberalization in the Uruguay Round. Working Paper No. 1500 August 1995. 


\section{Chapter V}

\section{Discussion of Scenario Analysis Results}

\section{1. Definition of the Baseline Scenario}

Before discussing the results of the simulation scenarios, it is important to take a closer at the results of the baseline scenario. This procedure is commonly used to estimate the impact of policy shocks on the economy, especially in the case of dynamic general equilibrium (recursive or inter-temporal dynamic general equilibrium analysis). Once the baseline model has been generated, the results of simulation scenarios are compared with the results of the baseline model. Differences between the baseline scenario and any other counterfactual scenario are generally presented in percentage changes. There are two important components that influence the baseline scenario. Firstly, some variables (exogenous and endogenous variables as mentioned earlier) will be up-dated, using some assumptions that are provided in Table 5.1. As presented in this table, imposing these assumed growth rates of factor endowment, especially labour supplies and technology projection will obviously change the comparative advantage in the model. The labourintensive sector would certainly expand over time due to the increased supply of labour. For example, it can be expected that the textile sector would expand faster than for instance mining and service sectors. Likewise, the different assumed technology projection will determine the real GDP growth rates. These annual total factor productivity (TFP) growth rates will be implemented as a Hicks neutral across all inputs. It is important to emphasise here that this model rules out the impact or the presence of the economic crisis, hitting most ASEAN member states. So the real GDP projected by the model will reflect the economy without any disruptions. In other words, real GDP growth rates are endogenously determined in this model and they will alter over time.

Secondly, the most important information needed to generate the baseline model is the level of import tariffs and other policy measures such as export and output subsidies to be used. These issues will be elaborated in more detail in the section on the mechanism of reducing trade barriers. As a result, the magnitude of the results from the baseline scenario is subject to the values or levels of two of the above-specified components. 
Table 5.1 Assumptions on Exogenous Growth Rates

\begin{tabular}{lccc}
\hline & $\begin{array}{c}\text { Unskilled } \\
\text { labour } \\
\text { (\% per year) }\end{array}$ & $\begin{array}{c}\text { Skilled labour } \\
\text { (\% per year) }\end{array}$ & $\begin{array}{c}\text { Total Factor } \\
\text { Productivity } \\
\text { (\% per year) }\end{array}$ \\
\hline Indonesia & 2.0 & 7.7 & 1.6 \\
Malaysia & 2.4 & 7.7 & 0.7 \\
Philippines & 2.3 & 3.4 & 0.5 \\
Singapore1) & 3.6 & 6.9 & 1.4 \\
Thailand & 0.8 & 6.4 & 1.6 \\
EU & 0.1 & 9.2 & 0.3 \\
Japan & 0.0 & 4.7 & 0.3 \\
USA & 0.7 & 4.6 & 0.3 \\
ROW & 1.7 & 2.6 & 1.0 \\
\hline SOurce
\end{tabular}

Source: SCOLLAY and GILBERT. (1999a)

1) Labour growth rates for Singapore are calculated based on information provided by JING (2000) ${ }^{50}$ and a growth rate of Singaporean TFP is based on the study of MARTIN (1996) in FILIPE (1997).

However, according to article 20 of the Uruguay Round (UR) Agreement on Agriculture (AoA), countries strive to work towards the objective of substantial progressive reductions in support and protection in agriculture. This agreement also emphasises the importance of a commitment to the continuation of the reform process in agriculture (KONANDREAS, 1999). In accordance with the general commitment to reducing trade barriers, this study assumes that countries will continue to further reduce bound tariffs and other trade measures, following the UR-type formula. As a result, developed countries will be required to reduce import tariffs by 36 percent on the average. Similarly, developing countries will be taking the same procedure at two thirds the level of the rate of developed countries. This reduction applies to all products (no discrimination basis). Following the UR-type formula, it is expected that the developed countries would require 5 years for complete implementation (2005-2009) and 10 years for developing countries (2005-2014).

\footnotetext{
${ }^{50}$ Personal Communication
} 
Table 5.2 Possible Outcomes of the Millennium Round

\begin{tabular}{|c|c|c|}
\hline & Developing Countries & Developed Countries \\
\hline $\begin{array}{l}\text { A. Market Access } \\
\text { - Reduction of border } \\
\text { tariffs } \\
\end{array}$ & by 24 percent & by 36 percent \\
\hline $\begin{array}{ll}\text { B. } & \text { Domestic Support } \\
\text { - } & \text { Reduction of support to } \\
\text { agricultural production }\end{array}$ & by 13 percent & by 20 percent \\
\hline $\begin{array}{ll}\text { C. } & \text { Export subsidies } \\
\text { - } & \text { Reduction in values of } \\
\text { export subsidies }\end{array}$ & by 24 percent & by 36 percent \\
\hline $\begin{array}{l}\text { D. Period of } \\
\text { implementation }\end{array}$ & $2005-2009$ & 2005-2014 \\
\hline
\end{tabular}

Note: These levels of reductions refer to the pre-Uruguay Round levels.

Source: Adapted from FERYDHANUSETYAWAN, PANGESTU and ERWIDODO (1999).

The simulation results depend not only on the assumed growth rates of labour supplies and technological coefficients (TFP), but also on the initial tariff rates to be reduced. Therefore, the description of the initial import tariff levels based on the GTAP database version 4 is required in order to understand the likely impact of the on-going trade liberalisation, undertaken by the ASEAN economies ${ }^{51}$. Table 5.3 provides a list of aggregate import tariff.

In general, the level of protection in Indonesia is far lower than those imposed in other ASEAN countries. Focusing on an individual sectoral basis, for the import of rice, tariffs are the highest in Malaysia and Thailand, followed by Singapore. The higher level of import tariff rates in Malaysia, Philippines and Thailand reflect the direction of the government policy to protect rice farmers from the declining rice price if the government reduces import tariff rates. The higher level of protection has also been found in the case of cereal with the exception of Indonesia and Singapore. As for import rates on processed agricultural products, most ASEAN countries impose relatively high import tariff rates on processed milk, processed meat and beverages and tobacco products. For instance import tariff rates for processed milk and processed meat in Malaysia, Philippines and Thailand are $96 \%$ and 101\%, respectively.

\footnotetext{
${ }^{51}$ see MARTIN et. al; (1998), TSIGAS (1998); and ACAR and MCDOUGALL (1998) for more details about the construction of import tariff rates in the GTAP database version 4.
} 
Table 5.3 Weighted Average Import Tariff Levels, 1995 (\%) ${ }^{52}$

\begin{tabular}{lrrrrr}
\hline & Indonesia & Malaysia & Philippines & Singapore & Thailand \\
\hline Rice & 0.00 & 127.00 & 127.00 & 44.00 & 103.00 \\
Grain & 1.00 & 142.00 & 71.00 & 8.00 & 101.00 \\
Crops & 6.00 & 16.00 & 10.00 & 17.00 & 22.00 \\
Vegetable oil & 3.00 & 5.00 & 29.00 & 25.00 & 19.00 \\
Oil seeds & 12.00 & 2.00 & 0.00 & 21.00 & 24.00 \\
Livestock & 1.00 & 1.00 & 9.00 & 21.00 & 30.00 \\
Sugar & 1.00 & 0.00 & 1.00 & 22.00 & 38.00 \\
Processed other & 9.00 & 8.00 & 27.00 & 19.00 & 41.00 \\
crops & & & & & \\
Processed milk & 5.00 & 96.00 & 96.00 & 8.00 & 96.00 \\
Processed meat & 15.00 & 101.00 & 101.00 & 25.00 & 101.00 \\
Beverage and & 36.00 & 31.00 & 30.00 & 25.00 & 55.00 \\
tobacco & & & & & \\
Mining & 4.00 & 3.00 & 2.00 & 2.00 & 3.00 \\
Textiles & 17.00 & 17.00 & 24.00 & 1.00 & 26.00 \\
Manufacturing & 8.00 & 8.00 & 24.00 & 0.00 & 15.00 \\
& & & & & \\
\hline
\end{tabular}

Source: GTAP Database Version 4

The level of protection provided by the numbers of weighted average import tariff rates seems to be irrelevant in the context of measuring the impact of trade liberalisation in the ASEAN region. This is because studies on the likely impact of regional integration, using general equilibrium models, emphasise on the removal or reduction of tariffs on the basis of bilateral trade flows. The degree of protection is an important determinant of the impacts of trade liberalisation. In other words, the magnitude of trade changes is largely associated with to what extent the degree of protection exists within the regions. Hence, the larger the initial bilateral import tariff rates, the greater the impacts of the removal of such tariffs on the bilateral trade structures. Tables 5.4-5.8 summarise ad valorem import protection (tariff plus NTB) levels for sector and country of origin for the ASEAN countries, which are main focuses of this study. However, it should be emphasised here that the concept of import tariffs used in the GTAP database. Bilateral tariffs at the GTAP level of aggregation were constructed by aggregating tariff rates from the tariff lines supplied by countries to the GTAP sectors using bilateral import weights. This procedure results in significant differences in aggregated tariff rates for the same GTAP commodity imported from different sources (GELHAR et. al. 1997). HERTEL et. al. (1997) acknowledged the compositional effect due to this tariff averaging method used for the GTAP database. This is because this method would lead to a downward bias in tariff

\footnotetext{
${ }^{52}$ See Appendix Table 5.1 for Post Uruguay Round import tariff rates.
} 
aggregations. Because imports are a decreasing function of tariffs, higher tariff rates will lead to smaller import values.

Looking at these Tables, it is apparent that import protection levels vary substantially by sector and by source of imports. Indonesia protects the beverage and tobacco sectors (with their rates varying from 111\% against Philippines to around $20 \%$ against Japan and USA), as well as the other crop sector, specifically against the Philippines and, oil seeds against the Philippines (25\%), Thailand (20\%) and Singapore (18\%). Textile industries are also given protection from the government, particularly imports from rest of the world. For example, its import tariff levels range from 19\% (ROW), to 18\% (the Philippines), to 17\% (Malaysia). Among unprocessed agricultural sectors, rice and cereal farmers seem not to be highly protected as seen from very low bilateral import tariff rates, particularly against Japan and USA in the case of rice and against Thailand, EU, Japan and ROW in the case of cereal.

By contrast, both sectors in Malaysia are heavily protected, where its import tariff rates are more than $100 \%$, even close to $200 \%$ in the case of cereal. On the other side, the Malaysian government provides little protection for the livestock sector (with rates varying from $6 \%$ against Japan to $0 \%$ against Indonesia). High protections in the processed meat and milk sectors are also documented. To protect industries in both sectors, the Malaysian government imposes the same tariff rates regardless of the source of imports. Because of the same initial import tariff levels, the magnitude of change in trade flows in both sectors, caused by the removal of such tariffs, is largely determined by the trade intensity between the ASEAN members. Beverage and tobacco sectors are also reported to have relatively high protections that vary from 39\% against imports from USA to $25 \%$ against imports from the Philippines. Similar to the case in the textile sector, this sector receives relatively high protections, especially against imports from the ASEAN members

In Singapore, the government protects its rice sector with the same rates (44\%) for every country. Surprisingly, this level is the highest import tariff rate provided to protect rice industry, even though rice sector is not economically important in this country. Similar patterns are observed in the protection of processed meat and milk despite the fact that the degree of protection in the processed meat sector is relatively low (8\%). Comparing its protection levels for agricultural products imported from ASEAN countries, products from 
Thailand tend to receive relatively low trade barriers. For instance, import tariff rates for crops and oil seeds are $5 \%$, while the tariff rates for products from other countries range from 27 \% (EU, Japan and USA) to 10\% (Malaysia). Likewise, processed crops, vegetable oil and sugar from Thailand have the lowest tariff levels.

The Philippines' import tariff structures are similar to Malaysia's in terms of protections in rice, grain, processed meat and processed milk sectors. Both countries apply high tariff rates regardless of the source of imports with exception of rice imported from USA. Even the degrees of protection for processed meat and processed milk products are surprisingly equal, that is, $96 \%$ and $101 \%$, respectively. More important, the government levies the same tariff rates for processed agricultural products regardless of from where it imports.

Thailand's protection structure is quite similar to that of Malaysia and the Philippines. The rice, grain, processed meat and processed milk sectors get large protection from the government. The import tariff rates for rice range from $1.28 \%$ against the EU, Japan and ROW to $89 \%$ against USA. It protects cereal (ranging from 1.98\% against Malaysia, the Philippines, EU and Japan; and around 100\% against USA and ROW), processed meat by $96 \%$ regardless of the source of imports. 
Table 5.4 Indonesia’s. Import Tariff Rates, 1995 (\%)

\begin{tabular}{|c|c|c|c|c|c|c|c|c|}
\hline Sector & Malaysia & $\begin{array}{l}\text { Philippine } \\
\text { s }\end{array}$ & Singapore & Thailand & EU & Japan & USA & ROW \\
\hline \multicolumn{9}{|l|}{$\begin{array}{l}\text { Unprocessed } \\
\text { agricultural } \\
\text { products }\end{array}$} \\
\hline Rice & 0.00 & 5.00 & 5.00 & 0.00 & 0.00 & 0.00 & 0.77 & 0.07 \\
\hline Cereals & 4.00 & 4.00 & 0.00 & 0.01 & 0.01 & 0.22 & 1.82 & 0.32 \\
\hline Other crops & 5.57 & 4.89 & 7.69 & 9.06 & 8.75 & 4.35 & 7.02 & 5.69 \\
\hline Oil seeds & 5.00 & 25.00 & 18.00 & 20.00 & 7.75 & 0.00 & 3.00 & 16.92 \\
\hline \multicolumn{9}{|l|}{$\begin{array}{l}\text { Processed } \\
\text { agricultural } \\
\text { products }\end{array}$} \\
\hline $\begin{array}{l}\text { Processed } \\
\text { other crops }\end{array}$ & 13.00 & 26.00 & 12.00 & 3.00 & 10.51 & 10.00 & 16.00 & 6.55 \\
\hline $\begin{array}{l}\text { Processed } \\
\text { meat }\end{array}$ & 5.00 & 5.00 & 5.00 & 5.00 & 5.00 & 5.00 & 5.00 & 5.00 \\
\hline $\begin{array}{l}\text { Processed } \\
\text { milk }\end{array}$ & 15.00 & 15.00 & 15.00 & 15.00 & 15.00 & 15.00 & 15.00 & 15.00 \\
\hline Vegetable oil & 0.00 & 5.00 & 1.00 & 17.00 & 6.84 & 10.00 & 0.00 & 1.04 \\
\hline Sugar & 2.00 & 10.00 & 2.00 & 2.00 & 1.42 & 6.00 & 1.00 & 0.44 \\
\hline $\begin{array}{l}\text { Beverages and } \\
\text { tobacco }\end{array}$ & 40.00 & 111.00 & 55.00 & 20.00 & 78.42 & 20.00 & 17.00 & 66.74 \\
\hline \multicolumn{9}{|l|}{$\begin{array}{l}\text { Non } \\
\text { agricultural } \\
\text { products }\end{array}$} \\
\hline $\begin{array}{l}\text { Mining and } \\
\text { mineral } \\
\text { products }\end{array}$ & 3.06 & 3.91 & 3.92 & 7.09 & 3.13 & 6.85 & 4.44 & 3.49 \\
\hline Textile & 17.23 & 18.23 & 15.10 & 16.29 & 12.57 & 13.05 & 2.41 & 18.88 \\
\hline Manufacturing & 6.95 & 11.05 & 6.84 & 8.50 & 8.75 & 9.54 & 7.21 & 7.18 \\
\hline Service & 0.00 & 0.00 & 0.00 & 0.00 & 0.00 & 0.00 & 0.00 & 0.00 \\
\hline
\end{tabular}

Source: GTAP database (version 4) 
Table 5.5 Malaysia’s Import Tariff Rates, 1995 (\%)

\begin{tabular}{|c|c|c|c|c|c|c|c|c|}
\hline Sector & Indonesia & Philippines & Singapore & Thailand & EU & Japan & USA & ROW \\
\hline \multicolumn{9}{|l|}{$\begin{array}{l}\text { Unprocessed } \\
\text { agricultural } \\
\text { products }\end{array}$} \\
\hline Rice & 0.00 & 0.00 & 0.00 & 126.98 & 127.00 & 0.00 & 127.00 & 127.00 \\
\hline Cereals & 195.00 & 0.00 & 0.00 & 195.00 & 195.00 & 195.00 & 180.54 & 113.71 \\
\hline Other crops & 8.44 & 0.10 & 9.48 & 3.56 & 7.06 & 10.85 & 10.25 & 22.43 \\
\hline Oil seeds & 11.00 & 0.00 & 9.00 & 10.00 & 4.80 & 3.00 & 0.00 & 4.35 \\
\hline Livestock & 0.17 & 0.62 & 1.98 & 0.57 & 2.46 & 6.09 & 3.57 & 1.24 \\
\hline \multicolumn{9}{|l|}{$\begin{array}{l}\text { Processed } \\
\text { agricultural } \\
\text { products }\end{array}$} \\
\hline $\begin{array}{l}\text { Processed } \\
\text { other crops }\end{array}$ & 7.00 & 20.00 & 9.00 & 8.00 & 7.26 & 6.00 & 9.00 & 7.60 \\
\hline $\begin{array}{l}\text { Processed } \\
\text { meat }\end{array}$ & 96.00 & 96.00 & 96.00 & 96.00 & 96.00 & 96.00 & 96.00 & 96.00 \\
\hline $\begin{array}{l}\text { Processed } \\
\text { milk }\end{array}$ & 101.00 & 101.00 & 101.00 & 101.00 & 101.00 & 101.00 & 101.00 & 101.00 \\
\hline Vegetable oil & 1.00 & 5.00 & 10.00 & 3.00 & 4.28 & 4.00 & 2.00 & 7.59 \\
\hline Sugar & 0.00 & 0.00 & 40.00 & 0.00 & 0.00 & 0.00 & 0.00 & 0.00 \\
\hline $\begin{array}{l}\text { Beverages and } \\
\text { tobacco }\end{array}$ & 26.00 & 25.00 & 27.00 & 31.00 & 29.51 & 30.00 & 39.00 & 36.47 \\
\hline \multicolumn{9}{|l|}{$\begin{array}{l}\text { Non } \\
\text { agricultural } \\
\text { products }\end{array}$} \\
\hline $\begin{array}{l}\text { Mining and } \\
\text { mineral } \\
\text { products }\end{array}$ & 4.84 & 10.55 & 2.06 & 5.35 & 1.53 & 4.94 & 5.11 & 2.99 \\
\hline $\begin{array}{l}\text { Textile and } \\
\text { clothing }\end{array}$ & 18.40 & 18.73 & 19.46 & 18.42 & 19.91 & 18.10 & 14.23 & 16.27 \\
\hline Manufacturing & 10.35 & 4.32 & 9.21 & 7.99 & 6.37 & 8.79 & 6.40 & 7.45 \\
\hline Service & 0.00 & 0.00 & 0.00 & 0.00 & 0.00 & 0.00 & 0.00 & 0.00 \\
\hline
\end{tabular}

Source: GTAP database (version 4) 
Table 5.6 The Philippines’s Import Tariff Rates, 1995 (\%)

\begin{tabular}{|c|c|c|c|c|c|c|c|c|}
\hline Sector & Indonesia & Malaysia & Singapore & Thailand & $\mathrm{EU}$ & Japan & USA & ROW \\
\hline \multicolumn{9}{|l|}{$\begin{array}{l}\text { Unprocessed } \\
\text { agricultural } \\
\text { products }\end{array}$} \\
\hline Rice & 0.00 & 0.00 & 127.00 & 127.00 & 0.00 & 127.00 & 25.00 & 127.00 \\
\hline Cereals & 0.00 & 0.00 & 113.40 & 195.00 & 195.00 & 0.00 & 70.07 & 79.02 \\
\hline Other crops & 28.88 & 21.79 & 27.05 & 3.05 & 5.88 & 26.30 & 14.73 & 6.65 \\
\hline Oil seeds & 0.00 & 0.00 & 0.00 & 0.00 & 0.00 & 0.00 & 0.00 & 0.00 \\
\hline Livestock & 0.08 & 22.94 & 18.04 & 15.52 & 22.15 & 30.00 & 29.08 & 4.97 \\
\hline \multicolumn{9}{|l|}{$\begin{array}{l}\text { Processed } \\
\text { agricultural } \\
\text { products }\end{array}$} \\
\hline $\begin{array}{l}\text { Processed } \\
\text { other crops }\end{array}$ & 30.00 & 30.00 & 30.00 & 30.00 & 29.82 & 30.00 & 30.00 & 22.83 \\
\hline $\begin{array}{l}\text { Processed } \\
\text { meat }\end{array}$ & 96.00 & 96.00 & 96.00 & 96.00 & 96.00 & 96.00 & 96.00 & 96.00 \\
\hline $\begin{array}{l}\text { Processed } \\
\text { milk }\end{array}$ & 0.00 & 101.00 & 101.00 & 101.00 & 101.00 & 101.00 & 101.00 & 101.00 \\
\hline Vegetable oil & 30.00 & 30.00 & 30.00 & 0.00 & 29.26 & 30.00 & 30.00 & 28.71 \\
\hline Sugar & 0.00 & 0.00 & 0.00 & 0.00 & 0.00 & 0.00 & 30.00 & 0.00 \\
\hline $\begin{array}{l}\text { Beverages and } \\
\text { tobacco }\end{array}$ & 30.00 & 30.00 & 30.00 & 30.00 & 29.93 & 30.00 & 30.00 & 29.96 \\
\hline \multicolumn{9}{|l|}{$\begin{array}{l}\text { Non } \\
\text { agricultural } \\
\text { products }\end{array}$} \\
\hline $\begin{array}{l}\text { Mining and } \\
\text { mineral } \\
\text { products }\end{array}$ & 0.00 & 1.54 & 10.02 & 27.87 & 9.63 & 12.86 & 19.64 & 0.31 \\
\hline $\begin{array}{l}\text { Textile and } \\
\text { clothing }\end{array}$ & 20.88 & 24.00 & 26.13 & 22.26 & 27.41 & 24.05 & 29.14 & 22.94 \\
\hline Manufacturing & 25.50 & 26.23 & 24.14 & 25.62 & 23.70 & 22.97 & 25.83 & 22.69 \\
\hline Service & 0.00 & 0.00 & 0.00 & 0.00 & 0.00 & 0.00 & 0.00 & 0.00 \\
\hline
\end{tabular}

Source: GTAP database (version 4) 
Table 5.7 Singapore’s Tariff Rates, 1995 (\%)

\begin{tabular}{|c|c|c|c|c|c|c|c|c|}
\hline Sector & Indonesia & Malaysia & Philippines & Thailand & $\mathrm{EU}$ & Japan & USA & ROW \\
\hline \multicolumn{9}{|l|}{$\begin{array}{l}\text { Unprocessed } \\
\text { agricultural } \\
\text { products }\end{array}$} \\
\hline Rice & 0.00 & 44.00 & 0.00 & 43.85 & 44.00 & 44.00 & 43.50 & 43.84 \\
\hline Cereals & 16.00 & 13.28 & 0.00 & 16.00 & 16.00 & 16.00 & 6.93 & 7.83 \\
\hline Other crops & 14.00 & 10.00 & 24.00 & 5.00 & 27.00 & 27.00 & 27.00 & 20.12 \\
\hline Oil seeds & 14.00 & 10.00 & 24.00 & 5.00 & 27.00 & 27.00 & 27.00 & 21.10 \\
\hline Livestock & 4.81 & 24.06 & 3.65 & 3.09 & 16.43 & 3.28 & 24.56 & 15.06 \\
\hline \multicolumn{9}{|l|}{$\begin{array}{l}\text { Processed } \\
\text { agricultural } \\
\text { products }\end{array}$} \\
\hline $\begin{array}{l}\text { Processed } \\
\text { other crops }\end{array}$ & 20.00 & 25.00 & 23.00 & 15.00 & 24.02 & 18.00 & 23.00 & 15.62 \\
\hline $\begin{array}{l}\text { Processed } \\
\text { meat }\end{array}$ & 8.00 & 8.00 & 8.00 & 8.00 & 8.00 & 8.00 & 8.00 & 8.00 \\
\hline $\begin{array}{l}\text { Processed } \\
\text { milk }\end{array}$ & 0.00 & 25.00 & 25.00 & 25.00 & 25.00 & 25.00 & 25.00 & 25.00 \\
\hline Vegetable oil & 20.00 & 25.00 & 23.00 & 15.00 & 24.07 & 18.00 & 23.00 & 21.48 \\
\hline Sugar & 20.00 & 25.00 & 23.00 & 15.00 & 24.03 & 18.00 & 23.00 & 20.42 \\
\hline $\begin{array}{l}\text { Beverages and } \\
\text { tobacco }\end{array}$ & 0.00 & 27.00 & 27.00 & 27.00 & 27.00 & 27.00 & 10.00 & 27.00 \\
\hline \multicolumn{9}{|l|}{$\begin{array}{l}\text { Non } \\
\text { agricultural } \\
\text { products }\end{array}$} \\
\hline $\begin{array}{l}\text { Mining and } \\
\text { mineral } \\
\text { products }\end{array}$ & 2.87 & 0.41 & 42.58 & 0.00 & 26.41 & 27.76 & 6.65 & 0.83 \\
\hline $\begin{array}{l}\text { Textile and } \\
\text { clothing }\end{array}$ & 1.65 & 2.04 & 3.59 & 3.24 & 1.58 & 0.19 & 0.52 & 1.35 \\
\hline Manufacturing & 0.26 & 0.70 & 0.13 & 0.04 & 0.44 & 0.34 & 0.01 & 0.22 \\
\hline Service & 0.00 & 0.00 & 0.00 & 0.00 & 0.00 & 0.00 & $0 . .00$ & 0.00 \\
\hline
\end{tabular}

Source: GTAP database (version 4) 
Table 5.8 Thailand's Import Tariff Rates, 1995 (\%)

\begin{tabular}{|c|c|c|c|c|c|c|c|c|}
\hline Sector & Indonesia & Malaysia & $\begin{array}{l}\text { Philippine } \\
\text { s }\end{array}$ & Singapore & $\mathrm{EU}$ & Japan & USA & ROW \\
\hline \multicolumn{9}{|l|}{$\begin{array}{l}\text { Unprocessed } \\
\text { agricultural } \\
\text { products }\end{array}$} \\
\hline Rice & 0.00 & 0.00 & 0.00 & 0.00 & 128.00 & 128.00 & 89.38 & 128.00 \\
\hline Cereals & 0.00 & 195.00 & 195.00 & 0.00 & 195.00 & 195.00 & 101.98 & 100.47 \\
\hline Other crops & 33.68 & 31.83 & 22.88 & 22.00 & 18.85 & 36.22 & 25.73 & 18.79 \\
\hline Oil seeds & 35.00 & 35.00 & 0.00 & 23.00 & 47.00 & 32.00 & 21.00 & 37.45 \\
\hline \multicolumn{9}{|l|}{$\begin{array}{l}\text { Processed } \\
\text { agricultural } \\
\text { products }\end{array}$} \\
\hline $\begin{array}{l}\text { Processed } \\
\text { other crops }\end{array}$ & 57.00 & 46.00 & 56.00 & 41.00 & 29.73 & 44.00 & 28.00 & 45.24 \\
\hline $\begin{array}{l}\text { Processed } \\
\text { meat }\end{array}$ & 96.00 & 96.00 & 96.00 & 96.00 & 96.00 & 96.00 & 96.00 & 96.00 \\
\hline $\begin{array}{l}\text { Processed } \\
\text { milk }\end{array}$ & 0.00 & 101.00 & 101.00 & 101.00 & 101.00 & 101.00 & 101.00 & 101.00 \\
\hline Vegetable oil & 10.00 & 30.00 & 11.00 & 30.00 & 14.84 & 24.00 & 9.00 & 10.33 \\
\hline Sugar & 0.00 & 0.00 & 41.00 & 41.00 & 29.04 & 41.00 & 42.00 & 41.11 \\
\hline $\begin{array}{l}\text { Beverages and } \\
\text { tobacco }\end{array}$ & 0.00 & 47.00 & 0.00 & 41.00 & 59.01 & 43.00 & 33.00 & 52.99 \\
\hline \multicolumn{9}{|l|}{$\begin{array}{l}\text { Non } \\
\text { agricultural } \\
\text { Products }\end{array}$} \\
\hline $\begin{array}{l}\text { Mining and } \\
\text { mineral } \\
\text { products }\end{array}$ & 3.05 & 0.49 & 7.07 & 6.83 & 1.73 & 6.73 & 5.42 & 1.63 \\
\hline $\begin{array}{l}\text { Textile and } \\
\text { clothing }\end{array}$ & 22.06 & 27.37 & 27.73 & 26.48 & 23.80 & 26.41 & 11.25 & 27.16 \\
\hline Manufacturing & 22.06 & 27.37 & 27.73 & 26.48 & 23.80 & 26.41 & 11.25 & 27.16 \\
\hline Service & 0.00 & 0.00 & 0.00 & 0.00 & 0.00 & 0.00 & 0.00 & 0.00 \\
\hline
\end{tabular}

Source: GTAP Database Version 4 
The level of average export taxes/subsidies and output taxes/subsidies is given in Tables 5.9 and 5.10. In order to support exports of rice, cereals, processed meat and processed milk, ASEAN member countries with the exception of Singapore and Indonesia (a case of processed milk export) apply export subsidies on these products as indicated by a negative sign of the export taxes. For instance, the Malaysian government provides such supports by around $56 \%$ (rice) and $62 \%$ (cereals). Similar high export supports also apply for cases in the Philippines and Thailand. In other words, exports of these sectors are heavily subsidised in all nations ${ }^{53}$. However in some cases, the Malaysian government also imposes export taxes as a means of raising its national income.

Table 5.9 Average Rates of Export Tax, 1995 (\%)

\begin{tabular}{|c|c|c|c|c|c|}
\hline $\begin{array}{l}\text { Sectors } \\
\text { Unprocessed agric. } \\
\text { products }\end{array}$ & Indonesia & Malaysia & Philippines & Singapore & Thailand \\
\hline Rice & -0.56 & -56.00 & -43.73 & 0.00 & -55.80 \\
\hline Cereal & -3.00 & -62.00 & -66.00 & 0.00 & -63.69 \\
\hline Crops & 0.00 & 13.94 & 0.00 & 0.00 & 0.00 \\
\hline Oil seeds & 0.00 & 14.00 & 0.00 & 0.00 & 0.00 \\
\hline Livestock & 0.00 & 10.442 & 0.00 & 0.00 & 0.00 \\
\hline \multicolumn{6}{|l|}{$\begin{array}{l}\text { Processed } \\
\text { agricultural } \\
\text { products }\end{array}$} \\
\hline Sugar & 0.00 & 14.00 & 0.00 & 0.00 & 0.00 \\
\hline Vegetable oil & 0.00 & 14.00 & 0.00 & 0.00 & 0.00 \\
\hline Processed meat & 0.00 & -42.00 & -42.00 & 0.00 & -42.00 \\
\hline Processed milk & 0.00 & -50.00 & -50.00 & 0.00 & -50.00 \\
\hline $\begin{array}{l}\text { Processed other } \\
\text { crops }\end{array}$ & 0.00 & 14.00 & 0.00 & 0.00 & 0.00 \\
\hline $\begin{array}{l}\text { Beverage and } \\
\text { tobacco }\end{array}$ & 0.00 & 14.00 & 0.00 & 0.00 & 0.00 \\
\hline \multicolumn{6}{|l|}{$\begin{array}{l}\text { Non agricultural } \\
\text { Products }\end{array}$} \\
\hline $\begin{array}{l}\text { Mining and mineral } \\
\text { products }\end{array}$ & 0.00 & 14.00 & 0.00 & 0.00 & 0.00 \\
\hline Textile & 0.90 & 15.68 & 27.12 & 0.27 & 1.87 \\
\hline Manufacturing & 0.00 & 13.58 & 1.54 & 0.00 & 0.00 \\
\hline Services & 0.00 & 20.01 & 0.00 & 0.00 & 0.00 \\
\hline
\end{tabular}

Negative signs indicate export subsidies

Source: GTAP DatabaseVersion 4

53 ASEAN members proposed special and different treatment (S\&D) based on the article of 9.4 Agreement of the Agriculture (WTO Secretariat). Due to different stage of economic development, the ASEAN members are given the flexibility on the issue of export subsidies, domestic support and market access (.The Manila Bulletin Online, December 1, 1999). 
Table 5.10 Output Tax Rates, 1995 (\%)

\begin{tabular}{|c|c|c|c|c|c|}
\hline Sectors & Indonesia & Malaysia & Philippines & Singapore & Thailand \\
\hline \multicolumn{6}{|l|}{$\begin{array}{l}\text { Unprocessed agric. } \\
\text { products }\end{array}$} \\
\hline Rice & 0.00 & 0.00 & 1.46 & 0.00 & 0.00 \\
\hline Other cereal & 0.00 & 0.00 & 2.00 & 0.00 & 0.00 \\
\hline Crops & 0.00 & 0.00 & 2.00 & 1.99 & 0.48 \\
\hline Oil seeds & 0.00 & 0.00 & 2.00 & 2.00 & 0.00 \\
\hline Livestock & 0.00 & 0.00 & 2.56 & 1.80 & 0.00 \\
\hline \multicolumn{6}{|l|}{$\begin{array}{l}\text { Processed agric. } \\
\text { products }\end{array}$} \\
\hline Sugar & 0.00 & 0.00 & 2.00 & 1.00 & 4.00 \\
\hline Vegetable oil & 0.00 & 0.00 & 2.00 & 1.00 & 1.00 \\
\hline Processed meat & 0.00 & 0.00 & 2.00 & 2.00 & 1.00 \\
\hline Processed milk & 0.00 & 0.00 & 4.00 & 1.00 & 1.00 \\
\hline Processed crops & 0.00 & 0.00 & 2.00 & 1.00 & 8.00 \\
\hline Beverage and tobacco & 0.00 & 0.00 & 14.00 & 1.00 & 44.00 \\
\hline \multicolumn{6}{|l|}{ Non agric. products } \\
\hline $\begin{array}{l}\text { Mining and mineral } \\
\text { products }\end{array}$ & 0.00 & 0.00 & 14.37 & 0.64 & 9.20 \\
\hline Textile & 0.00 & 0.00 & 1.36 & 2.30 & 0.48 \\
\hline Manufacturing & -2.08 & 0.00 & 2.75 & 1.04 & 2.11 \\
\hline Services & 0.00 & 0.00 & 3.14 & 2.20 & 2.78 \\
\hline
\end{tabular}

Negative signs indicate output subsidies

Source: GTAP Database Version 4

Concerning the reduction of the export subsidy, the commitment of countries to reducing such subsidy would have an impact on world markets due to an increased export from subsidising countries. In addition, the reduction or elimination of export subsidy is an efficient means of reforming agricultural supports because they are usually the critical elements of the price support system. It is expected that with the reduction of export subsidy resources will be reallocated into more profitable sectors than protected sectors ${ }^{54}$.

However, when looking at the output taxes/subsidies, it is obvious that all products in the ASEAN member countries are subject to output taxes except for Malaysia where no output taxes or subsidies are reported. This indicates that governments in all ASEAN member countries raise their national income by taxing agricultural sectors. Only output in the manufacturing sector in Indonesia is subsidised (2.1\%). In contrast to this, agricultural producers in developed countries receive output subsidies. Among the developed countries, the European Union has been reportedly subsidising all agricultural products covered in

\footnotetext{
${ }^{54}$ ABARE Current Issues, July 2001.
} 
this model. Reducing output subsidies will lead to reduce domestic prices. By looking at the level of export and output subsidies in each individual sector, the magnitude of changes in export and output due to the reduction of such trade barriers could be predicted. The higher the initial level of protection, the larger the changes in the export and production.

To conform to the UR outcome, this study applies the procedure proposed by FRANCOIS and STRUTT (1997) who developed and calculated the post UR tariff rates based on the GTAP database. Import tariff rates in some sectors, particularly agricultural products remain unaltered. As a result, in the simulation specifically the reduction between 19962000 for developed countries and 1996-2004 for developing countries (the ASEAN nations and ROW), the levels of import tariffs for such sectors are unchanged. Looking at Japan's average rate for rice, no tariff reduction is applied in this study. Neither the Agricultural Market Access Database (AMAD) nor the EU's Market Access Database reports the Japanese applied tariff for rice. This is due the fact that rice is a highly sensitive product. Thus, this product is excluded from the commitment to transfer non-tariff barriers into tariffs (SHOGENJI, 1996). Adding to this Japan's case, TANGERMANN (1996) also explained that "in the few cases where countries avoided tariffication altogether, for the time being, they had to accept larger and faster growing minimum access commitments. Rice in Japan is the outstanding case in that category”. The government allows import of rice under a certain condition. In addition, only does the government body import and distribute to the consumers. This import is merely to meet the level of its market access, committed to being parallel to the UR proposal. At the end of the UR implementation for developed counties (2000), Japan has committed itself to importing rice by $6 \%$ of the total domestic demand. Thus, following this committed level of its market access for rice, Japan is expected to increase this level to $14 \%$ in the second trade liberalisation under the scenario of the Millennium Round, beginning from 2005 to 2009. This required market access level is made by varying the level of the Japan's import tariff for rice. Once the required level of $14 \%$ is reached, the model maintains this tariff level during the simulation.

In accordance with the possible outcome of next WTO (Doha) negotiation, the baseline simulation assumes an additional 36 percent cut of border tariffs for USA, EU and Japan, and another 24 percent for the ASEAN members and the rest of the world (ROW). A path of border tariff reduction rates is presented in Figure 5.1. These further reductions are 
based on the pre-UR tariff levels. Similar to the period of the UR implementation, European Union, Japan and USA are required to reduce their import tariffs in 5 years (2005-2009) and 10 years (2005-2014) for the ASEAN members and ROW. Because the simulation period of this model ends in 2010, the simulation results are based on the 2010 import tariff levels. In addition, the level of import tariffs for European Union, Japan and USA remain constant after $2009^{55}$.

Figure 5.1. A Path of Border Tariff Reduction under Post and Next WTO (Doha) Negotiation

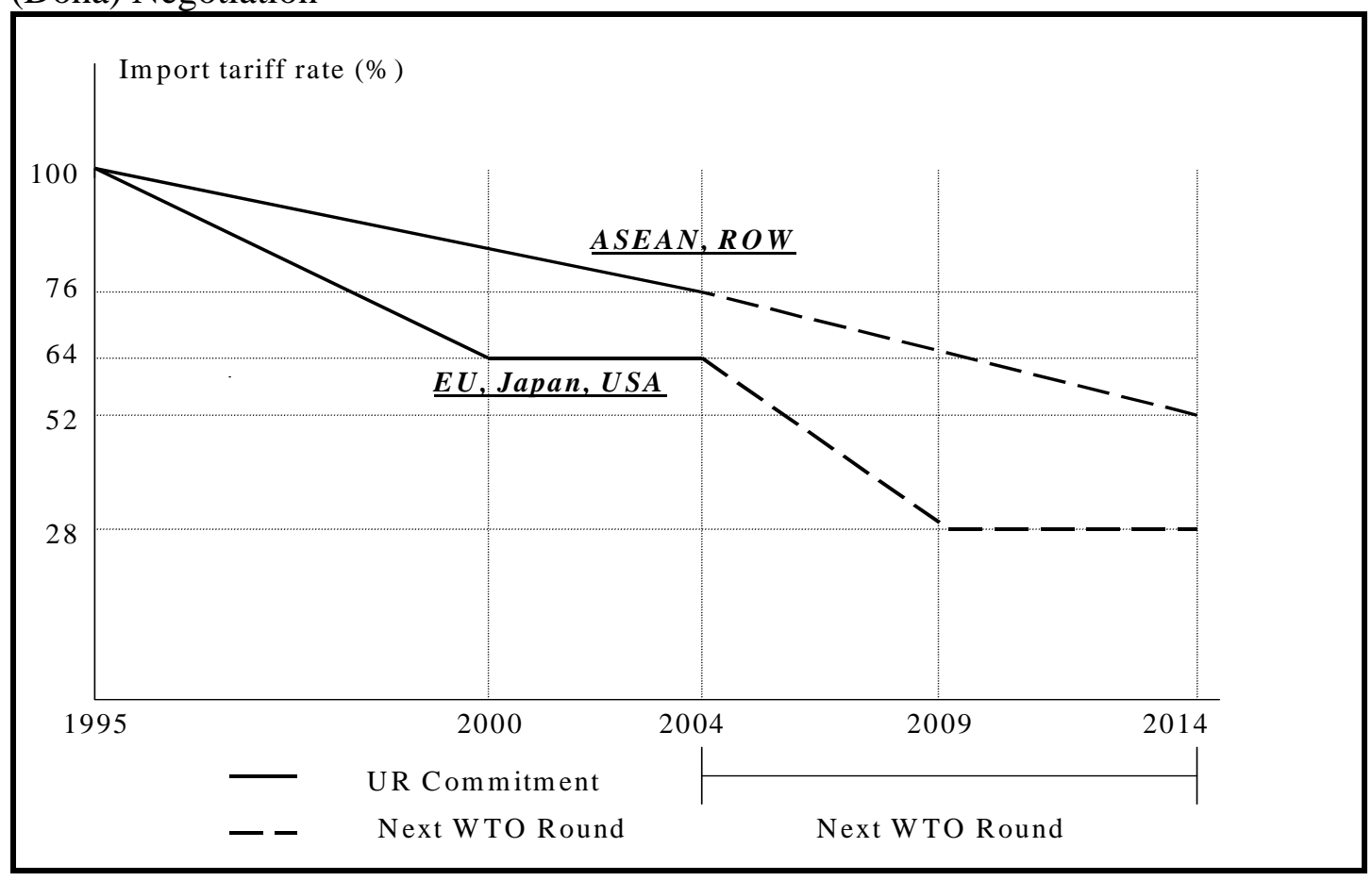

Source: Own Description

Apart from the reduction of border tariffs, it is important to discuss other trade barriers such as export subsidies and output subsidies. As mentioned earlier this study uses the GTAP database version 4 whose all data is based on the year 1995 trade. Due to a lack of data on the level of export and output subsidies reported in each country or region

\footnotetext{
${ }^{55}$ In this study the reduction of trade barriers following the outcome of the Uruguay Round and the Millennium Round was selected to be the reference basis. These barriers include import tariff rates, export subsidies and output subsidies. It is important to emphasise here that those issues are not the only central outcome of the Uruguay Round. Another important issue is the agreement of textiles and clothing. It is acknowledged that textiles are one of the hardest-fought issues in the WTO (WTO, 2000). Trade barriers in this sector were largely dominated by the system of import quota. By 2005 this sector will be treated under the normal GATT rules. However, such issue was not fully included in the simulation. Hence the impacts of the reduction of trade barriers on textile sectors (production, export and import) would be limited. In other words, if the reduction of import quotas on textiles were explicitly modelled in this study, the simulation results would have a greater impact, especially on the production and export in the ASEAN member countries. As mentioned earlier, ASEAN countries, specifically Indonesia, Thailand and Philippines have greater comparative advantages in textile sectors.
} 
following the UR commitment, it is assumed that the level of these subsidies in 1995 is the level at which the countries have reduced these subsidies in the first year of the UR implementation. The level of subsidies in each country or region is then further reduced linearly until 2000 by 36 \% for developed countries (EU, Japan and USA) and 2004 by 24 $\%$ for the ASEAN members and ROW. With regard to the possible outcome of the Millennium Round, these subsidies are also reduced similar with the border tariff reductions ${ }^{56}$.

\section{2 Results of the Baseline Scenario}

As mentioned earlier, the baseline model incorporates the impact of increased total factor productivity, labour supply, capital accumulation and the reduction of trade barriers under the UR/WTO commitment and the possible outcome of the next WTO round on macroeconomic variables such as real GDP, total export, total import, real exchange rate, wages and investment. Later, the impact on sectoral production, export and import will be presented and discussed. The baseline scenario starts 1995, the reference year, when the database was constructed. The simulation terminates in 2010, the period where the CEPT scheme is fully implemented for old ASEAN members (Indonesia, Malaysia, the Philippines, Singapore and Thailand).

The development of the regional real GDP relative to the initial values is presented in Figure 5.2. In accordance to the prior expectation the members would experience a steadily increasing real GDP due to the increase in the labour supply, induced technology as indicated by the increased total factor productivity (TFP) and more importantly capital accumulation that is induced by the increasing total investment. The increased supply of such factors in the economy would shift the national production frontier outward, thereby reaching a higher output. Looking at this figure, the ASEAN members could be grouped based on the annual real GDP growth: a low growth: Philippines; a middle growth: Singapore, Indonesia and Malaysia; and a fast growth: Thailand. The growth rate of real GDP in Thailand is projected to grow by around $11 \%$ while the Philippine real GDP is

\footnotetext{
${ }^{56}$ According to the Agreement on Agriculture, the reduction of export subsidy includes the reduction of the volume of subsidised exports by $21 \%$ and the value of export subsidies by $36 \%$. For developing countries, the reduction is two-thirds as large. However, in this study this procedure is implemented by reducing the export subsidy rates, see MARTIN and WINTERS (1996) in BACH and FRANDSEN (1998). As a result, the results of simulation should be interpreted carefully since the model did not exactly assess which of the actual restriction that will bind.
} 
observed to rise by around 4\% per year. Real GDP in Indonesia, Malaysia and Singapore is projected to grow by $9 \%, 9 \%$ and $11 \%$. This projected real GDP growth is quite different from the study of FRANCOIS, MCDONALD and NORDSTRÖM (1996). They estimated that the ASEAN economies would experience an increase in the real GDP by $6.3 \%$. Their study did not take a continual supply of labour into account. They focused mostly on the effect of capital accumulation on the real GDP. Omitting important changes in the increased supply of labour would prevent the economy from higher real GDP growth that it might attain. In addition, some labour-intensive industries would not benefit from the trade liberalisation because labours are not allowed to grow. In the context of a static model, the benefit of trade liberalisation stems from factor allocation. But in relation to dynamic analysis, not only capital accumulation but also labour supply affects the economic growth. A low growth of the Philippines' real GDP is due to (a) a low growth in the labour supply, especially its skilled labour supply and its total factor productivity and (2) capital stock /capital accumulation. HANSLOW, PHAMDUC and VERIKIOS (1999) also found that the growth rate of real GDP in Philippines was the lowest compared with the growth rates in the other ASEAN member countries. For instance, the growth rate of real GDP in the Philippines is 3.5\% while the real GDP is Singapore is projected to grow by $8.5 \%$.

Figure 5.2. The Development of Regional GDP (1995=100)

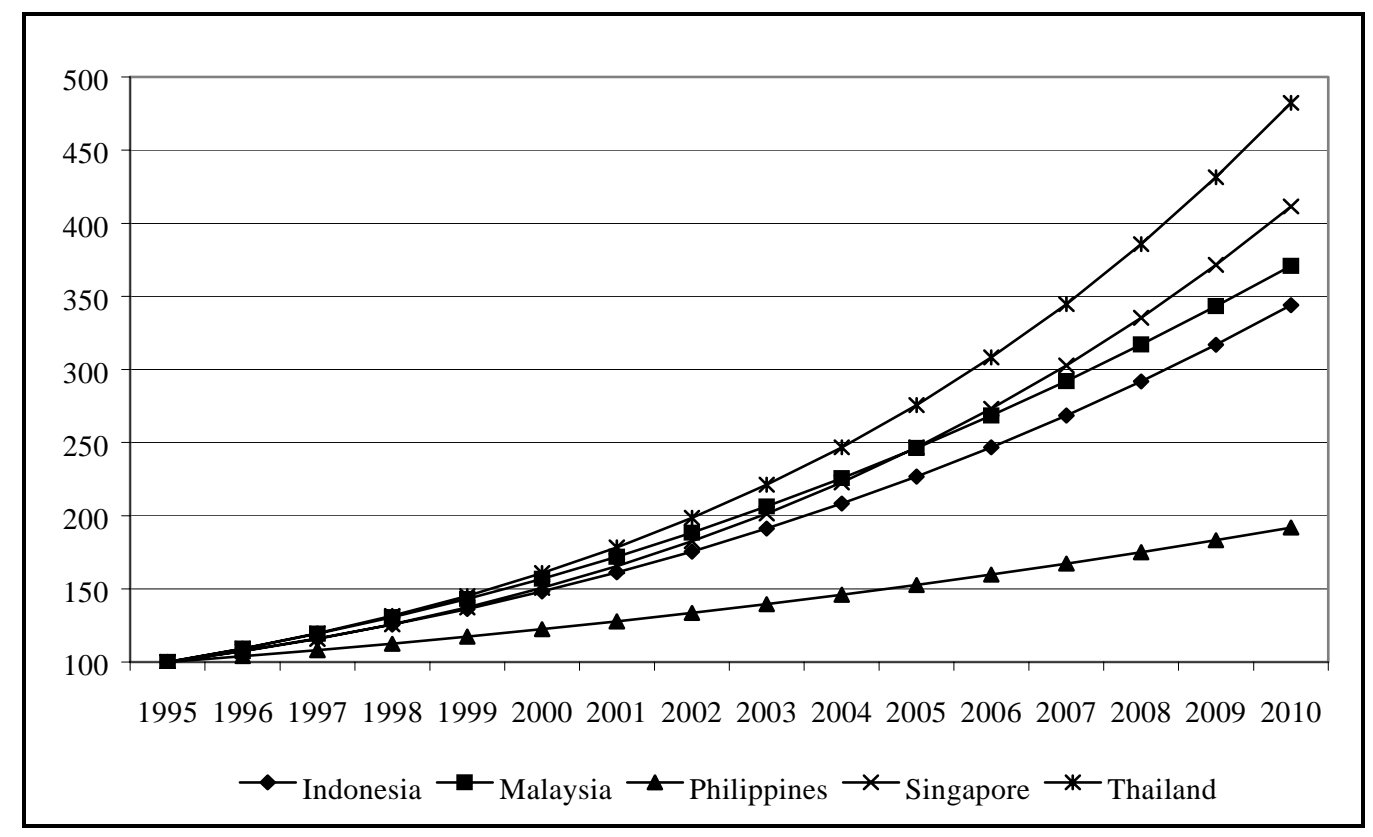

Source: Model Simulation 
Compared with the actual GDP growth in each ASEAN member, these simulation results are quite similar. In 1995 the GDP growth in the Philippines was the lowest among the ASEAN members. The GDP in this country was recorded to grow by 4.7 percent while Malaysia, Thailand, Indonesia and Singapore experienced their GDP growth by 9.8 percent, 9.3 percent, 8.2 percent and 8.0 percent, respectively. However, the GDP growth in 1998 in all ASEAN economies except Singapore was recorded to drop quite sharply. Most of the ASEAN members experienced a negative GDP growth. For instance, GDP growth in Indonesia and Thailand shrank sharply by 13.1 and 10.8 percent. This is because these economies experienced financial turmoil. The recovery period seemed to take place relatively short. In 1999 the GDP in all ASEAN economies went up. More importantly, in 2003 the GDP in some ASEAN was reported to have grown close to the rate prior to the financial crisis.

In the Indonesian case, the economic recovery is related to the fiscal and trade policies carried out by the government under the IMF supervision. The Indonesian government committed itself to implementing all agreement under the Letter of Intent (LoI). With the pressure on the budget deficit the government decided to reduce its subsidy on fuel, electricity and telecommunication. On the other side, the IMF provided the government financial assistance to finance some government projects. The government also liberalised import taxes of rice and sugar ${ }^{57}$. These policies, together with the Indonesian banking restructuring resulted in speeding up the Indonesian economic recovery.

The total export and import level are projected to increase in all ASEAN member countries as presented in Figures 5.3 and 5.4. Similar with real GDP growth, the growth of total export and total import for Thailand and Singapore would be higher than for other members. Likewise Philippines would face only a slow increase in total foreign trade. Focusing on the Figures 5.2 and 5.3, the increase in the real GDP is closely related to the increase in the total export as evidenced by the similar pattern of the growth rate of gross output and total export for Thailand. This pattern also applies for other ASEAN economies. Based on the figures, it can be concluded that the increased supply of primary

\footnotetext{
${ }^{57}$ This policy raised critics concerning its impact on the domestic rice and sugar prices. As these products are associated with million farmers in the rural region, the pressure to the domestic prices will harm the farmers' income. This will further deteriorate their term of trade. SIREGAR (2004) indicated that the farmer's term of trade continuously deteriorates. This implies that they pay non-agricultural products higher than agricultural prices they receive.
} 
factors would induce the economy to reach higher aggregate output, export and import.

Figure 5.3 The Development of Regional Export (1995=100)

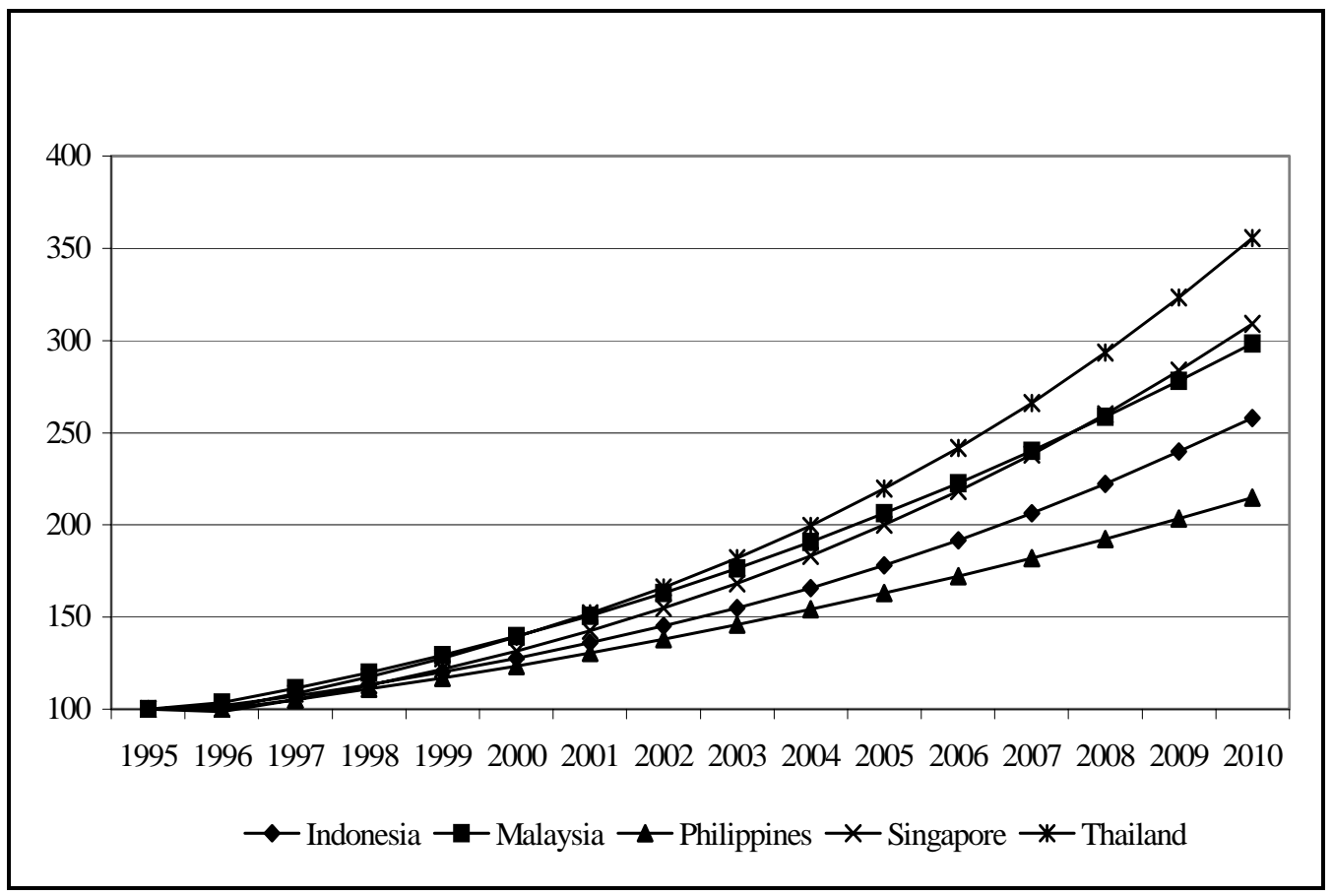

Source: Model Simulation

When comparing with the actual foreign trade development in these ASEAN economies, simulation results differ in some respects. In the period 1993-2001 statistics exhibits export and import in the ASEAN economies grew up quite sharply, especially in the case of the Philippines. The Philippine export and import increased by 14.82 percent and 7.91 percent, respectively. In contrast, export and import in Indonesia were reported to grow less than of the Philippine case. Export and import in Indonesia in the same period rose by 6.22 percent and 3.53 percent, respectively. A remarkable rise in foreign trade in the ASEAN economies particularly prior to the financial crisis was due to the export promotion strategy committed by the governments. The government often used a devaluation strategy to accelerate its export. This strategy also received government incentives by providing low import tariff rates for capital goods. In addition, this growth was attributable partly to a stable macroeconomic environment. 
Figure 5.4. The Development of Regional Import (1995=100)

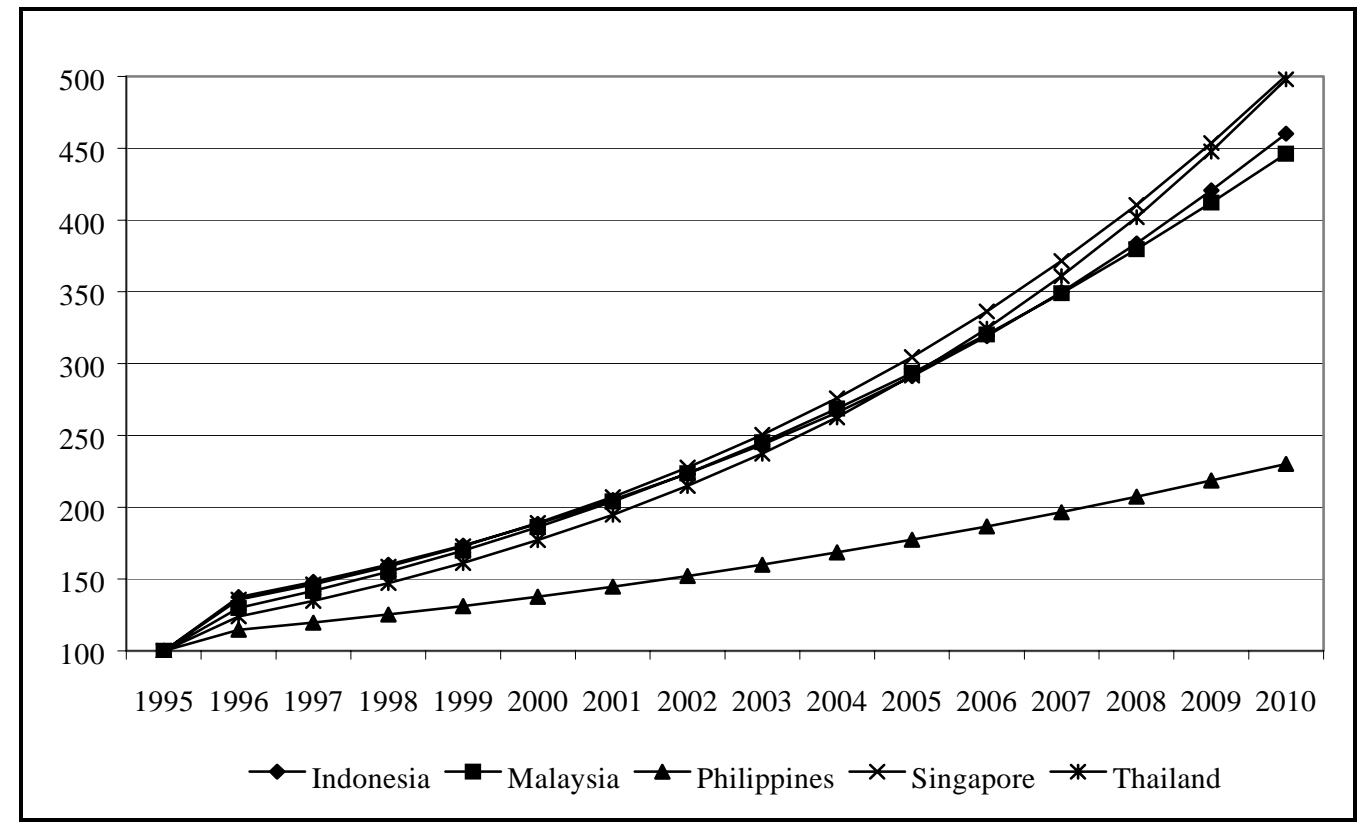

Source: Model Simulation

Figure 5.5 The Development of Investment (1995=100)

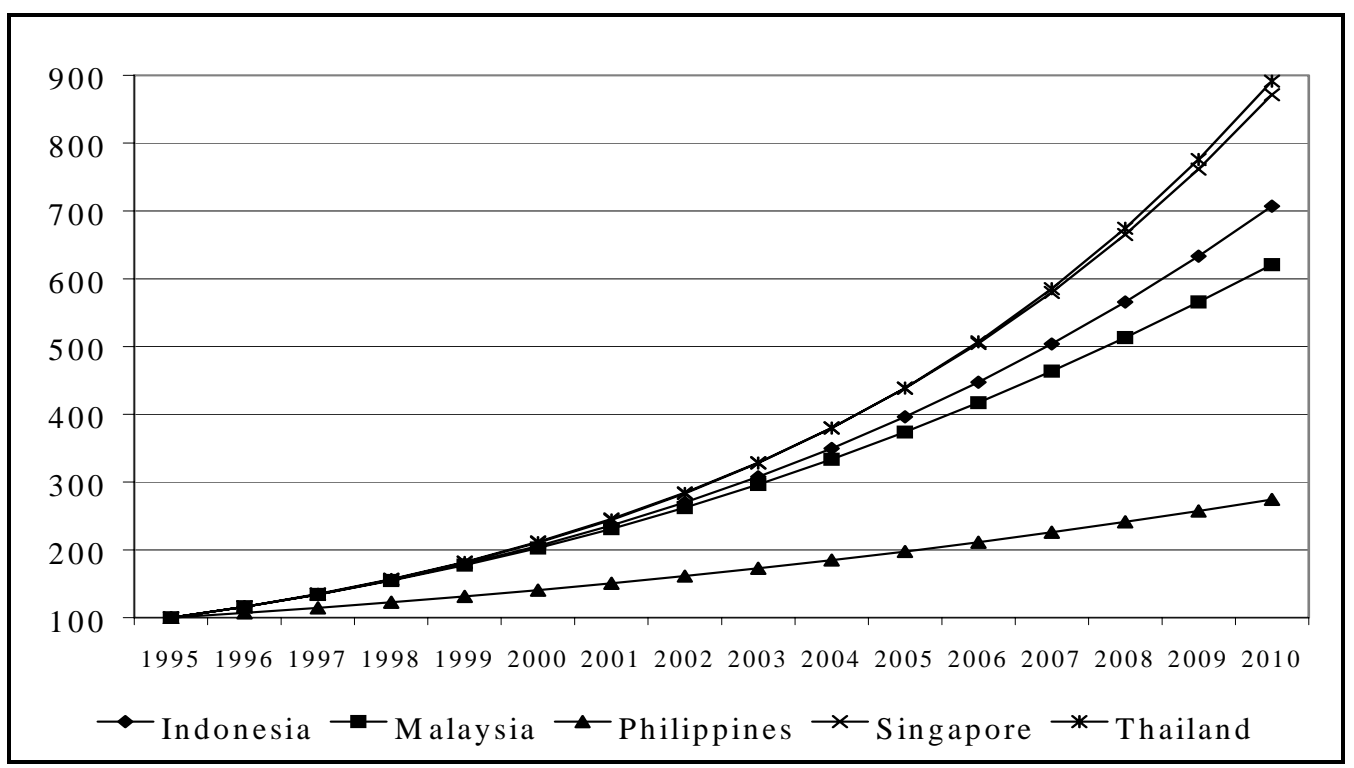

Source: Model Simulation

The level of capital stock in the t period will be influenced by the growth of savings and investment. Since the capital stock evolves over time resulting from the depreciated capital stock in the t-1 period and investment in t period, the annual growth rate of investment becomes very critical to the economy. If the annual growth rate of investment suffices to replace the worn out capital stock, thus the capital stock will be greater in the t period. 
However, it should be borne in mind that for each region in this study, the model includes the saving-investment balance. The positive impact on national income as shown by the steady increase in the real GDP is closely associated with the development of regional investment. In other words, the larger the increase in the GDP, the higher the changes in the regional investment. Therefore, there is more investment occurring in Singapore and Thailand than in the Philippines. For instance the growth rate of investment in Singapore and Thailand are around $16 \%$ while it rises annually by $7 \%$ in the Philippines.

Figure 5.6 The Development of Real Exchange Rates (1995=100)

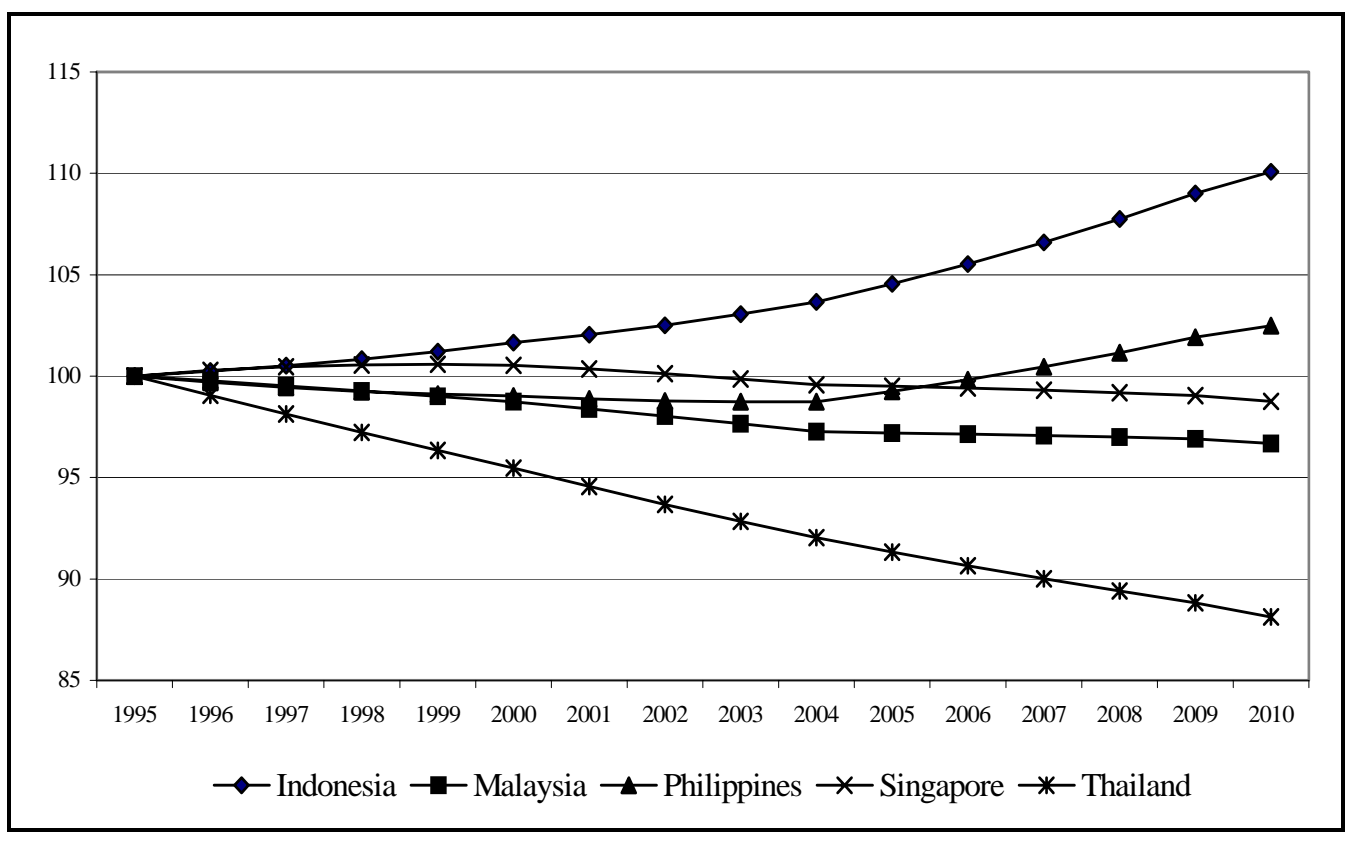

Source: Model Simulation.

Before discussing the development of real exchange rates in the ASEAN member countries under the baseline scenario, it is important to take a note that in this study there is no financial market and the real exchange rate is determined endogenously ${ }^{58}$. Across ASEAN regions, the development of real exchange rates is mixed. Focusing on the period of 19952004 (the implementation of the Uruguay Round), Indonesia and Singapore would

\footnotetext{
${ }^{58}$ Following KRUGMAN and OBSTFELD (2000) and YELDAN and DIAO (1998), the real exchange rate is defined as a relative cost of the common reference basket of goods between two nations/regions. In this study, the cost of reference basket of goods is represented with the consumer price index $\left(\operatorname{PINDEX_{(R)}}\right)$, where

$$
\operatorname{PINDEX}(R)=\sum_{i} \Pi_{i} P C_{i}, \Pi_{i} \text { is the share of expenditure, spent into } i \text {-th good. }
$$

$P I N D E X_{(U S A)}$ is then chosen as a deflator price. As a result, the real exchange rate is given by the following relation: $\left.P I N D E X_{(R)} / P I N D E X_{(U S A}\right)$. A real depreciation in the country/region $R$ then refers to the situation where the ratio of $\left.P I N D E X_{(R)} / P I N D E X_{(U S A}\right)$ decreases, conversely.
} 
experience a real appreciation. Because of their low import tariff rates the baseline scenario implies greater demand for exports in these countries than for imports. Therefore, these countries experience an appreciation of real exchange rate. On the other hand, a real depreciation occurs in other ASEAN member countries. These results are consistent with the prior expectation. Reducing trade barriers under the UR commitment and the outcome of the Doha agreement, these countries are projected to demand more imported goods. As a result of higher imports than exports their real exchange rates are depreciated. The baseline scenario would have a noticeable impact on the development of the real exchange rate in the period of 2005-2010, particularly in the Philippines. In this country, an appreciation of the real exchange rate would be observed. Similar to the discussion about the actual GDP development, the simulation results differ significantly with the actual exchange rate development. The actual development of exchange rates in the ASEAN region is closely associated with the current economic development, particularly in the period of financial crisis. Exchange rates in all ASEAN economies depreciate with different rates in some respects. Prior to the financial turmoil in 1997 one US\$ against the Indonesian Rupiah was 2.909. In 1998 when the crisis occurred the Rupiah lost its value to 10.014. Likewise the Thai Baht and Phillipine Peso experienced the similar pattern. In 1997 one US\$ against the Thai Baht and Phillipine Peso was 31.32 and 29.47, respectively. Their values further declined in 1998 becoming 41.31 and 40.89, respectively. In 1999 all ASEAN currencies appreciated against US\$. More interestingly, the Indonesian government has succeeded to stabilise its Rupiah against US\$ where one US\$ was equal to 7.855 Rupiah. In response to the increasing efforts of the government to export more products in restoring their balance of trade, their currencies are reported to appreciate however at the moderate level. In 2002 one US\$ against the Indonesian Rupiah, the Thai Baht, the Malaysian Ringgit and the Philippine Peso was as follows; 9.318, 42.96, 3.80 and 51.77, respectively. 
Figure 5. 7. The Development of Real Wages $(1995=100)$

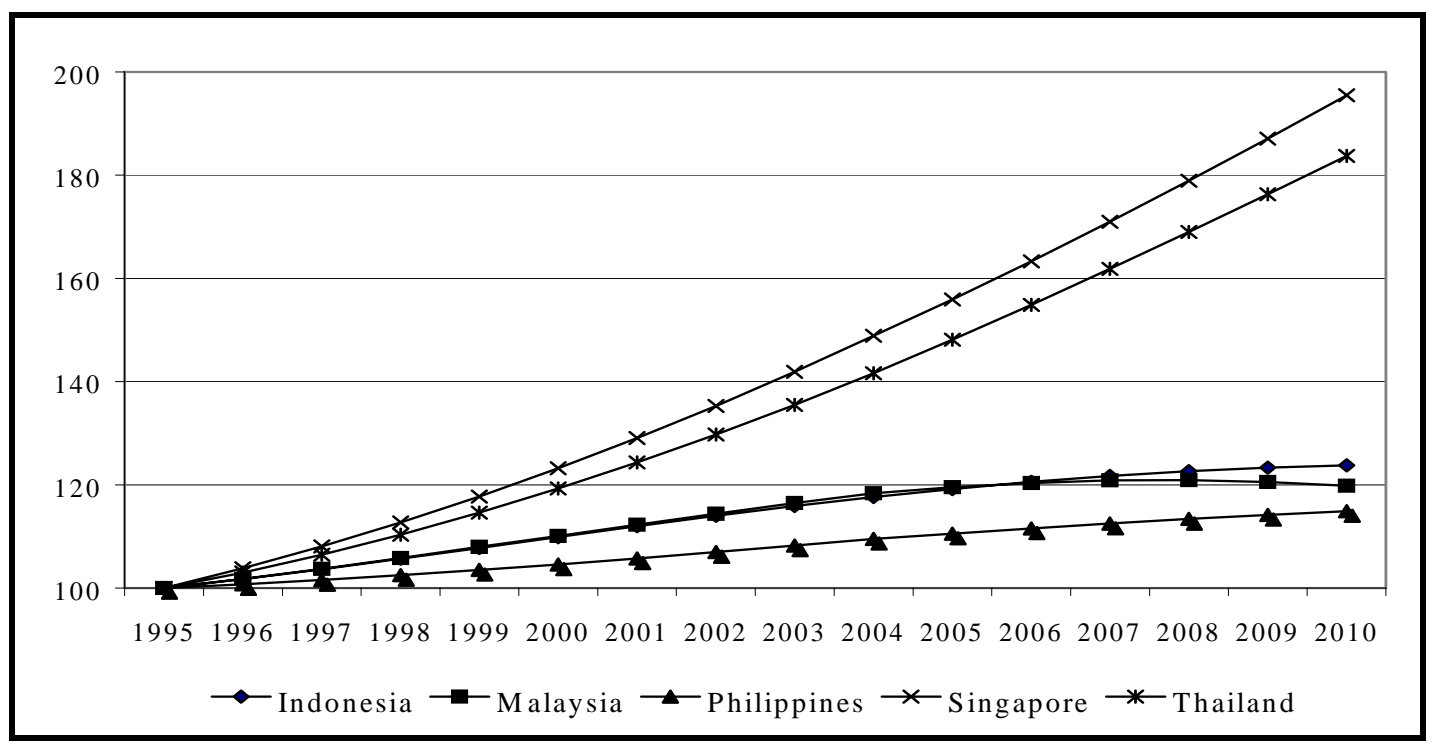

Source: Model Simulation

Regarding the impact on the real wage rate, real wage rates in all ASEAN member countries are expected to rise. For instance, within the period of simulation, real wage rates in the Philippines and Singapore would rise approximately by $1 \%$ and $5 \%$, respectively. In addition, the growth rate of real wages in Indonesia and Malaysia are nearly the same. The increase in the real wage rates in all ASEAN countries is consistent with the prior expectation. The increase in real wages is associated largely with the increasing demand for labour, following the expansion of economic sectors due to increases in a given supply of primary factor, capital accumulation, and technological changes.

Having discussed the development of macroeconomic variables that were generated from the baseline model, the following section will elaborate the development of production, export, import and demand for primary factors in the individual sector. By looking at the individual sector, one may see which sector would be affected by the changes in factor supplies. Appendix Figures 5.1-5.10 show the development of production in agricultural sectors relative to the initial values. The impact on the production of unprocessed agricultural products: rice, cereal, oil seeds, crops and livestock are first discussed. The output development of these products relative to the 1995 initial values is exhibited in Appendix Figures 5.1-5.5. Surprisingly, Thailand would experience a steadily declining rice production. Prior to the simulation it is expected that reducing trade barriers for rice in its trading partners, particularly the ASEAN economies, would induce this economy to 
boost its rice output. This is because, for the ASEAN members Thailand together with Vietnam are the major rice supplier. However, under this simulation, the output of Thai rice would decline. The decrease in the Thai rice output is due to the observed increase in demand for imported rice in this region. In addition, the demand for the Thai export of rice is projected to decrease. As a result, the country would encounter a reduction of rice output. However, the domestic price of Thai rice is expected to rise under this scenario. This indicates that an increased import of rice does not cause a decrease in domestic price due to a small share of imported rice in the total rice demand. The increase in domestic price is associated with the pressure of the consumer demand. Given a decline in rice output due to limited resources allocated in the rice sector, the pressure on the demand side induces the domestic price to rise.

In contrast, rice output in other ASEAN members are observed to increase. Compared to the average annual growth rate, rice output in Singapore is reported to be extremely higher. If looking only at the annual increase in factor supplies, the value of TFP, and its initial and post Uruguay tariff levels, it is clear that these factors contribute marginally to the increase in rice output. Thus, this increase is due to the increase in capital stock allocated to this sector, following the increase in its total investment over time. This also applies to the cereal production. In terms of cereal production, the Millennium Round would have a negative impact on the cereal production as evidenced from the decline in the production, beginning in 2005. In other words, this sector in Indonesia, Malaysia, Philippines and Thailand would contract in response to the opening up of their domestic market resulting from the further reduction of import tariffs for cereal. It is then projected that the demand on factors in this sector would decline. Concerning the development of oil seeds production, Malaysia is observed to experience a decrease in their production while in other ASEAN nations this product is estimated to rise. Because oil seeds are intermediate inputs for the vegetable oil industries, the decline in oil seed output in Malaysia is closely related to the decrease in vegetable oil output.

Looking at the different patterns of crop production in the ASEAN members, output of this sector is projected to grow constantly in the Philippines and Thailand. In contrast, other three ASEAN member countries would experience a decline in the output of this sector. The different development of this output is due to the unskilled labour allocated into this 
sector. It seems that the availability of unskilled labour plays an important role. This is because this sector is an unskilled-labour intensive sector. In other words, the development of crop production coincides with the allocation of unskilled labour into this sector.

Table 5.11 Production of Selected Agricultural Products (000 MT)

\begin{tabular}{|c|c|c|c|c|c|c|c|}
\hline \multirow[t]{2}{*}{ Comodity } & \multicolumn{7}{|l|}{ Indonesia } \\
\hline & 1995 & 1996 & 1997 & 1998 & 1999 & 2000 & 2001 \\
\hline Cereals & 57,990 & 60,409 & 58,148 & 59,406 & 60,070 & 61,575 & 59,808 \\
\hline Rice, Paddy & 49,744 & 51,102 & 49,377 & 49,237 & 50,866 & 51,898 & 50,461 \\
\hline Meat & 1,903 & 2,042 & 2,041 & 1,715 & 1,607 & 1,712 & 1,773 \\
\hline \multirow[t]{2}{*}{ Milk } & 731 & 754 & 745 & 677 & 727 & 786 & 793 \\
\hline & Malaysia & & & & & & \\
\hline Cereals & 2,170 & 2,273 & 2,168 & 1,994 & 2,094 & 2,206 & 2,161 \\
\hline Rice, Paddy & 2,127 & 2,228 & 2,120 & 1,944 & 2,037 & 2,141 & 2,094 \\
\hline Meat & 1,011 & 1,027 & 1,055 & 1,041 & 943 & 953 & 972 \\
\hline \multirow[t]{2}{*}{ Milk } & 45 & 43 & 41 & 39 & 36 & 36 & 39 \\
\hline & \multicolumn{7}{|c|}{ The Philippines } \\
\hline Cereals & 14,702 & 15,629 & 15,600 & 12,377 & 16,371 & 16,901 & 17,480 \\
\hline Rice, Paddy & 10,541 & 11,284 & 11,000 & 8,554 & 11,787 & 12,389 & 12,955 \\
\hline Meat & 1,414 & 1,538 & 1,650 & 1,700 & 1,796 & 1,873 & 1,977 \\
\hline \multirow[t]{2}{*}{ Milk } & 12 & 12 & 10 & 9 & 10 & 10 & 11 \\
\hline & Thailand & & & & & & \\
\hline Cereals & 26,413 & 27,144 & 27,635 & 28,265 & 28,661 & 30,519 & 31,203 \\
\hline Rice, Paddy & 22,016 & 22,332 & 23,580 & 23,450 & 24,172 & 25,844 & 26,514 \\
\hline Meat & 1,856 & 1,879 & 1,876 & 1,933 & 1,866 & 1,889 & 2,053 \\
\hline Milk & 307 & 343 & 386 & 437 & 465 & 520 & 564 \\
\hline
\end{tabular}

Source: ASEAN Secretariat (2003)

Actual production development of selected agricultural products in the ASEAN region is presented in Table 5.11. Singapore is omitted since the contribution of agricultural products in her GDP is very small. Prior to the financial crisis the ASEAN countries enjoyed constantly increasing growths of agricultural production. For instance, rice production in Indonesia and Thailand in 1996 rose by 4 percent and 6 percent. Indonesia is one of the largest rice importers in the world while Thailand is the largest rice exporter. Rice in the ASEAN region is a staple food. It is not surprising the governments in the 
region are devoted to increasing rice production in meeting the increasing demand for rice. In fact, rice consumption per capita tends to decline in line with the increase in household incomes. In response to the increased rice demand the governments constantly provided rice farmers subsidies for fertiliser and pesticide, price incentives (floor price), better infrastructure such water irrigation and credits. Due to the pressure to the fiscal budget and the agreement between the Indonesian government and the International Monetary Fund (IMF), the government terminated its subsidies for fertiliser and pesticide. The increase in rice production is also attributable to the increase in rice productivity resulting from the cultivation of high-yielding-varieties.

Livestock are one of the important economic activities for rural population. Livestock in the ASEAN region are largely dominated by small scale farmers. As people's income rises, the demand for meat and milk tends to grow. Income elasticities for meat and milk in the Asian region are considered to be still high. For instance, income elasticities for meat and milk are 0.63 and 0.57 , respectively. These values even tend to be higher for low income population. However, current domestic production cannot meet meat and milk consumption. As a result, to meet the increasing demand for beef meat and milk the countries rely largely on imports. Australia and New Zealand are the main ASEAN beef meat and milk supplier. To accelerate domestic meat and milk production the governments in the ASEAN region put a high priority of livestock sector in their development. As presented in Table 5.11 meat and milk production in the ASEAN countries grew, especially in the period 1995-1996. These increases were partly due to the government policy to imports of germplasm, dairy production and processing equipment and technology and to undertake research and extension program. More importantly, given a considerable number of small scale farmers involved in livestock farming, a concept of a strategic partnership between large companies and small farmers (Livestock Nucleus Scheme) has been introduced in Indonesia, the Philippines and Thailand ${ }^{59}$. Under this partnership, small scale farmers are given guarantee in terms of selling their production with a previously agreed selling price.

Different patterns of the output growth in the case of processed agricultural products are obvious. It is reported that the output of these products in all ASEAN economies with the exception of sugar and processed meat in Malaysia is projected to steadily rise. More

\footnotetext{
${ }^{59}$ Commercial Livestock Production by Asian Smallholders. Food and Fertilizer Technology Center. Taiwan (http://www.agnet.org/library/article/ac1995c.html)
} 
importantly, the growth rates of most processed products in Singapore are obviously high, except for the case of processed milk. Malaysia is also predicted to experience a relatively high rate of its production of processed milk (Appendix Figure 5.8). These figures suggest that despite their commitment to reducing their import tariffs under the WTO and the next WTO Round, most of sectors would expand. Two factors explain the increase in the continuous production of processed agricultural products. First, the reduction of import tariffs in the ASEAN's trading partners as well as ROW would lead to intensifying the ASEAN trade with these countries due to cheaper imported goods. In other words, the positive production effects for these products are due to increased trade with non-ASEAN nations and lower distortions, following the reduction of trade barriers. Second, these sectors are relatively capital-intensive sectors. The principal source of their growth is an increase in the total investment, thereby supplying more capital stock to these sectors.

Changes over time in outputs of non-agricultural products relative to the 1995 production levels are estimated to occur. The patterns of such changes are quite similar with the patterns facing the processed agricultural sectors. Annual increases in the labour supply, technological progress, capital accumulation and a reduction in trade barriers result in the expansion of these sectors. Again an increase in capital stock plays an important role in explaining these changes. This is because there is a minor change in the border tariffs between the initial and post Uruguay tariff levels. Even the level of import tariffs for service remains unchanged. In addition, the positive changes in the production are partly induced by the growth in the domestic demand, following the increased income and also the assumed income elasticities.

Appendix Figures 5.12-5.22 and 5.23-5.33 provide change trends of export and import volume for individual agricultural sector in the baseline. Different patterns of export are noticeable when elaborating the development of export in the unprocessed agricultural sectors with the exception of the case of exports of the livestock product. In this sector, all ASEAN members would experience an increase their export, particularly Singapore and Thailand. A large increase of Singapore export is due to its relatively small share of its export to the total production. Using a Constant Elasticity of Transformation function to represent an imperfect substitutability between exported goods and domestic goods, a small change in export prices would lead to great changes in the volume of export. This change is also governed by the value of transformation elasticities used in the model. 
Likewise the magnitude of changes in imports is determined by the changes in relative prices of domestic and imported goods as well as the values of import substitution elasticities.

In the case of the rice export, Indonesia and Philippines would experience an increase in their export. In contrast, Malaysia and Thailand are reported to be in decline. This picture seems to be surprising because Thailand is regarded as one of the largest rice exporting countries. A reduction of border barriers in its trading partners in turn would lead to demand more import of Thai rice. The next question is how the increase in imported rice induces a decrease in the export side. The increase in the domestic demand resulting from the lowering of the border tariff may depress the domestic output. This is due to the decrease in the domestic price, which causes the contraction of the domestic production. In other words, the economy will experience a contracting sector, hence reducing its export of the product in question. However, a different pattern emerges when looking at the change trend of the rice export for Indonesia and Philippines. Rice exports in these countries are predicted to increase over time until 2010. The increase in rice exports is partly attributed to the increased supply of labour. Provided that this economic sector in these countries is relatively labour-intensive, thus it will induce this sector to produce more output. Following their comparative advantage in this sector, rice exports in these countries are expected to increase over time.

A change in cereal export, resulting from the trade liberalisation, is noticeable, especially in the case of Malaysia. Prior to the implementation of the possible outcome of the next WTO Round, this country would have an increasing cereal export. Following the next WTO tariff reduction, its cereal export is expected to decline. Here the same question is relevant as in the case of Thailand: if $\mathrm{M}$. is an exporter of cereals, why should the tariff reduction then affect domestic price? This picture suggests that next multilateral trade liberalisation would tend to reduce the cereal export in Malaysia. The declining export of cereal in most of ASEAN countries already occurs with the first implementation of the WTO commitment.

Trends of changes in export of other unprocessed agricultural sectors: oil seeds, livestock and other crops are provided in Appendix Figures 5.14 - 5.16. A markedly increasing export of livestock in all ASEAN members is presented in Appendix Figure 5.16. The 
increase in the production is closely related to the assumed growth rates of labour supply and total factor productivity (TFP). In addition, a rise in the output is due to the reduction in trade barriers in other countries. Hence, ASEAN member countries have a larger access to the foreign markets. On the side, import levels of livestock in the ASEAN region are quite low. Therefore, the source of an increased demand for export seems to be nonASEAN markets. Compared to other ASEAN countries, the annual average export growth rate in Singapore is reported to be higher and the Philippines would experience a slower growth rate. It seems that under the baseline scenario, particularly in the presence of an annual increase of primary factors as well as TFP, this sector would benefit from this situation. Thus, the reduction of trade barriers seems not to have an impact on the change in export. Different patterns, however, exist in the case of exports of oil seeds and crops. Looking at the path of the export growth, particularly in Thailand, the Philippines and Singapore (oil seeds and crops) and Indonesia (other crops), a change in the export growth takes place in the year 2005 as the first implementation of the possible outcome of the next Round. These figures indicate that those ASEAN members with the exception of Indonesia would experience an increase in exports of both products. In contrast, a fall in exports would occur in Malaysia. The magnitude of these changes is presented in different rates of their export growth.

Regarding to the export changes in the case of processed agricultural products, exports of most of these products are projected to rise (Appendix Figures $5.17-5.22$ ). Due to a small share of its exports, it is not surprising that Singapore would have a higher rate of its export growth relative to the growth facing other ASEAN members. These large changes in its exports do not necessarily affect the whole economy. The impact of the possible outcome of the Millennium Round on the exports of processed agricultural is apparent, particularly in the export of processed milk. Three ASEAN members would experience a significant increase their export of processed milk product following the possible outcome of the next WTO round. Within the period of 1995-2004 Singapore, Indonesia, and Thailand are reported to increase their exports of this product by $8.1 \%$, $8.8 \%$ and $4.9 \%$, relative to the baseline scenario. In the period of 2005-2010 their average annual increases are $13.7 \%$, $9.2 \%$ and $5.4 \%$, respectively, relative to the baseline scenario. This figure also indicates that in the period of 2000-2004 the growth rates of export of processed milk in these countries are higher than the period of 1995-2000, but lower than the period 2004-2010. In the period of 2000-2004 the level of import tariffs in the developed countries remain 
unchanged. This results in relatively lower export growths.

With regard to the changes in the export of non-agricultural products: textile, mining and mineral products, manufacturing and services under the baseline scenario, the results show that exports of these products tend to rise. Among ASEAN members, Singapore again benefits most in this scenario as presented by a relatively higher annual rate of its export. Philippines on the other side would experience only small or modest changes. These patterns are consistent with the trend of their production of non-agricultural products. These rises are not only due to the reduction of border tariffs in their trading partners where their high trade intensity with the developed countries, especially USA, Japan and EU exists. Because these sectors are relatively capital-intensive sectors and capital stock rises due to the increased investment, these sectors would expand. In addition, most of ASEAN member countries have comparative advantages in the production of, for example, textiles and light manufacturing industries where these industries are relatively labourintensive industries. Following the increase in labour supply and the reduction of border tariffs in other trading partners, exports of these products are expected to go up. It is not surprising that ASEAN countries except for Singapore are benefiting from the relatively cheap labour wage.

The changes in imports of the individual agricultural products under the baseline scenario are presented in Appendix Figures 5.23-5.33. The impacts on imports of unprocessed agricultural products are discussed first. As seen in these figures, imports of these products in all ASEAN members are projected to increase steadily. It is interesting to see that Malaysia faces a relatively higher annual average growth rate. Two possible reasons can be identified to explain the increase in imports of these products. As outlined in Table 5.2 some of the ASEAN member countries had very high average tariff, particularly on unprocessed agricultural products. Reducing their tariffs under the WTO commitment and the possible outcome of next WTO Round would have a significant impact on the import side. Following the declining import price thereby reducing the composite price, the demand for imported goods rises. Thus, this country is expected to experience an increase in imports. In addition, the regional income also increases over time because of the increase of factor payments together with tax revenues particularly output and intermediate taxes. Looking at Appendix Figure 5.23, it seems that the annual average growth rates of rice import in all ASEAN members in the period 2005-2010 are less than those in the 
period 1995-2004. The magnitude of changes in imports is largely dependent on the initial level of import tariffs. The higher the initial tariff, the larger the impact of the reduction of the import tariffs on imports.

Under the baseline scenario, the increase in imports of processed agricultural products in all ASEAN members is also projected. Compared to the development of import of these products in other ASEAN countries, Philippines would have relatively low annual growth rates with the exception of import of processed meat in the period 1995-2004. Despite the fact that this country had imposed high import tariff levels, import changes are lower than what would occur in other ASEAN countries. Focusing on import of processed meat, the possible outcome of the next WTO round would have a significant impact on import in Thailand and Philippines. Imports of processed meat in Thailand and Philippines are expected to decrease. By contrast, the next WTO Round seems not to have a significant impact on import of this product in Malaysia. The level of import for the period of 20052010 would be the same with the level in the year 2004. This different magnitude of import changes in these countries compared to import changes in Indonesia and Singapore is due to the different level of the post Uruguay import tariffs.

Reducing trade barriers and changes in supplies of primary factors as well as increasing productivity would have a positive impact on the overall imports of non-agricultural products. Again these increases result not only from the reduction of border tariffs; the increase in regional income may also induce the regional household to demand more imported products. It would then lead to raise the demand for imported goods. And looking at the income elasticities used in this study, these findings are in accordance with the prior expectation. The use of the LES function allows for the changes in consumption patterns as income increases. And more importantly, income elasticities for nonagricultural products are relatively higher than those for agricultural products. As a result, policy shocks lead to increase household income, the share of income spent for nonagricultural products increases more than being spent into agricultural products.

The development of factor prices is given in Appendix Figures 5.34-35. The different changes in factor prices are noticeable when comparing not only between factors but also across ASEAN members. In accordance with the prior expectation the land rent is predicted to increase over time. For instance, annual growth rates of land rent are 
approximately 14 \% (Indonesia), 17 \% (Malaysia), 11 \% (Philippines), 16 \% (Singapore) and $14 \%$ (Thailand). Since the supply of land remains unchanged across countries, this factor then becomes scarce. For unprocessed agricultural sectors the supply of land will be a limiting factor. In other words, the output of these sectors depends largely on the availability of land. The mobility of land within these sectors is also dependent on the size of substitution elasticity between primary factors. The limitation of this model is that the value of substitution elasticity between primary factors is the same. So there is no differential pattern of complementary. This requirement is often unrealistic (LAYARD and WALTERS, 1978). Since the implementation of the GATT/WTO agreement, the likely outcome of the Millennium Round and the assumed yearly increase in productivity in the 15-years period would cause the expansion of some producing sectors, the demand for land in unprocessed agricultural sectors would be increased. Given the scarcity of land there would be excess demand for land. Consequently land rent is expected to increase. By contrast capital rate of return is projected to decrease over time with the exception of a case in Singapore. Capital rate of return would decline annually by $1.8 \%$ (Indonesia), $1.8 \%$ (Malaysia), $0.5 \%$ (Philippines) and $0.1 \%$ (Thailand). It should be emphasised here that the supply of capital involves over time following the development of total investment. The supply of capital is closely associated with the investment. Investment in last period will affect the capital stock in the current period. Therefore, as investment increases over time, the supply of capital then rises. The reduction in capital rate of return will have an economic implication, particularly for sectors that are capital-intensive. These sectors will expand faster compared to the less capital-intensive sectors.

In the context of a recursive-dynamic CGE model the development of factor demand and its allocation in association with the relative development of sectoral output should be identified. While the previous section was focused in the relative changes in production and trade, this section provides details on the driving forces of output changes, i.e. changes in factor prices and changes in demand for factors. Using a CES production function the level of primary factors demanded depends on the relative prices of primary factors, the value of substitution elasticity among factors, the share of individual factor in the production cost and a level of output. In other words, this substitution elasticity will determine the ability of the sector to change the output in response to changes in relative prices or changes in the endowment of primary factors (DIMARAMAN, MC DOUGALL, HERTEL, 1998). In this study, the values of this elasticity quite vary from sector to sector. 
In comparison between sectors, these values tend to increase parallel with the degree of industrialisation. In other words, substitution elasticities in the processed agricultural sector and the non-agricultural sectors are relative higher than those in the unprocessed agricultural sectors. The higher the elasticity, the easier one factor is substituted away by another factor. However, it seems to be unrealistic to see that the value of substitution elasticity between capital and unskilled labour and between capital and skilled labour is the same. One may expect that unskilled labour can be easily substituted by the machinery relative to skilled labour. Thus the elasticity of substitution between both factors would be higher than between capital and skilled labour.

In addition, under the assumption of factor mobility with the exception of land that is only employed in the agricultural sectors, the price of factors will be equal. And the allocation of factors demanded is then determined by which factor returns equal to the value of marginal product (VMP). Besides no wage differentials for the same category of labour are assumed across producing sectors. Therefore it will ease the welfare interpretation. This is because " it precludes the possibility of interpreting the reference solution as a second-best solution due to a distortion in the labo[u]r market caused by wage differentials” (DERVIS, DE MELO and ROBINSON, 1982:260).

The following figure describes the development of demand for primary factors in a single selected agricultural sector: processed meat sector. Figure 5.8 below shows the development of processed meat production together with the development of demand for primary factors in Malaysia. Observing the output growth three noticeable differences emerge. Between 1995 and 2000 the output of processed meat in this country seems to remain unchanged. The output tends to decrease in the period of 2000-2004. The positive growth of output is observed from the year 2004 where the first period of the Millennium round would occur. The development of output is parallel with the changes in the demand for primary factors. However between 1995 and 2000 the increase in the demand for capital induces a light decline in employment of skilled labour and a large reduction in demand for unskilled labour. This has a positive correlation with the growth rate of unskilled labour supply. The growth rate of availability of unskilled labour is much lower than that of skilled labour. This drives up the price of unskilled labour. The positive changes in capital demand relative to the 1995 base year are due the decreasing capital rate of return. On the other side, wages of skilled and unskilled labour tend to grow. As 
relative prices of capital-labour continue to decline, this sector demands more capital than other primary factors. Focusing on the output changes between 2004 and 2010, a reduction of trade barriers would have a positive impact on the output of processed meat. In average the output would be increased by around $2.5 \%$ annually. The demand for skilled labour increases lightly while the demand for unskilled labour continues to decline. The demand growth rate of skilled and unskilled labour in this period would be $2.5 \%$ and $-1.9 \%$, respectively. The domestic price is a determinant factor in explaining such changes in output. Changes in output are a response to changes in the domestic demand. As demand for processed meat increases the price tends to rise. In turn the production will be increased. Despite the fact that export price is observed to decline steadily, indicating that the export of processed meat in Malaysia tends to decline as well, its producer price is expected to go up. This is because processed meat products are largely for domestic consumption. In other words, the share of export in the total production is low. 
Figure 5.8 The Development of Production and Factor Demand in the Processed Meat Sector in Malaysia $(1995=100)$

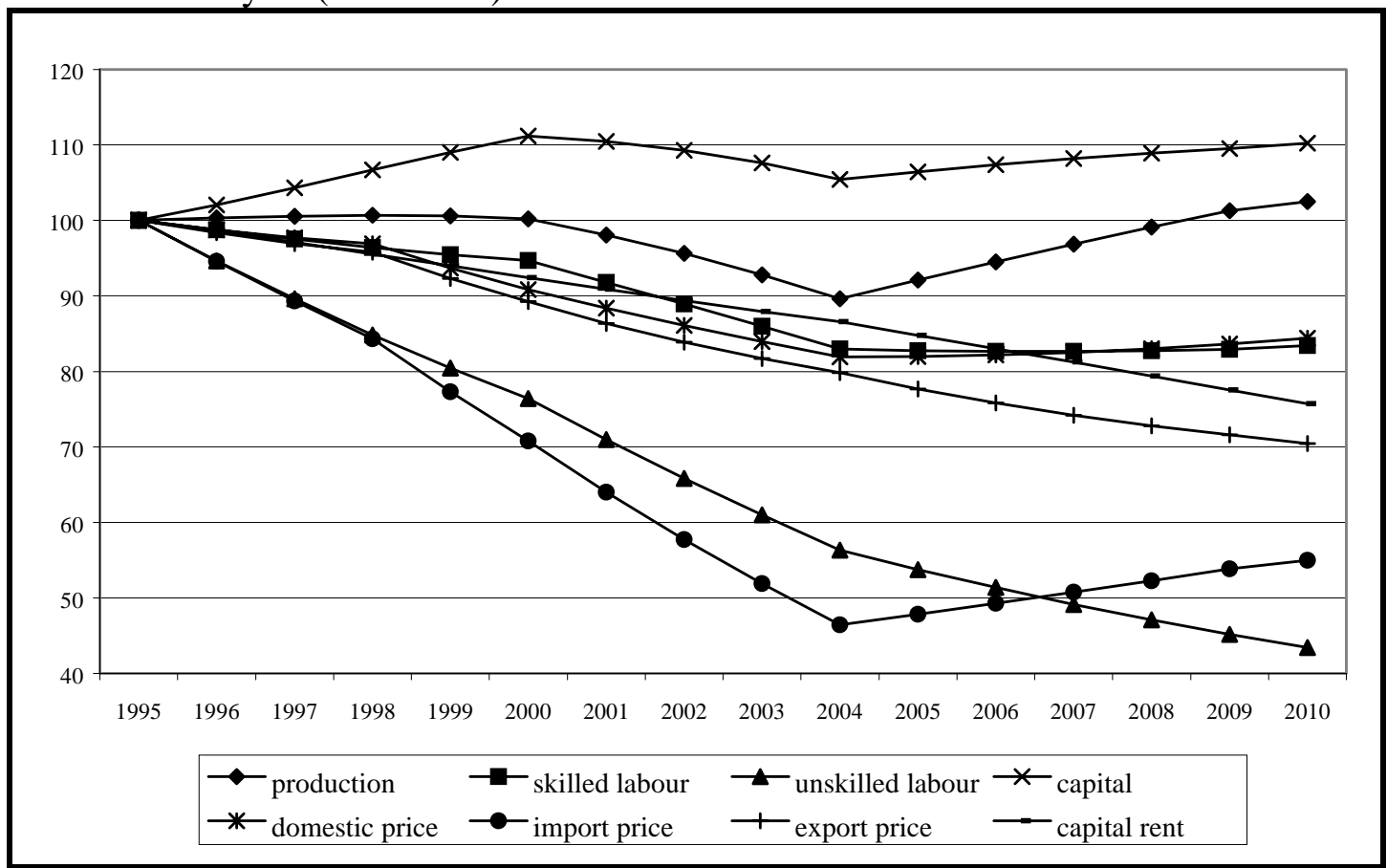

Source: Model Simulation.

\section{3. AFTA and APEC Trade Liberalisation Scenario}

According to the AFTA protocol, all members are required to reduce their import tariff for products that are imported from the members based on the CEPT (Common Effective Preferential Tariff) scheme. All products with the exception of products that are categorised as sensitive products and general exceptions will have import tariffs at the level of $0-5 \%$ in 2003. However, the period of reducing import tariff rates for sensitive products begins on 1 January 2001 and should be completed by 1 January 2010. The final level of import tariff for sensitive products and highly sensitive products will be $0-5$ and 20 percent, respectively. The Protocol on the Special Arrangement for Sensitive and Highly Sensitive Products provides a list of those products as presented in Annex 1 and 2. Indonesia, Malaysia and Philippines classify rice as a highly sensitive product. In addition, Indonesia, Malaysia and Singapore impose very high tariff level (specific duty) on alcoholic beverages and tobacco products due to religious and health reasons.

In the simulation, import tariffs for all normal products (Inclusion List and Temporary Inclusion List) are reduced to zero in 2003. Highly sensitive products (rice for Malaysia and Philippines; and Beverages and Tobacco products) will have a 0\% tariff level in 2010. 
Imposing a 20\% tariff level for this product category in 2010 would make the trade liberalisation under the CEPT scheme ineffective. This is because import tariff levels for this product in some ASEAN members in this year are already below 20\%. By imposing a zero tariff level in 2003 and 2010, this simulation would refer to the full ASEAN trade liberalisation. However, it should be stressed here that the trade liberalisation committed by the members includes only the reduction of border tariffs. In other words, the level of other trade measures such as export and output subsidies remains unchanged. The level of import tariffs is then reduced linearly, causing the same reduction in each year. The simulation path of this scenario is graphed in Figure 5.20. Looking at the tariff reduction path, the baseline import tariff levels decrease constantly. It is also estimated that the members would have different results between 1995-2003 and 2004-2010 due to the implementation of the zero tariff levels for normal products since 2003.

The question now is how absolute levels of tariffs in ASEAN countries in future years compare between the AFTA and APEC scenario. As has been seen, the full implementation of AFTA trade liberalisation is in 2010 for old countries. This period is 10 year earlier than when APEC developing countries remove their import tariff rates completely in 2020 as declared in the Bogor Leaders Meeting 1994. Following the Manila Meeting in 1996 and the Vancouver Meeting in 1997, the full liberalisation was then initiated for selected sectors (Early Voluntary Sectoral Liberalisation /EVSL). Import tariff rates for these selected sectors are required to be abolished by 2005 . Therefore, it is projected that the absolute levels of import tariffs in ASEAN countries mentioned above in future years (2020) under both scenarios will be similar. It seems that AFTA trade liberalisation reflects the preparation of ASEAN member countries for wider regional economic co-operation. In other words, the formation of a free trade area arrangement by the ASEAN member countries is a stepping-stone to wider trade liberalisation. 


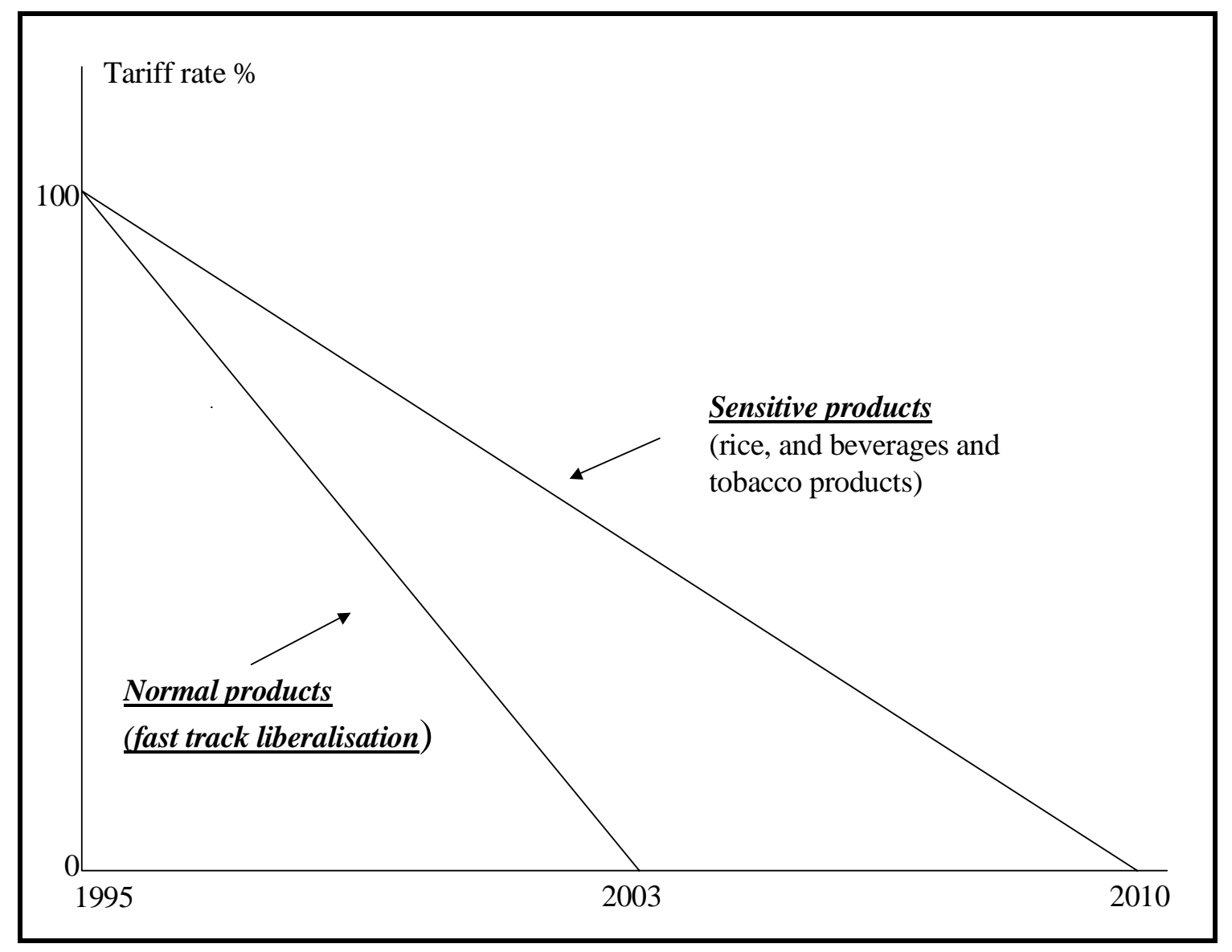

Source: Own Description.

At the regional level, the ASEAN members together with USA and Japan have been actively pursuing "an open regionalism” in Asian and Pacific region. And according to the Bogor Accord in 1994, the APEC (Asian and Pacific Economic Co-operation) members have scheduled the final period of reducing trade barriers. Developed countries are required to cut their border tariff rates to zero level in 2010 and 2020 for developing countries. It is acknowledged that trade liberalisation, undertaken by the members, is more progressive than trade liberalisation under the WTO. In response to the Bogor commitment, the APEC members have taken some actions. For instance, some products have been proposed to reduce their import tariff rates earlier than other products. This action is then called as early voluntary sector liberalisation (ESVL). Those include oil seed, energy products and manufacturing (see RAE, CHATTERJEE and SHAKAR, 1999). The members agreed that 2005 is the envisioned final year of the EVSL implementation. To implement the ESVL scheme, two periods of APEC trade liberalisation scenario are specified. Firstly, import tariffs for products under the EVSL are linearly reduced, starting 
from 1995 to 2005. This trade liberalisation is applied for all APEC members (developed and developing countries). Secondly import tariffs for non-ESVL products are also linearly reduced from 1995 to 2010 for developed countries and from 1995 to 2020 for developing countries, respectively. At the end, all import tariff rates will be zero. Because 2010 is the last year of the simulation, equilibrium levels of variables for developing countries are based on the 2010 import tariff levels. In this year, their import tariff rates are yet higher than zero $\left(\mathrm{tm}^{*}\right)$. The path of APEC trade liberalisation is shown in Figure 5.10. Similar to the AFTA scenario, this experiment is undertaken solely on the basis of a complete removal of import tariff rates. Other trade barriers such export and output subsidies remain unchanged. These have been included and addressed under the multilateral trade agreement. More importantly, it is very unlikely that the USA would further reduce such subsidies without the EU involvement.

Figure 5.10 A Path of Import Tariff Reduction under APEC Scenario

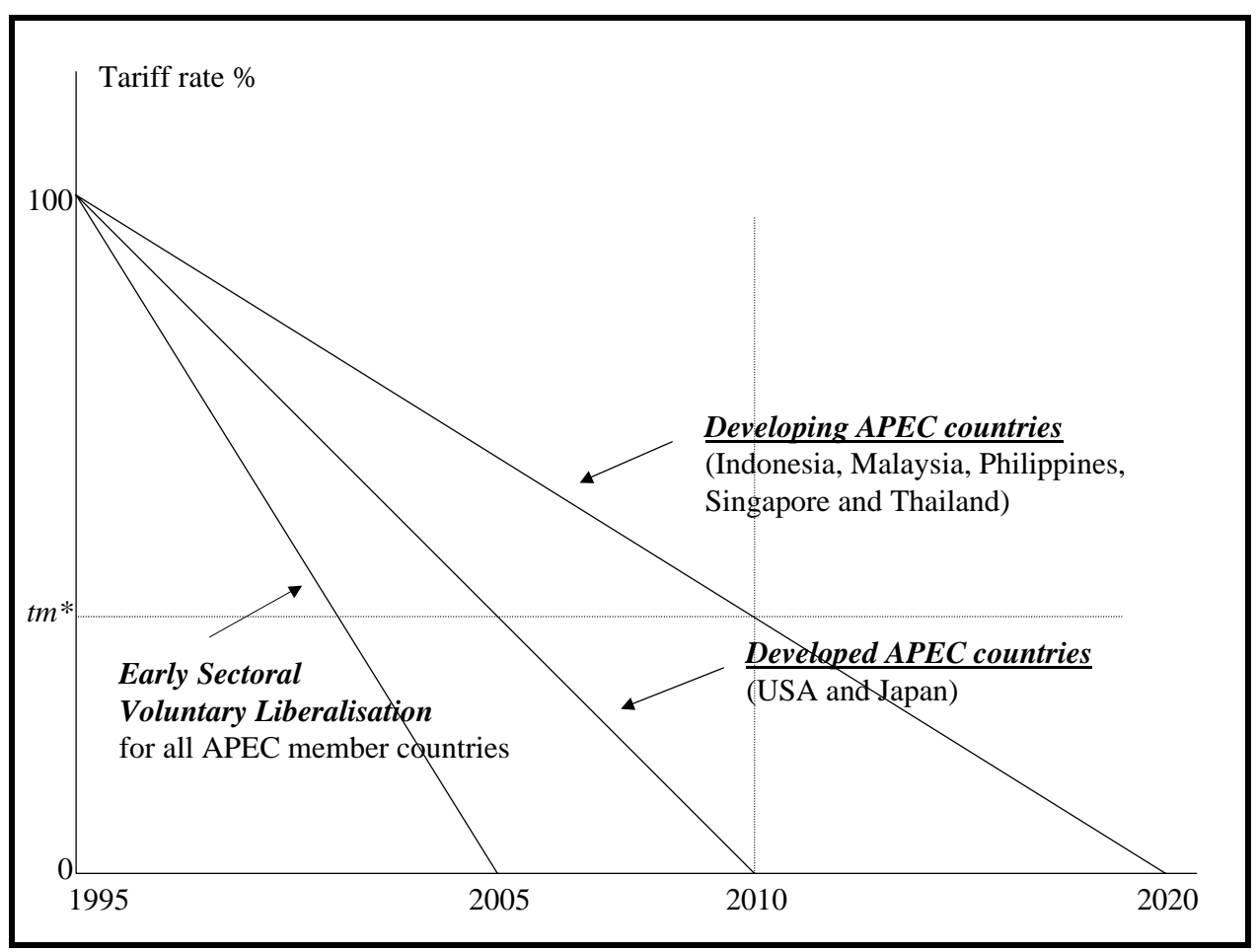

Source: Own Description.

\section{3. 1. Results from AFTA and APEC Scenarios}

Having discussed the development of macro economic variables and sectoral performances such as output, export and import under the baseline scenario, this section will discuss the impact of two main scenarios, namely AFTA and APEC scenarios on the economy of the 
ASEAN member countries. In the AFTA scenario, all ad-valorem import tariff rates are removed. The year 2003 is the final year of the AFTA tariff reduction under the CEPT scheme, especially for products that are categorised as normal products. For the sensitive products such as rice, and beverage and tobacco products their import tariffs are fully eliminated in 2010. By contrast, a full elimination of border tariff under the APEC scenario applies only for products that are included in the early voluntary sector liberalisation (EVSL). The APEC members have set 2005 as the final year of full import tariff reduction for such products above. In addition, parallel to the Bogor declaration, developed countries are committed to eliminating all import tariffs in 2010.

Since the focus of this study is to investigate and examine the impact of the AFTA trade liberalisation, all results accordingly refer to the period of 2004-2010. Results reported in this section are to be interpreted as average annual changes within the period of 2004-2010 relative to what would occur in the baseline scenario. Results of both the AFTA and the APEC scenarios will be simultaneously compared, whether the ASEAN member countries would gain from a wider scope of trade liberalisation. Before proceeding to the discussion on the impact of both scenarios on the sectoral output, export and import, the changes in the macroeconomic variables will be discussed. Figure 5.11 presents the impact of AFTA and APEC trade liberalisation on the real GDP in the ASEAN member countries. This figure suggests that the real GDP would rise by $0.2 \%$ in Indonesia to $3 \%$ in Malaysia, relative to the baseline. Including the APEC tariff reduction (APEC scenario) would lead to the increase in the real GDP with the exception of the case for Singapore. The removal of trade barriers would lower import prices, hence raising real purchasing power of domestic consumers. This certainly induces the production in many domestic industries.

Under the AFTA scenario, Singapore and Malaysia would become the primary beneficiaries of trade liberalisation among the ASEAN countries when import barriers are lowered in the three highly protected members. Interestingly, Singapore would be no longer the primary beneficiary of the trade liberalisation extended to the APEC members. In the second scenario Singapore seems to be faced with greater competition for its intraregional exports. This is related to its relatively liberal initial trade regime. Based on the WTO scenario Singapore already reduces its import tariffs to all its trading partners. This reduction significantly leads to low tariff rates. Therefore, the tariff reduction under the APEC scenario does not significantly affect the current tariff levels. As a result, the 
domestic demand in Singapore for its imports from other countries in this scenario would be decreased. As import tariff rates in other ASEAN member countries are further reduced under the APEC scenario, foreign suppliers, especially from Japan and USA, see a large opportunity to export their goods to the ASEAN member countries, except for Singapore. By contrast, consumers in Singapore see no price differences between goods under either the AFTA scenario or the APEC scenario due to its low import tariff levels. As a result, no increased imports are observed in this country under the APEC scenario.

It is interesting to see that the real GDP in the Philippines and Thailand under the APEC scenario are projected to grow by more than twofold compared with the result of the AFTA scenario. TAN (2000) simulated the impact of different economic co-operations that involve ASEAN member countries. Despite the different nature of the model, he also found that enlarging the AFTA membership to cover the whole of APEC would improve the real GDP considerably. He argued that this considerable increase in the real GDP in the ASEAN member countries reflects the heavy reliance of the ASEAN member countries on the United States and Japan for trade and investment respectively. In addition, these results would be important factors in relation to the unified ASEAN initiatives in trade and investment liberalisation vis-a-vis other trading blocs. As has been well known, USA and Japan together with the European Union (EU) are the major ASEAN trading partners and important ASEAN sources of foreign direct investment (FDI) ${ }^{60}$

\footnotetext{
${ }^{60}$ In this study, FDI is not included in the model. Readers interested to know the economic impact of Japan's FDI in Asia may refer to OTSUBO (1999).
} 
Figure 5.11 The Impact of Different Regional Economic Integration on Real GDP Relative to the Baseline Scenario (\%)

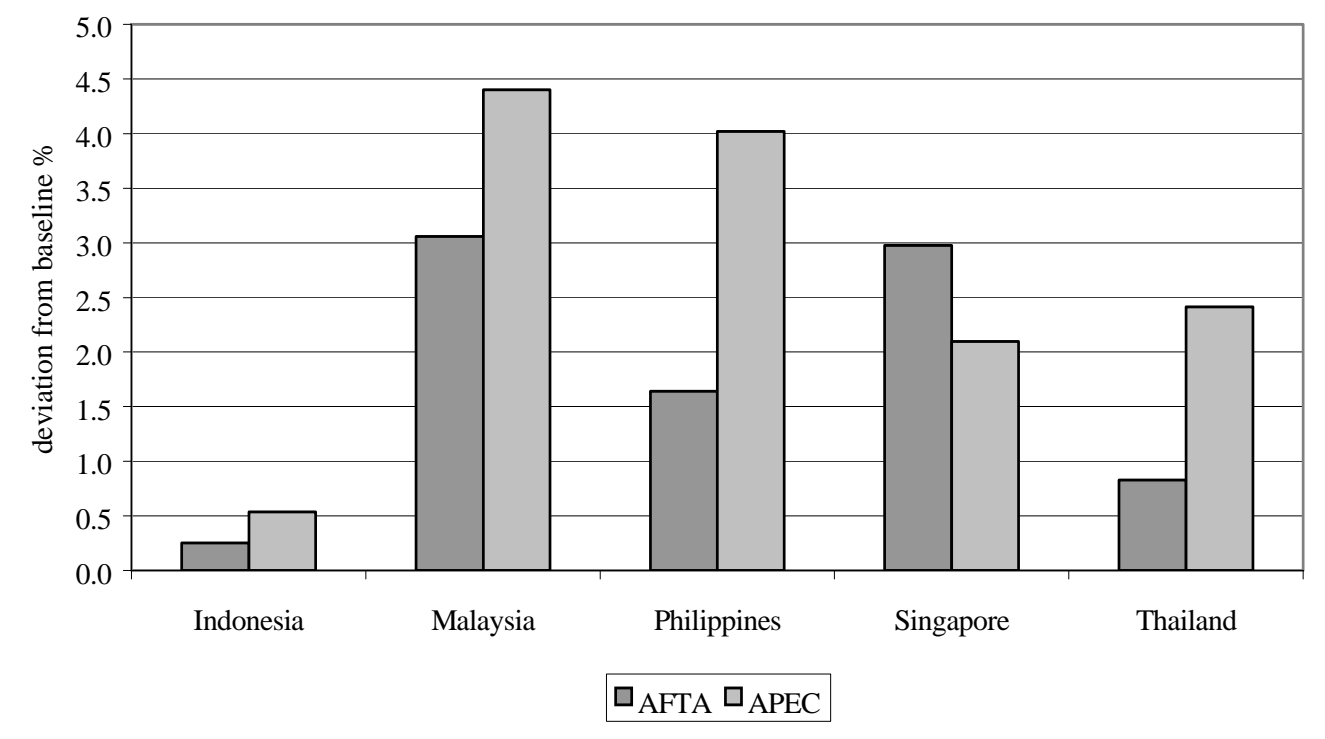

Source: Model Simulation.

Trade volumes would expand in line with the expansion of real GDP in the economies of ASEAN. Figure 5.12 shows the impact on the exports of the ASEAN member countries under the AFTA and APEC scenarios. Under the AFTA scenario, the Philippines would generate greater export volumes than under the baseline, followed by Singapore and Malaysia. Export volumes in these countries are projected to grow approximately by $4 \%$ and $3 \%$, respectively. Likewise, widening the trade liberalisation within APEC nations would cause export volumes in the ASEAN region to grow, particularly in Thailand and the Philippines. In both countries, the changes in the export volumes under the APEC scenario are nearly doubled compared with the export changes under the AFTA scenario. As USA and Japan open their markets following the reduction of their import tariff rates, ASEAN member countries, especially Thailand and Philippines have greater access to the US and Japanese market. On the other side, a large reduction in import tariffs sharply reduces the price of intermediate inputs, causing a significant decline in domestic costs. This thereby improves the competitiveness and causes export expansion. As a result, the competitiveness of exports from these countries would rise due to reasons mentioned above. The greater increase in the export volumes under the APEC scenario reflects that in the coming years, ASEAN trade would continue to expand faster when the economies in 
the ASEAN region are further integrated with economies in the APEC region. However, it is not the case for Singapore. Exports in Singapore are projected to shrink. The contraction in exports is associated with the reduction in export prices relative to the domestic prices. On the other side, as USA and Japan reduce their import tariffs for products from the ASEAN member countries, there would be an increase in demand for exports from the ASEAN member countries. The same patterns of the changes in the import volumes also apply. The ASEAN member countries would import more goods as a result of reducing the border import tariff within the APEC region. Looking back at the regional aggregation undertaken in this study, the impact of the APEC scenario on the real GDP, total export and import volumes seems to be limited. This is because this study incorporates only a limited number of APEC nations, namely USA and Japan. The inclusion of, for instance, Australia/New Zealand would have a positive impact of the ASEAN economies. DAVIS, MCKIBBIN and STOECKEL (2000) examined the impact of the AFTA-CER (Close Economic Relation) on the economies of both parties (ASEAN and Australia/New Zealand). On the regional basis, ASEAN would gain $0.3 \%$ of additional GDP above what it would be otherwise be in 2010. Using a forward looking dynamic general equilibrium model, they also came to the conclusion that the time profile of GDP would rise gradually over time. They argued that this constant increase in the ASEAN's GDP is a typical of all formation of trade groupings where the liberalisation is phased in over time. In addition, “ there is a lag before the extra production comes onstream from increased investment that occurs as a result of the liberalisation. Besides the fact that physical capital cannot move instantaneously, there are adjustment costs associated with reallocating capital from inefficient protected industries to more efficient industries"61

\footnotetext{
${ }^{61}$ DAVIS, L., W. MCKIBBIN and A. STOECKEL. (2000). Economic Benefits from an AFTA-CER Free Trade Area. Centre for International Economics. Sydney and Canberra. (http://www.dfat.gov.au/cer_afta/afta_cer_report.pdf
} 
Figure 5.12 The Impact of Different Regional Economic Integration on Total Export Relative to the Baseline Scenario (\%)

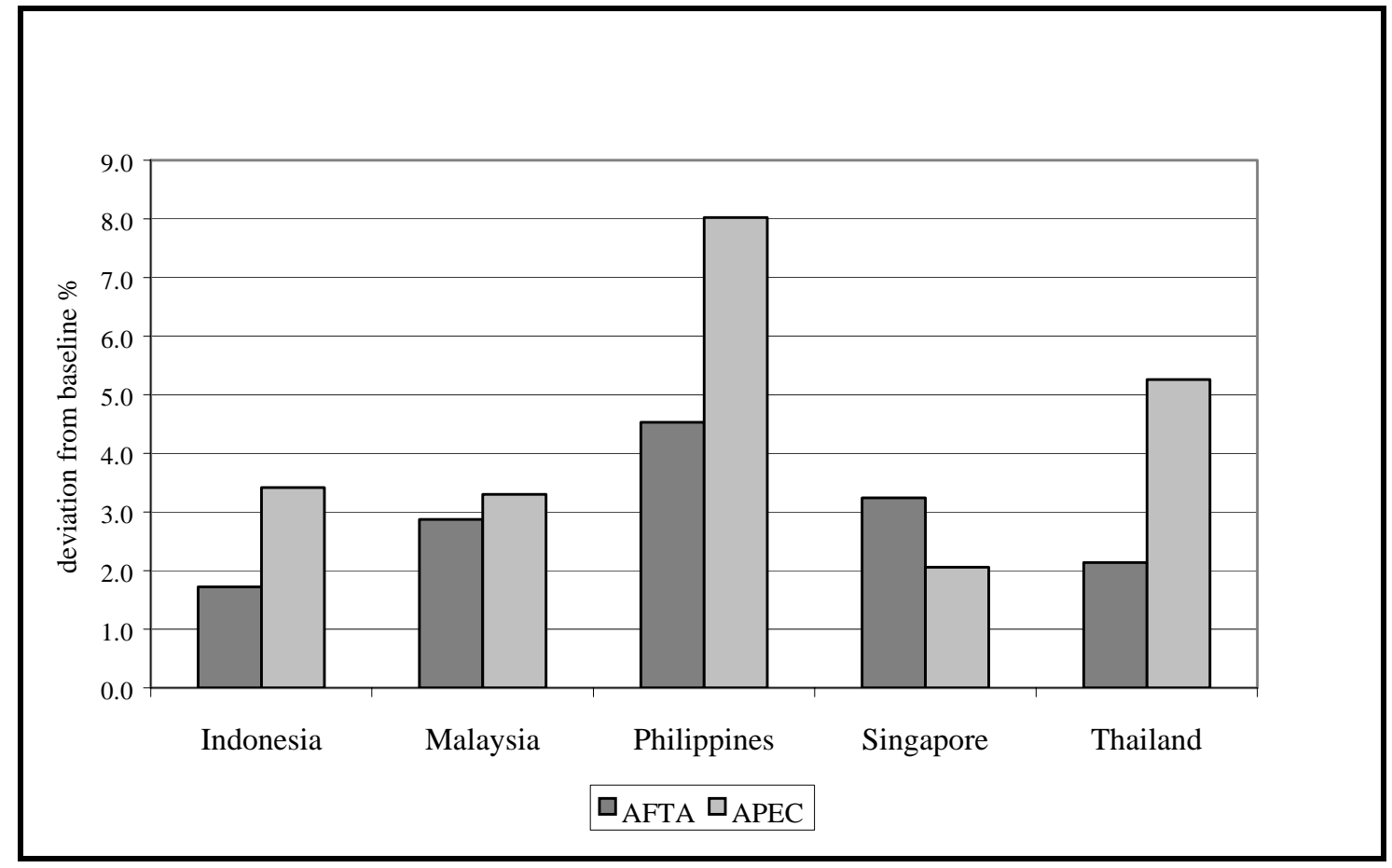

Source: Model Simulation. 
Figure 5.13 The Impact of Different Regional Economic Integration on Total Import Relative to the Baseline Scenario (\%)

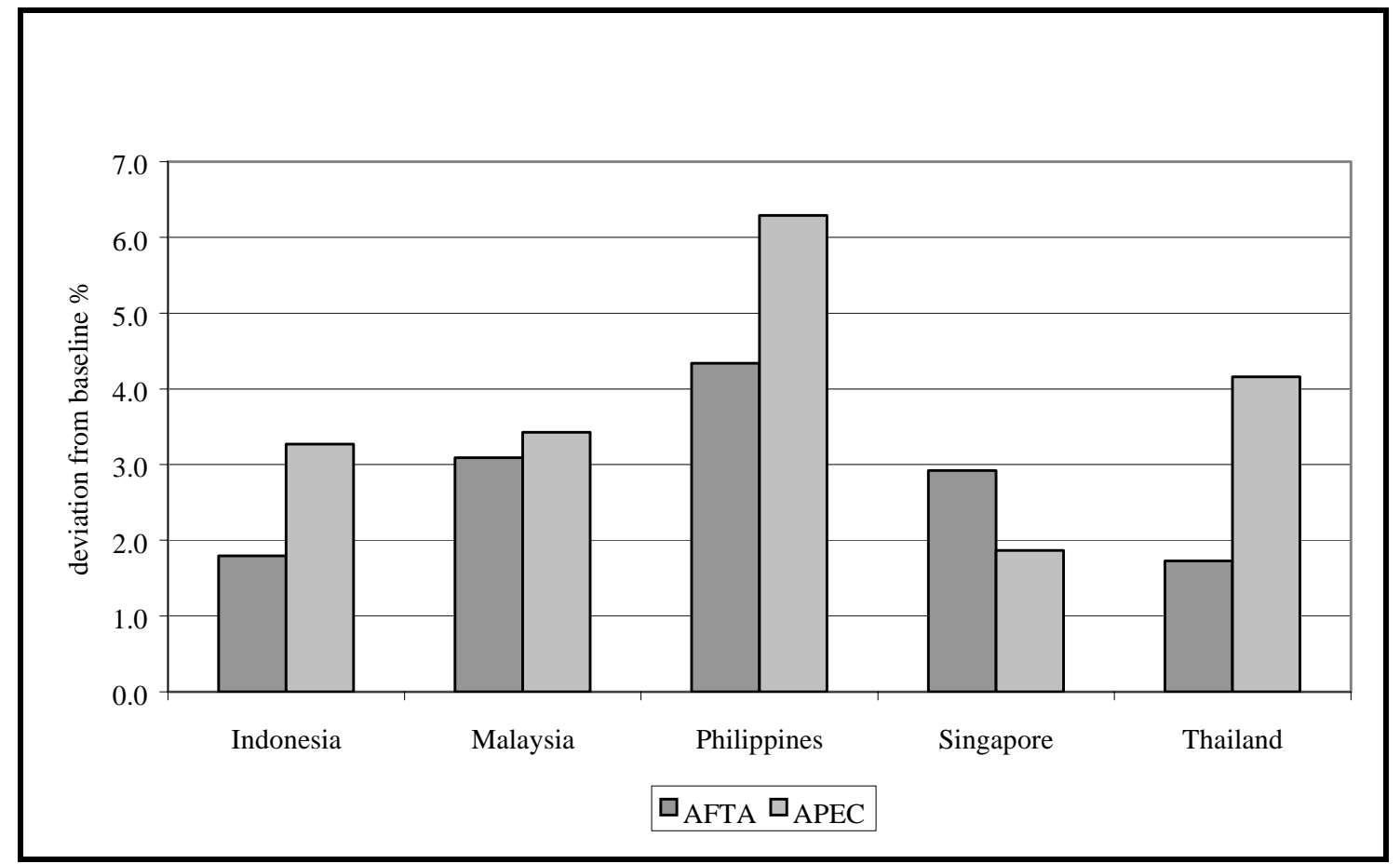

Source: Model Simulation.

Both trade liberalisation options would have a different impact on the investment development in the ASEAN member countries. Investment changes in Indonesia, Malaysia and Singapore are expected to rise, but tend to decrease as a result of being further involved in the APEC trade liberalisation. It is interesting to note that on the contrary, investment in other ASEAN member countries, namely the Philippines and Thailand are projected to decrease, resulting from the reduction of import tariff under both scenarios. Focusing on the case in the Philippines and Thailand, the reason why investment decreases is that both countries, particularly the Philippines, would experience a loss of tariff revenues due to removing their import tariffs. The decreasing import tariff revenues lower the marginal propensity to save, thereby dampening the investment. 
Figure 5.14 The Impact of Different Economic Integration on Investment Relative to Baseline Scenario (\%)

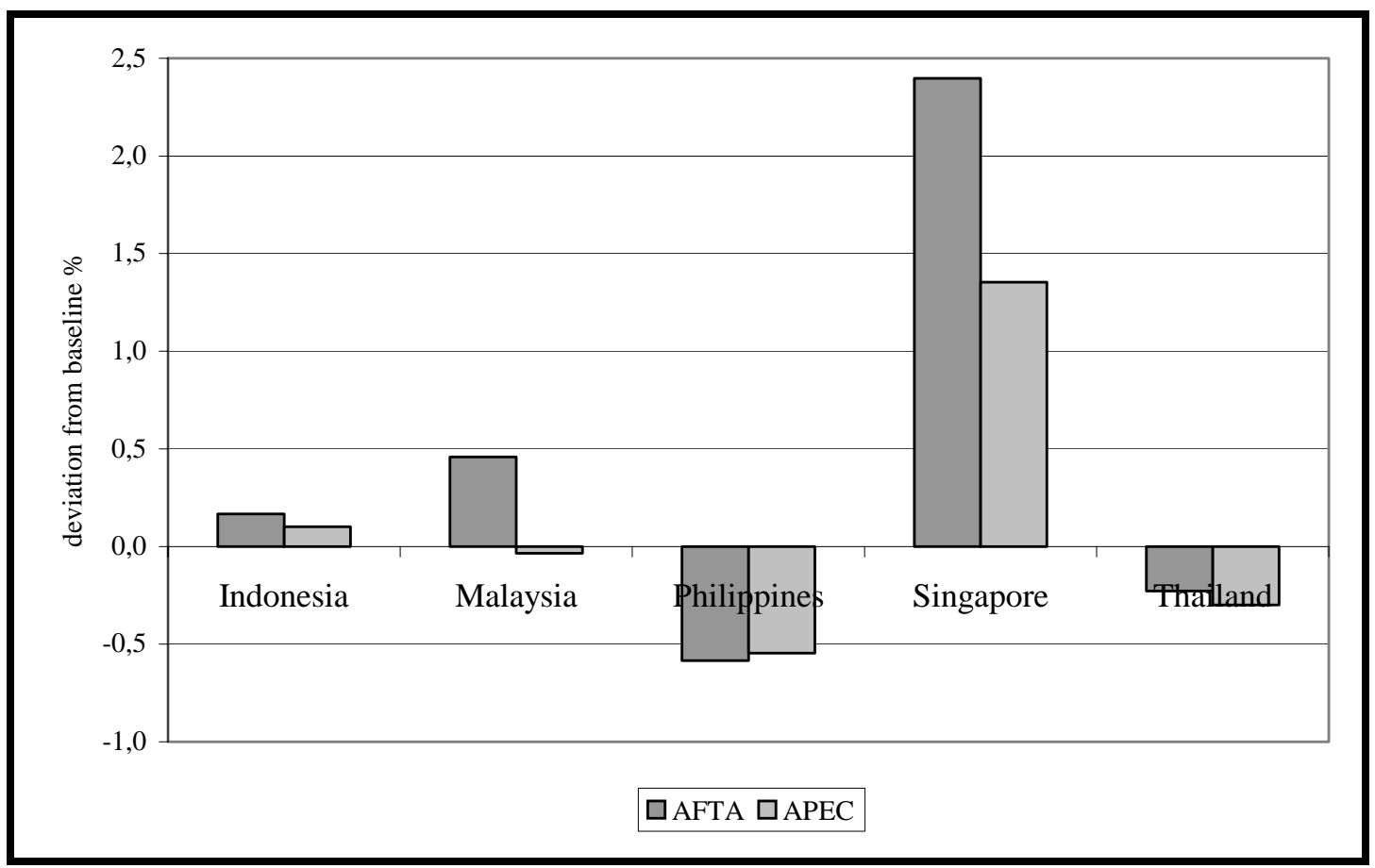

Source: Model Simulation.

Different changes in real exchange rate in the ASEAN countries under the AFTA scenario or under the APEC scenario are given in Figure 5.15. First, the changes in the real exchange rate due to the former scenario are discussed. Indonesia and Singapore experience an appreciation of their real exchange rate. This result is quite similar with DEROSA (1995). Both countries are characterised with relatively low import tariffs prior to the AFTA arrangement. As a consequence of reducing trade protection, the demand for exports of these countries is greater than that for imports. In order to maintain trade balance, an appreciation of real exchange rate must take place. On the other side, other ASEAN member countries are expected to experience a depreciation of real exchange rates. Widening the scope of trade liberalisation (the APEC scenario) would lead most of the ASEAN member countries to increase their exports. Increases in exports are required to restore trade deficit. Hence, the economy experiences a depreciation of the real 
exchange rate. A large depreciation would happen in Thailand by more than $5 \%$ compared to the baseline scenario.

Figure 5.15 The Impact of Different Regional Integration on Real Exchange Rates Relative to Baseline Scenario (\%)

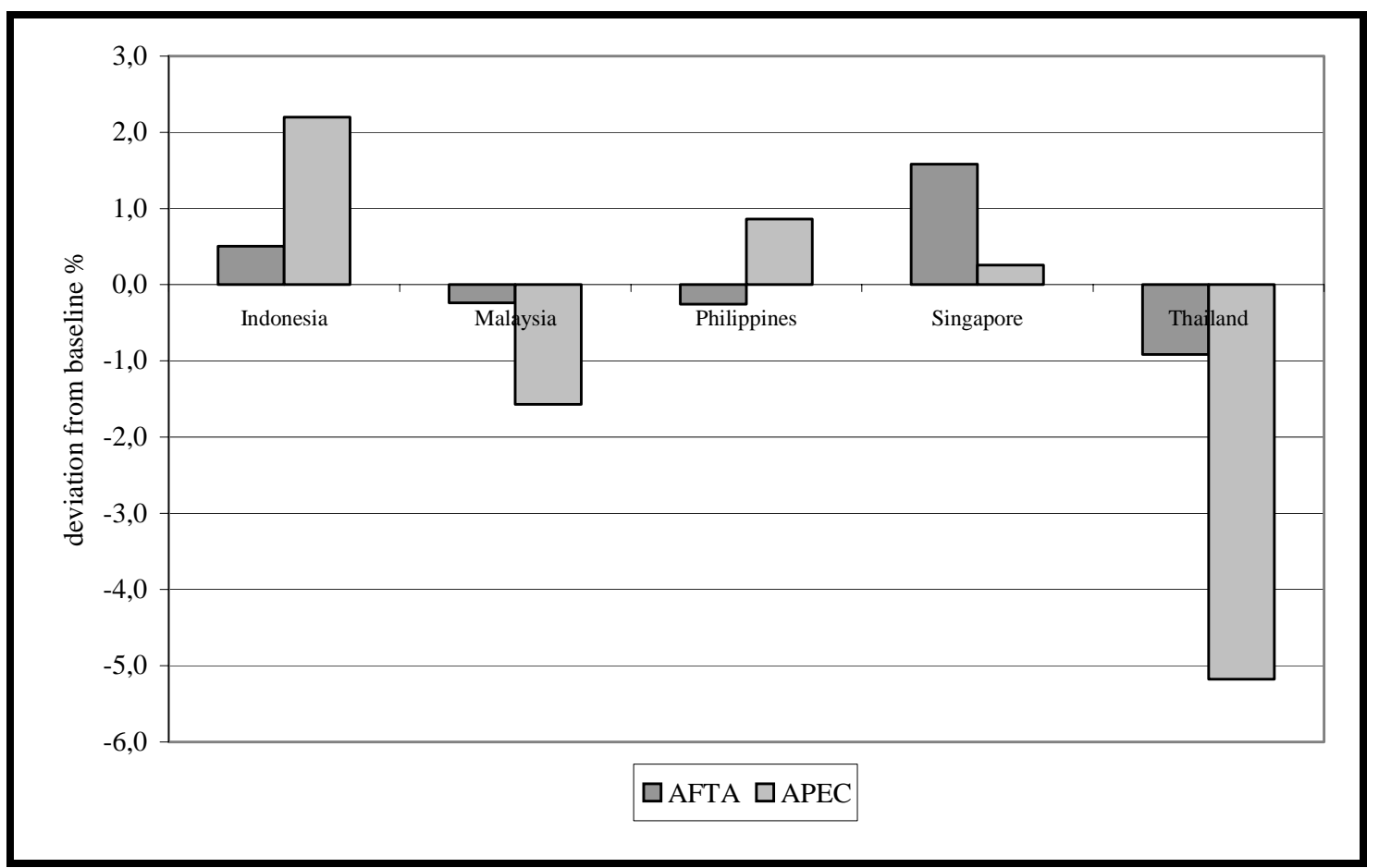

Source: Model Simulation.

Different from the discussion on the baseline results, of which all results are illustrated in the graphical forms, the results of scenario analysis however are illustrated in the tabular forms the preceding sections discussed results of scenarios based on graphs. A first focus is given to the average annual changes in the sectoral output. The impact of the AFTA and APEC trade liberalisation on the sectoral output is summarised in Table 5.12. Similar with the discussion on the changes in the macroeconomic variables, the changes in the sectoral output, trade patterns, demand for primary factors, and prices refer to the period of 20042010. The period of 2004-2010 is the chosen to indicate the full implementation of the AFTA trade liberalisation. The model is actually simulated from 1995 (the base year of the GTAP database). This is because the objective of the study is to assess the impact of the complete AFTA tariff reduction, not the period of the AFTA implementation.

Focusing first on the impact of AFTA trade liberalisation, rice output in the ASEAN member countries with the exception of the case in Thailand is projected to shrink. For instance, in Singapore and Malaysia, this sector would contract by $12 \%$ and $2 \%$, 
respectively, relative to the baseline. A very low output change would happen in Indonesia which its average annual change would be close to zero. This very small change is due to the very low initial Indonesian import tariff structure for rice (see Tables 5.3-8). By contrast, the rice sector in Thailand would expand by 6\%. This rise in rice output in Thailand is not surprising. Thailand is the largest rice-exporting country. This result suggests that this sector would benefit from the reduction of trade barriers for rice in the other ASEAN member countries. In other words, the increase in import demand for rice in other ASEAN member countries, resulting from the reduced import prices would stimulate the Thai rice sector to expand. The question to be answered is how farmer's income is affected by this rice output change. Rural population with the exception of Singapore is predominantly engaged in rice farming. Relating to this number some observers were concerned with the likely impact of the AFTA agreement on farmer's income and wealth. The results however suggest that with a very marginal decline in rice output in Indonesia, Malaysia and the Philippines, farmer's income would be slightly affected. It is important to note that rice farming is cultivated largely by small scale farmers where their land ownership is very limited. Due to their small size land ownership, it is often that farmers derive their income mostly not from the rice sale or agricultural wage. They diversify their income by seeking works in urban areas or off farm activities or cultivating at the same other crops (multi-crops farming). With this nature it can be predicted trade liberalisation would not reduce farmer's income very significantly.

Despite the large change in the Singapore rice output, the absolute change in this sector would not necessarily be large relative to the overall level of economic activity in this country. This is because total production of the rice sector in the Singapore GDP is also very low. With regard to output changes in the other unprocessed agricultural sectors, such as cereal, oil seeds, livestock and crops, the results suggest that the AFTA trade liberalisation would have a low impact on the output of the Indonesian agricultural sectors. Across ASEAN member countries, cereal output in Malaysia, the Philippines, Singapore and Thailand is estimated to grow considerably, particularly in Singapore and Thailand which have average increases of $23 \%$ and $38 \%$, respectively. Different patterns of the sectoral output changes under the APEC trade liberalisation would occur. However, in general all outputs in the unprocessed agricultural sectors would obviously decrease, specifically cereal output relative to the baseline scenario. For example, under the AFTA scenario, the cereal output would rise by $10 \%$ in Malaysia. But under the APEC scenario, 
the output would be reduced by around $23 \%$. This large output decline is due to the high import tariff rates imposed in this country for cereal imported from Japan and USA. The government imposes import tariff rates around $195 \%$ and $180 \%$ to Japanese and US suppliers. A reduced domestic price following the reduction of import tariffs suppresses the production of this sector. Under this scenario, the cereal output in Singapore and Thailand in fact are expected to rise but by less than what might occur under the AFTA scenario. Across ASEAN countries, the APEC trade liberalisation would cause a small impact on the output in the Indonesia unprocessed agricultural sectors.

Across the processed agricultural products, most products in the Philippines and Thailand are projected to decrease marginally under the AFTA scenario. By contrast, output in all sectors except vegetable oil in Singapore would rise surprisingly. Output changes in Singapore are closely associated with the changes in exports (Table 5.12). Its export to production ratio is extremely high. Because this study uses the CET functional form to transform output into domestic and export markets, a level of output is largely dependent on the share parameter. The fall in demand for exports reduces the level of output. And in the same time, demand for domestic goods also declines due to the import tariff reduction. On the other side, domestic goods to production ratios in the Philippines and Thailand are reported to be high. Therefore, the decrease in output of processed agricultural sectors in both countries is related to the fall in the demand for domestic goods, resulting from the substitution to imported goods. These findings are similar to FERIDHANUSETYAWAN (1998). Extending to the APEC scenario, the output of most processed agricultural sectors in Singapore would further increase. Looking at other ASEAN member countries, APEC trade liberalisation would have a limited impact on the output of processed agricultural sector.

With respect to the non-agricultural sectors, the AFTA scenario would lead to small sectoral output changes in Indonesia and Thailand. All outputs in these countries are projected to alter by less than $1 \%$, relative to the baseline scenario. By contrast, textile, mining and mineral products and manufacturing outputs in the Philippines would rise considerably. It is interesting to see that the output of the textile sector is projected to grow as a result of the further reduction of the import tariff rates. There are some factors affecting such increases in output of this sector. With the continual income growth over time, the demand for this product is projected to rise. This stimulates the increase in output 
of this sector. Given relative high income elasticities for this product, the increased income induces the demand for textile products to rise. The expansion of this sector is also due to the availability of cheaper imports that are used by the sector as intermediate inputs following the trade liberalisation. This result supports and is parallel to the study undertaken by FERIDHANUSETYAWAN (1998). Using the version 3 of the GTAP database and the standard GTAP model, the author estimated that the output of the textile and garment sectors rises in all countries with the exception for Singapore. In this country, textile and garment outputs fall by $22 \%$. This figure suggests that most ASEAN member economies have a comparative advantage in this sector due to their relative cheap labour. It is interesting to discuss here the strategy carried out by the Thai government to accelerate the production and export of textile. The Seventh National Economic and Social Development Plan (SNESDP) has identified six industries to be put in the first priority. These industries play an important role in determining Thailand's economic development. One of these industries is textile and garments. The SNESDP recommends the Thai government to reduce import duties for upstream and intermediate textiles. This recommendation aims at promoting investment in weaving and spinning (PUPPHAVESA and GREWE, 1994). The implication of the increase in the output of this sector is that labour would tend to move from the agricultural sector (rural area) to the manufacturing sector (urban area). Following the simulation results, the ASEAN textile industries could then compete in the global market. In other words, these industries would be capable of being exposed to the global competition. However, one should take a closer look at the current textile trade regime. This study excluded China in the simulation. There are growing concerns among textile industries as this country became officially a member of WTO and textile quota exports under the WTO have been eliminated. With the overwhelmingly abundant labour supply together with more efficient textile production, Chinese textile producers can exploit her competitiveness by supplying cheaper textile products. Without re-structuring the ASEAN textile industries, Chinese textile products can replace the ASEAN competitiveness. This is because intensive talks between ASEAN and the Chine (East Asian countries) are being held to establish a free trade area between these countries. 
Table 5.12 Average Annual Output Changes, Relative to the Baseline Scenario (\%)

\begin{tabular}{|c|c|c|c|c|c|c|c|c|c|c|}
\hline \multirow[t]{2}{*}{ Sector } & \multicolumn{2}{|c|}{ Indonesia } & \multicolumn{2}{|c|}{ Malaysia } & \multicolumn{2}{|c|}{ Philippines } & \multicolumn{2}{|c|}{ Singapore } & \multicolumn{2}{|c|}{ Thailand } \\
\hline & AFTA & IPEC & AFTA & APEC & & & AFTA & APEC & FTA & PEC \\
\hline \multicolumn{11}{|l|}{ Unprocessed } \\
\hline \multicolumn{11}{|l|}{ agric. products } \\
\hline Rice & -0.1 & -0.1 & -1.7 & -1.5 & -1.4 & -1.4 & -12.7 & -11.2 & 6.2 & 6.5 \\
\hline Cereal & 0.7 & 0.1 & 9.6 & -22.6 & -0.4 & -11.7 & 22.3 & 16.7 & 38.7 & 9.1 \\
\hline Oil seeds & -0.3 & -0.5 & 1.2 & 3.2 & 2.6 & 4.1 & -2.4 & -2.0 & -1.2 & -3.1 \\
\hline Livestoc & 0.1 & 0.2 & 1.5 & 1.1 & -1.0 & -1.6 & -3.8 & -3.5 & -1.2 & 1.9 \\
\hline Other crops & 0.0 & 0.0 & 1.0 & 0.6 & 0.0 & 0.9 & 2.6 & 3.1 & -1.5 & -1.2 \\
\hline \multicolumn{11}{|l|}{$\frac{\text { Processed }}{\text { agric. products }}$} \\
\hline$\overline{\text { Vegetable oil }}$ & -0.3 & -0.5 & 1.6 & 4.7 & -0.9 & 0.7 & -2.8 & -2.3 & -1.6 & -2.1 \\
\hline $\begin{array}{l}\text { Processed. } \\
\text { other crop }\end{array}$ & 0.7 & 0.5 & 2.7 & 2.9 & -1.1 & -0.9 & 4.8 & 8.0 & 0.0 & 2.5 \\
\hline Processed meat & 1.2 & 1.9 & -0.7 & 1.0 & -1.7 & -2.3 & 9.7 & 17.1 & -1.0 & 5.6 \\
\hline Processed. milk & 18.8 & 18.8 & -1.6 & -2.4 & -1.3 & -1.8 & 40.7 & 47.0 & 3.1 & 3.1 \\
\hline Sugar & 0.0 & -0.2 & 18.2 & 17.9 & -0.1 & -1.2 & 3.9 & 6.2 & -1.1 & -1.3 \\
\hline $\begin{array}{l}\text { Beverage and } \\
\text { tobacco }\end{array}$ & -0.1 & 0.0 & -0.8 & -1.0 & -4.4 & -5.0 & 2.6 & 4.2 & -0.2 & -0.7 \\
\hline \multicolumn{11}{|l|}{$\underline{\text { Non-agric. }}$} \\
\hline Text & 0.9 & 6.9 & 0.6 & 6.3 & 3.5 & 16.4 & 2.0 & 11.0 & 1.2 & 7.5 \\
\hline $\begin{array}{l}\text { Mining and } \\
\text { mineral } \\
\text { products }\end{array}$ & -0.7 & -0.2 & -3.3 & -3.7 & 3.2 & 3.5 & -3.3 & -1.4 & -0.2 & 0.5 \\
\hline Manufacturing & -0.2 & -1.1 & 1.5 & 1.7 & 5.2 & 7.0 & 2.4 & 0.9 & -0.2 & -1.6 \\
\hline Services & 0.1 & 0.0 & -0.3 & -0.5 & -0.8 & -1.4 & -1.3 & -0.8 & -0.1 & 0.3 \\
\hline
\end{tabular}

Source: Model Simulation.

The changing patterns of export and import across ASEAN member countries and by commodity are summarised in Table 5.13 and 5.14. The AFTA tariff reduction would cause the increase in exports in most ASEAN economic sectors. Focusing on the export changes in the agricultural sectors, it is reported that cereals and processed milk sectors are predicted to have noticeable increases in their exports. In the period of 2004-2010 average export changes range from around $7 \%$ in the Philippines to $187 \%$ in Thailand. In addition, marked export growths for processed milk products are apparent, particularly in Indonesia, whose average changes would be approximately $143 \%$, compared to the export change under the baseline scenario. By contrast, Malaysia would also experience an increase in its export of processed milk products by around $8 \%$. This large export change however has no large impact on farmer's income. Milk industry in the ASEAN region relies largely on imports of their intermediate inputs. Australia and New Zealand are their 
major milk suppliers. Milk industries in the region are facing difficulties in term of increasing milk production. Milk productivity is still low compared with milk productivity in Australia and New Zealand. This is due to small scale ownership and traditional farming management. Small scale ownership hampers the application of modernised farming management. To copy with the increased demand for export of milk product, the governments should re-organise the farming system by establishing collaboration between large (modernised) scale farming and small scale farming. This would enable the small scale farmers to have access to product and input markets and new technology.

In addition, the AFTA tariff reduction would induce the exports of processed crops and sugar in this country to rise considerably by around $10 \%$ and $26 \%$, relative to the baseline scenario. The relatively large export changes for cereal and processed milk products are due to very large shares of both products to the total export. The smaller the export share, the larger the export change. Again it should be emphasised here that these large export changes do not indicate large changes in absolute terms.

Turning to the impact of the second scenario (the APEC trade liberalisation), the results show that more progressive tariff reduction would cause a relatively large increase in the exports of unprocessed agricultural products, particularly in Indonesia and Singapore. With regard to exports of processed agricultural products, exports of processed meat and processed milk would tend to rise further. For example, the exports of both commodities in Thailand would markedly rise by around $30 \%$, compared to the level in the baseline scenario. Likewise, the impact of APEC trade liberalisation on the export of nonagricultural products, especially textiles is significant. In other words, this commodity would benefit from the APEC liberalisation. This result indicates that ASEAN economies generally have larger comparative advantages in producing textile products. FERIDHANUSETYAWAN, PANGESTU and ERWIDODO (1999) found a similar result. The textile exports rise, ranging from approximately $20 \%$ in Malaysia to $52 \%$ in the Philippines, relative to the initial values (1995). A report prepared for an Initiative of APEC Committee on Trade and Investment indicates Indonesia and Thailand have been building their textile industry with low cost labour ${ }^{62}$. Therefore, it is not surprising more progressive trade liberalisation would cause this industry to continuously expand.

\footnotetext{
${ }^{62}$ Textile Industry in Thailand, in The Impact of Liberalisation: Communicating with APEC Communities (http://ww.arts.monash.edu.au/ausapec/cacthai.htm).
} 
When looking at the export changes under the ASEAN trade liberalisation, the magnitude of these changes is relatively less than what might happen under the APEC scenario. This is because, as has been discussed in Chapter 2, ASEAN trade intensities, either exports or imports are not with the members. But they trade largely with their major trading partners. As a result of reducing border tariffs between the ASEAN members, trade growth is expected to be minimal in spite of their initial ASEAN import rates are relatively high. Nevertheless, general rises in exports are associated with the increases in the export prices.

Table 5.13 Average Annual Changes in the Sectoral Export, Relative to the Baseline Scenario (\%)

\begin{tabular}{|c|c|c|c|c|c|c|c|c|c|c|}
\hline \multirow{4}{*}{$\begin{array}{l}\text { Sector } \\
\text { Unprocessed } \\
\text { agric. products }\end{array}$} & \multicolumn{2}{|c|}{ Indonesia } & \multicolumn{2}{|c|}{ Malaysia } & \multicolumn{2}{|c|}{ Philippines } & \multicolumn{2}{|c|}{ Singapore } & \multicolumn{2}{|c|}{ Thailand } \\
\hline & \multicolumn{2}{|c|}{ AFTA APEC } & \multicolumn{2}{|c|}{ AFTA APEC } & \multicolumn{2}{|c|}{ AFTA APEC } & \multicolumn{4}{|c|}{ AFTA APEC AFTA APEC } \\
\hline & & & & & & & & & & \\
\hline & -0.4 & 0.0 & 5.8 & 5.6 & 3.6 & 3.5 & -7.5 & -5.8 & 14.3 & 14.5 \\
\hline ereal & 157.2 & 117.2 & 40.1 & 2.3 & 6.6 & -3.2 & 73.9 & 55.9 & 186.8 & 102.6 \\
\hline il se & 4.8 & 5.7 & 6.2 & 7.4 & 2.8 & 4.3 & -1.0 & -0.4 & 2.4 & 1.1 \\
\hline Lives & 1.2 & 1.9 & 18.2 & 17.5 & -1.2 & -2.2 & -0.8 & -0.3 & -1.6 & 1.2 \\
\hline Crops & 2.1 & 2.5 & 2.8 & 2.1 & 2.3 & 7.9 & 3.2 & 3.7 & -2.4 & -0.5 \\
\hline$\frac{\text { Processed }}{\text { agric.products }}$ & & & & & & & & & & \\
\hline Veget & -0.9 & -0.9 & 2.1 & 6.1 & -0.7 & 1.3 & -2.8 & -2.0 & -0.6 & -0.7 \\
\hline $\begin{array}{l}\text { Processed other } \\
\text { crops }\end{array}$ & 4.8 & 4.3 & 10.2 & 11.0 & 1.3 & 2.2 & 7.8 & 11.9 & 1.3 & 5.1 \\
\hline eat & 6.0 & 9.6 & 3.1 & 6.0 & 1.0 & -0.6 & 11.5 & 19.4 & -0.2 & 29.0 \\
\hline oces & 142.5 & 141.5 & 7.7 & 6.7 & 44.0 & 63.6 & 105.1 & 119.7 & 26.6 & 28.2 \\
\hline Sugar & -0.4 & -3.1 & 25.6 & 25.4 & 0.9 & -5.6 & 6.0 & 7.8 & -1.3 & -1.4 \\
\hline $\begin{array}{l}\text { Beverage and } \\
\text { tobacco }\end{array}$ & 1.0 & 0.2 & 7.6 & -0.6 & -1.6 & -3.8 & 3.4 & 5.1 & 5.4 & 4.3 \\
\hline$\frac{\text { Non-agric. }}{\text { Products }}$ & & & & & & & & & & \\
\hline & & 9.0 & 4.0 & 11.4 & 5.8 & 22.3 & 5.8 & 22.3 & 3.4 & 13.7 \\
\hline $\begin{array}{l}\text { Mining and } \\
\text { mineral }\end{array}$ & -0.9 & 0.1 & -5.2 & -5.4 & 7.1 & 8.1 & -2.7 & 0.0 & 1.0 & 2.9 \\
\hline Idiluic & 1.1 & & 2.7 & 3.3 & 8.3 & 13.3 & 2.8 & 1.1 & 1.8 & 4.0 \\
\hline Services & -0.2 & -0.1 & -1.2 & -1.3 & -1.1 & -2.1 & -2.8 & -1.8 & 0.2 & 1.5 \\
\hline
\end{tabular}

Source: Model Simulation

The impact of the ASEAN tariff reduction on import changes is summarised in the Table 5.14. The simulation results suggest that imports of these products are estimated to rise with the exception, for instance, of rice in Indonesia and Thailand, cereal Philippines, Singapore and Thailand, and oil seeds in Philippines and Singapore. Within the group of these commodities, imports of rice in Malaysia as well as in the Philippines would grow 
significantly by $20 \%$ and $27 \%$, compared with the baseline scenario. This large change in the rice import in these countries is because both of these countries, as well as Singapore, are reported to impose high import tariff rates on rice. For example, bilateral rice import tariff rate against Thailand was around $130 \%$. In addition, Thailand is a major ASEAN source of rice import. As a result, the a removal of rice import tariffs within ASEAN member countries would cause the decrease in the rice import prices, thereby increasing rice imports in these countries. The higher the initial tariff rates, the larger the import changes. Therefore, the magnitude of the import changes depends as well on to what extent trade intensities among ASEAN member countries occur. In other words, the ASEAN members are expected to gain from the trade liberalisation as long as the ASEAN economy represents major import sources for the ASEAN itself. In other words, as a consequence of fully eliminating ASEAN border tariffs for rice, ASEAN members, specifically Malaysia and the Philippines, would have a great opportunity to replace their rice import in favour of rice import from Thailand. By contrast, a decrease in the rice import would happen in Thailand. Again, this result is in line with the increase in the Thai rice export.

Looking at the percentage changes in rice exports and imports in Malaysia and the Philippines, both countries would have the increase in both cases. These changes, particularly export changes in this general equilibrium effect can be understood in the light of two effects (BLONIGEN et. al.1997). In this study, domestic and export goods are differentiated using a Constant Elasticity of Transformation (CET) functional form. The first refers to domestic output effects due to expansions or contraction of the CET frontier. The second is relative price effects, referring to movements along the CET frontier. Following the reduction in import tariffs, protected domestic prices fall relative to export prices to such extent that domestic supply tends to be diverted to export markets. An aggregation procedure may also contribute to such phenomenon. This aggregation results in the heterogeneity of goods. In other words, rice in this case is no longer homogenous. Rice is an aggregated product from paddy rice and processed rice. More important, using both CET and CES functional forms the model provides a mechanism for economic sectors to experience increases in exports and imports. 
Compared with the simulation results under the AFTA scenario, the additional import changes under the APEC scenario would not be very significant, except what might happen in the case of cereal import and oil seed import in the Philippines and Thailand as well as livestock import in the Philippines. This is due to the fact that ASEAN member countries are not required to fully remove their import tariff rates. This is different from what they do under the AFTA tariff reduction. As given in Figure 5.20, the level of ASEAN import tariff levels in 2010 is $\mathrm{tm}^{*}$. On the other side, the ASEAN member countries have further reduced their border tariff under the baseline scenario (Uruguay Round and the next WTO Round). These reduction processes contribute to the small changes in the ASEAN import levels under the second scenario.

Table 5.14 Average Annual Changes in the Sectoral Imports, Relative to the Baseline Scenario (\%)

\begin{tabular}{|c|c|c|c|c|c|c|c|c|c|c|}
\hline \multirow[t]{2}{*}{ Sector } & \multicolumn{2}{|c|}{ Indonesia } & \multirow{2}{*}{\multicolumn{2}{|c|}{ Malaysia }} & \multirow{2}{*}{\multicolumn{2}{|c|}{$\begin{array}{l}\text { Philippines } \\
\text { AFTA APFC }\end{array}$}} & \multirow{2}{*}{\multicolumn{2}{|c|}{ Singapore }} & \multicolumn{2}{|c|}{ Thailand } \\
\hline & AFTA & & & & & & & & & PEC \\
\hline \multicolumn{11}{|l|}{ Unprocessed } \\
\hline Rice & 0.1 & -1.1 & 19.9 & 28.4 & 26.9 & 35.7 & 6.3 & 8.1 & -3.5 & -4.1 \\
\hline Cereal & 0.9 & 1.3 & 1.2 & 2.0 & -1.5 & 17.4 & -0.9 & -0.6 & -7.8 & 11.8 \\
\hline Oil seeds & 1.1 & 1.5 & 1.3 & 2.5 & -0.2 & 0.7 & -0.8 & 1.5 & 1.0 & 1.5 \\
\hline Livestock & 2.1 & 1.3 & -1.6 & -1.3 & 0.9 & 5.7 & 12.5 & 9.0 & 2.2 & 6.6 \\
\hline Crops & 1.3 & 1.0 & 1.9 & 2.6 & 1.1 & 2.7 & 0.1 & 0.1 & 5.5 & 11.4 \\
\hline \multicolumn{11}{|l|}{$\frac{\text { Processed }}{\text { aqric.prod }}$} \\
\hline Vegetable oil & 2.3 & 3.2 & -0.5 & -4.1 & 2.9 & 2.8 & 10.3 & 11.4 & 6.3 & 6.0 \\
\hline $\begin{array}{l}\text { Processed } \\
\text { other crops }\end{array}$ & 2.4 & 3.3 & 2.4 & 2.0 & 5.0 & 6.3 & 5.0 & 4.4 & 5.0 & 4.4 \\
\hline Process & 1.7 & 0.6 & 8.8 & 10.3 & 9.1 & 13.2 & 1.1 & 1.6 & 35.8 & 29.1 \\
\hline Processed milk & 0.0 & -0.7 & 3.6 & 23.1 & 1.4 & 9.1 & -4.3 & -5.9 & -0.2 & 2.6 \\
\hline Sugar & 2.4 & 2.3 & 0.4 & 0.4 & -3.0 & -1.5 & 3.4 & 3.2 & 1.6 & 6.9 \\
\hline $\begin{array}{l}\text { Beverage and } \\
\text { tobacco }\end{array}$ & 11.4 & 2.5 & 9.1 & 0.0 & 18.8 & 29.2 & 3.1 & 0.9 & -0.7 & 0.1 \\
\hline \multicolumn{11}{|l|}{ Non-agric. } \\
\hline Textile & 3.0 & 5.2 & 7.6 & 11.5 & 5.1 & 15.3 & 5.1 & 3.5 & 3.5 & -0.3 \\
\hline $\begin{array}{l}\text { Mining and } \\
\text { mineral } \\
\text { products }\end{array}$ & 1.6 & 1.8 & 3.0 & 4.2 & 2.0 & 3.9 & 1.9 & 1.4 & -0.2 & -1.6 \\
\hline Manufacturing & 1.5 & 3.5 & 1.7 & 2.2 & 2.3 & 5. & 2.2 & 1.2 & 1.4 & 4.4 \\
\hline Services & 0.9 & 0.2 & 2.6 & 1.9 & 0.1 & 1.5 & 7.1 & 4.2 & -1.7 & -5.1 \\
\hline
\end{tabular}

Source : Model Simulation 
The AFTA trade liberalisation would also have a positive impact on the import of the processed agricultural products. However, large import changes would be observed in the case of processed meat and processed milk, particularly in Malaysia and the Philippines. Similar to the changes in the rice import, the initial import tariff rates and ASEAN trade intensities certainly determine the import structure of these commodities. Besides relatively high initial import tariff rates, Malaysia and the Philippines are reported to have imported beverages and tobacco products from Singapore that accounted approximately for more than $15 \%$ of their total import. Imports of processed meat and processed milk in both countries would be also increased under the APEC scenario. For example, under the AFTA scenario average import changes in processed milk are around $4 \%$ in Malaysia and $1 \%$ in Philippines. Import of these products would be increased by $23 \%$ and $9 \%$, respectively.

Focusing on average import changes of textile, mining and mineral product and manufacturing, trade liberalisation either under the AFTA scenario or the APEC scenario is expected to increase. The increase in imports of manufacturing goods would have an important implication. The economy would face cheaper capital goods that are required in most producing sectors. Given relatively low market prices for these goods, the demand for imported intermediate inputs or for capital goods would increase. This would cause decreased production costs and induce the rise in output. Therefore it can be expected the industries would expand.

The impacts of trade liberalisation under the WTO round (baseline scenario), the AFTA and the APEC scenarios on the import share of aggregate products are shown in Tables 5.15-5.20. Focusing on the agricultural products under the WTO scenario, the results suggest that it is clear that dependency of the other ASEAN countries, specifically Indonesia, Malaysia and Philippines on Thailand, as a trading partner for agricultural products is quite obvious. For instance, Malaysian and Singapore imports of unprocessed agricultural products from Thailand would account for around $17 \%$ and $14 \%$, respectively. Among the ASEAN member countries, the higher import dependency for agricultural sectors in Singapore is noticeable where imports from other ASEAN member countries contributes to approximately $45 \%$ of its total import of unprocessed agricultural products. Similar patterns also apply to the case of processed agricultural products. 
However related to the import of non-agricultural products, the demand for imports of such products is largely from Singapore. Malaysian and Thai imports of non-agricultural products from Singapore would be around $23 \%$ and 10\%, respectively. On the side, Malaysia would be a major supplier to Singapore where around $14 \%$ of its import comes from Malaysia. These figures support the vital position of this country as an entrepot country. This is also parallel with criticism that excluding Singapore from the AFTA would certainly contribute to a limited impact, even marginal. As expected reducing import tariff rates within the ASEAN region would change the import structure of the ASEAN countries. Reduced import prices from products supplied by the ASEAN countries would induce an increase in demand for imported goods. The share of imports from the ASEAN member countries is projected to rise, following the reduction of import tariffs.

Relative to the baseline scenario (the WTO round), trade within the ASEAN member countries would tend to grow significantly. For instance, Malaysian imports of unprocessed agricultural products from the other ASEAN members under this scenario account for around $34 \%$. This number would certainly increase to $39 \%$ under the AFTA scenario. Similar patterns also apply to imports on processed agricultural and nonagricultural products. These results stress the importance of the role of the AFTA trade liberalisation in enhancing trade within this region. In other words, the AFTA agreement would not erode or deteriorate trade among the members. Therefore, the results answer the critics concerning whether the AFTA would enhance trade among its members. Widening the trade liberalisation would not necessarily reduce trade in this region, especially in the case of agricultural products. This is because the share of imports from the members under the APEC scenario would not change very much. Therefore fears that focusing largely on trade with non-members would lead to a very low ASEAN intra trade are without foundation. The reason why import shares of agricultural products in general would not be significantly affected is that most ASEAN countries are largely agriculture-based countries. As a result, their dependency on Japan and USA for the import of agricultural products is not very high. These figures might change if open regionalism as envisioned by the APEC member occurred. Trade intensity between the ASEAN member countries and the rest of the world (ROW) is high. Reducing import tariffs against the ROW would cause a reduction in ASEAN import shares. 
However, regarding the changes in import structure in the case of non-agricultural products, the APEC trade liberalisation would significantly induce the reduction in the import share, particularly in Malaysia, Philippines and Thailand. For example, under the AFTA scenario the import shares from the ASEAN countries in Philippines and Thailand are around $36 \%$ and $32 \%$, respectively. These shares would be decreased to approximately $29 \%$ and $27 \%$, respectively. Small changes in import shares from the ASEAN countries in Indonesia and Singapore are due to their low border tariff levels. The implication of these results might be that the opponent of global trade liberalisation would increase. Concerns over the impact of the APEC agreement that would cause a reduction in intra-ASEAN trade might be relevant. This is because the increasing imports from nonASEAN member countries would threat the domestic industries, thereby inducing the unemployment of primary factors, specifically labour. In other words, focusing largely on the regional level would be more important rather than extending to the global level. However for industries which intermediate inputs are largely imported and for domestic consumers the reduction of border tariffs would substitute their demand from domestic goods into imported goods. Since most of intermediate inputs are manufacturing goods, reduced import prices of these goods that lead to the reduction in domestic prices would affect the production cost. As a result, it is expected that industries would expand.

As outlined in Tables 5.12-5.14 diverse changes in production, exports and imports are observed. However, different patterns would occur if the individual product or sector is aggregated into three products: unprocessed agricultural, processed agricultural and nonagricultural products. Dealing with the impact of trade liberalisation under the AFTA and APEC scenarios, output in the three sectors would not alter considerably. For example, output of unprocessed agricultural product is projected to decline by $1 \%$ in Singapore and to increase by $1 \%$ in Thailand. Despite the fact that output in Singapore would increase, this change would not affect the overall economic activity in this country. Given relatively high comparative advantage of the unprocessed agricultural sector in Thailand, this sector would expand. Looking at Tables 5.12 and 5.15 the changes in rice output largely contribute to the output changes in the unprocessed agricultural products. For instance although cereal output in Malaysia is expected to rise by around $10 \%$ under the AFTA scenario, the output of unprocessed agricultural sector in this country would greatly decrease. This reflects the importance of the rice sector in the ASEAN economy. 
As stated in the chapter Introduction, Indonesia and Malaysia were concerned about opening up their markets to unprocessed agricultural products. This is because the inclusion of sensitive products in the CEPT will affect millions of farmers. If the protection of unprocessed agricultural products in this list is lifted immediately, it will lead to unemployment of resources or even social disruption. However, given the relatively small changes in the output of unprocessed agricultural products, such concern or fear is without foundation. Focusing on the case in Malaysia, Philippines and Singapore, where unprocessed agricultural sector would contract, this very small contraction in output would have no large impact of the unemployment of resources and even social disturbance. In these countries, the simulation result projects a small decrease in demand for labour. For example, the number of labours employed in unprocessed agricultural sectors declines by 1 $\%$. By contrast these sectors in Indonesia and Thailand demand slightly more labour, compared to the baseline scenario.

Similar to the case of unprocessed agricultural product the AFTA and the APEC scenarios would cause the contraction of processed agricultural sector in Philippines. The decrease in output in both sectors is positively related to the rise in imports. With high initial border tariff levels, opening up its market to imported goods will suppress the domestic prices. In turn this leads to the contraction of these sectors. These patterns do not apply for cases in other ASEAN countries. In other words, the contraction of these sectors is not necessarily associated with the large increase in the imports. It depends largely on the importance of individual product on the aggregated product. For example, under the APEC scenario the increase in the Thai imports of unprocessed agricultural product also coexists with the rise in its output.

In general, changes in export and import structures would occur and exports and imports of all products are expected to grow. These figures are quite different from what Tables 5.13 and 5.14 show. Large increases in exports of processed milk in most ASEAN countries have a low impact on overall exports of processed agricultural products. For example it is projected that the export of processed agricultural product in Philippines would be increased by less than $1 \%$ despite a very large increase in export of processed milk. This reflects a lower level importance of this product in the overall product aggregation. It seems that negative changes in exports of vegetable oil, and beverages and tobacco products would offset the positive export changes of processed milk. It is also interesting 
to see the case in Malaysia. Although exports of individual processed food, especially processed other crops and sugar would experience a relatively high rise, the change at the aggregate level would be low.

Under the AFTA scenario, import changes in all aggregated product categories are expected to mount. On the country basis, import changes in agricultural products in Indonesia would be less than in other ASEAN member economies. Again the initial import tariff levels play an important role in explaining these changes. However it is interesting to see that extending the simulation into the APEC scenario, large import changes of unprocessed agricultural products would occur in Philippines and Thailand. Under the AFTA scenario imports of this product category in these countries would be 2.4 $\%$ and $2.9 \%$, respectively, relative to the baseline scenario. Under the APEC scenario the imports would rise by $10.9 \%$ (Philippines) and $7.8 \%$ (Thailand). With regard to the change in imports of processed agricultural products and non-agricultural products, imports of these product categories in all ASEAN member countries would increase. It is apparent that the AFTA agreement would tend to increase the trade of the ASEAN countries in both products. In other words, it is projected that there would be an expansion of intra-ASEAN trade in the three product categories. However, as the coverage of import liberalisation is widened to include the APEC members (Japan and USA), the adjustment of ASEAN import appears to follow the underlying dependency of ASEAN economy on manufacturing goods from non-ASEAN members. The magnitude of change in manufacturing imports dictates the import changes of non-agricultural products. Imports of manufacturing goods remain a large portion of total imports of non-agricultural products. Due to less comparative advantage in the ASEAN economies on the production of manufacturing, reducing import barriers against Japan and USA would provide cheaper supplies in the domestic markets. The results also support the nature of the ASEAN economies that is that they have comparative advantages in natural resource-intensive goods and more labour-intensive manufacturers (textile and other light manufacturing industries). 
Table 5.15 Average Import Shares of Unprocessed Agricultural Products under the Baseline Scenario (\%)

\begin{tabular}{|c|c|c|c|c|c|}
\hline & \multicolumn{5}{|c|}{ Importing countries*) } \\
\hline & Indonesia & Malaysia & Philippines & Singapore & Thailand \\
\hline Indonesia & - & 6.23 & 4.02 & 11.11 & 3.70 \\
\hline Malaysia & 3.82 & - & 3.80 & 14.80 & 3.46 \\
\hline Philippines & 3.83 & 4.31 & - & 4.88 & 3.42 \\
\hline Singapore & 3.92 & 6.26 & 3.90 & - & 3.54 \\
\hline Thailand & 7.86 & 16.79 & 9.92 & 13.83 & - \\
\hline ASEAN & 19.43 & 33.60 & 21.65 & 44.61 & 14.14 \\
\hline
\end{tabular}

*) calculated from total import value for the same product category Source: Model Simulation.

Table 5.16 Average Import Shares of Processed Agricultural Products under the Baseline Scenario (\%)

\begin{tabular}{lrrrrr}
\hline & \multicolumn{5}{c}{ Importing countries } \\
\cline { 2 - 6 } Indonesia & Indonesia & Malaysia & Philippines & Singapore & Thailand \\
Malaysia & - & 8.34 & 4.80 & 4.66 & 6.78 \\
Philippines & 7.06 & - & 4.88 & 16.87 & 5.54 \\
Singapore & 5.18 & 5.13 & - & 4.30 & 4.30 \\
Thailand & 13.90 & 11.16 & 10.16 & - & 8.43 \\
ASEAN & 34.25 & 36.19 & 27.05 & 37.16 & 25.04 \\
\hline
\end{tabular}

Source: Model Simulation.

Table 5.17 Average Import Shares of Non-agricultural Products under the Baseline Scenario (\%)

\begin{tabular}{|c|c|c|c|c|c|}
\hline \multirow[b]{3}{*}{ Indonesia } & \multicolumn{5}{|c|}{ Importing countries } \\
\hline & Indonesia & Malaysia & Philippines & Singapore & Thailand \\
\hline & - & 4.27 & 4.94 & 5.65 & 4.07 \\
\hline Malaysia & 5.16 & - & 5.10 & 13.77 & 6.63 \\
\hline Philippines & 3.83 & 3.55 & - & 3.76 & 3.88 \\
\hline Singapore & 9.51 & 23.02 & 9.39 & - & 9.86 \\
\hline Thailand & 5.07 & 5.19 & 4.66 & 9.06 & - \\
\hline ASEAN & 23.57 & 36.03 & 24.09 & 32.25 & 24.45 \\
\hline
\end{tabular}

Source: Model Simulation. 
Table 5.18 Average Import Shares of Unprocessed Agricultural Products (\%)

\begin{tabular}{lrrrrrrrrrrr}
\hline & \multicolumn{10}{c}{ Importing countries } \\
\cline { 2 - 12 } & \multicolumn{1}{c}{ Indonesia } & \multicolumn{1}{c}{ Malaysia } & \multicolumn{1}{c}{ Philippines } & \multicolumn{3}{c}{ Singapore } & \multicolumn{2}{c}{ Thailand } \\
& AFTA & APEC & AFTA & APEC & AFTA APEC & AFTA & APEC & AFTA APEC \\
\hline Indonesia & - & - & 6.92 & 6.93 & 5.24 & 5.14 & 12.09 & 11.98 & 5.39 & 5.34 \\
Malaysia & 4.69 & 4.68 & - & - & 4.77 & 4.70 & 16.45 & 16.33 & 4.59 & 4.59 \\
Philippines & 4.72 & 4.70 & 5.06 & 5.04 & - & - & 6.08 & 5.99 & 4.45 & 4.44 \\
Singapore & 4.82 & 4.82 & 7.08 & 7.13 & 5.20 & 5.09 & - & - & 4.88 & 4.89 \\
Thailand & 7.90 & 7.84 & 19.94 & 19.42 & 13.03 & 12.25 & 14.24 & 13.97 & - & - \\
ASEAN & 22.13 & 22.04 & 39.00 & 38.52 & 28.24 & 27.18 & 48.86 & 48.27 & 19.31 & 19.26 \\
\hline
\end{tabular}

Source: Model Simulation.

Table 5.19 Average Import Shares of Processed Agricultural Products (\%)

\begin{tabular}{lrrrrrrrrrrr}
\hline & \multicolumn{10}{c}{ Importing countries } \\
\cline { 2 - 12 } & \multicolumn{1}{c}{ Indonesia } & \multicolumn{1}{c}{ Malaysia } & \multicolumn{1}{c}{ Philippines } & \multicolumn{3}{c}{ Singapore } & \multicolumn{2}{c}{ Thailand } \\
& AFTA APEC & AFTA & APEC & AFTA & APEC & AFTA & APEC & AFTA & APEC \\
\hline Indonesia & - & - & 10.19 & 10.01 & 5.22 & 5.23 & 4.82 & 4.83 & 10.66 & 10.55 \\
Malaysia & 7.59 & 7.33 & - & - & 5.63 & 5.68 & 19.07 & 19.06 & 6.45 & 6.44 \\
Philippines & 8.46 & 8.44 & 5.41 & 5.40 & - & - & 4.44 & 4.44 & 4.74 & 4.73 \\
Singapore & 5.67 & 5.43 & 14.34 & 13.47 & 20.41 & 20.22 & - & - & 12.09 & 11.95 \\
Thailand & 14.54 & 14.30 & 12.89 & 13.02 & 7.65 & 7.68 & 12.91 & 12.65 & - & - \\
ASEAN & 36.27 & 35.51 & 42.83 & 41.90 & 38.91 & 38.81 & 41.25 & 40.98 & 33.94 & 33.67 \\
\hline
\end{tabular}

Source: Model Simulation.

Table 5.20 Average Import Shares of Non-agricultural Products (\%)

\begin{tabular}{lrrrrrrrrrrr}
\hline & \multicolumn{10}{c}{ Importing countries } \\
\cline { 2 - 12 } & \multicolumn{1}{c}{ Indonesia } & \multicolumn{1}{c}{ Malaysia } & \multicolumn{1}{c}{ Philippines } & \multicolumn{3}{c}{ Singapore } & \multicolumn{2}{c}{ Thailand } \\
& AFTA APEC & AFTA & APEC & AFTA & APEC & AFTA & APEC & AFTA APEC \\
\hline Indonesia & - & - & 4.67 & 4.54 & 6.15 & 5.49 & 5.68 & 5.70 & 4.82 & 4.34 \\
Malaysia & 5.65 & 5.47 & - & - & 7.38 & 6.15 & 14.36 & 14.85 & 8.77 & 7.34 \\
Philippines & 3.79 & 3.76 & 3.44 & 3.43 & - & - & 3.69 & 3.76 & 4.25 & 3.93 \\
Singapore & 11.16 & 10.61 & 28.99 & 27.26 & 15.46 & 11.86 & - & - & 13.92 & 11.18 \\
Thailand & 5.91 & 5.67 & 5.94 & 5.72 & 6.68 & 5.72 & 9.80 & 9.95 & - & - \\
ASEAN & 26.51 & 25.51 & 43.03 & 40.94 & 35.66 & 29.22 & 33.53 & 34.27 & 31.76 & 26.80 \\
\hline
\end{tabular}

Source: Model Simulation. 
Table 5.21 Average Changes in Aggregate Production, Export and Import under the AFTA and APEC Scenarios (\%)

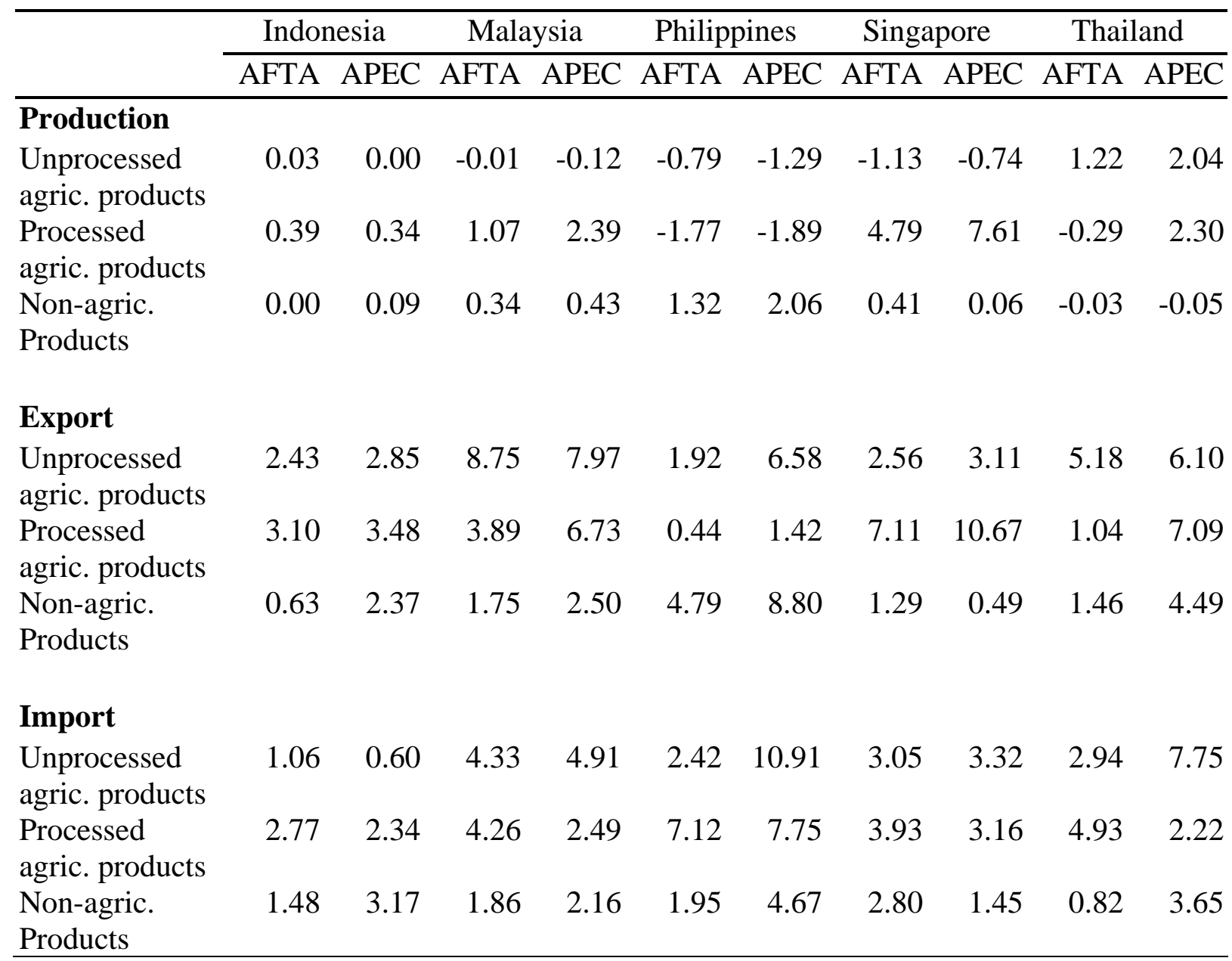

Source: Model Simulation.

\section{3. 2. Factor Allocation}

Resource reallocations as a result of trade liberalisation following the AFTA and APEC tariff reduction schemes in each ASEAN member country are summarised in Tables 5.225.26. The results suggest that the demand for primary factors is largely associated with the changes in the outputs. In the case of the AFTA and APEC trade liberalisation, the development of output results from the increased export possibilities due to the removal border tariffs in trading partner countries. The tariff elimination under both scenarios would induce the increase in the ASEAN exports, thereby leading to the increase in the output. Accordingly, the demand for production factors is projected to rise.

In the Indonesian case, a large increase in the demand for primary factors is expected to occur in processed milk sector. As processed milk output increases in both the AFTA and 
APEC scenarios, the demand for primary factors also rises accordingly. However, the demand for capital under the AFTA scenario is expected to increase but less than those for other primary factors. For instance, the processed milk sector in Indonesia increases the demands for capital by 11.9 \% compared to the baseline scenario, while the demand for skilled labour rises by $18.9 \%$. Given a perfectly mobile capital among sectors, this result indicates factor re-allocations from shrinking sectors to expanding sectors. By contrast, some sectors would reduce their demand for primary factors, following the contraction of these sectors. Sectors that demand less primary factors include for example oil seeds, vegetable oils, and manufacturing sectors however with marginal changes. Under the APEC scenario, apart from processed milk sectors, resources would move to textile sectors in which demands for factors rise by approximately $7 \%$, relative to the baseline scenario. It seems that resources re-allocate themselves from unprocessed agricultural sectors to their traditional labour-intensive manufacturing sectors. The results suggest that in near future Indonesian economy will continue to depend on the labour intensive industries. These results are similar with the study of FERIDHANUSETYAWAN (1998). It is expected that resources allocated into more capital and technology intensive sectors such mining and manufacturing would be less than what might otherwise occur under the baseline scenario. As insisted by FERIDHANUSETYAWAN (1998) these findings have economic implications. As unprocessed agricultural sectors, which are mainly located in rural areas contract, unskilled labour would migrate to the urban sectors, especially the labour intensive industries (textile industries). Hence, in the future the Indonesian comparative advantages will remain in its cheap labour. In other words, textile industries will continually benefit from the wider trade liberalisation. The abolition of textile quotas under the MFA arrangement will certainly have a positive impact on the textile industries.

The changing patterns of demands for primary factors, while differing across other ASEAN member countries are in line with changes in outputs. Malaysia, Thailand and Singapore would encounter considerable rises in the demand for primary factors in the cereal sector, following the increase in the output of this sector. Despite the fact that the demand for capital and labour grows, following the increase in the output, the demand for land changes is greater than demand for other primary factors. For example, the demand for capital and labour in Malaysia cereal sector would increase by $6.3 \%$ and $8.8 \%$, respectively, while demand for land would be $9.9 \%$, relative to the baseline scenario. There are two possible reasons explaining the different patterns of factor allocations. 
Capital is relatively scarce. Due to limited capital availability, the change in capital demand is quite different from what might occur in the demand for labour. However, with a low elasticity substitution among primary factors the demand for one primary factor cannot be easily replaced by the other factors. A similar pattern also applies in the case in oil seeds sector in the Philippines. As a main primary factor for unprocessed agricultural sectors, the expanding output is largely dependent on the supply of land. Land will be moved from the contracting sectors to the expanding sectors. Due the limited supply of land it is estimated that the land rent in these countries would be high.

Focusing on the Philippine case, the relatively large rise in the demand for primary factors would exist in non-agricultural sectors, particularly textile, mining and mineral products and manufacturing sectors. As their output continues to increase considerably under the APEC scenario, the demand for primary sectors, especially the textile sector, would rise approximately by $16 \%$ (capital) and $17 \%$ (unskilled labour). By contrast, the demand for such primary factors under the AFTA scenario increases by only $2 \%$ and $4 \%$, respectively. Under the later scenario, the findings also suggest that the response of capital to the changes in the output would be less than that of either skilled labour or unskilled labour. On the side, under the APEC scenario, all sectors would experience the same change rates of the demands for primary factors. Since the region would lose their import tax revenue due to the further reduction of import tariff for goods imported from the USA and Japan. This in turn would cause a decrease in investment. Finally, the supply of capital would be scarce and the expanding sector would move into other primary factors.

Looking at overall changes in factor re-allocations, particularly under the APEC scenario, all ASEAN member countries would encounter a similar pattern. Having a wider access into foreign markets, textile outputs are expected to rise considerably. In fact, textile outputs are also projected to rise under the AFTA scenario, however only with small changes. With the exception of the case in Thailand where demands for primary factors in rice and cereal sectors would be increased, these results support the labour transformation process in the ASEAN member countries. As labour moves from agricultural sectors to manufacturing sectors (textile sectors), there would be labour scarcity in rural areas. To keep up with the expanding output in manufacturing industries, these industries have to 
demand more labour by absorbing expelled labourers. If this mechanism continues to occur, the real wage rate is expected to rise.

Table 5.22 Indonesia. Average Annual Changes of Demand for Primary Factors Relative to the Baseline (\%)

\begin{tabular}{lrrrrrrrr} 
Sector & Capital & \multicolumn{3}{c}{ Skilled Labour } & \multicolumn{1}{c}{$\begin{array}{c}\text { Unskilled } \\
\text { Labour }\end{array}$} & \multicolumn{2}{c}{ Land } \\
& AFTA & APEC & AFTA & APEC & AFTA & APEC & AFTA & APEC \\
\hline $\begin{array}{l}\text { Unprocessed } \\
\text { agric. products }\end{array}$ & & & & & & & & \\
Rice & 0.0 & -0.2 & 0.0 & -0.1 & 0.0 & -0.2 & 0.0 & 0.0 \\
Cereal & 0.5 & 0.1 & 0.8 & 0.1 & 0.8 & 0.1 & 0.7 & 0.1 \\
Oil seeds & -0.2 & -0.5 & -0.3 & -0.5 & -0.3 & -0.5 & -0.3 & -0.5 \\
Livestock & 0.1 & 0.2 & 0.1 & 0.2 & 0.1 & 0.2 & 0.1 & 0.2 \\
Crops & 0.0 & -0.1 & 0.0 & 0.0 & 0.0 & -0.1 & -0.1 & 0.0
\end{tabular}

Processed agric.

Products

\begin{tabular}{lrrrrrrrr} 
Vegetable oil & -0.2 & -0.5 & -0.3 & -0.4 & -0.3 & -0.5 & - & - \\
$\begin{array}{l}\text { Processed other } \\
\text { crop }\end{array}$ & 0.5 & 0.5 & 0.7 & 0.5 & 0.7 & 0.5 & - & - \\
Processed meat & & & & & & & & \\
Processed milk & 1.0 & 1.9 & 1.2 & 1.9 & 1.2 & 1.9 & - & - \\
Sugar & 0.0 & -0.2 & 0.0 & -0.2 & 0.0 & -0.2 & - & - \\
$\begin{array}{l}\text { Beverage and } \\
\text { tobacco products }\end{array}$ & -0.1 & 0.0 & 0.0 & 0.0 & -0.1 & 0.0 & - & - \\
Non-agric. & & & & & & & & \\
Products & & & & & & & & \\
$\begin{array}{l}\text { Textiles } \\
\text { Mining and mineral }\end{array}$ & 0.6 & 6.9 & 1.0 & 7.0 & 1.0 & 6.9 & - & - \\
products & -0.4 & -0.2 & -0.6 & -0.2 & -0.7 & -0.2 & - & - \\
Manufacturing & -0.1 & -1.1 & -0.1 & -1.1 & -0.2 & -1.1 & - & - \\
Services & 0.0 & 0.0 & 0.1 & 0.1 & 0.1 & 0.0 & - & - \\
\hline
\end{tabular}

Source: Model Simulation 
Table 5.23 Malaysia. Average Annual Changes of Demand for Primary Factors Relative to the Baseline Scenario (\%)

\begin{tabular}{|c|c|c|c|c|c|c|c|c|}
\hline \multirow[t]{2}{*}{ Sector } & \multicolumn{2}{|c|}{ Capital } & \multicolumn{2}{|c|}{ Skilled Labour } & \multicolumn{2}{|c|}{$\begin{array}{l}\text { Unskilled } \\
\text { Labour }\end{array}$} & \multicolumn{2}{|c|}{ Land } \\
\hline & AFTA & APEC & AFTA & APEC & AFTA & APEC & AFTA & APEC \\
\hline $\begin{array}{l}\text { Unprocessed } \\
\text { agric. products }\end{array}$ & & & & & & & & \\
\hline Rice & -2.5 & -2.4 & -2.7 & -2.4 & -2.7 & -2.5 & -0.1 & -0.1 \\
\hline Cereal & 6.3 & -23.1 & 8.8 & -23.1 & 8.8 & -23.1 & 9.9 & -22.4 \\
\hline Oil seeds & 1.0 & 2.4 & 0.4 & 2.4 & 0.4 & 2.4 & 1.5 & 3.5 \\
\hline Livestock & 0.0 & 0.7 & 1.0 & 0.7 & 0.0 & 0.7 & 2.1 & 1.7 \\
\hline Crops & 0.8 & -0.1 & 0.2 & -0.1 & 0.2 & -0.2 & 1.3 & 0.9 \\
\hline $\begin{array}{l}\text { Processed agric. } \\
\text { Products }\end{array}$ & & & & & & & & \\
\hline Vegetable oil & 1.8 & 4.8 & 1.6 & 4.8 & 1.6 & 4.6 & - & - \\
\hline $\begin{array}{l}\text { Processed other } \\
\text { crop }\end{array}$ & 2.2 & 3.0 & 2.7 & 3.0 & 2.7 & 2.8 & - & - \\
\hline Processed meat & -0.6 & 1.0 & -0.8 & 1.0 & -0.7 & 0.9 & - & - \\
\hline Processed milk & -0.4 & -2.4 & -1.6 & -2.4 & -1.6 & -2.5 & - & - \\
\hline Sugar & 13.7 & 17.9 & 18.2 & 17.9 & 18.2 & 17.8 & - & - \\
\hline $\begin{array}{l}\text { Beverage and } \\
\text { tobacco products }\end{array}$ & -0.5 & -0.9 & -0.8 & -0.9 & -0.8 & -1.1 & - & - \\
\hline $\begin{array}{l}\text { Non-agric. } \\
\text { Products }\end{array}$ & & & & & & & & \\
\hline Textiles & 0.4 & 6.3 & 0.6 & 6.3 & 0.6 & 6.2 & - & - \\
\hline $\begin{array}{l}\text { Mining and mineral } \\
\text { products }\end{array}$ & -2.2 & -3.7 & -3.3 & -3.7 & -3.3 & -3.7 & - & - \\
\hline Manufacturing & 1.1 & 1.7 & 1.5 & 1.7 & 1.5 & 1.6 & - & - \\
\hline Services & -0.2 & -0.5 & -0.3 & -0.5 & -0.3 & -0.6 & - & - \\
\hline
\end{tabular}

Source: Model Simulation 
Table 5.24 The Philippines. Average Annual Changes of Demand for Primary Factor Relative to the Baseline Scenario (\%)

\begin{tabular}{|c|c|c|c|c|c|c|c|c|}
\hline \multirow[t]{2}{*}{ Sector } & \multicolumn{2}{|c|}{ Capital } & \multicolumn{2}{|c|}{ Skilled Labour } & \multicolumn{2}{|c|}{$\begin{array}{l}\text { Unskilled } \\
\text { Labour }\end{array}$} & \multicolumn{2}{|c|}{ Land } \\
\hline & AFTA & APEC & AFTA & APEC & AFTA & APEC & AFTA & APEC \\
\hline \multicolumn{9}{|l|}{$\begin{array}{l}\text { Unprocessed } \\
\text { agric. products }\end{array}$} \\
\hline Rice & -1.6 & -2.8 & -2.0 & -2.6 & -2.0 & -2.7 & -1.2 & -1.0 \\
\hline Cereal & -0.5 & -12.8 & -0.9 & -12.7 & -1.0 & -12.8 & 0.0 & -10.9 \\
\hline Oil seeds & 1.5 & 2.8 & 2.1 & 2.9 & 2.0 & 2.9 & 3.0 & 5.1 \\
\hline Livestock & 0.0 & -2.1 & -1.2 & -2.0 & 0.0 & -2.0 & -0.3 & 0.0 \\
\hline Crops & -0.4 & -0.3 & -0.5 & -0.2 & -0.6 & -0.2 & 0.4 & 1.9 \\
\hline \multicolumn{9}{|l|}{$\begin{array}{l}\text { Processed agric. } \\
\text { Products }\end{array}$} \\
\hline Vegetable oil & -0.5 & 0.6 & -0.6 & 1.3 & -0.7 & 0.9 & - & - \\
\hline $\begin{array}{l}\text { Processed other } \\
\text { crop }\end{array}$ & -0.7 & -1.0 & -0.8 & -0.4 & -0.9 & -0.7 & - & - \\
\hline Processed meat & -1.2 & -2.4 & -1.4 & -1.7 & -1.5 & -2.0 & - & - \\
\hline Processed milk & -0.9 & -1.8 & -0.9 & -1.2 & -1.1 & -1.5 & - & - \\
\hline Sugar & 0.0 & -1.4 & 0.2 & -0.7 & 0.0 & -1.0 & - & - \\
\hline $\begin{array}{l}\text { Beverage and } \\
\text { tobacco products }\end{array}$ & -2.9 & -5.1 & -4.1 & -4.5 & -4.3 & -4.8 & & \\
\hline \multicolumn{9}{|l|}{$\begin{array}{l}\text { Non-agric. } \\
\text { Products }\end{array}$} \\
\hline Textiles & 2.2 & 16.2 & 3.8 & 17.1 & 3.6 & 16.6 & - & - \\
\hline $\begin{array}{l}\text { Mining and } \\
\text { mineral products }\end{array}$ & 2.1 & 3.5 & 3.3 & 3.7 & 3.3 & 3.6 & - & - \\
\hline Manufacturing & 3.3 & 6.8 & 5.6 & 7.6 & 5.3 & 7.2 & - & - \\
\hline Services & -0.6 & -1.6 & -0.4 & -0.8 & -0.7 & -1.2 & & \\
\hline
\end{tabular}

Source: Model Simulation 
Table 5.25 Singapore. Average Annual Changes of Demand for Primary Factor Relative to the Baseline Scenario (\%)

\begin{tabular}{|c|c|c|c|c|c|c|c|c|}
\hline \multirow[t]{2}{*}{ Sector } & \multicolumn{2}{|c|}{ Capital } & \multicolumn{2}{|c|}{ Skilled Labour } & \multicolumn{2}{|c|}{$\begin{array}{l}\text { Unskilled } \\
\text { Labour }\end{array}$} & \multicolumn{2}{|c|}{ Land } \\
\hline & AFTA & APEC & AFTA & APEC & AFTA & APEC & AFTA & APEC \\
\hline $\begin{array}{l}\text { Unprocessed } \\
\text { agric. products }\end{array}$ & & & & & & & & \\
\hline Rice & -6.9 & -11.2 & -3.1 & -2.4 & -13.1 & -11.3 & -0.7 & 0.2 \\
\hline Cereal & 7.3 & 4.2 & 0.0 & 0.0 & 21.6 & 16.5 & 23.0 & 16.9 \\
\hline Oil seeds & -0.2 & -0.5 & -0.3 & -0.5 & -0.3 & -0.5 & -1.9 & -1.9 \\
\hline Livestock & 0.0 & -3.6 & -4.3 & -3.6 & 0.0 & -3.7 & -3.3 & -3.4 \\
\hline Crops & 1.4 & 3.0 & 2.0 & 2.9 & 2.0 & 2.9 & 3.1 & 3.2 \\
\hline $\begin{array}{l}\text { Processed agric. } \\
\text { Products }\end{array}$ & & & & & & & & \\
\hline Vegetable oil & -2.2 & -2.2 & -2.8 & -2.2 & -3.0 & -2.4 & - & - \\
\hline $\begin{array}{l}\text { Processed other } \\
\text { crop }\end{array}$ & 3.8 & 8.1 & 4.8 & 8.1 & 4.6 & 7.8 & - & - \\
\hline Processed meat & 9.0 & 17.3 & 9.8 & 17.2 & 9.5 & 17.0 & - & - \\
\hline Processed milk & 25.4 & 47.1 & 40.7 & 47.0 & 40.4 & 46.7 & - & - \\
\hline Sugar & 2.8 & 6.4 & 3.9 & 6.3 & 3.7 & 6.1 & - & - \\
\hline $\begin{array}{l}\text { Beverage and } \\
\text { tobacco products } \\
\text { Non-agric. } \\
\text { Products }\end{array}$ & 1.8 & 4.2 & 2.6 & 4.2 & 2.3 & 3.9 & - & - \\
\hline Textiles & 1.5 & 11.2 & 2.1 & 11.1 & 1.9 & 10.8 & - & - \\
\hline $\begin{array}{l}\text { Mining and } \\
\text { mineral products }\end{array}$ & -2.0 & -1.4 & -3.4 & -1.4 & -3.4 & -1.5 & - & - \\
\hline Manufacturing & 1.7 & 1.0 & 2.4 & 0.9 & 2.2 & 0.7 & - & - \\
\hline Services & -0.8 & -0.7 & -1.3 & -0.7 & -1.5 & -1.0 & - & - \\
\hline
\end{tabular}

Source: Model Simulation 
Table 5.26 Thailand. Average Annual Changes of Demand for Primary Factor Relative to the Baseline Scenario (\%)

\begin{tabular}{|c|c|c|c|c|c|c|c|c|}
\hline \multirow[t]{2}{*}{ Sector } & \multicolumn{2}{|c|}{ Capital } & \multicolumn{2}{|c|}{ Skilled Labour } & \multicolumn{2}{|c|}{$\begin{array}{l}\text { Unskilled } \\
\text { Labour }\end{array}$} & \multicolumn{2}{|c|}{ Land } \\
\hline & AFTA & APEC & AFTA & APEC & AFTA & APEC & AFTA & APEC \\
\hline $\begin{array}{l}\text { Unprocessed } \\
\text { agric. products }\end{array}$ & & & & & & & & \\
\hline Rice & 6.8 & 8.0 & 7.1 & 7.9 & 7.0 & 7.7 & 5.4 & 5.1 \\
\hline Cereal & 22.4 & 10.3 & 39.6 & 10.2 & 39.5 & 10.1 & 38.2 & 8.4 \\
\hline Oil seeds & -0.2 & -0.5 & -0.3 & -0.5 & -0.3 & -0.5 & -1.6 & -3.7 \\
\hline Livestock & 0.0 & 2.6 & -0.8 & 2.5 & 0.0 & 2.4 & -1.8 & 0.9 \\
\hline Other crops & -0.9 & -0.1 & -0.9 & -0.2 & -0.9 & -0.3 & -1.9 & -1.9 \\
\hline $\begin{array}{l}\text { Processed agric. } \\
\text { Products }\end{array}$ & & & & & & & & \\
\hline Vegetable oils & -1.3 & -2.1 & -1.6 & -2.4 & -1.9 & -2.9 & - & - \\
\hline $\begin{array}{l}\text { Processed other } \\
\text { crop }\end{array}$ & -0.2 & 2.6 & 0.0 & 2.2 & -0.3 & 1.7 & - & - \\
\hline Processed meat & -0.7 & 5.9 & -0.9 & 5.5 & -1.2 & 5.0 & - & - \\
\hline Processed milk & 1.9 & 3.2 & 3.2 & 2.8 & 2.9 & 2.4 & - & - \\
\hline Sugar & -0.9 & -1.1 & -1.0 & -1.4 & -1.3 & -1.9 & - & - \\
\hline $\begin{array}{l}\text { Beverage and } \\
\text { tobacco products }\end{array}$ & -0.1 & -0.5 & -0.1 & -0.9 & -0.4 & -1.3 & - & - \\
\hline $\begin{array}{l}\text { Non-agric. } \\
\text { Products }\end{array}$ & & & & & & & & \\
\hline Textiles & 0.6 & 7.8 & 1.2 & 7.3 & 0.9 & 6.7 & - & - \\
\hline $\begin{array}{l}\text { Mining and } \\
\text { mineral products }\end{array}$ & -0.1 & 0.5 & -0.1 & 0.4 & -0.2 & 0.2 & - & - \\
\hline Manufacturing & -0.1 & -1.5 & -0.1 & -1.9 & -0.5 & -2.4 & - & - \\
\hline Services & 0.0 & 0.5 & 0.0 & 0.0 & -0.4 & -0.5 & - & - \\
\hline
\end{tabular}

Source: Model Simulation.

\section{4. Effects on Trade Creation and Diversion}

The important and challenging issue in the context of regional economic integration is that when a country or region pursues such integration, the country might encounter the socalled trade creating effect and trade diverting effect. Both terms were initially introduced by VINER (1950) in his seminal paper. Trade creation effect refers to the situation where the agreement provides new opportunities through the movement of the production of goods from inefficient countries to more efficient countries, whereas trade diversion effect refers to the extent to which production of goods moves from relatively efficient countries to less efficient countries inside the union. In other words, trade creation results from the fact that after tariff reductions consumers in home countries pay lower prices for goods from a partner country and hence overall the volume of import rises while the trade 
diversion means that consumers in their home country shift the origin of their import products to a partner country enjoying a tariff preference, though in that partner country the price is higher than price for the same good coming from the rest of the world.

Trade diverting effect in the context of the ASEAN Free Trade Area (AFTA) might rise. For example, the ASEAN member countries imported goods mostly from efficient sources: major ASEAN trading partners (EU, USA and Japan) or rest of the world (ROW). Following a full removal of import tariff rates within ASEAN member countries, imports from non-ASEAN member countries would fall. In this relation, concerns over the impact of the establishment of the AFTA have arisen (WTO, 1999). However, in the longer term, a further reduction of trade barriers in this country as well as in other ASEAN member economies would minimise this effect. Despite the fact that trade diversion is unavoidable due the nature of the regional integration arrangement itself, TAN (2000) insisted that the trade creation effect of the free trade area will offset the trade diversion effect. In addition to the net positive trade creation effect in each ASEAN member nation will benefit from the free trade agreement. This study investigates the impact of the AFTA trade liberalisation on trade creation and trade diversion, using the changes in the bilateral imports. For the sake of simplicity, the discussion will focus solely on the changes in the bilateral trade in selected ASEAN member countries (Malaysia, the Philippines and Singapore).

Tables 5.27- 5.29 present the effects of the AFTA trade liberalisation on the changes in the value of imports. These tables bring a direct measure of trade diversion in Malaysia, the Philippines and Singapore in the simulation. The values presented in these tables indicate the average annual import deviations during the period of 2004-2010 from the baseline scenario. First, the discussion focuses solely on imports of aggregated products (unprocessed agricultural products, processed agricultural products and non-agricultural products). The simulation results suggest in general the rise in the bilateral imports within the ASEAN member countries, resulting from the total removal of border tariffs.

From these tables, it can be seen that imports in Malaysia, Philippines and Singapore from other ASEAN member countries would increase by US \$ 11369.6 million, US \$ 5817.9 million and US\$2746.7 million, respectively. These increased imports would have an adverse impact on imports from non-ASEAN countries. In the case of Malaysia, for 
example, the increased imports in this country would displace imports from the APEC countries (Japan and USA), EU and ROW by US\$ 3361.1 million, US\$ 1247.5 million and US\$ 2347.5 million, respectively. The amount of trade diversion would occur in Japan/USA, EU and ROW whose exports to Philippines would decline by US\$2212.3 million, US\$ 648.8 million and US\$ 1595.6 million, respectively. However, different import patterns would be experienced by Singapore, whose imports from either other ASEAN member countries or non-ASEAN member countries are projected to grow. For example, there would be an additional import of Singapore from other ASEAN member countries by US\$2746.7 million. In the same time, Japan, USA, EU and ROW would increase their exports to Singapore by US\$2584.1 million, US\$ 1013.7 million and US\$ 1336.4 million, respectively. This figure suggests that Singapore would experience trade creation following the establishment of the AFTA agreement. However, the increased imports in Singapore are due to the low import tariff rates.

On an aggregate product basis, the majority of additional imports to the ASEAN member countries and also reductions of imports from non-ASEAN countries originates from nonagricultural products. For instance, exports from Japan, USA, EU and ROW to Malaysia for non-agricultural products decrease by US\$ 6956.1 million. Likewise, Philippine imports from these countries/region decline by US\$ 4456.7 million. As tariff rates are removed in Malaysia and Philippines following the full implementation of the AFTA agreement, consumers in these countries purchase imported products from other ASEAN countries cheaper than products from non-ASEAN member countries. As a result, they substitute the cheaper ASEAN products. However, examining the difference between additional imports and decreased imports, both countries would experience trade creation. In other words, trade creation for Malaysia and Philippines exceeds the trade diversion by US\$ 2,787 million and US\$ 685.4 million, respectively.

With regard to the APEC trade liberalisation, result simulations indicate changes in import directions. Reducing import tariffs, consumers in the ASEAN member countries face cheaper products from Japan and USA. Hence they substitute their demand for relatively higher priced products (EU and ROW). In addition, the APEC trade liberalisation affects the imports within the ASEAN region. Imports from other ASEAN member countries would increase, but by less than what might occur under the AFTA scenario. For example, Malaysian imports from Japan/USA would rise by US\$ 4243.0 million, relative to the 
baseline scenario. This increase displaces imports from EU and ROW by US\$ 2508.9 million and US\$ 3729.3 million, respectively. This country would import from other ASEAN member countries by US $\$ 5797.8$ million, which is less than under the AFTA scenario (US\$ 11369.6 million). The same patterns also apply in the case of the Philippines. Exports of EU and ROW to Philippines would decline by US\$ 1309.2 million and US\$ 2961.1 million. In response to lower import prices for US import products, the demand for Japan/US imports would increase by US\$ 4546.3 million.

Surprisingly, APEC scenario has an adverse impact on the export of Japan/USA to Singapore, while EU and ROW exports to this country are reported to increase but by less than the level increase under the AFTA scenario. Overall, trade diversion in Singapore still outweighs the trade creation however with a less amount compared to trade creation under the AFTA scenario. The likely reason for such impact is that due to limited market absorption in Singapore and low levels of import tariff rates, demands for Japan and US products are lower than that of in Malaysia and Philippines. As a result, Japan and USA shift their export to these countries rather than to Singapore.

Appendix Tables 5.7 -5.16 identify average annual import deviations under the AFTA and APEC scenario compared to the baseline scenario. Focusing first on the bilateral import changes in the unprocessed agricultural products, the results support the importance of Thailand as a major rice exporter in this region as indicated by with the large increase in the rice imports in Malaysia and the Philippines. For instance, changes in rice imports from Thailand to Malaysia and Philippines are US\$ 746 million and US\$ 98 million, respectively. Malaysian and Philippine increased imports from Thailand displace rice imports from ROW by US\$ 106.6 million and US\$ 13.9 million, respectively. A large import increase is also reported in the case of cereal in Malaysia, which is expected to rise by US\$ 189.2 million. Likewise, Indonesian exports of cereal to Malaysia are projected to grow by US\$ 49 million as a result of reducing import tariff rates in Malaysia. Comparing import changes in unprocessed agricultural products, these figures suggest that such increases are largely due to additional imports of rice. The simulation also provides an indication of a creating trading effect with regard to these products.

Concerning the processed agricultural products, Malaysian and Philippine imports from other ASEAN member countries also result in some trade diversion. The region that is 
mostly affected adversely by the increased imports of processed agricultural products in both countries is ROW. Malaysia imports of processed meat from other ASEAN member countries increase by US\$ 157.7 million displacing some US\$ 67.2 million of ROW imports and US\$ 8.6 million of EU imports of processed meat. Similarly, EU and ROW exports of processed milk to Malaysia are adversely affected. The same patterns also apply for the Philippines, which experiences large additional imports of processed milk, processed other crops and beverages and tobacco products. However, in the same time, such increases displace imports from EU and ROW. In the case of the import of processed milk, EU and ROW exports to Philippines fall by US\$ 10.4 million and US\$ 59.7 million, respectively. Largely decreased exports of beverages and tobacco products in EU and ROW are projected to occur which decline by US\$ 55.5 million and US\$ 54.6 million. It is interesting to take note that Japanese exports to ASEAN member countries falls, however with very marginal magnitudes. In other words, Japan would not really suffer trade diversion as a consequence of ASEAN increasing their imports, especially for a case of agricultural products. This finding is not surprising, since ASEAN imports of agricultural products from Japan are very marginal. Besides Japan has no comparative advantage in agricultural sectors.

From Appendix Tables 5.7 -5.11, the simulation results suggest that the bulk of additional imports in ASEAN member countries are manufactured goods. For example, Malaysian and Philippine imports of manufactured goods from other ASEAN member countries increase by US\$ 8871.3 million and US\$ 4644 million, respectively. However, this increase causes a decrease in imports from non-ASEAN member countries. Among nonASEAN members, Japan seems to be mostly affected. This country suffers from a loss of exports of manufactured goods to Malaysia and Philippines by US\$ 2237.0 million and US\$ 1356.8 million, respectively. Another important finding is that the increases of imports in ASEAN member countries are strongly based on Singapore products. This result is in line with the Singapore's very significant role in entrepot trade with the ASEAN (KRUEGER, 1999). ASEAN imports from Singapore are projected to increase markedly, followed by the fall in the imports from non-ASEAN members, with the exception of imports of textile products. On the other side, Singapore demand for imports from non-ASEAN members would rise significantly. Apart from import rise from ROW, EU and Japan would benefit from the AFTA scenario. The demand for Singapore's imports in EU and Japan is estimated to expand by US\$ 1050.1 millions and US\$ 1682.6 
millions, respectively. This finding is quite interesting to discuss. This is because the increased demand for imported goods under the AFTA scenario does not correspond with the actual Singapore's trade policy. Import duties in Singapore are already very low, even zero. Therefore one cannot consider the increased import as trade creating effect. It seems that import flows are re-oriented through Singapore, and then to the other ASEAN member countries ${ }^{63}$.

Extending the simulation into the APEC trade liberalisation, it is reported that the imports of some products from the other APEC countries - JAPAN and USA are projected to rise, particularly imports of non-agricultural products. However, these large changes in imports from Japan and USA are followed by the relatively smaller rise in imports from the ASEAN member countries. This finding suggests that in some cases, imported goods from the APEC members would replace goods imported from the ASEN member countries. Focusing on the changes in the imports of textiles, mining and mineral products as well as manufacturing products, ASEAN countries especially Philippines and Malaysia would import more from Japan and USA, but reduce imports from EU and ROW. For example, Philippine imports of manufactured products from Japan and USA are expected to increase by US\$2077.2 million and US\$1974.1 million, respectively. By contrast, EU and ROW lose their exports to the Philippines by US\$ 1349.8 million and US\$ 2735.0 million, respectively. It is interesting to note that increased imports of Japanese and US manufactured goods in Philippines as well as in Malaysia affect the imports of these countries from other ASEAN member countries. Their imports are projected to rise but by less than what might occur under the AFTA scenario. Reducing import tariffs for goods coming from Japan or USA lead to lower import prices. Now consumers in ASEAN regions demand more of the cheaper Japanese or USA products by reducing their demand for products imported from other ASEAN member countries. The large increase in imports of manufactured products from Japan and USA are associated with the results of the early trade liberalisation for these products (early voluntary trade liberalisation). All APEC members are committed to removing all border tariffs on oil seeds, mining and mineral products and manufacturing products by 2005 . However, this early trade

\footnotetext{
${ }^{63}$ Concerns have arisen concerning a progressive negotiation between Singapore and other countries outside the ASEAN members to establish a free trade area agreement. For example, Singapore and New Zealand have signed an agreement. It also hopes to pursue a similar attempt with the EU and the USA. Such agreement would then weaken the AFTA and provide back-door entry for non-ASEAN member countries to the ASEAN markets (http:www.worldpaper.com/regionaltrade/amidglobalization.html).
} 
liberalisation seems not to have an impact on the import of oil seeds with the exception of the case in Singapore.

These results suggest the positive trade effect of pursuing a wider regional economic cooperation. As has been discussed earlier, the impact of ASEAN countries from the APEC commitment seems to be limited due to the fact that the only non-ASEAN APEC members represented in this study are Japan and USA. Extending the analysis by including New Zealand-Australia and China would certainly enhance trade among APEC member economies. In addition, the debate over the likely impact of China-ASEAN free trade plan is also quite relevant, where around 2 billion people reside in these regions. Another limitation is that no reciprocal mechanism and no discriminatory basis are included in this study. The APEC members envisioned the openness of the APEC in which trade liberalisation should be extended to non-members regardless of whether they reduce their border tariffs against APEC member countries.

Table 5.27 Indonesia. Average Annual Import Changes Relative to the Baseline Scenario (US\$ million)

\begin{tabular}{lrrrr}
\hline Products & ASEAN & $\begin{array}{c}\text { Japan and } \\
\text { USA }\end{array}$ & EU & ROW \\
\hline $\begin{array}{l}\text { Unprocessed } \\
\text { agric. products }\end{array}$ & -46.9 & 27.2 & 4.7 & 118.1 \\
& $(10.1)$ & $(103.9)$ & $(-6.8)$ & $(-35.1)$ \\
$\begin{array}{l}\text { Processed agric. } \\
\text { Products }\end{array}$ & 109.3 & -6.5 & -4.4 & -16.2 \\
& $(35.9)$ & $(33.0)$ & $(-6.4)$ & $(-22.6)$ \\
$\begin{array}{l}\text { Non-agric. } \\
\text { Products }\end{array}$ & 2125.0 & -335.9 & -244.4 & -406.5 \\
& $(1283.0)$ & $(4456.4)$ & $(-1450.7)$ & $(-1967.5)$ \\
Total & 2187.4 & -335.2 & -244.2 & -304.6 \\
& $(1329.0)$ & $(4593.3)$ & $(-1463.9)$ & $(-2025.2)$ \\
\hline
\end{tabular}

Note: Results under the APEC scenario are in parentheses.

Source: Model Simulation 
Table 5.28 Malaysia. Average Annual Import Changes Relative to the Baseline Scenario (US\$ million)

\begin{tabular}{lrrrr}
\hline Products & ASEAN & $\begin{array}{c}\text { Japan and } \\
\text { USA }\end{array}$ & EU & ROW \\
\hline $\begin{array}{lrrr}\text { Unprocessed } \\
\text { agric. products }\end{array}$ & 1191.9 & -27.7 & -2.1 & -195.6 \\
& $(9.7)$ & $(446.9)$ & $(0.4)$ & $(-290.1)$ \\
Processed agric. & 434.6 & -18.8 & -43.4 & -151.8 \\
Products & & & & \\
& $(-3.8)$ & $(8.3)$ & $(-7.1)$ & $(13.1)$ \\
Non-agric. & 9743.1 & -3314.6 & -1211.9 & -1999.8 \\
Products & & & & \\
& $(5791.8)$ & $(3787.7)$ & $(-2502.2)$ & $(-3452.4)$ \\
Total & 11369.6 & -3361.1 & -1247.5 & -2347.5 \\
& $(5797.8)$ & $(4243.0)$ & $(-2508.9)$ & $(-3729.3)$ \\
\hline
\end{tabular}

Note: Results under the APEC scenario are in parentheses

Source: Model Simulation

Table 5.29 Philippines. Average Annual Import Changes Relative to the Baseline Scenario (US\$ million)

\begin{tabular}{lrrrr}
\hline Products & ASEAN & $\begin{array}{c}\text { Japan and } \\
\text { USA }\end{array}$ & EU & ROW \\
\hline $\begin{array}{l}\text { Unprocessed } \\
\text { agric. products }\end{array}$ & 142.3 & -22.7 & -2.0 & -33.5 \\
& $(4.5)$ & $(214.0)$ & $(-1.9)$ & $(-49.9)$ \\
$\begin{array}{l}\text { Processed agric. } \\
\text { Products }\end{array}$ & 533.5 & -31.1 & -76.1 & -156.1 \\
Non-agric. & $(79.9)$ & $(31.8)$ & $(-23.1)$ & $(-21.3)$ \\
Products & 5142.1 & -2158.5 & -570.7 & -1406.1 \\
& & & & \\
Total & $(1991.7)$ & $(4300.6)$ & $(-1284.1)$ & $(-2889.9)$ \\
& 5817.9 & -2212.3 & -648.8 & -1595.6 \\
& $(2076.0)$ & $(4546.3)$ & $(-1309.2)$ & $(-2961.1)$ \\
\hline
\end{tabular}

Note: Results under the APEC scenario are in parentheses

Source: Model Simulation 
Table 5.30 Singapore. Average Annual Import Changes Relative to the Baseline Scenario (US\$ million)

\begin{tabular}{lrrrr}
\hline Products & ASEAN & $\begin{array}{c}\text { Japan and } \\
\text { USA }\end{array}$ & EU & ROW \\
\hline $\begin{array}{l}\text { Unprocessed } \\
\text { agric. products }\end{array}$ & 547.4 & -36.8 & -11.3 & -205.9 \\
& $(142.2)$ & $(87.5)$ & $(-7.2)$ & $(-123.9)$ \\
Processed agric. & 433.5 & -38.6 & -25.1 & -122.5 \\
Products & & & & \\
& $(-1.1)$ & $(0.5)$ & $(27.1)$ & $(28.4)$ \\
Non-agric. & 1765.8 & 2659.5 & 1050.1 & 1664.8 \\
Products & & & & \\
& $(2213.6)$ & $(-206.4)$ & $(724.7)$ & $(1195.8)$ \\
Total & 2746.7 & 2584.1 & 1013.7 & 1336.4 \\
& $(2354.7)$ & $(-118.3)$ & $(724.7)$ & $(1100.4)$ \\
\hline
\end{tabular}

Note: Results under the APEC scenario are in parentheses

Source: Model Simulation

Table 5.31 Thailand. Average Annual Import Changes Relative to the Baseline Scenario (US\$ million)

\begin{tabular}{lrrrr}
\hline Products & ASEAN & $\begin{array}{c}\text { Japan and } \\
\text { USA }\end{array}$ & EU & ROW \\
\hline $\begin{array}{l}\text { Unprocessed } \\
\text { agric. products }\end{array}$ & 182.8 & 12.9 & 0.1 & 17.0 \\
& $(29.6)$ & $(488.8)$ & $(-14.0)$ & $(-186.2)$ \\
Processed agric. & 735.1 & -47.7 & -53.8 & -192.6 \\
Products & & & & \\
& $(-59.1)$ & $(45.8)$ & $(-53.8)$ & $(-97.6)$ \\
Non-agric. & 18194.1 & -5046.9 & -2134.4 & -3371.0 \\
Products & & & & \\
& $(4727.4)$ & $(20116.2)$ & $(-7017.6)$ & $(-10273.2)$ \\
Total & 19112.0 & -5081.6 & -2188.1 & -3546.6 \\
& $(4697.9)$ & $(20650.8)$ & $(-7085.4)$ & $(-10557.0)$ \\
\hline
\end{tabular}

Note: Results under the APEC scenario in parentheses

Source: Model Simulation 


\section{5. Sensitivity Analysis}

As has been discussed in the section of the calibration procedure, one of the fundamental issues related to the use of CGE models is the selection of elasticity parameters. This is because the magnitude of models depends largely on such parameters used in the model. The selection of values of elasticity particularly in the case of a nested CES Armington structure as used in this study certainly affects the changes in trade structure. BROWN (1987) in HERTEL, IANCHOVICHINA and MCDONALD (1997) summarised two important conclusions regarding the use of Armington elasticity in the two-level nested CES Armington function. Terms of trade effects tend to decrease as $\operatorname{\sigma im}_{2}$ (substitution elasticity between sources of import) approaches infinite. However, the value of $\sigma m_{1}$ (elasticity substitution between domestic goods and import composite) has an ambiguous effect. Due to uncertainty about the appropriate values of substitution elasticities, it is then strongly recommended to carry out systematic elasticity analysis on these parameters. In addition, values of substitution elasticities provided by the GTAP consortium are found to be too low to capture changes in trade patterns over time (see GEHLHAR (1994) in ANDERSON, et al. 1997). It is found that doubling values of substitution elasticity in this procedure led to better prediction of historical changes in export share. Following this suggestion, the doubled Armington elasticities are then used to conduct a sensitivity elasticity analysis. To examine the impact of a change in the values of the Armington elasticities on the magnitude of the model, the simulation focuses mainly on the AFTA scenario.

It is important to stress here the likely impact of changing the values of elasticity substitution. As mentioned earlier, there are two types of Armington substitution elasticity. Increasing the value of elasticity substitution between sources of imports will imply that imports of certain goods from one trading country can quite easily be replaced by the imports from other trading country. Similarly, due to the increased values of elasticity substitution between domestic goods and import composite, domestic users in turn can easily substitute away domestic goods in favour of imported goods. As a result, it can be expected that export volumes and import volumes will increase. This is the reason for the need to of double the values of Armington substitution elasticities provided by the GTAP consortium. Maintaining the level of such elasticities will hamper the possibility of trade enhancement in the long run. 
To avoid very diverse numbers, the sensitivity analysis will focus on aggregated product levels (unprocessed agricultural, processed agricultural and non-agricultural products) in the selected AFTA countries: Indonesia, Malaysia and Thailand. Simulation results are presented in Table 5.31. In columns "AFTA" in each selected ASEAN countries, the simulation assumes no changes in values of trade substitution elasticity. In columns "High" values of such elasticities are doubled. Results suggest that by increasing the value of both elasticities outputs, exports and imports would be obviously increased, except for the case where output changes are already reduced under the unchanged (reference) substitution elasticities. For example, under the reference values of substitution elasticities outputs of unprocessed agricultural sector in Indonesia and Thailand rise by around $0.03 \%$ and $1.22 .8 \%$, relative to the baseline scenario. With the doubled values of such elasticities, outputs are projected to increase by $0.06 \%$ and $2.77 \%$, respectively. These patterns also apply for a case of outputs of other products.

Higher substitution elasticities induce the increase in export and imports of most products. Exports and imports of agricultural products are expected to significantly rise. Exports of unprocessed and processed agricultural products in Malaysia would increase by around $16.7 \%$ and $6.7 \%$, respectively, relative to the baseline scenario. These numbers are twice compared to export changes under the reference case (AFTA scenario). Similarly, Indonesian exports of unprocessed and processed agricultural products increase significantly compared to export changes under the unaltered values of trade substitution elasticity. For instance, exports of both products in Indonesia are projected to rise by $2.43 \%$ and $3.10 \%$, respectively. Increases in exports in ASEAN member countries with higher values of trade substitution elasticity reflect that importing countries more readily substitute among alternative foreign suppliers. Give higher substitutability among sources of imports, the simulation results in increases in total imports in the selected ASEAN member countries (Indonesia, Malaysia and Thailand). With unaltered values of trade substitution elasticities, total imports of processed agricultural products in Indonesia, Malaysia and Thailand are expected to rise by $2.77 \%, 4.26 \%$ and 4.93 $\%$, respectively, relative to the baseline scenario. By increasing values of such elasticities, the imports of these products in these countries increase by $5.66 \%, 8.34 \%$ and $13.00 \%$, respectively. These changes are almost doubled compared to the reference case. Similar patterns apply for other products, however with different magnitudes. 
Concentrating on the value of elasticity of substitution between domestic goods and import composite, high values of this elasticity will cause a large responsiveness of the import composite-domestic goods ratio to small changes in their relative price. Given decreased import prices as a result of reducing border tariff levels and high values of the elasticity substitution, it can be expected that demand for imports will rise. Likewise, increased values of elasticity of substitution among sources of imports and the responsiveness of the ratio of imports from different suppliers to small changes their price ratio are very great. In other words, given higher such elasticities, imports from one exporting country can easily replace imports from other exporting countries despite the fact that import price ratio changes marginally. Therefore, the robustness of the simulation results of the model applied in this study is subject to the selected exogenous parameters (values of substitution elasticities). This indicates substitution elasticities play a very important role in determining simulation results. These findings are also parallel to BROWN (1987), cited in HERTEL, IANCHOVICHINA and MCDONALD (1997), insisting that the magnitude of trade effects vary substantially with the substitution elasticities. In addition, FRANCOIS (1996), cited in HERTEL, IANCHOVICHINA and MCDONALD (1997) suggests that gains to all participating countries in all regional trading arrangement can be attributed to the Armington parameters. 
Table 5.32 Average Changes in Aggregate Production, Export and Import with High Armington Elasticities

\begin{tabular}{|c|c|c|c|c|c|c|}
\hline & \multicolumn{2}{|c|}{ Indonesia } & \multicolumn{2}{|c|}{ Malaysia } & \multicolumn{2}{|c|}{ Thailand } \\
\hline & AFTA & High & AFTA & High & AFTA & High \\
\hline \multicolumn{7}{|l|}{ Production } \\
\hline $\begin{array}{l}\text { Unprocessed } \\
\text { agric. products }\end{array}$ & 0.03 & 0.06 & -0.01 & -0.46 & 1.22 & 2.77 \\
\hline $\begin{array}{l}\text { Processed } \\
\text { agric. products }\end{array}$ & 0.39 & 0.96 & 1.07 & 1.24 & -0.29 & -0.86 \\
\hline $\begin{array}{l}\text { Non-agric. } \\
\text { Products }\end{array}$ & 0.00 & 0.01 & 0.34 & 0.60 & -0.03 & -0.01 \\
\hline \multicolumn{7}{|l|}{ Export } \\
\hline $\begin{array}{l}\text { Unprocessed } \\
\text { agric. products }\end{array}$ & 2.43 & 5.40 & 8.75 & 16.65 & 5.18 & 13.56 \\
\hline $\begin{array}{l}\text { Processed } \\
\text { agric. products }\end{array}$ & 3.10 & 7.86 & 3.89 & 6.69 & 1.04 & 2.62 \\
\hline $\begin{array}{l}\text { Non-agric. } \\
\text { Products }\end{array}$ & 0.63 & 1.33 & 1.75 & 3.00 & 1.46 & 2.57 \\
\hline \multicolumn{7}{|l|}{ Import } \\
\hline $\begin{array}{l}\text { Unprocessed } \\
\text { agric. products }\end{array}$ & 1.06 & 1.66 & 4.33 & 5.97 & 2.94 & 6.63 \\
\hline $\begin{array}{l}\text { Processed } \\
\text { agric. products }\end{array}$ & 2.77 & 5.66 & 4.26 & 8.34 & 4.93 & 13.00 \\
\hline $\begin{array}{l}\text { Non-agric. } \\
\text { Products }\end{array}$ & 1.48 & 2.63 & 1.86 & 2.93 & 0.82 & 0.79 \\
\hline
\end{tabular}

Source: Model Simulation. 


\section{Chapter VI}

\section{Conclusions and Implications}

The ASEAN member economies have been pursuing different economic co-operation in order to enhance trade among the members. In 1977 an ASEAN Preferential Trading Arrangement (PTA) was established. Due to limited product coverage and a lack of pro-competitive environment, the ASEAN PTA did not bring about what the members expected. A successful history of the integration of Europe (European Union) and the challenge of North American Free Trade Area have forced the ASEAN member countries to re-evaluate their past cooperation and to strengthen their own co-operative arrangement. The establishments of the European Single Market 1992 and NAFTA would affect the economic structure (trade) of the ASEAN countries. Driven by the emerging markets in several regions such as China and Southeast Asia, intra-regional trade among ASEAN has been profound. The flows of intraregional investment have also complemented the growth of intra-regional trade in reinforcing the inter-dependence of ASEAN economies. In response to the more open world economy, economic deregulation and trade liberalisation provide a solid foundation for the success of regional co-operation. Therefore in 1992 the ASEAN nations reviewed their past and current trade agreement and agreed to move to a deeper economic co-operation by establishing the socalled ASEAN Free Trade Area (AFTA).

The establishment of AFTA, however, raises criticisms and concerns whether AFTA tariff would boost intra AFTA trade. A similarity in natural endowment, diverse in economic development within the ASEAN member countries and a high dependency of their trade on other trading partners such USA, Japan and EU would impede and prohibit trade among the members. In addition, the 1992 agreement also excluded agricultural products from tariff reduction. Therefore, the effectiveness of the establishment of AFTA was overwhelmingly questionable. Despite the fact that the member reviewed the 1992 AFTA agreement and decided to include unprocessed agricultural products in the CEPT scheme, Indonesia and Malaysia expressed their concerns over the possible impact of the AFTA on millions of farmers. 
However, simulation results, particularly the results of the AFTA scenario, contradict the perception that the AFTA plan would have a limited impact on enhancing trade in this region. Results of the AFTA trade liberalisation shows that the AFTA scenario is trade creating and could expand trade among the ASEAN members. For example, a net trade creating effect occurring in Indonesia and Philippines under this scenario would be approximately US\$ 1303 million and US\$ 1361 million. These countries would also have a net trade creating effect in the agricultural sector however with a minor magnitude. Expanding trade liberalisation attempts into a wider scope (the APEC scenario), trade creating effects would outweigh trade diverting effects, except for Singapore. This is due to its relatively low initial import tariffs where the other APEC members (USA and Japan) would have more markets accesses to the other ASEAN member countries.

By using a recursive dynamic multi-region computable general equilibrium, trade liberalisation pursued by the ASEAN countries such as global multilateral agreement under the auspices of WTO, ASEAN Free Trade Area (AFTA), and Asia Pacific Economic Cooperation (APEC), would improve their economy at whole. Under the Uruguay Round and the Millennium Round, real GDP in all ASEAN member countries is expected to rise, Singapore and Malaysia would experience higher real GDP growth than on average over the ASEAN countries. On the other side, real GDP growth in the Philippines is projected to grow less than the average. Likewise real GDP in all ASEAN member countries is projected to further increase under the AFTA scenario. Compared to real GDP increases in the other ASEAN member countries, Indonesia would have the lowest real GDP rise in response to AFTA trade liberalisation. This is due to the fact that Indonesia had relatively low trade barriers. However, Indonesia would gain from the growing export resulting from better market access to other ASEAN countries. This would affect an increase in real GDP in this country. Under the AFTA scenario, Singapore and Malaysia would become the primary beneficiaries of trade liberalisation among the ASEAN countries when import barriers are lowered in the three highly protected countries. When extending the simulation into the APEC scenario, Singapore's real GDP is expected to increase by less than what might otherwise occur under the AFTA scenario. In other words, Singapore would no longer be the primary beneficiary with the trade liberalisation extended to the APEC members. Given the relatively low import tariffs imposed in this country, the tariff reduction under the APEC 
scenario would not significantly affect the current tariff levels. As a result, domestic demand in Singapore for imports from other countries would be limited.

Trade would expand in line with the expansion of real GDP in the economies of ASEAN. Under the AFTA scenario, the Philippines would experience larger exports, followed by Singapore and Malaysia. Likewise, widening the trade liberalisation within APEC nations would cause exports in the ASEAN region to grow, particularly in Thailand and the Philippines. In both countries, the changes in exports under the APEC scenario are nearly doubled, compared to the export changes under the AFTA scenario. The reason why Thailand and the Philippines gain more is that they are making greater liberalisations than the other members compared to their initial trade barriers. A large reduction in import tariffs sharply reduces the domestic price of intermediate inputs and production factors, causing a significant decline in domestic costs. This thereby improves the competitiveness and export expansion. The greater increase in the export under the APEC scenario reflects that in the coming years, ASEAN trade would continue to expand faster when the economies in the ASEAN region are further integrated into the APEC region.

Under the AFTA trade liberalisation, rice output in the ASEAN member countries with the exception of Thailand is projected to shrink. The rise in rice output in Thailand is not surprising. Thailand is the largest rice-exporting country. That rice output in Thailand expands in response to trade liberalisation is associated with the nature of the policy change in Thailand where the rate of protection was low before liberalisation compared with the policy change in other ASEAN countries. The increase in import demand for rice in other ASEAN member economies, resulting from the reduced import tariffs will stimulate the Thai rice sector to expand. With regard to output changes in the other unprocessed agricultural sectors, such as cereals, oil seeds, livestock and other crops, the results suggest that the AFTA trade liberalisation would have a low impact on the output of the Indonesian agricultural sectors. Across ASEAN member countries, cereal output in Malaysia, the Philippines, Singapore and Thailand is estimated to grow considerably, particularly in Singapore and Thailand. Different patterns of the sectoral output changes under the APEC trade liberalisation would occur. APEC would have a small impact on the output of unprocessed agricultural product. Related 
to processed agricultural sectors, processed meat and milk sectors in Malaysia and the Philippines are expected to expand more than other processed agricultural sectors.

With respect to the non-agricultural sectors, the AFTA scenario would lead to small sectoral output changes in Indonesia and Thailand. All outputs are projected to alter by less than $1 \%$, relative to the baseline scenario. By contrast, textile, mining and mineral products and manufacturing outputs in the Philippines would rise considerably. It is interesting to see that the output of the textile sector is projected to grow as a result of a further reduction of the import tariff rates. There are some factors affecting such increases in the output of this sector. With the continual income growth over time, the demand for this product is projected to rise. This stimulates the increase in output of this sector. Given the relatively high income elasticities for this product, the increased income induces the demand for textile products to rise. The expansion of this sector is also due to the availability of cheaper imports that are used by the sector as intermediate inputs following the trade liberalisation. This figure suggests that most ASEAN member economies have a comparative advantage in this sector due to their relatively cheap labour.

The AFTA tariff reduction would cause an increase in exports in most ASEAN economic sectors. Focusing on the export changes in the agricultural sectors, it is reported that the cereal and processed milk sectors are predicted to have noticeable increases in their exports. In the period of 2004-2010 average annual cereal export changes range from around $7 \%$ in the Philippines to $187 \%$ in Thailand. Extending to the impact of the APEC trade liberalisation, the results show that more progressive tariff reduction would cause a relatively large increase in the exports of unprocessed agricultural products, particularly in Indonesia and Singapore. With regard to exports of processed agricultural products, exports of processed meat and processed milk would tend to rise further. For example, the exports of both commodities in Thailand would markedly rise by around $30 \%$, compared with the level in the baseline scenario. Likewise, the impact of APEC trade liberalisation on the export of non-agricultural products, especially textiles is significant. In other words, this sector would benefit from the APEC liberalisation. Therefore, it is not surprising that more progressive trade liberalisation would cause this industry to continuously expand. 
As import tariff levels are completely removed, the demand for imported goods would certainly be increased. This is because domestic consumers (private consumers and industries) would face decreasing domestic prices. However, the size of import changes depends on the initial tariff rates. The higher the initial intra-regional tariffs, and the larger the tariff cuts, the higher the gains from the trade creation. Following the reduction of intraASEAN tariffs, imports of these products would be significantly increased. Reducing import tariff rates for products imported from the APEC members (USA and Japan) would not affect imports very much. This is because the ASEAN countries are not required to completely remove their border tariffs in 2010. However, related to changes in imports of manufacturing under the APEC scenario, this would have a positive economic implication for the economy. Given the relatively low market prices for imported capital goods or intermediate inputs, the demand for these goods would be increased. This would decrease production costs and induce the rise in output. Therefore, it can be expected the industries would expand.

Based on the macroeconomic parameters such as real GDP, total export and total import, the AFTA trade liberalisation should be speeded up. The analysis of trade-creating effect and trade-diverting effect also suggest that trade liberalisation under the CEPT scheme trade creation outweighs trade diversion. However, since the trade liberalisation would have adverse effects on the uncompetitive producing sectors, adjustment assistance is highly recommended in order to compensate for any losses; for instance, reduced farm incomes. Apart from compensating for reduced incomes, adjustment assistance is also needed to promote and re-structure the inefficient sectors. Therefore, it is hoped that with such assistance the sectors could cope with the dynamic changes by, for instance, re-arranging production technologies. In terms of adjustment in labour market the government may improve rural labour market by providing better information on job availabilities and opportunities, and appropriate training for unemployed rural labour. This training is given to such labour in order them to find new jobs in off-farm activities. Empirical data show that agricultural sectors in the ASEAN countries and also in developing economies are characterised with the so-called disguised unemployment. It is hoped agricultural productivity could improved resulting from re-allocation of rural labour. Another adjustment needed to increase farmer's income is the amalgamation of small farmer in order to achieve greater economies of scale (RAHMAN, 1997). This in turn enables farmers to apply appropriate 
mechanisation, efficient uses of fertiliser and pesticide, low hiring of labour and effective farming management. Finally it could result in low production cost and hence improving agricultural competitiveness in relation to facing imported agricultural products.

Concerns over the future of millions of farmers that might be negatively affected are found to have no fundamental reasons. Despite a decline in some of agricultural output it seems that both AFTA would not have a significant impact of farmer's welfare. Concerning rice farmers in Indonesia, Malaysia and the Philippines, rice output in the period 2004-2010 would decline very marginally. Recalling the AFTA simulation results, rice sector in these countries is predicted to contract by 0.1 percent (Indonesia), 1.7 percent (Malaysia) and 1.4 percent (the Philippines). In the current discussion particularly in Indonesia, rice price tends to decline not due merely to the trade policy carried out by the government. The decline in the rice price corresponds largely with the excess supply of rice during the harvest season and rice smuggling. These in turn will depress the rice price in the domestic market. In the short run, to reduce the continuing decline in the rice price, the government could use an appropriate import management policy. Rice importers are only allowed to import rice during off-harvest season. During off-harvest season the rice price tends to rise and market operation to reduce the rice price does not exist any more, the government might allow the rice importers to import rice from abroad. However in the long run, the government policy to increase efficiency in the rice production is the only appropriate policy. This policy among others includes agricultural diversification and rural development strategy. This agricultural diversification policy is sensible. This is because the simulation results show that cereal output in Indonesia, Malaysia and Thailand is estimated to expand. However, cereal production under the current agricultural policy is not one of the highest priorities. When taking production strategy on this sector, agricultural or rural labour may move from the rice sector to the cereal sector. This movement of such labour in rural area is not so problematic. Rural labour market operates perfectly. If this movement took place, wage from the cereal sector could compensate rural household income for their lost from the rice sector. However, the APEC liberalisation would have a negative impact on the cereal sector especially in Malaysia and the Philippines. It seems that the program of increasing cereal production in both countries in future is not economically feasible. These countries would have no comparative advantage in producing cereal. Cheaper cereals from the APEC members (USA or Australia/New Zealand) 
would replace the domestic production. Farmers in these countries would face difficulties copying with the increased cereal imports from the APEC members. Two alternative policies are required in response to the increased cereal imports. In terms of wheat imports, the countries will further rely on import. This is because the countries have no comparative advantages in growing wheat. Opening market access for wheat product does not harm wheat farmers. Concerning other cereal products such corn the government could take price policy to assist corn farmers from their reduced incomes. The Malaysian and Thai governments could provide floor price mechanism to absorb farmer's excess supply. This policy however will have fiscal burden. The government also cannot rely on state-owned marketing agencies to purchase such excess supply. Under the WTO agreement, state-owned marketing agencies lose their monopoly power. In the long run, an increase in the corn productivity seems the only strategy to compete with imported corn.

The only sector would gain from the APEC liberalisation is the oil seed sector. The gain from the APEC trade liberalisation for oil seeds corresponds with the fact that the ASEAN members especially Indonesia and Malaysia are the largest producers and exporters of crude palm oil (CPO) in the world. This sector accounts for the second largest export earnings after manufactured products. The question to answer is whether this sector could absorb primary factors such as labour and agricultural land from all other contracting agricultural sectors. If this sector is limited to absorb these primary factors, it can be predicted rural household income would further decline. If the government is persistently determined to support the agricultural sector, the strategy of improving the efficiency of the agricultural production is the only choice.

The simulation results also indicate that unskilled labour intensive industries like textile sector in all the ASEAN economies would expand resulting from the reduced trade barriers. The rise in the textile output is not merely related to the widening market access in the region. The increase in the export competitiveness also corresponds with the reduced cost of production due to cheaper intermediate inputs. The textile output and export would further expand following the reduce trade barriers under the APEC scenario. Manufactured products are also estimated to go up under the same scenario. This positive change support the objective of the elimination of tariff and non-tariff barriers under the AFTA trade liberalisation. By referring 
to the ASEAN secretariat's statement, MAULE (1996) said that the AFTA agreement is expected to have the effect of making ASEAN's manufacture sector more efficient and competitive in the global market and therefore making ASEAN economies more attractive for multinational companies to invest in the region. In addition, consumers at the same time will have cheaper goods sourcing from the most efficient producers. This results in creating intraASEAN trade. The policy implication reveals that industrialisation which has been one of the prime development strategies pursued by the ASEAN economies should be focused on how to absorb labour excess supply, especially unskilled labour supply. By removing rural labour to the urban sectors it is hoped that agricultural production per labour will increase. This also indicates that the ASEAN members should be actively involved in negotiating the reduction in trade barriers either at the regional level or the multilateral level. By freeing up their market to the imported products the members can gain or benefit from the technological spill over. Despite the fact that this issue is not elaborated in this study, many suggest the spill over can affect the production method thereby improving their industrial competitiveness.

Apart from changes in the trade policy, trade liberalisation under the multilateral agreement might result in larger economic benefit rather than limited regions involved. From the view of economic theory, economic benefit or welfare will be larger if a number of countries included in the trade liberalisation are large enough. These results however do not undermine the AFTA trade liberalisation. In fact, the AFTA provides a strong basis for facing a wider trade liberalisation. In addition ASEAN is considered as one of most successful regional integration among developing countries. The next question to be answered is whether the AFTA agreement is politically feasible. The AFTA plan receives political supports from policy makers in the region. In response to the slow growth of investment the leaders launched the ASEAN Investment Area (AIA) to attract foreign investment

The inclusion of sectors to the ESVL trade liberalisation reflected the interests of the exporters in the APEC members. However during the negotiation the resistance of domestic producers who will compete with imports emerged (YARNAZAWA, 1999). In addition product by product trade liberalisation does not fit with the WTO trade liberalisation (OXLEY, 1999). The submission of the ESVL to the WTO according to the Kuala Lumpur Summit might be an effective political strategy to show that the APEC trade liberalisation is in line with the WTO 
trade liberalisation. Concerns arise whether this proposal can secure the on-going liberalization. The wider the liberalised sectors, the larger the benefits accruing to the members. The APEC scenario suggests the members would benefit when the trade liberalization were extended to all sectors, not selected products. Therefore the ASEAN members, together with other APEC members should pursue a wider sector liberalisation. It is acknowledged that import tariff rates for agriculture and manufacture are quite high either in developed countries or developing countries. Bringing them down to zero near 2010 for developed countries and 2010 for developing countries is feasible. In addition, this process would contribute to speeding up the liberalization under the auspice of the WTO.

Another intriguing question concerning the development of the AFTA is whether the AFTA trade liberalisation is politically feasible. Non-discriminatory approach is the best option for the ASEAN members. The members would maximise the benefit of regional integration. This approach also avoids trade diversion and trade depletion. However, looking back at one of the AFTA objectives that the AFTA agreement could be considered as a pace of integrating the region to the global economy, one can argue that the AFTA trade liberalisation would be feasible. Despite some objections from private sectors, the agreement received remarkable strong political supports from the ASEAN leaders. In response to the financial crisis, the leaders agreed to speed up the AFTA one year ahead. Trade barriers were reduced by 2002, not 2003. Concerns might emerge when extending the AFTA into countries in transition, especially Myanmar, Cambodia and Laos. The difference in economic development among the members becomes wider. It seems the benefits are distributed among members unevenly. To accommodate such concerns the countries above have given longer period in implementing the CEPT scheme. But as the country is not ready enough to face the competing imported products, the country might postpone trade liberalisation for products that are highly sensitive or are found vulnerable. It has already happened as Malaysia postponed their market access for automotive industries and Indonesia applied for including sugar as its highly sensitive products. The AFTA itself provides mechanism to accommodate such disputes by using the so-called safeguard protocol. If the countries in transition with some reasons also applied for the same problem, the AFTA trade liberalisation would encounter difficulties in promoting trade and investment in the region. The members should not focus solely on the elimination of trade barriers. Trade facilitation and harmonisation should be given to these countries. The members should also set a mechanism how to provide compensation for countries that might 
be negatively affected by the CEPT scheme. In addition, a lack of trade policy harmonisation would result in limited benefit of the AFTA trade liberalisation received by the members.

To accelerate trade among members, the members should diversify their attention not merely on enhancing regional investment. It seems that AFTA is described as more investment pact than a trade pact (PLUMMER, 1997). The members should also deepen trade liberalising by removing other trade barriers such as export subsidies and domestic support. One may argue that export subsidies are not a popular trade policy undertaken by the governments. ASEAN countries like other developing countries are always practising export taxes in order to raise government revenue.

Regarding the political feasibility of the APEC trade liberalisation, it is worth noting what DAMOND (2003) pointed out. In a pace of liberalising trade and investment in the APEC region, several collective and individual actions plan have been finalised. To accelerate the reduction of trade barriers, selected products are then included in the early voluntary sectoral liberalisation (ESVL). Focusing largely on certain products and lack of close sustained intention, trade liberalisation seems politically feasible in a limited amount. Another factor affecting the limited benefit is that there is no clear determination whether APEC is perceived as a nascent FTA or a catalyst for global liberalization. This in turn affects most APEC members not to take part fully in deep trade liberalisation. APEC trade liberalisation seems to focus mainly on industrial or high-tech products as seen from products or sectors included in the EVSL program. And further liberalising agricultural sector remains unclear. The United States in the context of APEC is unwilling to forgo further in terms of liberalising her agricultural trade regime. With the exception of reduction or elimination of import duties other trade measures remain WTO agenda.

Concerning the CGE model used in this study, the modelling apparatus can be regarded as a useful policy tool in the analysis of the impact of trade liberalisation involving many sectors and countries or regions. Given the complexity of real economies, such a model will serve and provide the understanding of the interaction between production, export and import activities. Using this model, the impact of policy options on the macroeconomic indicators such as real GDP, real wages and investment can also be traced. 


\section{References}

Acar, M. and R. McDougall. (1998). Agricultural Protection non-OECD Countries. In Global Trade, Assistance, and Protection, The GTAP Data Base, edited by Mc Dougall, R.A., A. Elbehri., and T.P. Truong (1998). Center for Global Trade Analysis. Purdue University.

Adelman, I. and S. Robinson. (1978). Income Distribution Policy in Developing Countries. A Case Study of Korea. Standford University Press.

Akrasanee, N. and D. Stifel. (1992). The Political Economy of the ASEAN Free Trade Area. In AFTA: The Way Ahead, edited by Naya, S and P. Imada. Institute of Southeast Asian Studies. Singapore.

Anderson, K. (1995). Agricultural Competitiveness After the Uruguay Round. Review of Marketing and Agricultural Economics 63 (3),

Anderson, K., B. Dimaranan., T.W. Hertel and W. Martin. (1997). Asia-Pacific Food Markets and Trade in 2005: A Global, Economy-Wide Perspective. Australian Journal of Agricultural and Resource Economics 41(1):19-44.

Armington, P.S. (1969). A Theory of Demand for Products Distinguished by Place of Production. IMF Staff Papers 16.

Arndt, C., T.W. Hertel., B. Dimaranan., K. Huff and R. McDougall. (1997). China in 2005: Implications for the Rest of the World. Journal of Economic Integration 12(4):505-547.

Asian Development Bank. (2000). Asia Development Outlook 2000 Update. Manila

Athukorala, P. and J. Menon. (1996). Foreign Direct Investment in ASEAN: Can AFTA Make a Difference. In AFTA in the Changing International Economy. edited by Tan, J. Institute of Southeast Asian Studies. Singapore.

Austria, M. S. (2000). Philippine Productivity Performance in the 1990s: An Assessment. Discussion Paper Series No. 2000-28. Philippine Institute for Development Studies.

Bach, C. F. and S. E. Frandsen. (1998). European Integration and the Common Agricultural Policy. The Danish Institute of Agricultural and Fisheries Economics.

Balassa, B. (1961). The Theory of Economic Integration. George Allen Unwin Ltd. London.

Baldwin R.E. (1989). The Growth Effects of 1992. Economic Policy:. 2, pp. 247-281.

Ballard, C.L., D. Fullerton, J.B. Shoven and J. Whalley. (1985). A General Equilibrium Model for Tax Policy Evaluation. Universty of Chicago Press for the National Bureau of Economic Research. Chicago. 
Banse, M. (1997). Die Analyse der Transformation der Ungarischen Volkwirtschaft. Eine Empirische Allgemeine Gleichgewichtsanalyse unter Besonderer Berücksichtigung des Agrarsektors und der Ernäahrungsindustrie. Dissertation zur Erlangung des Doktogrades des Fachbereichs Agrarwissenschaften der Georg-August Universität Göttingen.

Banse, M. (1999). Impacts of EU-accesssion on Consumers' Welfare in Central European Countries. Paper in Second Annual Conference on Global Economic Analysis June 2022, 1999 Denmark

Beghin, J. (1996). General Equilibrium Modelling of Trade and the Environment. Technical papers:116. OECD Development Centre. Paris.

Bergsten, C.F. (2001). Fifty Years of Trade Policy: The Policy Lessons. The World Economy 24(1):1-14.

Bettendorf, L. (1994). A Dynamic Applied General Equilibrium Model for a Small Open Economy. Leuven : Univ.

Blonigen, B.A., J.E. Flynn, and K.A. Reinert. (1997). Sector-Focused General Equilibrium Modeling. In Applied Methods for Trade Policy Analysis. A Handbook edited by Francois, J. F., and K. A. Reinert. Cambridge University Press.

Bosworth, B. and S.M. Collins. (1999). From Boom to Crisis and Back Again: What Have We Learned ?. (Draft). Paper presented fo Workshop on Development Paradigms, 10 December 1999. Asian Bank Development Institute (ADBI).

Brown, D.K., A.V. Deardorff, and R.M. Stern. (2000). CGE Modeling and Analysis of Multilateral and Regional Negoitiating Option. Paper presented in the Conference of Issues and Options for the Multilateral, Regional, and Bilateral Trade Policies on the United States and Japan. October 5-6, 2000 in Michigan University. Ann Arbor, Michigan, United States of America.

Brown, D.K., A.V. Deardorff, and R.M. Stern. (2000). CGE Modeling and Analysis of Multilateral and Regional Negoitiating Option. Research Seminar in International Economics. Discussion Paper No. 468. School of Public Policy. The University of Michigan. Ann Arbor, Michigan, United States of America.

Burniaux, J.M., J. P. Martin, G. Nicoletti and J.O. Martins. (1992). GREEN. A Multi-sector, Multi-region Dynamic General Equilibrium Model for Quantifying the Costs of Curbing $\mathrm{CO}_{2}$ Emissions: A Technical Manual. Working Paper no. 116. Economic Department. Organisation for Economic Co-operation and Development. Paris.

Chan, K. K. And J. B. Nugent. (1998). Factor Endowment, Trade Liberalization and the Future of APEC Trade Patterns. Paper Presented at the 73rd Annual WEA International Conference, June 29, 1998. Lake Tahoe Nevada. 
Chang, C. and S. Hsu. (1999). A Partial Equilibrium Analysis on the Effects of Trade Liberalization in APEC Food Sector. Paper presented at the Conference on Towards APEC's Second Decade: Chalanges, Oppoetunities and Priorities. 31 May - 2 June, 1999. Auckland, New Zealand.

Chatterjee, S. (1990). Asean Economic Co-operation in the 1980s and 1990s. in Asean into the 1990 edited by Broinowski, A. Macmillan Press Ltd. London.

Chirathivat, S. (1996). ASEAN Economic Integration with the World through AFTA. In AFTA in the Changing International Economy. edited by Tan, J. Institute of Southeast Asian Studies. Singapore.

Coe, D.T., E. Helpman and A.W. Hoffmmeister. (1997). Notz-South R\&D Spillovers. The Economic Journal (107):134-149.

Coyle, W.T. and Z. Wang. (1998). Open Regionalism in APEC: Impacts on US and the World. Paper presented at the International Agricultural Trade Research Consortium Annual Meeting, December 13-15, 1998, St. Petersburg, Florida, USA.

Crafts, N. (1999). East Asian Growth Before and After the Crisis. IMF Staff Papers 46(2):139166.

Damond, J. M. (2003). The APEC Decision Making Process for Trade Policy Issues: The Experience and Lessons of 1994-2001.

Davis, L., W. McKibbin, and A. Stoeckel. (2000). Economic Benefits from an AFTA-CER Free Trade Area. Year 2000 Study. Center for International Economics. Canberra and Sydney.

Deaton, A. and J. Muellbauer. (1980). Economics and Consumer Behavior. Cambridge University Press: Cambridge.

De Melo, J and Panagriya, A (edts). (1993 ). Introduction. In New Dimensions in Regional Integration, edited by De Melo, J and Panagriya (1993), A. Cambridge University Press.

De Melo, J., A. Panagriya and D. Rodrik. (1993). The New Regionalism: a Country Perspective. In New Dimensions in Regional Integration, edited by De Melo, J and A. Panagriya. Cambridge University Press.

De Melo, J.A.P. and K. Dervis. Moelling the Effects of Protection in a Dynamic Framework. Journal of Development Economics 4(1977) p.149-172.

DeRosa, D.A. (1995). Regional Trading Arrangements Among Developing Countries: The ASEAN Example. International Food Policy Research Institute. Washington, D.C.

Dervis, K., J. De Melo and S. Robinson. (1982). General Equilibrium Models for Development Policy. A World Bank Research Publication. Cambridge University Press. New York. 
Diao, X., T. Roe and A. Somwaru. (2001). What is the Cause of Growth in Regional Trade: Trade Liberalisation or RTAs? The Case of Agriculture . The World Economy 24(1):5180.

Dimaranan, B. (1998). Capital Stock and Depreciation. In Global Trade, Assistance, and Protection: the GTAP 4 Data Base, edited by R.A. McDouglass, A. Elbehri and T.P. Truong (1998). Center for Global Trade Analysis. Purdue University.

Dinwiddy, C.L. and Teal, F.J. (1988), The Two-Sector General Equilibrium Model - A New Approach. Oxford / New York: Phillip Allen / St. Martin's Press.

Dixon, P.B., J. Sutton and D.P. Vincent. (1982). ORANI: A Multisectoral Model of the Austrealian Economy. Contribution to Economic Analysis. North-Holland.

Drysdale, P. (1988). International Economic Pluralism: Economic Policy in East Asia and the Pacific. Columbia University Press. New York.

Felipe, J. (1997). Total Factor Productivity Growth in East Asia: A Critical Survey. EDRC Report Series No. 65. Asian Development Bank (ADB). Manila.

Felipe, J. (1999). Total Factor Productivity Growth in East Asia: A Critical Survey. The Journal of Development Studies 35(4):1-41.

Feridhanusetyawan, $\mathrm{T}$ (1998). The Impacts of Trade Liberalization on Welfare and Employment in ASEAN. Working Paper 98.05. ACIAR Indonesia Research Project. Adelaide University. Adelaide.

Feridhanusetywan, T., M. Pangestu and Erwidodo. (1999). The Benefits of Agricultural Liberalization in Asia Pacific. Working papaer 99.02. ACIAR Indonesia Research Project. Adelaide University. Adelaide.

Fields, G.S. (1977). Rural-Urban Migration, Urban Unemployment and Underemployment, and Job-Search Activity in LDCs. Journal of Development Economics 2 (1977) p. 165187.

Filho, J. B. D. F. (1999). Trade Creation $X$ Trade Diversion: Evidences from the GTAP Model in the MERCOSUR Integration Process. Paper presented in Second Annual Conference on Global Economic Analysis. June 20-22, 1999. Denmark.

Foroutan, F. (1993). Regional Integration in Sub-Saharan Africa: Past Experience and Future Prospects. In New Dimensions in Regional Integration, edited by De Melo, J and A. Panagriya (1993). A. Cambridge University Press.

Francois, J.F., B.J. McDonald and H. Nordström. (1996). Liberalization and Capital Accumulation in the GTAP Model. GTAP Technical Paper No 7. Purdue University. USA. 
Francois, J.F., B.J. McDonald and H. Nordström. (1997). Capital Accumulation in Applied Trade Models. In Applied Methods for Trade Policy Analysis. A Handbook, edited by Francois, J.F. and K.A. Reinert (1997). Cambridge University Press.

Francois, J.F. and K.A. Reinert. (1997). Applied Methods for Trade Policy Analysis. A Handbook. Cambridge University Press. United Kingdom.

Francois, J., and A. Strutt. (1999). Post Uruguay Round Tariff Vectors for GTAP Version 4. Memo, June.

Freeman, F., Mélanie, J., Roberts, I., Vanzetti, D., Tielu, A., and Beutre, B. (2000). The Impact of Agricultural Trade Liberalisation on Developing Countreis. ABARE Research Report 200.6, Canberra.

Frisch, R. (1959). A Complete Scheme for Computing All Direct and Cross Demand Elasticities in A Model with Many Sectors. Econometrica (27): 177-196.

Gelhar, M.,D. Gray., T.W. Hertel., K.M. Huff., E. Ianchovichina., B.J. McDonald., R. McDougall, M.E. Tsigas. and R. Wilge. (1997). Overview of the GTAP Database. In Global Trade Analysis. Modeling and Applications, edited by Hertel, T.W (1997). Cambridge University Press. New York

Genberg, $\mathrm{H}$ and Nadal de Simone, F. (1993). Regional Integration Agreements and Macroeconomic Discipline. In Regional Integration and the Global Trading System, edited by Anderson, K and Blackhurst, R (1993). St. Martin’s Press. New York.

Gilbert, J., R. Scollay and T. Wahl (2000). The APEC Food System: Implications for Agricultural and Rural Development Policy. The Developing Economies, 38(3):308329.

Goulder, L.H. and B. Eichengreen. (1989). Trade Liberalization in General Equilibrium: Intertemporal and Inter-Industry Effects. Working Paper No. 89-110. University of California Berkeley.

Grennway, D. (1983). International Trade Policy. From Tariffs to the New Protectionism. The Macmillan Press Ltd. London. UK.

Gunning, J.W. and M.A. Keyzer. (1995). Applied General Equilibrium Model for Policy Analysis. In Handbook of Development Economics, Volume III, edited by Behrman, J. and T. N. Srinivasan (1995). Elsevier Science B.V. Amsterdam.

Hanoch, G. (1975). Production and Demand Models in Direct or Indirect Implicit Additivity. Econometrica 43:395-419.

Hanslow, K., T. Phamduc and G. Verikios. (1999). The Structure of the FTAP Model. Staff Research Memorandum. Australian Productivity Commission . 
(http://www.pc.gov.au/research/memoranda/ftap/)

Harris, R.G. (1986). Market Structure and Trade Liberalization: A General Equilibrium Assessment. In General Equilibrium Trade Policy Modeling, edited by Srinivasan, T.N., and J. Whalley, J. (1986). Proceedings of a Conference on General Equilibrium Trade Policy Modeling, held at Columbia University in April 1984. The MIT Press Cambridge, Massachusetts.

Harrison, G. and L. Kimbell. (1985). Economic Interdependence in the Pacific Basin: A General Equilibrium Approach. In New Development in Applied General Equilibrium Analysis, edited by Piggot, J. and J. Whalley. (1985). Cambridge University Press. Cambridge.

Harrison, G.W. (1986). A General Equilibrium Analysis of Tariff Reductions. In General Equilibrium Trade Policy Modeling, edited by Srinivasan, T.N., and J. Whalley (1986). Proceedings of a Conference on General Equilibrium Trade Policy Modeling, held at Columbia University in April 1984. The MIT Press Cambridge, Massachusetts.

Hertel, T.W. (1997). Global Trade Analysis. Modeling and Applications. Cambridge University Press. New York.

Hertel, T.W., E. Ianchovichina and B.J. McDonald. (1997). Multi-Region General Equilibrium Modeling. In Applied Methods for Trade Policy Analysis. A Handbook edited by Francois, J. F., and K.A. Reinert (1997). Cambridge University Press.

Hertel, T.W., and M.E. Tsigas. (1997). Structure of GTAP. In Global Trade Analysis. Modeling and Applications, edited by Hertel, T.W (1997). Cambridge University Press. New York.

Hertel, T.W. and W. Martin. (1999). Would Developing Countries Gain from Inclusion of Manufactures in the WTO Negotiations? Paper Presented in at the Conference on WTO and The Millennium Round. Geneva, September 20-21, 1999

Hertel, T.W. (2000). Potential Gains from Reducing Trade Barriers in Manufacturing, Services and Agriculture. Federal Reserve Bank of St. Louis Review 82(4):77-99.

Hill, H. (1994). Asean Economic Development: An Analytical Survey- The State of the Field. The Journal of Asian Studies 53(3), 832-866.

Huff, K.M., K. Hanslow., T.W. Hertel., and M.E. Tsigas. (1997). GTAP Behavioral Parameters. In Global Trade Analysis. Modeling and Applications, edited by Hertel, T.W (1997). Cambridge University Press. New York.

Ingco. M.D. (1995). Agricultural Trade Liberalization in the Uruguay Round. World Bank Working Paper No. 1500 August 1995.

Ingco, M.D. (1996). Tariffication in the Uruguay Round: How Much Liberalization. The World Economy (July 1996): 425-426. 
Innwon, P. (1995). Regional Integration among the ASEAN Nations : A Computable General Equilibrium Model Study. Praeger Publishers. Wesport. USA.

Islam, N. (1999). Capital Mobility in CGE Models: a Survey. Department of Economics. Emory University, Atlanta. USA.

Jensen, H.G., S.E. Frandsen and C.F. Bach. (1998). Agricultural and Economy-Wide Effects of European Enlargment: Modelling the Common Agricultural Policy. SJFI-Working Paper no: 11/1998.

Jorgerson, D.W. (1984). Econometric Methods for Applied General Equilibrium Analysis. In Applied General Equilibrium Analysis edited by Scharf, H.F. and J. Shoven (1984). Cambridge

Josling, T.E. (1993). Agriculture in a World of Trading Block. Australian Journal of Agricultural Economics 37 (3), 155-179.

Josling, T.E. (1997). Implications of Regional Trade Arrangements for Agricultural Trade. FAO. Rome.

Keppler, G and K. Springer. (2000). Benchmarking the Future: A Dynamic, Multi-Regional, Multi-Sectoral Trade Model for the Analysis of Climate Policies. Kiel Working Paper No. 976. Kiel Institute of World Economics. Kiel. Germany.

Keuning, S. and E. Thorbecke. (1989). The Impact of Budget Retrenchment on Income Distribution in Indonesia: a Social Accounting Matrix Application. Technical Paper No. 3. OECD Development Centre. Paris.

Keusching, C. and W. Kohler. (1992). Dynamic Effects of Tariff Liberalization: An Intertemporal CGE Approach. Discussion Paper No. A-386 December 1992. Rheinische Friedrich-Wilhems-Universität Bonn.

Konandreas, P. (1999). Next Round of Negotiations in Agriculture with Special Reference to the Dairy Sector. Paper Presented in the Symposium on the International Prospects for Dairying in the Next WTO Negotiating Round. Buenos Aires, 3-4 June 1999.

Krueger, A.O., M. Schiff., and A. Valdés. (1991). The Political Economy of Agricultural Pricing Policy. Vol. 2: ASIA. A World Bank Comparative Study.

Krugman, P.R., and M. Obstfeld. (2000). International Economics. Theory and Policy. Addison-Wesley Publishing Company. New York.

Langhammer, R.J. and Hiemenz, U. (1990). Regional Integration among Developing Countries. Opportunities, Obstacles and Options. Kieler Studien. Institut für Weltwirtschaft an der Universität Kiel. 
Lee, H. and D.V. Roland-Holst. (1997). Trade and the Environment. In Applied Methods for Trade Poicy Analysis. A Handbook, edited by J. F. Francois and K. A. Reinert (1997). Cambridge University Press. United Kingdom.

Lewis, J.D., S. Robinson and K. Thierfelder. (2001). Free Trade Agreements and the SADC Economies. Paper Presented in DESG Conference „Economic Policy and Poverty Reduction” 5-7 April 2001.

MacLaren, D. (1995). The Uruguay Round Agreement on Agriculture: A New World Order for Agricultural Trade?. Review of Marketing and Agricultural Economics 63(1).

Malakellis, M. (1993). Illustrative Results from ORANI-INT : an Intertemporal CGE Model for the Australian Economy. Clayton Monash University.

Mansur, A. and J. Whaley. (1984). Numerical Specification of Applied General Equilibrium Models: Estimation, Calibration, and Data. In Applied General Equilibrium Analysis edited by Scharf, H.F. and J. Shoven (1984). Cambridge.

Martin, W., J. Rozanski, E. Fukase and W. Yu. (1998). Sources of Merchandise Tariff. In Global Trade, Assistance, and Protection, The GTAP Data Base, edited by Mc Dougall, R.A., A. Elbehri., and T.P. Truong (1998). Center for Global Trade Analysis. Purdue University.

Maule, Andrew. (1996). Some Implications of AFTA for Thailand. A Revealed Comparative Advantage Approach. ASEAN Economic Bulletin Vol. 12 (1):14-37.

Mc Dougall, R.A., B. Dimaranan, and T.W. Hertel. (1998). Behavioral Parameters. In Global Trade, Assistance, and Protection, The GTAP Data Base, edited by Mc Dougall, R.A., A. Elbehri., and T.P. Truong (1998). Center for Global Trade Analysis. Purdue University.

Mc Dougall, R.A., A. Elbehri., and T.P. Truong. (1998). Global Trade, Assistance, and Protection: The GTAP 4 Data Base. Center for Global Trade Analysis. Purdue University.

McMillan, J. (1993 ). Does Regional Integration Foster Open Trade ? Economic Theory and GATT's Article XXIV. In Regional Integration and the Global Trading System, edited by Anderson, K and Blackhurst, R (1993). St. Martin’s Press. New York.

Medich, F.H., T.L. Sporleder, D.E. Hahn. (1996). Expected Changes in Food and Agricultural Sectors from Western Hemisphere Economic Integration: A Computable General Equilibrium Analysis. Paper Prepared for the International Food and Agribusiness Management Association's Sixth World Congress Entitled „Emerging Challenges for the Agri-Food Business in the 21st Century“ Held in Cancun, Mexico May 27-30, 1996.

Mokre, M.E., and D.G. Tarr. (1995). Reforming Hungarian Agricultural Trade Policy. Weltwirtschaftliches Archive (131):106-131. 
Molle, W.T. (1990). The Economics of European Integration : Theory, Practice, Policy. Dartmouth.

Müller, K. (1995). The Political Economy of Agricultural Trade of the ASEAN Countries. Verlag M. Wehle. Witterschlick/Bonn.

Mung-Heng, T. (1996). AFTA and Uruguay Round of Multilateral Trade Negoitations. In AFTA in the Changing International Economy. edited by Tan, Joseph L. H (1996). Institute of Southeast Asian Studies. Singapore.

Nadal de Simone, F.D. (1995). A Macroeconomic Perpestive of AFTA's Problems and Prospects. Contemporary Economic Policy 13:9-62.

Naya, S. and P. Imada. (1992). AFTA: The Way Ahead. Institute of Southeast Asian Studies. Singapore

Oktaviani, R. (2000), The Impact of APEC Trade Liberalisation on Indonesian Economy and Its Agricultural Sector. Ph.D thesis. The Sydney University.

OECD. (1993). Regional Integration and Developing Countries. Paris.

OECD. (1995). Regional Integration and the Multilateral Trading System Synergy and Divergence. Paris.

Otsubo, S. (1999). Computational Analysis of Economic Impact of Japan’s FDI in Asia. GSID APEC Discussion Paper Series No.25. Nagoya University. Japan.

Oxley, Alan. (1999). The Importance of the WTO Negotiations to APEC and Australia's Related National Interests. Australian APEC Study Centre Issues Paper 15. (http:www.apec.org.au).

Palmer, R.D.and T.J. Reckford. (1987). Building ASEAN. 20 Years of Southeast Asian Cooperation. The Center for Strategic and International Studies. Washington, D. C.

Panagarya, A. (1993). Should East Asia Go Regional ? No, No, and Maybe. World Bank, Policy Research Department Working Paper No. 1209. Washington, D.C.

Pearson, K.R. (1997). Implementing GTAP Using the GEMPACK Software. In Structure of GTAP in Global Trade Analysis. Modeling and Applications, edited by Hertel, T.W (1997). Cambridge University Press. New York.

Phlips. (1983). Applied Consumption Analysis.. Elsevier Science Publ. Co

Pupphavesa, Wisarn and M. Grewe. (1994). Pacific Trade and Investment: Options for the 90’s. Paper presented in Toronto June 6-8, 1994. Canada (http: www.info.tdri.or.th). 
Pyatt, G., and J.I. Round. (1985). Social Accounting Matrices. A Basis for Planning. A World Bank Symposium. The World Bank. Washington, D.C., U.S.A.

Rae, A.N., S. Chatterjee and S. Shakur. (1999). The Sectoral Approach to Trade Liberalisation: Should We Try to Do Better ?. Paper Presented at the Conference on Towards APEC's Second Decade: Chalanges, Opportunities and Priorities. 31 May - 2 June, 1999. Auckland, New Zealand.

Rae, A.N. and T.W. Hertel. (1998). Asia-Pacific Food Markets in 2005: The Influence of Livestock Productivity Convergence on Trade in Livestock Products and Grains. Paper Presented at the International Agricultural Trade Research Consortium Annual Meeting, December 13-15, 1998, St. Petersburg, Florida, USA

Rahman, A. A. A. (1997). Economic Reforms and Agricultural Development in Malaysia. ASAN Economic Bulletin Vol 15 (1):59-76.

Ratnawati, A.(1995). Membangun Model Computable General Equilibrium (CGE) Multisektor untuk Analisis Dampak Kebijakan Pemerintah (Fiskal dan Moneter) terhadap Distribusi Pendapatan di Indonesia. Program Studi Ekonomi Pertanian. Program Pascasarjana. Institut Pertanian Bogor (Bogor Agricultural University). Bogor.

Reiter, K. (1983). Regionale Wirtschaftliche Zusammenarbeit von Staaten der Dritten Welt. Sozialwissenschaftliche Studien zu Internationalen Problemen. Saarbrücken.

Robinson, S. (1989). Multisector Models. In Handbook of Development Economics, Volume II, edited by Chenery, H. and T. N. Srinivasan (1989). Elsevier Science Publishers B. V. Amsterdam.

Robinson, S., M. El-Said and N. N. San. (1998). Rice Policy, Trade, and Exchange Rate Changes in Indonesia: A General Equilibrium Analysis. Discussion Paper No. 27 . Trade and Macroeconomics Division. International Food Research Institute. Washington, DC. USA.

Rutherford, T.F. (1998). GTAPinGAMS: The Dataset and Static Model.. Working Paper, University of Colorado Department of Economics.

Sabirin, S. (1999). Recent Development in the Indonesian Economy. Bank of International Settlements (BIS) Review (34).

Sadoulet, E. and A. Janvry. (1995). Quantitative Development Policy Analysis. The Johns Hopkins University Press. Baltimore and London.

Sander, H. (1995). Deep Integration, Shallow Regionalism, and Strategic Openness. In International Economic Integration edited by Lang, F. P. and Ohr, R (1995). Studies in Contemporary Economics. Physica Verlag. Braunschweig.

Scollay, R. and J. Gilbert. (1999a). An APEC Food System: Trade and Welfare Implication by 2005. APEC Study Centre of New Zealand. 
Scollay, R. and J. Gilbert. (1999b). CGE Assesments of the Gains from APEC Trade Liberalisation: A Survey and Some New Results. APEC Study Centre of New Zealand.

Scollay, R. and J. Gilbert. (2000). Measuring the Gains from APEC Trade Liberalization: An Overview of CGE Assessment. The World Economy. Vol 23(2):175-197.

Scweickert, R. (1994). Regional Integration - a Worthwhile Strategy for Catching Up ?. Kiel Working Paper no 623. Institut für Weltwirtschaft an der Universität Kiel.

Sheffield, S. (1998). Agriculture, the GATT and Regional Agreements in Regional Trade Agreement and the US Agriculture. Economic Research Service, US Department of Agriculture, Washington.

Shogenji, S. (1996). JAPAN: Towards a Balanced Policy Framework for Food, Agriculture and Rural Areas in Japan. Paper Presented at a Workshop Entitled „, Effects of Institutional and Economic Changes on the Agri-food Industries of the ASIA-PACIFIC Region“. January 9-10, 1996. East-West Center Honolulu, Hawaii

Shoven, J. B., and J. Whalley. (1984). Applied General Equilibrium Models of Taxation and International Trade: An Introduction and Survey. Journal of Economic Literature, 22:1007-1051.

Shoven, J. B., and J. Whalley. (1992). Applying General Equilibrium. Cambridge Univ. Press. New York, N.Y.

Siregar, Hermanto. (2004). Changes in Farmer Terms of Trade and Agricultural Net-barter Terms of Trade: An Empirical Analysis. Journal of Management and Agribusiness vol 1(1):1-19.

Spencer, J.E. (1986). Trade Liberalization through Tariff Cuts and the European Economic Community: A General Equilibrium Evaluation. In General Equilibrium Trade Policy Modeling, edited Srinivasan, T.N., and J. Whalley (1986). Proceedings of a Conference on General Equilibrium Trade Policy Modeling, Held at Columbia University in April 1984. The MIT Press Cambridge, Massachusetts.

Springer, K. (998). Climate Policy and Trade: Modelling Dynamics in a Multi-regional Framework. Kiel Institute of World Economics.

Srinivasan, T.N., and J. Whalley, J (edts). (1986). General Equilibrium Trade Policy Modeling. Proceedings of a Conference on General Equilibrium Trade Policy Modeling, Held at Columbia University in April 1984. The MIT Press Cambridge, Massachusetts.

Suranovic, S. M. (2000). International Trade Theory \& Policy Analysis (an on-line version at : http://internationalecon.com/v1.0/index.html ) 
Takata, K. (1998). The Economic Effects of APEC Trade Liberalization (Sumary of the 1997 Study of the APECEconomic Committe. The Japanese Mission to the European Union.

Tan, J. (1986). AFTA in the Changing International Economy. Institut of Southeast Asian Studies. Singapore.

Tan, K.Y. (2000). Regional Trading Arrangements in the Asia-Pacific Region: Strategic Options for a Weakened ASEAN. Graduate School of International Economics and Finance. Brandeis University. Massachusetts.

Tangermann, Stefan. (1996). Implementation of the Uruguay Round Agreement on Agriculture: Issues and Prospects. Journal of Agricultural Economics, 47(3):315-337.

Taylor. (1979). Macro Models For Developing Countries. Economics Handbook Series. McGraw-Hill Book Company. New York.

Thiele, R. and Wiebelt, M. (1993), "National and International Policies for Tropical Rain Forest Conservation - A quantitative Analysis for Cameroon", Environmental and Resource Economics, 3:501-531.

Tsigas, M. (1998). Agricultural Protection OECD Countries. In Global Trade, Assistance, and Protection, The GTAP Data Base, edited by Mc Dougall, R.A., A. Elbehri., and T.P. Truong (1998). Center for Global Trade Analysis. Purdue University.

Tussie, D and Glover, D (edts). (1993). The Developing Countries in World Trade. Policies and Bargaining Strategies. Lynne Rienner Publishers. Boulder.

Twesten, H. and S. Tangermann. (1998). Agriculture, Regionalism and Integration in Central Europe. Paper prepared for the Annual Meeting of the International Agricultural Trade Research Consortium (IATRC) on "Multilateralism and Regionalism: Implications for Agricultural Trade Policy" in St. Petersburg Beach, Florida, December 13-15, 1998

United Nations. (1996). World Economic and Social Survey 1996. Trends and Policies in the World Economy. New York.

Viner, J. (1950). The Customs Union Issue. New York: Carnegie Endowment for International Peace

Wang, Z. and B. Coyle. (2002). APEC Open Regionalism and Its Impact on the World Economy. A Computable General Equilibrium Analysis. The World Economy (25): 563-589.

Whalley, J. (1985). Trade Liberalization among Major World Trading Areas. The MIT Press. Cambridge, Massachuttes.

Whalley, J. (1986). Impacts of a 50\% Tariff Reduction in an Eight-Region Global Trade Model. In General Equilibrium Trade Policy Modeling, edited by Srinivasan, T.N., and J. Whalley (1986). Proceedings of a Conference on General Equilibrium Trade Policy 
Modeling, Held at Columbia University in April 1984. The MIT Press Cambridge, Massachusetts.

Wong, J. (1980). ASEAN Economies in Perspective. A Comparative Study of Indonesia, Malaysia, the Philippines, Singapore \& Thailand. The Macmillan Press Ltd.

World Bank. (2001). East Asia Update: Regional Overview. East Asia and Pacific Region. The World Bank.

WTO. (1994). Developing Countries and the Uruguay Round: An Overview. Committee on Trade and Development Seventy-Seventh Session, 21 and 24 November 1994. (http://www.wto.wto.org/wto/legal//dc2_512.htm)

WTO. (1999). Trade Policy Reviews: The Philippines: September 1999.

Yarnazawa, I. (1999). APEC After Ten Years: How Much Has Been Achieved in Liberalization and Facilitation. Paper presented in Conference on „Towards APEC's Second Decade: Challenges, Opportunities and Priorities“ 31 May-2 June 1999, Auckland New Zeland.

Yeldan, A.E. (1986). A Computable General Equilibrium Model for Development Policy Analysis. Economic Development Center. Department of Economics. University of Minnesota. Minneapolis, USA.

Yeldan, A.E.. and X. Diao. (1998). Interface Trade Liberalization, Accumulation and Growth in a World of Multi-polar Trade Blocs: Lessons from a Multi-regional Global General Equilibrium Model. Department of Economics. Bilkent University, Ankara.

Young, S. (1993). East Asia as a Regional Force for Globalism. In Regional Integration and the Global Trading System, edited by Anderson, K and R. Blackhurst (1993). St. Martin's Press. New York.

Young, L. M. and K. M. Huff. (1997). Free Trade in the Pacific Rim: On What Basis ? In Global Trade Analysis. Modeling and Applications, edited by Hertel, T.W (1997). Cambridge University Press. New York.

Websites of International Organisations:

ASEAN Secretariat

APEC Secretariat

World Bank

WTO Secretariat (http://www.aseansec.org)

(http:// www.apecsec.org.sg)

(http://www.worldbank.org)

(http://www.wto.org) 
APPENDICES 
Table 5.1 Weighted Average Post Uruguay Import Tariff Levels (\%)

\begin{tabular}{lrrrrr}
\hline & Indonesia & Malaysia & Philippines & Singapore & \multicolumn{1}{c}{ Thailand } \\
\hline Rice & 0.00 & 38.10 & 50.80 & 17.60 & 41.20 \\
Cereal & 1.00 & 142.00 & 71.00 & 8.00 & 101.00 \\
Other crops & 6.00 & 16.00 & 10.00 & 17.00 & 22.00 \\
Oil seeds & 12.00 & 2.00 & 0.00 & 21.00 & 24.00 \\
Livestock & 3.00 & 1.00 & 8.10 & 21.00 & 15.00 \\
Sugar & 1.00 & 0.00 & 1.00 & 11.00 & 38.00 \\
Vegetable oil & 0.00 & 0.00 & 0.00 & 0.00 & 0.00 \\
Processed meat & 5.00 & 9.60 & 9.60 & 6.40 & 9.60 \\
Processed milk & 15.00 & 101.00 & 101.00 & 2.50 & 101.00 \\
Processed other & 9.00 & 5.60 & 13.50 & 9.50 & 20.50 \\
crops & & & & & \\
Beverages and & 25.20 & 18.60 & 30.00 & 10.00 & 55.00 \\
tobacco products & & & & & \\
Mining and mineral & 2.80 & 1.50 & 1.60 & 2.00 & 3.00 \\
products & & & & & \\
Clothing and & 17.00 & 17.00 & 24.00 & 1.00 & 20.80 \\
textiles & & & & & \\
Manufacture & 7.20 & 6.40 & 19.20 & 0.00 & 15.00 \\
\hline Source: Own Calcula
\end{tabular}

Source: Own Calculation based on the procedure proposed by FRANCOIS and STRUTT (1999). 
Table 5.2 Indonesia. Average Annual Import Changes under the AFTA Scenario Relative to the Baseline Scenario (US\$ million)

\begin{tabular}{|c|c|c|c|c|c|c|c|c|}
\hline & MYS & PHL & SGP & THA & EUR & JPN & USA & ROW \\
\hline Rice & 0.0 & 0.2 & 0.0 & -76.7 & 0.2 & 0.8 & 3.6 & 56.1 \\
\hline Cereal & -0.1 & 0.0 & 0.0 & -10.8 & 0.8 & 0.0 & 7.0 & 22.4 \\
\hline Other crops & 3.8 & 3.2 & 6.2 & 23.7 & 3.1 & 0.4 & 13.5 & 29.0 \\
\hline Oil seeds & 0.1 & 0.5 & 1.3 & 0.7 & 0.0 & 0.0 & 0.9 & 1.6 \\
\hline Livestock & -0.1 & 0.0 & 0.9 & 0.2 & 0.5 & 0.0 & 0.9 & 9.0 \\
\hline $\begin{array}{l}\text { Unprocessed } \\
\text { agric. products }\end{array}$ & 3.7 & 3.9 & 8.4 & -63.0 & 4.7 & 1.3 & 25.9 & 118.1 \\
\hline Vegetable oil & -0.1 & 0.0 & 0.4 & 15.8 & 0.0 & 0.0 & 0.0 & 0.1 \\
\hline Processed meat & 0.7 & 7.0 & -0.1 & 0.7 & 0.0 & 0.0 & 0.0 & 0.6 \\
\hline Processed milk & 3.4 & 0.2 & 0.2 & 0.5 & 0.0 & 0.1 & -0.1 & 0.0 \\
\hline $\begin{array}{l}\text { Processed other } \\
\text { crops }\end{array}$ & 1.2 & 0.0 & 0.0 & 0.1 & -1.1 & 0.0 & -0.3 & -0.8 \\
\hline Sugar & 10.6 & 9.1 & 15.3 & 8.5 & -2.7 & -0.1 & -2.2 & -10.7 \\
\hline $\begin{array}{l}\text { Beverages and } \\
\text { tobacco products }\end{array}$ & 11.5 & 0.8 & 9.3 & 14.2 & -0.7 & -0.1 & -3.9 & -5.4 \\
\hline $\begin{array}{l}\text { Processed agric. } \\
\text { Products }\end{array}$ & 27.3 & 17.1 & 25.1 & 39.8 & -4.4 & -0.1 & -6.5 & -16.2 \\
\hline $\begin{array}{l}\text { Clothing and } \\
\text { textiles }\end{array}$ & 19.2 & 0.8 & 80.9 & 10.4 & 2.2 & 0.7 & 0.6 & 25.5 \\
\hline $\begin{array}{l}\text { Mining and } \\
\text { mineral products }\end{array}$ & 76.5 & 8.5 & 16.5 & 96.5 & -9.2 & -11.7 & -3.6 & -90.4 \\
\hline Manufacturing & 328.6 & 65.7 & 904.8 & 516.5 & -292.3 & -270.0 & -78.7 & -376.5 \\
\hline Services & 0.1 & 0.3 & -1.2 & 0.8 & 54.9 & 1.6 & 5.2 & 34.9 \\
\hline $\begin{array}{l}\text { Non-agric. } \\
\text { Products }\end{array}$ & 424.5 & 75.3 & 1001.0 & 624.2 & -244.4 & -279.4 & -76.5 & -406.5 \\
\hline
\end{tabular}

Source: Model Simulation 
Table 5.3 Malaysia. Average Annual Import Changes under the AFTA Scenario Relative to the Baseline Scenario (US\$ million)

\begin{tabular}{|c|c|c|c|c|c|c|c|c|}
\hline & IDN & PHL & SGP & THA & EUR & JPN & USA & ROW \\
\hline Rice & 0.0 & 0.0 & 0.0 & 746.0 & 0.0 & 0.0 & -1.7 & -106.6 \\
\hline Cereal & 49.0 & 0.0 & 0.0 & 189.2 & -0.1 & 0.0 & -20.4 & -29.1 \\
\hline Other crops & 56.6 & -3.2 & 93.5 & 61.6 & -2.0 & -0.2 & -8.9 & -60.5 \\
\hline Oil seeds & 2.0 & 0.0 & 0.6 & 2.4 & 0.0 & 0.0 & 3.6 & 2.0 \\
\hline Livestock & -4.8 & 0.0 & -0.9 & 0.1 & -0.1 & 0.0 & -0.1 & -1.7 \\
\hline $\begin{array}{l}\text { Unprocessed } \\
\text { agric. Products }\end{array}$ & 102.7 & -3.2 & 93.1 & 999.3 & -2.1 & -0.2 & -27.4 & -195.9 \\
\hline Sugar & 0.0 & 0.0 & 1.8 & -1.6 & 0.0 & 0.0 & 0.0 & 2.4 \\
\hline Vegetable oil & -0.5 & 0.7 & 0.4 & -0.1 & -0.1 & 0.0 & -0.3 & -1.5 \\
\hline Processed meat & 85.0 & 0.3 & 61.5 & 10.9 & -8.6 & -1.2 & -3.9 & -67.2 \\
\hline Processed milk & 19.4 & 3.0 & 52.0 & 47.2 & -6.5 & 0.0 & -1.2 & -51.9 \\
\hline $\begin{array}{l}\text { Processed other } \\
\text { crops }\end{array}$ & 5.3 & 10.6 & 34.6 & 43.3 & -12.3 & -2.0 & -7.2 & -30.6 \\
\hline $\begin{array}{l}\text { Beverages and } \\
\text { tobacco products }\end{array}$ & 9.0 & 1.3 & 50.3 & 0.3 & -15.9 & -0.3 & -2.7 & -3.0 \\
\hline $\begin{array}{l}\text { Processed agric. } \\
\text { Products }\end{array}$ & 118.2 & 15.8 & 200.6 & 100.0 & -43.4 & -3.6 & -15.2 & -151.8 \\
\hline $\begin{array}{l}\text { Mining and } \\
\text { mineral products }\end{array}$ & 13.2 & 3.8 & 39.3 & 9.5 & 11.1 & 3.2 & 2.0 & 42.6 \\
\hline $\begin{array}{l}\text { Clothing and } \\
\text { textiles }\end{array}$ & 264.9 & 5.5 & 334.4 & 193.8 & -41.9 & -68.2 & -11.9 & -411.0 \\
\hline Manufacturing & 537.2 & 73.6 & 7434.7 & 825.8 & -1325.5 & -2237.0 & -1040.2 & -1737.9 \\
\hline Services & 1.0 & 1.6 & 3.4 & 1.5 & 144.4 & 6.1 & 31.5 & 106.6 \\
\hline $\begin{array}{l}\text { Non-agric. } \\
\text { Products }\end{array}$ & 816.3 & 84.5 & 7811.7 & 1030.6 & -1211.9 & -2296.0 & -1018.6 & -1999.8 \\
\hline
\end{tabular}

Source: Model Simulation 
Table 5. 4 The Philippines. Average Annual Import Changes under the AFTA Scenario Relative to the Baseline Scenario (US\$ million)

\begin{tabular}{|c|c|c|c|c|c|c|c|c|}
\hline & IDN & MYS & SGP & THA & EUR & JPN & USA & ROW \\
\hline Rice & 0.0 & 0.0 & 0.8 & 98.1 & 0.0 & -1.5 & 0.0 & -13.9 \\
\hline Cereal & 0.0 & 0.0 & 2.2 & 0.2 & 0.0 & 0.0 & -9.2 & -1.6 \\
\hline Other crops & 17.5 & 8.8 & 12.5 & 0.9 & -2.0 & -0.2 & -11.9 & -17.6 \\
\hline Oil seeds & 0.0 & 0.0 & -0.1 & -0.2 & 0.0 & 0.0 & 0.1 & 0.1 \\
\hline Livestock & -0.1 & 0.3 & 0.6 & 0.8 & 0.0 & 0.0 & -0.1 & -0.5 \\
\hline $\begin{array}{l}\text { Unprocessed } \\
\text { agric. Products }\end{array}$ & 17.4 & 9.1 & 16.1 & 99.8 & -2.0 & -1.7 & -21.0 & -33.5 \\
\hline Sugar & -0.1 & -0.2 & -0.2 & -3.4 & -0.3 & 0.0 & -0.1 & -1.0 \\
\hline Vegetable oil & 1.9 & 2.3 & 2.6 & 0.0 & -0.1 & 0.0 & 0.0 & -3.4 \\
\hline Processed meat & 1.8 & 17.8 & 25.9 & 2.8 & -1.1 & -0.1 & -2.7 & -12.4 \\
\hline Processed milk & 0.0 & 4.4 & 110.3 & 1.1 & -10.4 & 0.0 & -5.2 & -59.7 \\
\hline $\begin{array}{l}\text { Processed other } \\
\text { crops }\end{array}$ & 18.8 & 12.2 & 52.2 & 26.1 & -8.7 & -1.1 & -18.5 & -24.9 \\
\hline $\begin{array}{l}\text { Beverages and } \\
\text { tobacco products }\end{array}$ & 1.3 & 1.1 & 249.1 & 5.7 & -55.5 & -0.4 & -3.0 & -54.6 \\
\hline $\begin{array}{l}\text { Processed agric. } \\
\text { Products }\end{array}$ & 23.6 & 37.6 & 439.9 & 32.3 & -76.1 & -1.6 & -29.5 & -156.1 \\
\hline $\begin{array}{l}\text { Mining and } \\
\text { mineral products }\end{array}$ & -8.7 & 0.3 & 67.7 & 16.4 & -0.2 & -0.2 & -0.8 & -13.3 \\
\hline $\begin{array}{l}\text { Clothing and } \\
\text { textiles }\end{array}$ & 144.7 & 96.8 & 23.6 & 160.8 & -16.9 & -27.7 & -14.9 & -255.2 \\
\hline Manufacturing & 418.7 & 974.6 & 2586.7 & 664.0 & -562.7 & -1356.8 & -759.8 & -1142.6 \\
\hline Services & 0.1 & -0.3 & -3.7 & 0.4 & 9.0 & 0.0 & 1.8 & 4.9 \\
\hline $\begin{array}{l}\text { Non-agric. } \\
\text { Products }\end{array}$ & 554.8 & 1071.3 & 2674.4 & 841.6 & -570.7 & -1384.8 & -773.7 & -1406.1 \\
\hline
\end{tabular}

Source: Model Simulation 
Table 5.5 Singapore. Average Annual Import Changes under the AFTA Scenario Relative to the Baseline Scenario (US\$ million)

\begin{tabular}{|c|c|c|c|c|c|c|c|c|}
\hline & IDN & MYS & PHL & THA & EUR & JPN & USA & ROW \\
\hline Rice & 0.0 & 0.3 & 0.0 & 83.0 & 0.0 & 0.0 & -7.6 & -7.4 \\
\hline Cereal & -0.2 & -0.3 & 0.0 & -2.7 & 0.0 & 0.0 & 0.5 & 1.4 \\
\hline Other crops & 165.1 & 47.2 & 34.9 & 7.4 & -9.6 & -2.8 & -22.4 & -163.1 \\
\hline Oil seeds & 0.0 & 1.0 & 0.0 & 0.0 & 0.0 & 0.0 & 0.0 & -2.2 \\
\hline Livestock & 0.1 & 212.5 & 0.0 & -0.9 & -1.7 & -2.9 & -1.6 & -34.6 \\
\hline $\begin{array}{l}\text { Unprocessed } \\
\text { agric. Products }\end{array}$ & 165.1 & 260.7 & 34.9 & 86.8 & -11.3 & -5.7 & -31.1 & -205.9 \\
\hline Sugar & 0.1 & 12.7 & 0.9 & 6.9 & -1.0 & -0.1 & -0.3 & -8.8 \\
\hline Vegetable oil & 1.5 & 65.8 & 1.9 & 0.0 & -0.9 & -0.2 & -2.0 & -4.7 \\
\hline Processed meat & 1.8 & 31.6 & 0.2 & 13.2 & -5.0 & -0.5 & -5.6 & -11.6 \\
\hline Processed milk & 0.0 & 8.8 & -0.2 & -0.5 & -6.0 & -0.1 & -0.6 & -16.9 \\
\hline $\begin{array}{l}\text { Processed other } \\
\text { crops }\end{array}$ & 14.3 & 102.7 & 11.8 & 129.3 & -21.8 & -16.2 & -14.4 & -86.2 \\
\hline $\begin{array}{l}\text { Beverages and } \\
\text { tobacco products }\end{array}$ & 0.0 & 16.3 & 0.5 & 14.0 & 9.6 & 0.4 & 1.0 & 5.6 \\
\hline $\begin{array}{l}\text { Processed agric. } \\
\text { Products }\end{array}$ & 17.6 & 238.0 & 15.0 & 162.8 & -25.1 & -16.7 & -21.9 & -122.5 \\
\hline $\begin{array}{l}\text { Mining and } \\
\text { mineral products }\end{array}$ & 131.5 & -29.9 & 107.3 & 1.2 & 3.9 & 1.4 & 1.5 & 69.6 \\
\hline $\begin{array}{l}\text { Clothing and } \\
\text { textiles }\end{array}$ & 50.3 & 50.7 & 5.1 & 135.4 & -5.7 & -0.2 & -1.8 & -22.9 \\
\hline Manufacturing & -62.4 & 524.2 & 85.1 & 224.7 & 505.1 & 1233.5 & 528.4 & 991.4 \\
\hline Services & 15.8 & 10.4 & 22.2 & 29.8 & 562.2 & 464.2 & 469.7 & 743.6 \\
\hline $\begin{array}{l}\text { Non-agric. } \\
\text { Products }\end{array}$ & 152.8 & 809.8 & 235.2 & 567.9 & 1050.1 & 1682.6 & 976.8 & 1664.8 \\
\hline
\end{tabular}

Source: Model Simulation 
Table 5.6 Thailand. Average Annual Import Changes under the AFTA Scenario Relative to the Baseline Scenario (US\$ million)

\begin{tabular}{|c|c|c|c|c|c|c|c|c|}
\hline & IDN & MYS & PHL & SGP & EUR & JPN & USA & ROW \\
\hline Rice & 0.0 & 0.0 & 0.0 & 0.0 & 0.0 & 0.0 & 0.0 & 0.0 \\
\hline Cereal & 0.0 & 2.9 & 0.0 & 0.0 & 0.0 & 0.0 & -13.7 & -13.6 \\
\hline Other crops & 45.6 & 26.8 & 13.7 & 13.7 & 5.6 & 1.3 & 26.9 & 53.1 \\
\hline Oil seeds & 0.0 & 0.0 & 0.0 & 0.0 & 0.0 & 0.0 & 0.9 & 0.2 \\
\hline Livestock & 28.9 & 0.5 & 25.2 & 25.2 & -5.5 & -0.2 & -2.4 & -22.5 \\
\hline $\begin{array}{l}\text { Unprocessed } \\
\text { agric. Products }\end{array}$ & 74.6 & 30.3 & 39.0 & 39.0 & 0.1 & 1.2 & 11.7 & 17.0 \\
\hline Sugar & 0.0 & 0.0 & 0.2 & 0.2 & 0.0 & 0.0 & 0.0 & 0.0 \\
\hline Vegetable oil & 0.0 & 6.1 & 10.0 & 10.0 & -0.4 & 0.0 & 0.0 & -4.7 \\
\hline Processed meat & 11.0 & 25.7 & 34.0 & 34.0 & -3.7 & -2.2 & -1.7 & -8.3 \\
\hline Processed milk & 0.0 & 0.2 & 22.2 & 22.2 & -3.2 & 0.0 & -0.8 & -14.0 \\
\hline $\begin{array}{l}\text { Processed other } \\
\text { crops }\end{array}$ & 219.5 & 24.8 & 148.8 & 148.8 & -40.0 & -24.6 & -17.2 & -165.4 \\
\hline $\begin{array}{l}\text { Beverages and } \\
\text { tobacco products }\end{array}$ & 0.0 & 0.2 & 8.5 & 8.5 & -6.5 & -0.1 & -1.0 & -0.3 \\
\hline $\begin{array}{l}\text { Processed agric. } \\
\text { Products }\end{array}$ & 230.5 & 57.2 & 223.7 & 223.7 & -53.8 & -27.0 & -20.6 & -192.6 \\
\hline $\begin{array}{l}\text { Mining and } \\
\text { mineral products }\end{array}$ & 17.5 & -86.0 & 319.2 & 319.2 & -18.1 & -3.7 & -6.1 & -147.8 \\
\hline $\begin{array}{l}\text { Clothing and } \\
\text { textiles }\end{array}$ & 215.8 & 49.7 & 53.5 & 53.5 & -18.3 & -34.3 & -6.3 & -160.8 \\
\hline Manufacturing & 1197.6 & 3555.4 & 5903.9 & 5903.9 & -1877.0 & -3785.9 & -1092.1 & -2792.1 \\
\hline Services & -2.2 & -2.6 & -28.4 & -28.4 & -160.6 & -22.9 & -47.0 & -77.4 \\
\hline $\begin{array}{l}\text { Non-agric. } \\
\text { Products }\end{array}$ & 1659.3 & 3573.9 & 6480.5 & 6480.5 & -2134.4 & -3873.9 & -1173.0 & -3371.0 \\
\hline
\end{tabular}

Source: Model Simulation 
Table 5.7 Indonesia. Average Annual Import Changes under the APEC Scenario Relative to the Baseline Scenario (US\$ million)

\begin{tabular}{|c|c|c|c|c|c|c|c|c|}
\hline & MYS & PHL & SGP & THA & EUR & JPN & USA & ROW \\
\hline Rice & 0.0 & 0.1 & 0.0 & 3.6 & 0.0 & 0.3 & 0.9 & -5.4 \\
\hline Cereal & -0.1 & -0.1 & 0.0 & -3.4 & -1.1 & 0.0 & -7.4 & 16.2 \\
\hline Other crops & 0.9 & -0.8 & 2.2 & 4.7 & -5.7 & -0.5 & 97.7 & -39.2 \\
\hline Oil seeds & 0.0 & 0.4 & 1.3 & 0.6 & 0.0 & 0.0 & 11.6 & -6.2 \\
\hline Livestock & -0.1 & 0.0 & 0.6 & 0.1 & 0.0 & 0.4 & 0.9 & -0.6 \\
\hline $\begin{array}{l}\text { Unprocessed } \\
\text { agric. Products }\end{array}$ & 0.8 & -0.4 & 4.1 & 5.6 & -6.8 & 0.1 & 103.8 & -35.1 \\
\hline Vegetable oil & 0.0 & 0.0 & 0.2 & 12.0 & -0.7 & 0.1 & 0.2 & -5.0 \\
\hline Processed meat & 2.7 & -5.2 & 0.1 & -0.6 & 0.1 & -0.2 & 0.0 & 0.6 \\
\hline Processed milk & 1.2 & 0.1 & 0.1 & -0.5 & 0.0 & 0.6 & -1.8 & 1.5 \\
\hline $\begin{array}{l}\text { Processed other } \\
\text { crops }\end{array}$ & 0.8 & 0.0 & 0.0 & 0.0 & -0.6 & 0.1 & -2.6 & 3.7 \\
\hline Sugar & 4.1 & 2.6 & 4.2 & 4.4 & -4.6 & 3.2 & 27.5 & -19.3 \\
\hline $\begin{array}{l}\text { Beverages and } \\
\text { tobacco products }\end{array}$ & 3.4 & 0.1 & 1.9 & 4.5 & -0.5 & 0.2 & 5.8 & -4.2 \\
\hline $\begin{array}{l}\text { Processed agric. } \\
\text { Products }\end{array}$ & 12.2 & -2.4 & 6.3 & 19.8 & -6.4 & 4.0 & 29.1 & -22.6 \\
\hline $\begin{array}{l}\text { Clothing and } \\
\text { textiles }\end{array}$ & 13.2 & 0.6 & 93.4 & 9.8 & -3.9 & 10.8 & 10.6 & -38.9 \\
\hline $\begin{array}{l}\text { Mining and } \\
\text { mineral products }\end{array}$ & 20.9 & 2.1 & 4.8 & 34.4 & -6.2 & 80.8 & -0.3 & -55.4 \\
\hline Manufacturing & 206.1 & 55.0 & 501.8 & 344.6 & -1447.7 & 3766.7 & 588.7 & -1869.3 \\
\hline Services & -0.4 & -1.9 & -1.8 & 0.5 & 7.1 & -0.7 & -0.3 & -3.9 \\
\hline $\begin{array}{l}\text { Non-agric. } \\
\text { Products }\end{array}$ & 239.8 & 55.8 & 598.2 & 389.3 & -1450.7 & 3857.6 & 598.8 & -1967.5 \\
\hline
\end{tabular}

Source: Model Simulation 
Table 5.8 Malaysia. Average Annual Import Changes under the APEC Scenario Relative to the Baseline Scenario (US\$ million)

\begin{tabular}{|c|c|c|c|c|c|c|c|c|}
\hline & IDN & PHL & SGP & THA & EUR & JPN & USA & ROW \\
\hline Rice & 0.0 & 0.0 & 0.0 & -76.1 & 0.0 & 0.0 & 0.2 & 45.3 \\
\hline Other cereal & 3.2 & 0.0 & 0.0 & 7.2 & -0.8 & 0.0 & 372.2 & -385.9 \\
\hline Crops & 29.7 & -6.5 & 44.7 & -2.7 & 0.8 & 1.8 & 63.1 & 36.6 \\
\hline Oil seeds & 2.1 & 0.0 & 0.8 & 2.7 & 0.0 & 0.0 & 8.0 & 7.3 \\
\hline Livestock & 0.2 & 0.0 & 0.5 & 4.1 & 0.4 & 0.6 & 1.0 & 6.5 \\
\hline $\begin{array}{l}\text { Unprocessed } \\
\text { agric. Products }\end{array}$ & 35.1 & -6.5 & 46.0 & -64.9 & 0.4 & 2.5 & 444.5 & -290.1 \\
\hline Sugar & 0.0 & 0.0 & 0.5 & 1.9 & 0.0 & 0.0 & 0.0 & -4.2 \\
\hline Vegetable oil & -1.3 & -2.0 & -1.1 & -0.1 & -0.2 & -0.1 & -1.1 & -2.6 \\
\hline Processed meat & -29.5 & -0.1 & -19.7 & -5.0 & 5.4 & -2.6 & -9.1 & 44.5 \\
\hline Processed milk & 4.4 & 0.3 & 7.8 & 7.9 & -1.9 & 0.0 & 10.4 & -11.5 \\
\hline $\begin{array}{l}\text { Processed other } \\
\text { crops }\end{array}$ & 1.0 & 1.9 & 0.2 & 16.8 & -5.1 & 0.1 & 2.8 & -12.1 \\
\hline $\begin{array}{l}\text { Beverages and } \\
\text { tobacco products }\end{array}$ & 2.0 & 0.3 & 10.1 & 0.1 & -5.2 & 0.8 & 7.1 & -1.0 \\
\hline $\begin{array}{l}\text { Processed agric. } \\
\text { Products }\end{array}$ & -23.4 & 0.2 & -2.2 & 21.6 & -7.1 & -1.7 & 10.0 & 13.1 \\
\hline $\begin{array}{l}\text { Mining and } \\
\text { mineral products }\end{array}$ & 11.1 & 3.5 & 51.6 & 8.8 & 6.9 & 4.6 & 5.5 & 26.9 \\
\hline $\begin{array}{l}\text { Clothing and } \\
\text { textiles }\end{array}$ & 92.9 & 1.4 & 99.1 & 75.6 & -20.3 & 64.8 & 7.3 & -194.6 \\
\hline Manufacturing & 336.7 & 40.3 & 4584.4 & 481.7 & -2593.1 & 3003.7 & 677.0 & -3352.6 \\
\hline Services & 0.6 & 0.1 & 2.6 & 1.4 & 104.4 & 3.7 & 21.1 & 67.9 \\
\hline $\begin{array}{l}\text { Non-agric. } \\
\text { Products }\end{array}$ & 441.4 & 45.3 & 4737.7 & 567.5 & -2502.2 & 3076.9 & 710.8 & -3452.4 \\
\hline
\end{tabular}

Source: Model Simulation 
Table 5.9 Philippines. Average Annual Import Changes under the APEC Scenario Relative to the Baseline Scenario (US\$ million)

\begin{tabular}{|c|c|c|c|c|c|c|c|c|}
\hline & IDN & MYS & SGP & THA & EUR & JPN & USA & ROW \\
\hline Rice & 0.0 & 0.0 & 0.1 & -3.8 & 0.0 & -0.9 & 0.0 & 1.1 \\
\hline Other cereal & 0.0 & 0.0 & 0.2 & 0.0 & 0.0 & 0.0 & 176.3 & -35.8 \\
\hline Crops & 5.3 & 2.5 & 3.8 & -3.9 & -2.0 & 1.2 & 30.1 & -17.0 \\
\hline Oil seeds & 0.0 & 0.0 & 0.0 & -0.2 & 0.0 & 0.0 & 0.5 & 0.8 \\
\hline Livestock & 0.0 & 0.1 & 0.2 & 0.3 & 0.1 & 1.3 & 5.6 & 1.1 \\
\hline $\begin{array}{l}\text { Unprocessed } \\
\text { agric. Products }\end{array}$ & 5.2 & 2.6 & 4.3 & -7.6 & -1.9 & 1.6 & 212.3 & -49.9 \\
\hline Sugar & 0.1 & -0.1 & -0.1 & 0.5 & -0.4 & 0.0 & 1.8 & -1.7 \\
\hline Vegetable oil & -2.1 & -2.6 & -2.9 & 0.0 & 0.1 & 0.0 & 0.0 & 4.0 \\
\hline Processed meat & -0.5 & -5.9 & -7.0 & -1.1 & 2.7 & -0.4 & -16.8 & 24.4 \\
\hline Processed milk & 0.0 & 0.7 & 16.2 & 0.2 & -5.3 & 0.0 & 26.8 & -26.5 \\
\hline $\begin{array}{l}\text { Processed other } \\
\text { crops }\end{array}$ & 1.1 & 0.6 & 1.3 & 2.9 & -1.1 & 0.9 & 9.9 & -2.7 \\
\hline $\begin{array}{l}\text { Beverages and } \\
\text { tobacco products }\end{array}$ & 0.4 & 0.4 & 75.9 & 1.9 & -19.1 & 1.1 & 8.5 & -18.8 \\
\hline $\begin{array}{l}\text { Processed agric. } \\
\text { Products }\end{array}$ & -1.0 & -6.8 & 83.4 & 4.4 & -23.1 & 1.6 & 30.2 & -21.3 \\
\hline $\begin{array}{l}\text { Mining and } \\
\text { mineral products }\end{array}$ & -20.7 & -2.1 & 63.8 & 15.3 & -1.6 & 13.9 & 100.0 & -95.5 \\
\hline $\begin{array}{l}\text { Clothing and } \\
\text { textiles }\end{array}$ & 49.2 & 26.8 & 6.7 & 57.3 & -7.0 & 64.6 & 45.0 & -102.4 \\
\hline Manufacturing & 160.5 & 417.2 & 937.5 & 273.9 & -1349.8 & 2077.2 & 1974.1 & -2735.0 \\
\hline Services & 1.1 & 0.5 & 1.9 & 2.7 & 74.3 & 6.9 & 18.9 & 43.0 \\
\hline $\begin{array}{l}\text { Non-agric. } \\
\text { Products }\end{array}$ & 190.2 & 442.4 & 1009.8 & 349.2 & -1284.1 & 2162.5 & 2138.0 & -2889.9 \\
\hline
\end{tabular}

Source: Model Simulation 
Table 5.10 Singapore. Average Annual Import Changes under the APEC Scenario Relative to the Baseline Scenario (US\$ million)

\begin{tabular}{|c|c|c|c|c|c|c|c|c|}
\hline & IDN & MYS & PHL & THA & EUR & JPN & USA & ROW \\
\hline Rice & 0.0 & 0.0 & 0.0 & 3.5 & 0.0 & 0.0 & 0.7 & 0.0 \\
\hline Other cereal & 0.0 & -0.4 & 0.0 & -0.2 & 0.0 & 0.0 & 1.4 & -0.8 \\
\hline Crops & 57.0 & 11.2 & 6.5 & -12.1 & -6.5 & 8.4 & 67.6 & -105.4 \\
\hline Oil seeds & 0.0 & 0.9 & 0.0 & 0.0 & 0.0 & 0.2 & 3.7 & -3.5 \\
\hline Livestock & 0.1 & 74.8 & 0.0 & 0.9 & -0.7 & 0.0 & 5.5 & -14.1 \\
\hline $\begin{array}{l}\text { Unprocessed } \\
\text { agric. Products }\end{array}$ & 57.1 & 86.5 & 6.5 & -7.9 & -7.2 & 8.5 & 79.0 & -123.9 \\
\hline Sugar & 0.0 & 0.6 & 0.3 & 1.2 & -0.3 & 0.0 & 0.3 & -3.1 \\
\hline Vegetable oil & -0.6 & -28.4 & -0.9 & 0.1 & 2.2 & 0.0 & -1.4 & 10.6 \\
\hline Processed meat & 1.5 & 15.8 & 0.1 & -10.4 & 2.6 & 1.6 & -4.7 & 9.5 \\
\hline Processed milk & 0.0 & -13.1 & -0.4 & -3.0 & 1.9 & -0.5 & -3.9 & 6.9 \\
\hline $\begin{array}{l}\text { Processed other } \\
\text { crops }\end{array}$ & 1.0 & 7.1 & 0.5 & 28.4 & -2.0 & 3.2 & 3.7 & -6.8 \\
\hline $\begin{array}{l}\text { Beverages and } \\
\text { tobacco products }\end{array}$ & 0.0 & -1.1 & 0.0 & 0.3 & 22.6 & 2.0 & 0.3 & 11.3 \\
\hline $\begin{array}{l}\text { Processed agric. } \\
\text { Products }\end{array}$ & 1.9 & -19.2 & -0.4 & 16.6 & 27.1 & 6.2 & -5.7 & 28.4 \\
\hline $\begin{array}{l}\text { Mining and } \\
\text { mineral products }\end{array}$ & 92.8 & -66.9 & 100.8 & -3.9 & -12.7 & 271.5 & 63.4 & -214.2 \\
\hline $\begin{array}{l}\text { Clothing and } \\
\text { textiles }\end{array}$ & 30.9 & 1.8 & 0.9 & 91.3 & 2.0 & -13.1 & -3.0 & 21.6 \\
\hline Manufacturing & -35.7 & 1327.5 & 191.6 & 442.8 & 418.6 & -1110.9 & 92.9 & 995.5 \\
\hline Services & 8.3 & 4.6 & 7.6 & 19.2 & 316.8 & 239.3 & 253.7 & 392.9 \\
\hline $\begin{array}{l}\text { Non-agric. } \\
\text { Products }\end{array}$ & 96.3 & 1266.9 & 300.9 & 549.5 & 724.7 & -613.3 & 406.9 & 1195.8 \\
\hline
\end{tabular}

Source: Model Simulation 
Table 5.11 Thailand. Average Annual Import Changes under the APEC Scenario Relative to the Baseline Scenario (US\$ million)

\begin{tabular}{|c|c|c|c|c|c|c|c|c|}
\hline & IDN & MYS & PHL & SGP & EUR & JPN & USA & ROW \\
\hline Rice & 0.0 & 0.0 & 0.0 & 0.0 & 0.0 & 0.0 & 0.0 & 0.0 \\
\hline Other cereal & 0.0 & 0.1 & 0.0 & 0.0 & 0.0 & 0.0 & 131.2 & -70.4 \\
\hline Crops & 11.5 & 6.3 & 3.7 & 3.7 & -10.1 & 20.9 & 319.4 & -92.5 \\
\hline Oil seeds & 0.0 & 0.0 & 0.0 & 0.0 & 0.0 & 0.0 & 20.1 & -6.4 \\
\hline Livestock & 1.7 & -0.2 & 1.4 & 1.4 & -3.9 & -0.2 & -2.7 & -16.9 \\
\hline $\begin{array}{l}\text { Unprocessed } \\
\text { agric. Products }\end{array}$ & 13.3 & 6.2 & 5.1 & 5.1 & -14.0 & 20.7 & 468.1 & -186.2 \\
\hline Sugar & 0.0 & 0.0 & 0.0 & 0.0 & -0.3 & 0.9 & 1.1 & -0.9 \\
\hline Vegetable oil & -0.5 & -7.0 & -11.6 & -11.6 & 0.4 & -0.1 & 0.0 & 4.3 \\
\hline Processed meat & -5.2 & -13.0 & -15.0 & -15.0 & 3.0 & -4.4 & -3.7 & 6.0 \\
\hline Processed milk & 0.0 & 0.0 & 2.9 & 2.9 & -4.6 & 1.0 & 17.8 & -19.3 \\
\hline $\begin{array}{l}\text { Processed other } \\
\text { crops }\end{array}$ & 8.3 & 0.4 & 1.1 & 1.1 & -21.4 & 8.5 & -2.2 & -86.3 \\
\hline $\begin{array}{l}\text { Beverages and } \\
\text { tobacco products }\end{array}$ & 0.0 & 0.0 & 1.4 & 1.4 & -30.9 & 4.7 & 22.3 & -1.4 \\
\hline $\begin{array}{l}\text { Processed agric. } \\
\text { Products }\end{array}$ & 2.6 & -19.5 & -21.1 & -21.1 & -53.8 & 10.6 & 35.2 & -97.6 \\
\hline $\begin{array}{l}\text { Mining and } \\
\text { mineral products }\end{array}$ & 9.6 & -128.0 & 300.2 & 300.2 & -35.7 & 16.3 & 27.7 & -287.5 \\
\hline $\begin{array}{l}\text { Clothing and } \\
\text { textiles }\end{array}$ & 29.2 & 5.4 & 5.2 & 5.2 & -26.1 & 73.9 & -1.0 & -227.4 \\
\hline Manufacturing & 475.6 & 1132.9 & 1356.1 & 1356.1 & -6374.2 & 18917.3 & 1324.3 & -9473.5 \\
\hline Services & -7.6 & -7.3 & -52.8 & -52.8 & -581.7 & -75.2 & -167.1 & -284.9 \\
\hline $\begin{array}{l}\text { Non-agric. } \\
\text { Products }\end{array}$ & 506.8 & 1003.1 & 1608.8 & 1608.8 & -7017.6 & 18932.3 & 1183.9 & -10273.2 \\
\hline
\end{tabular}

Source: Model Simulation 
Figure 2.1 Destination of Rice Export (\%)

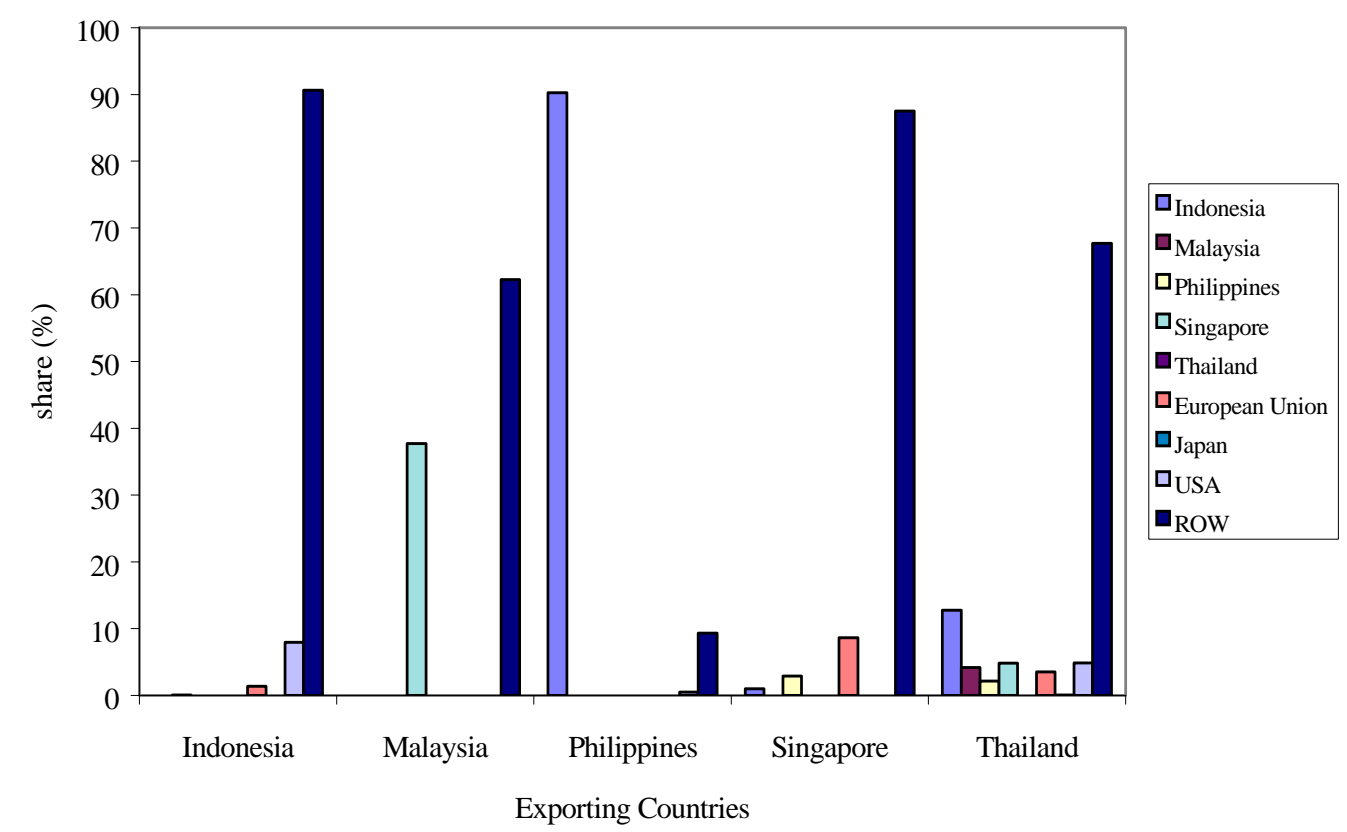

Source: GTAP Database Version 4

Figure 2.2 Destination of Cereal Export (\%)

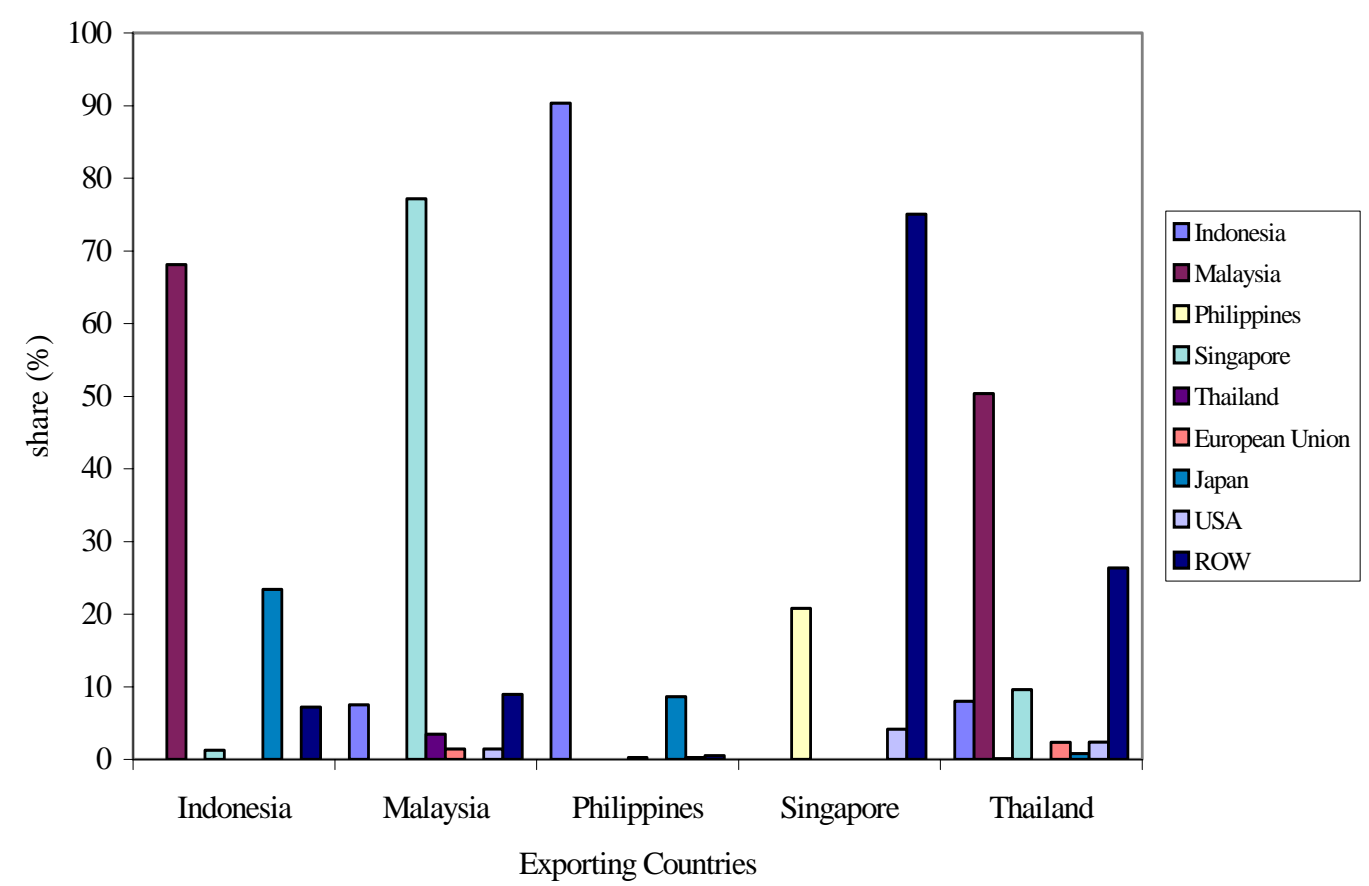

Source: GTAP Database Version 4 
Figure 2.3 Destination of Oil Seeds Export (\%)

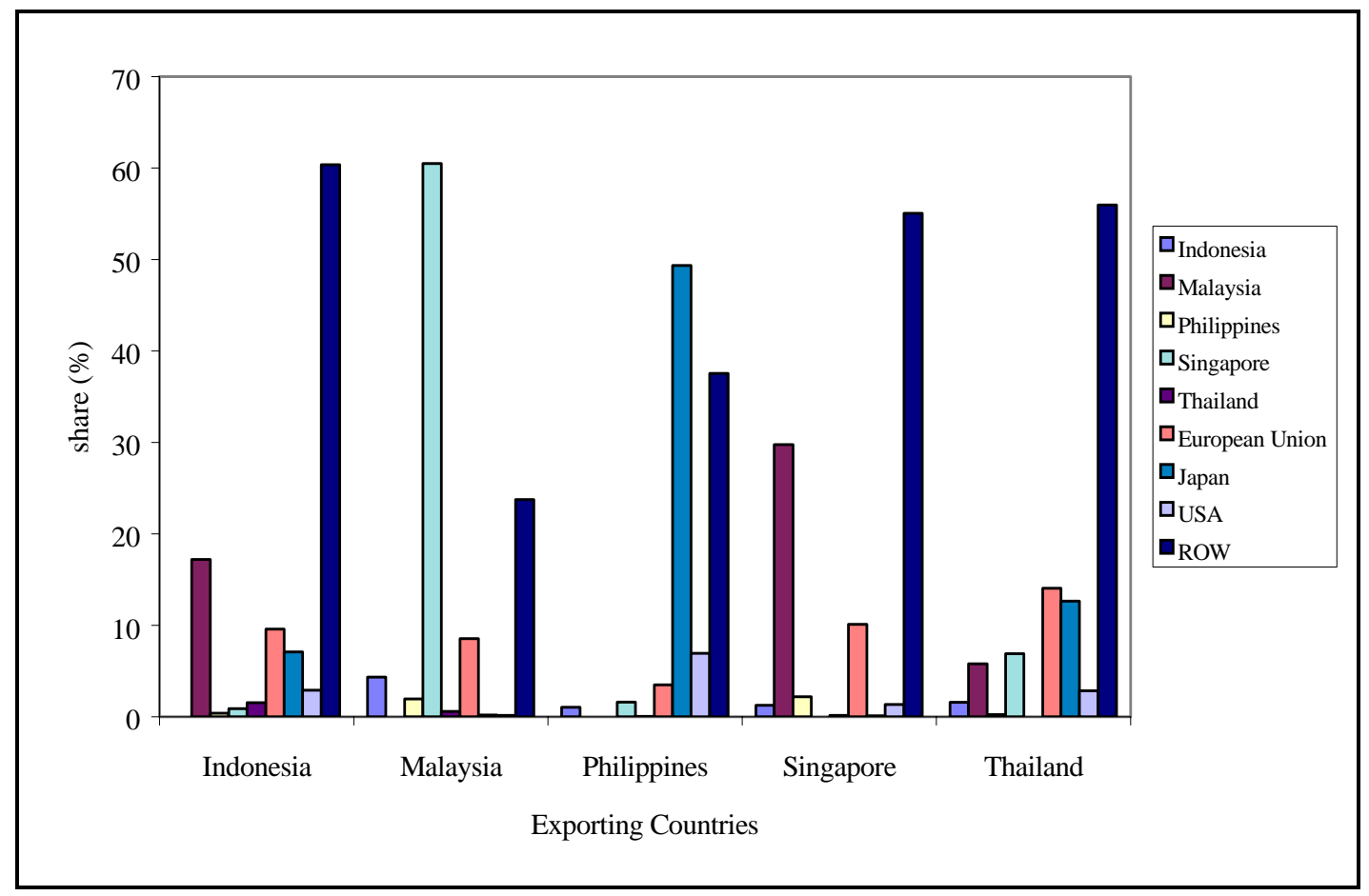

Source: GTAP Database Version 4

Figure 2.4 Destination of Other Crops Export (\%)

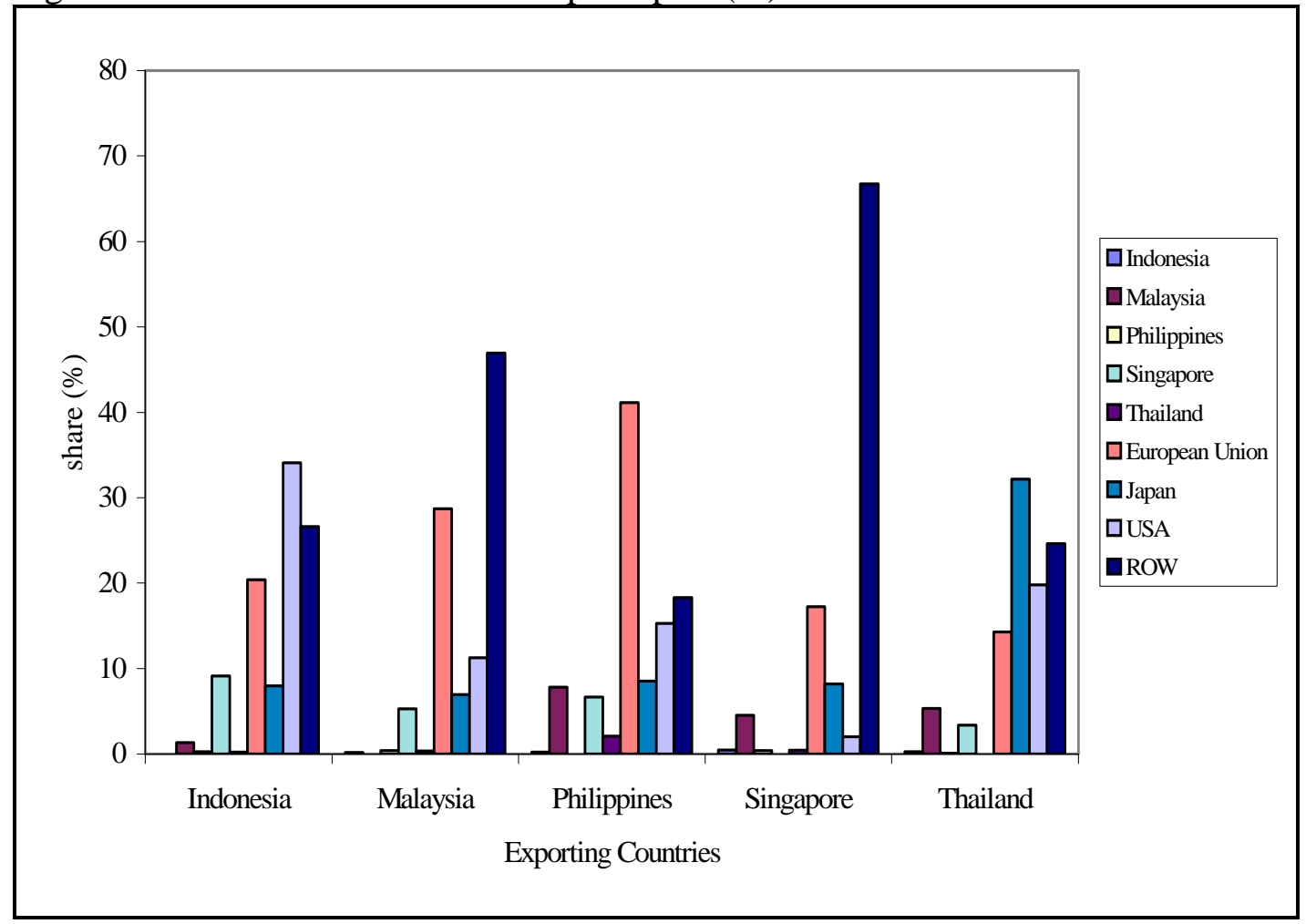

Source: GTAP Database Version 4 
Figure 2. 5 Destination of Livestock Export (\%)

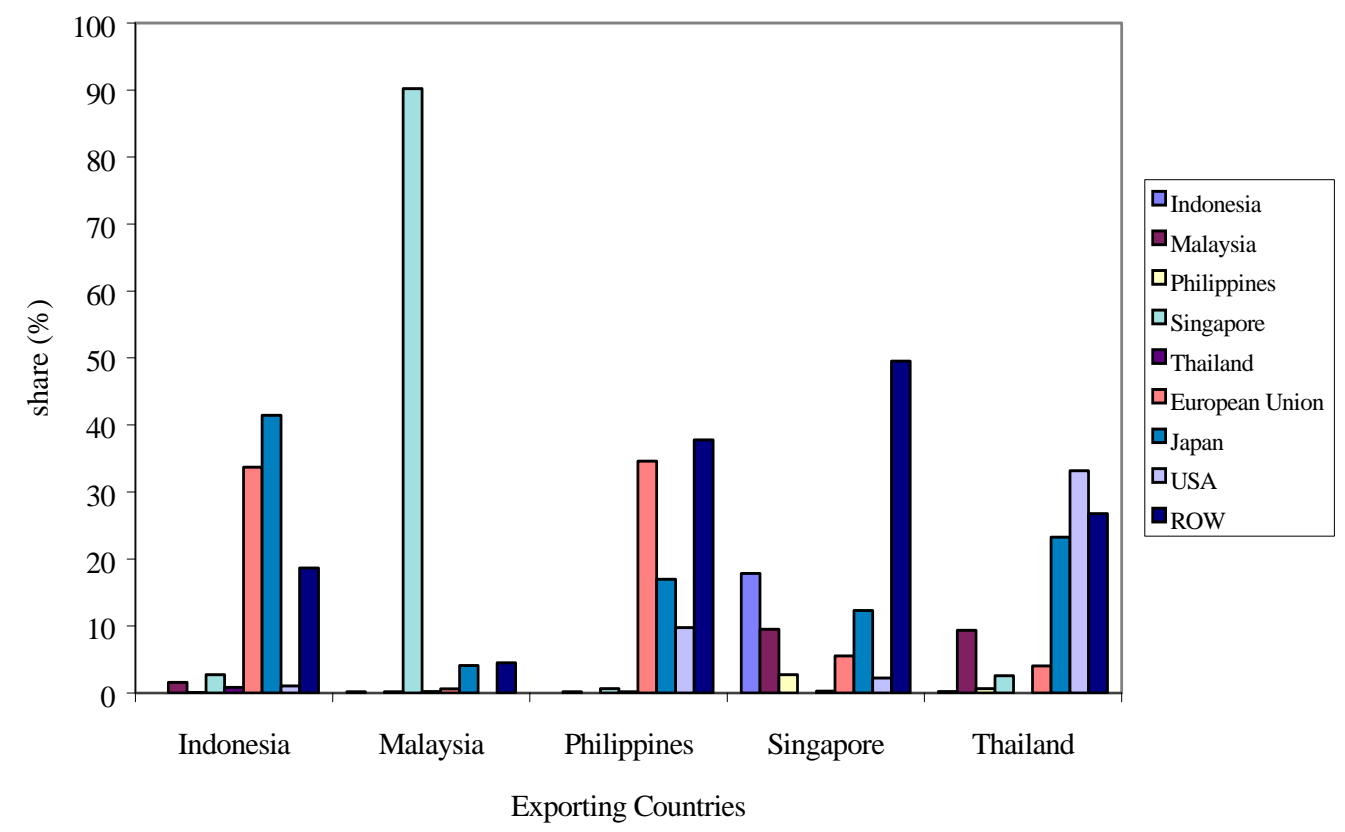

Source: GTAP Database Version 4

Figure 2. 6 Destination of Processed Meat Export (\%)

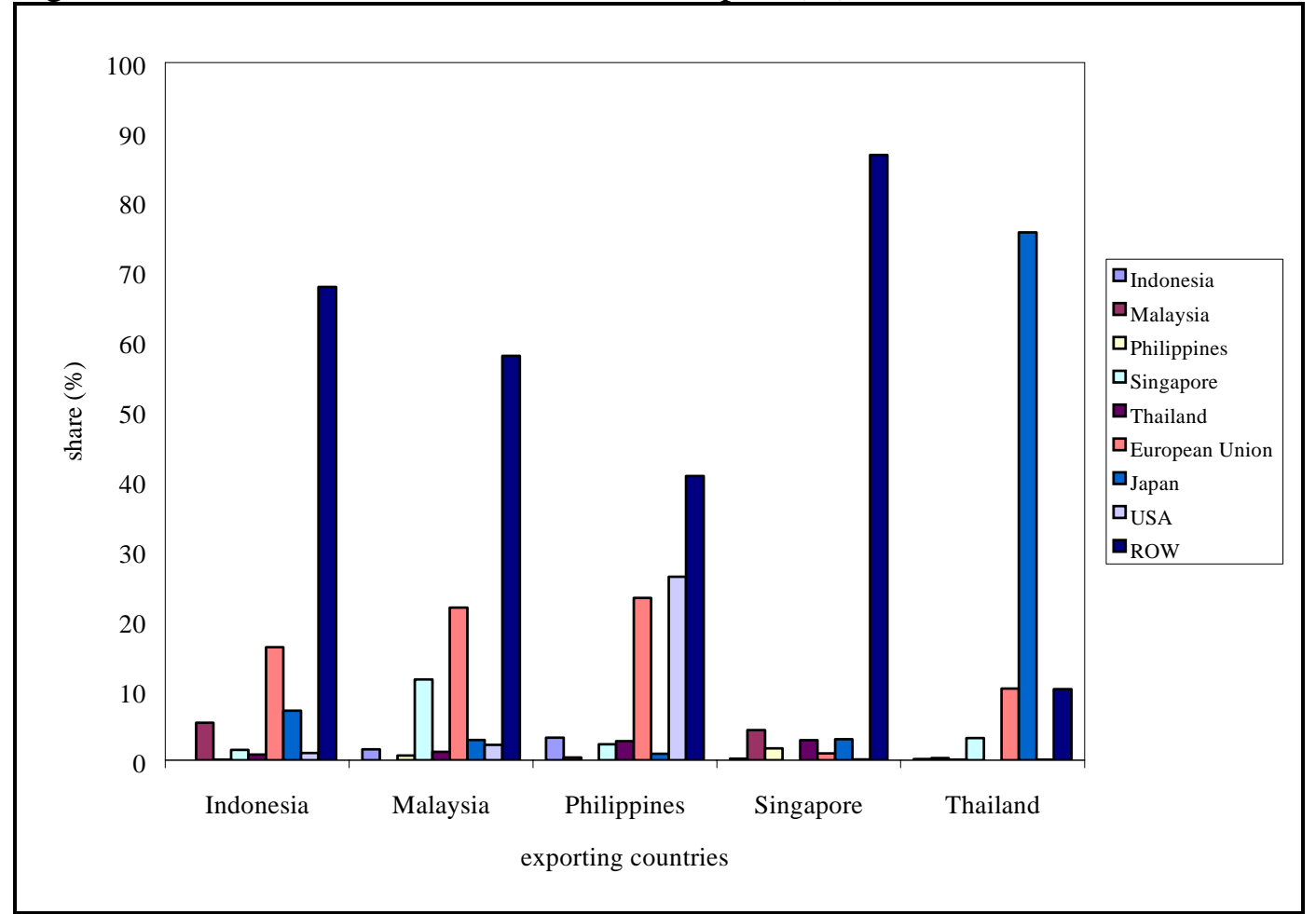

Source: GTAP Database Version 4 
Figure 2. 7 Destination of Processed Milk Export (\%)

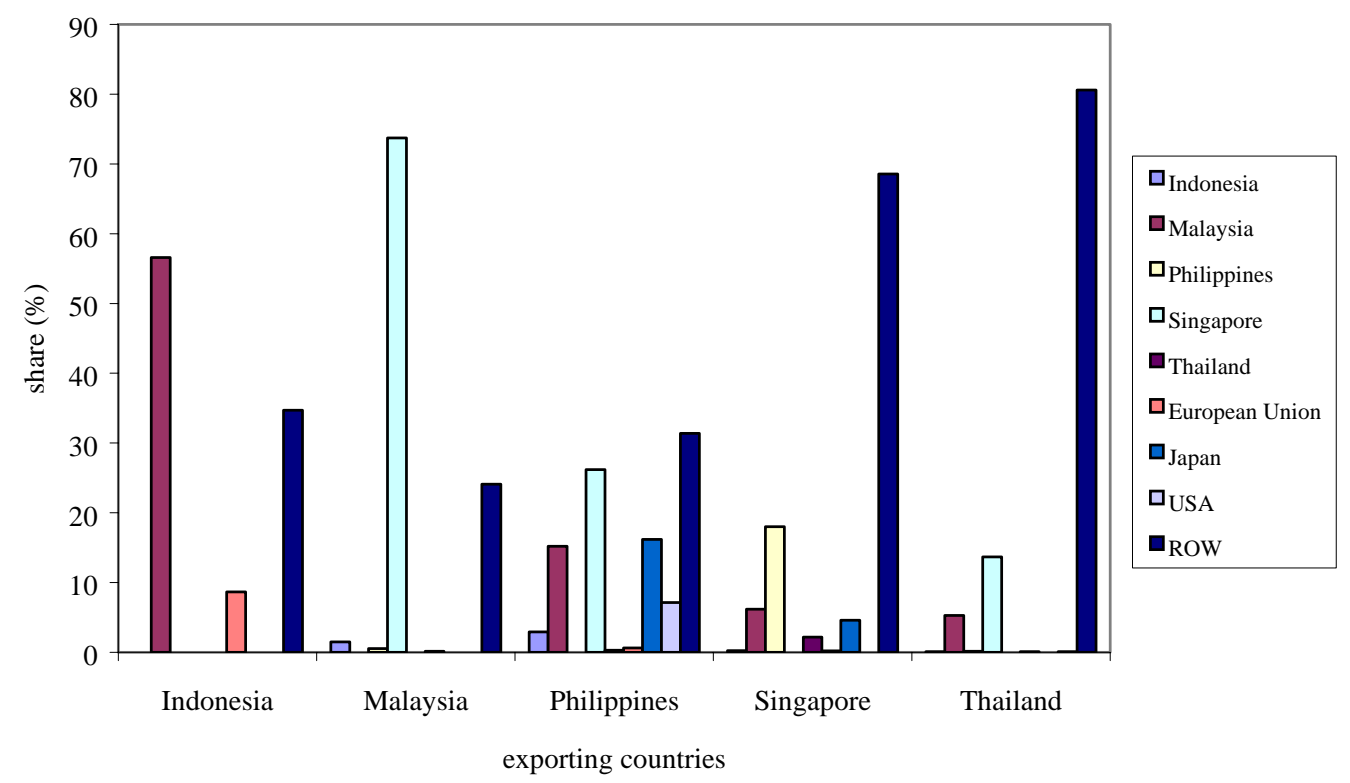

Source: GTAP Database Version 4

Figure 2. 8 Destination of Vegetable Oil Export (\%)

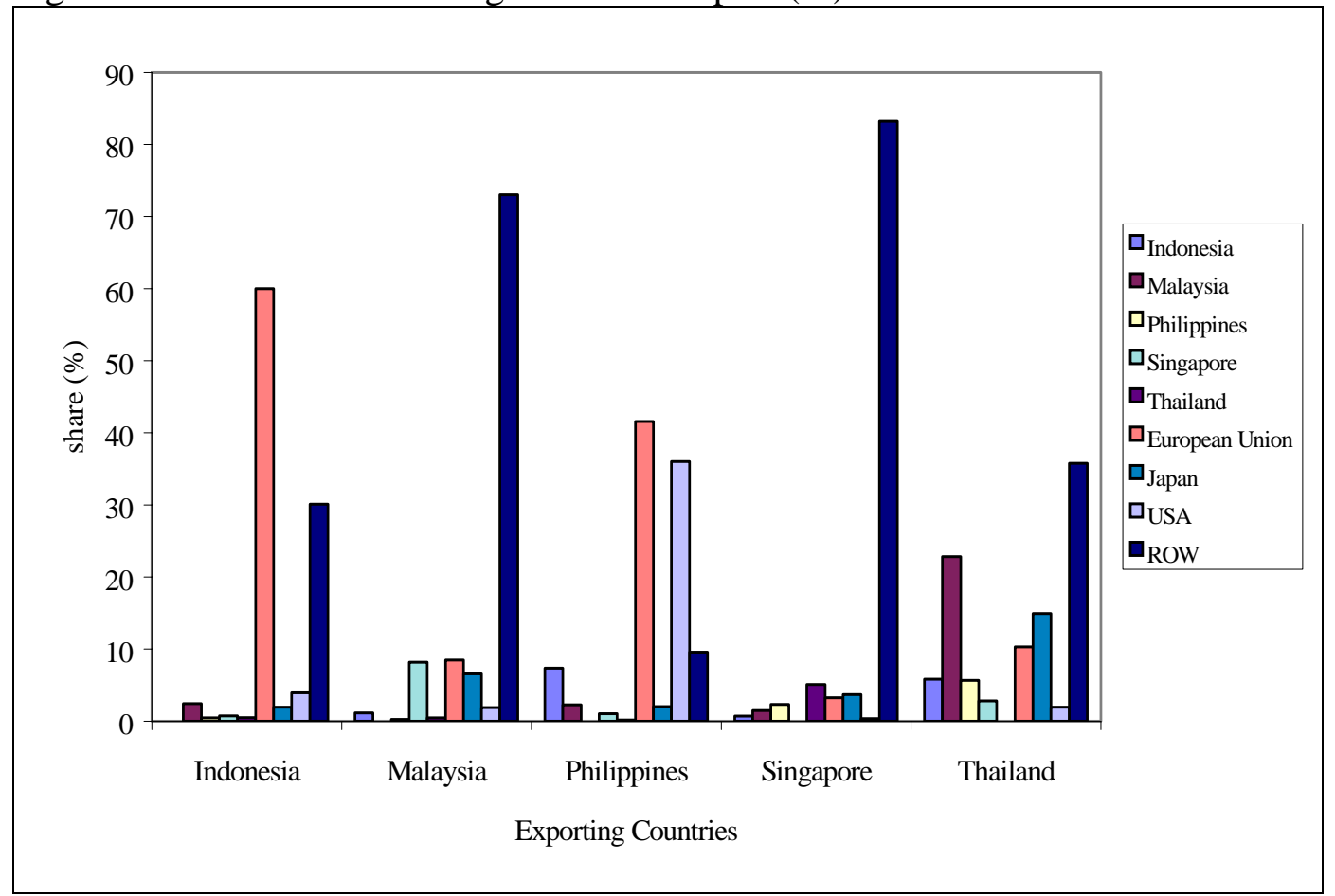

Source: GTAP Database Version 4 
Figure 2.9 Destination of Processed Other Crop Export (\%)

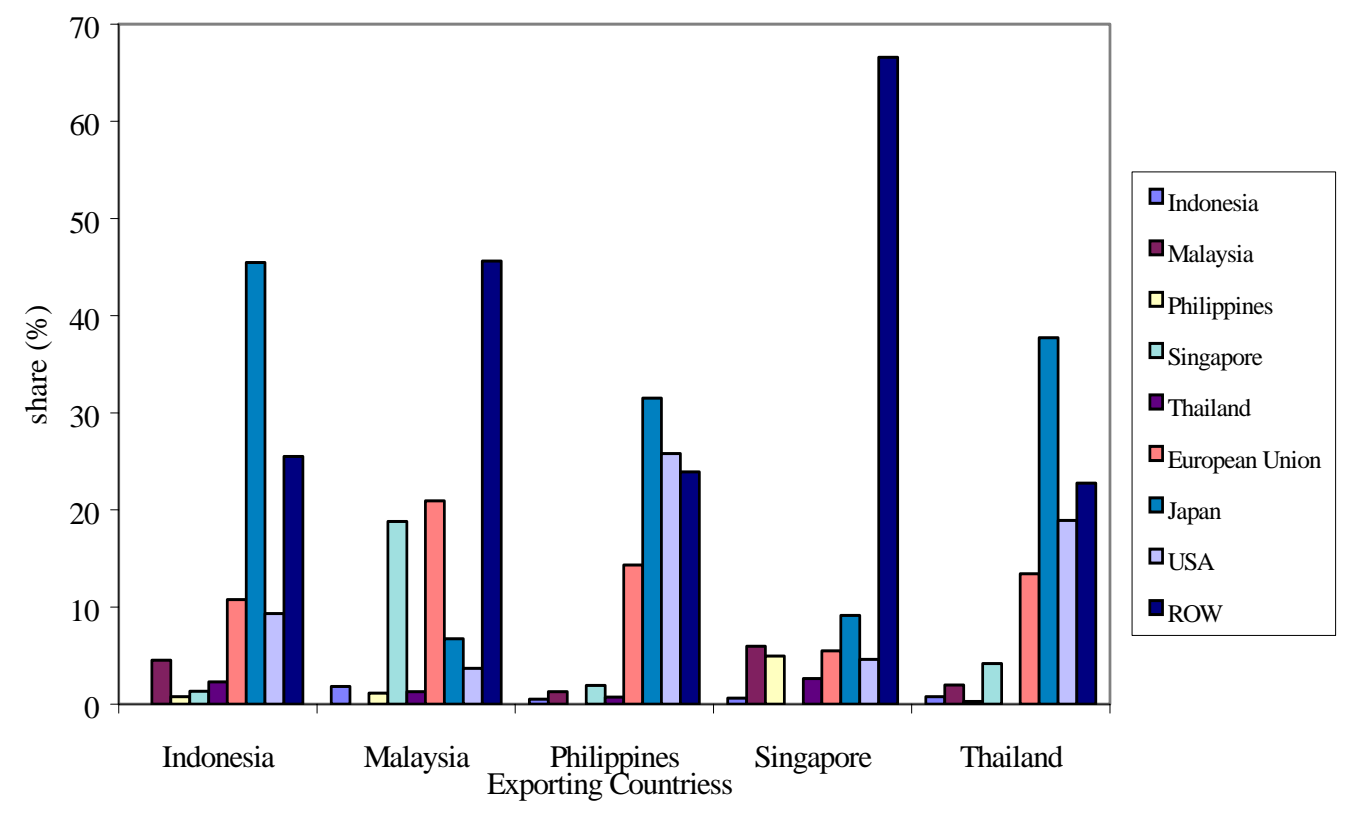

Source: GTAP Database Version 4

Figure 2. 10 Destination of Sugar Export (\%)

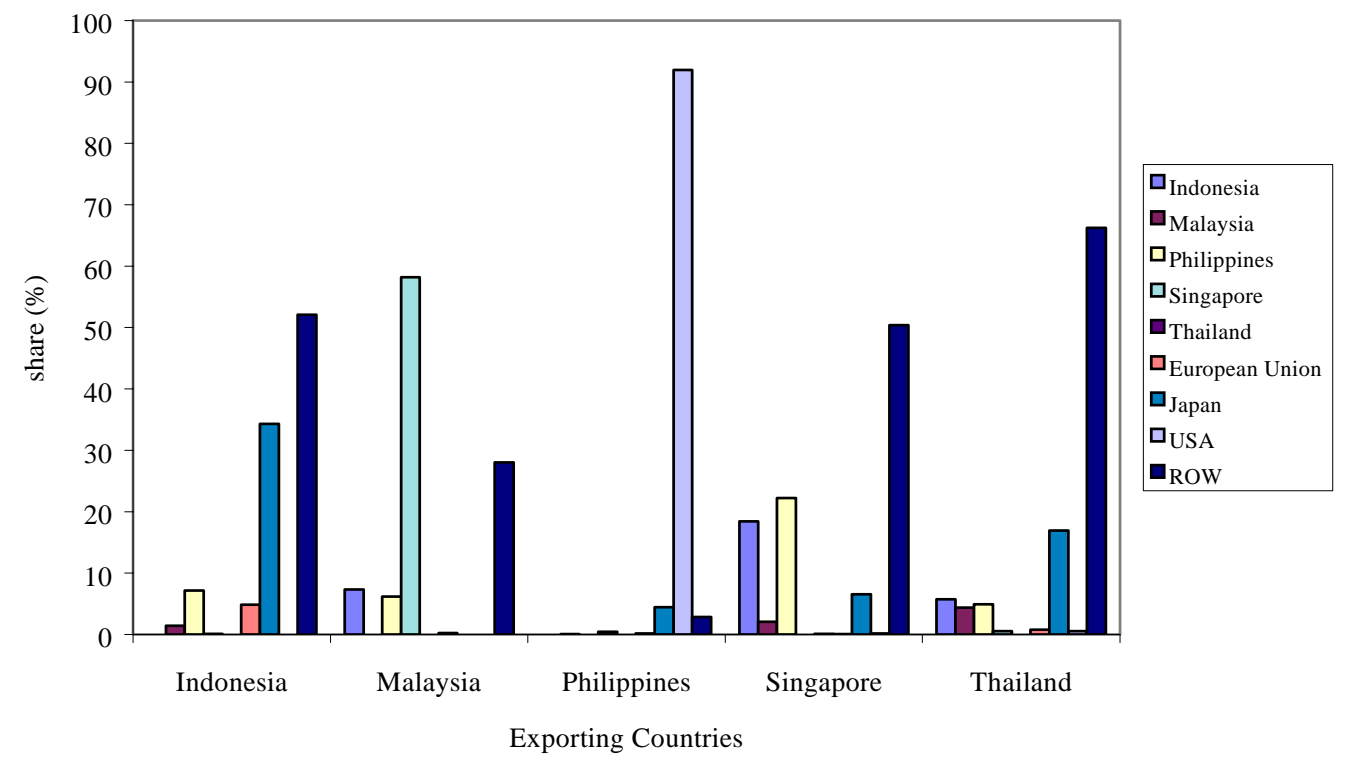

Source: GTAP Database Version 4 
Figure 2.11 Destination of Beverages and Tobacco Export (\%)

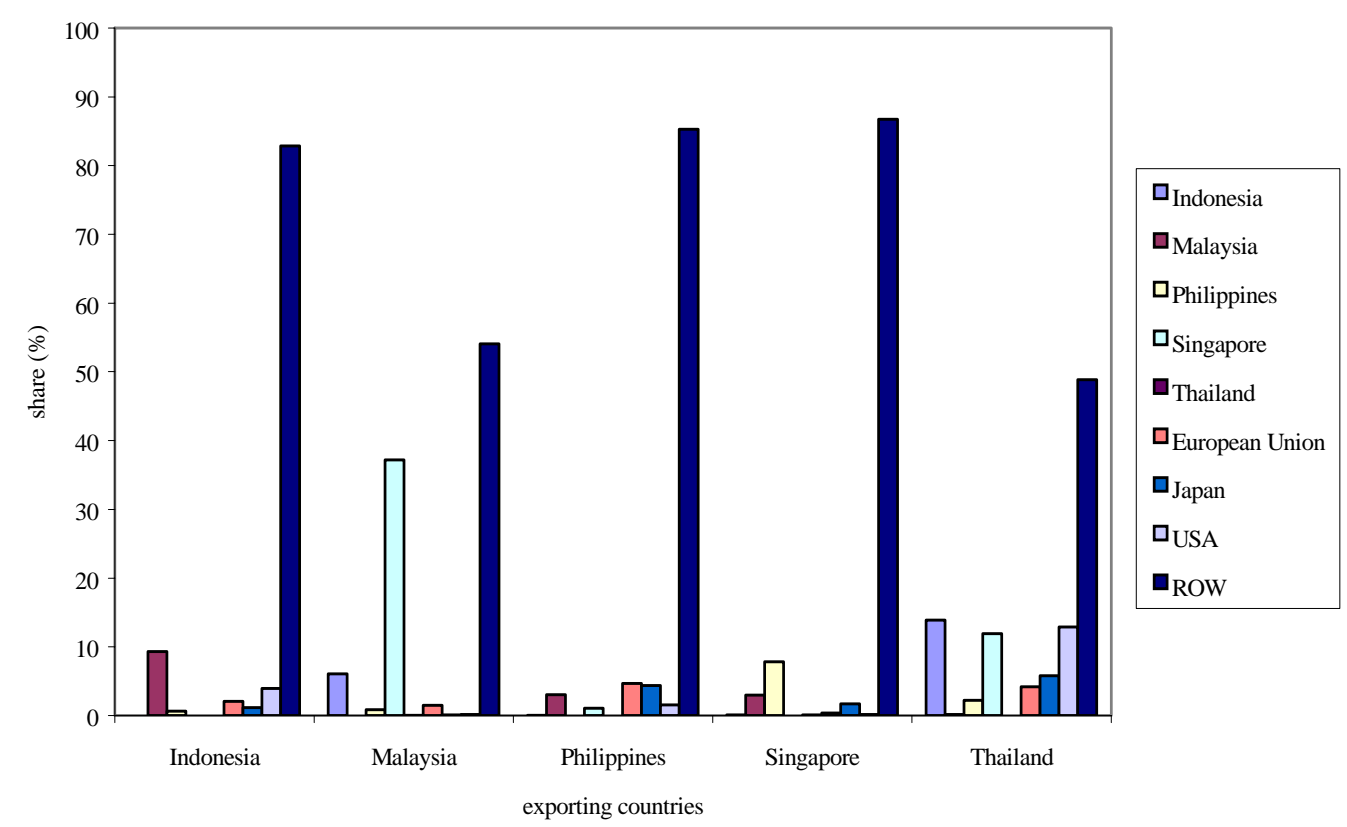

Source: GTAP Database Version 4

Figure 2.12 Source of Rice Import (\%)

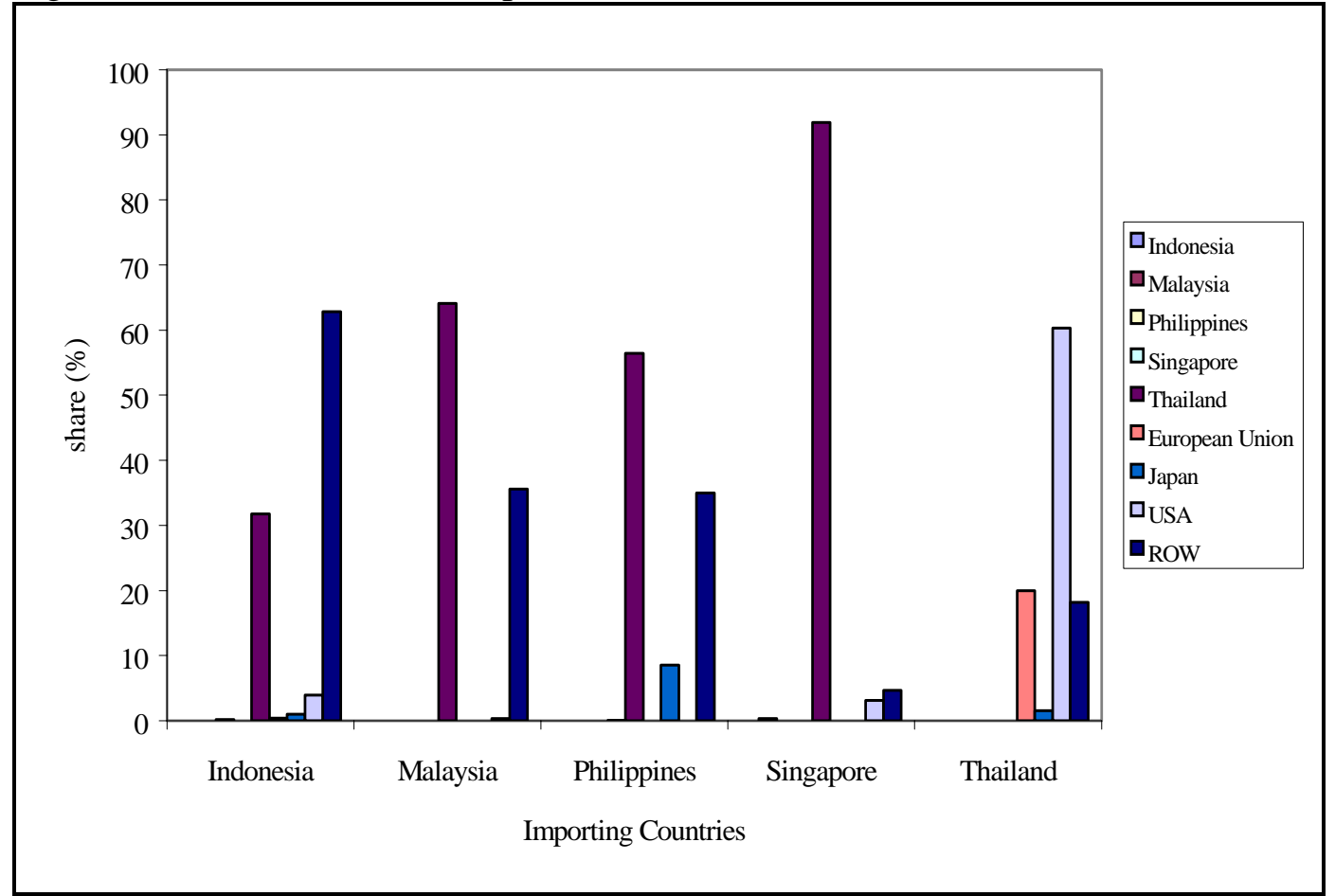

Source: GTAP Database Version 4 
Figure 2. 13 Source of Cereal Import (\%)

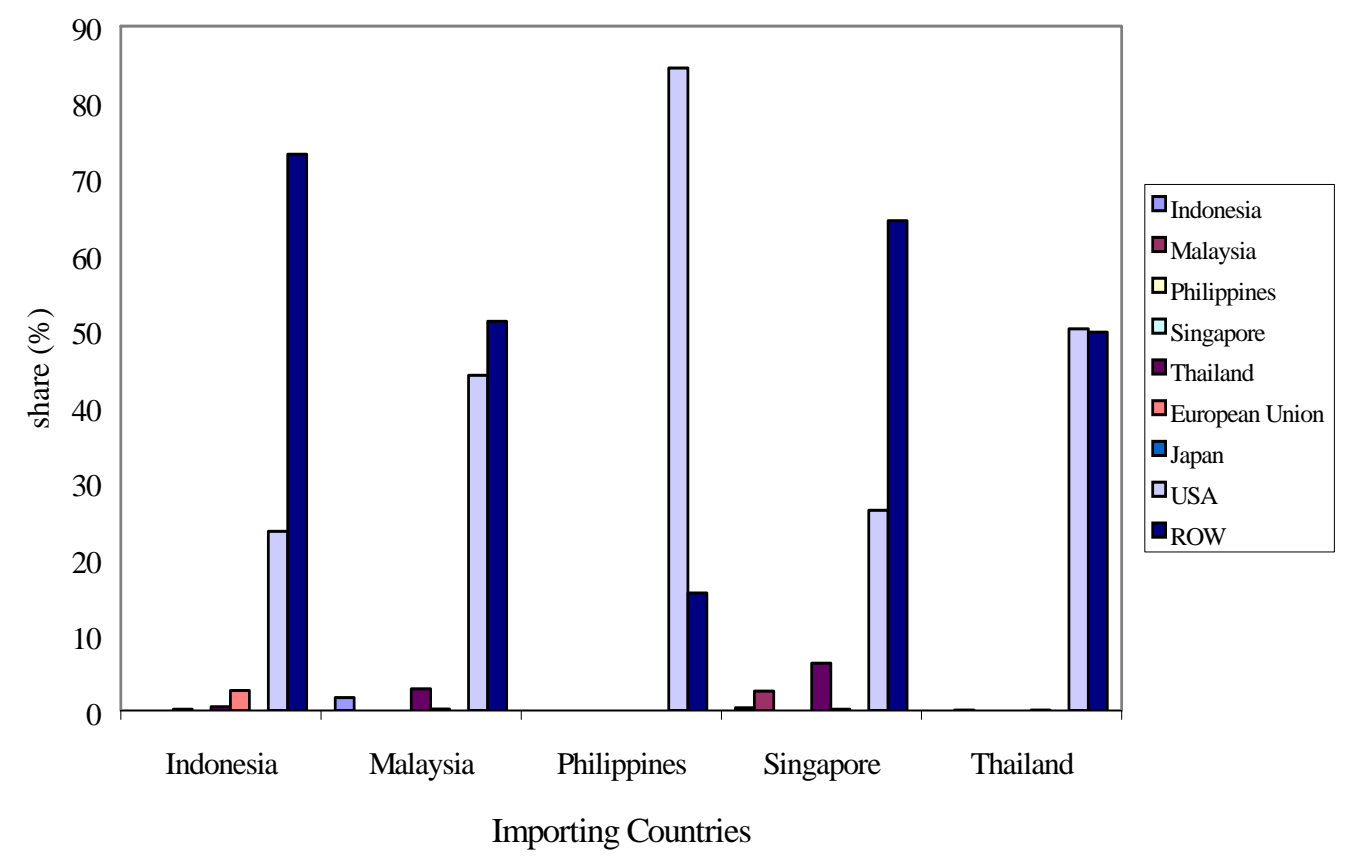

Source: GTAP Database Version 4

Figure 2. 14 Source of Vegetable Oil Seeds Import (\%)

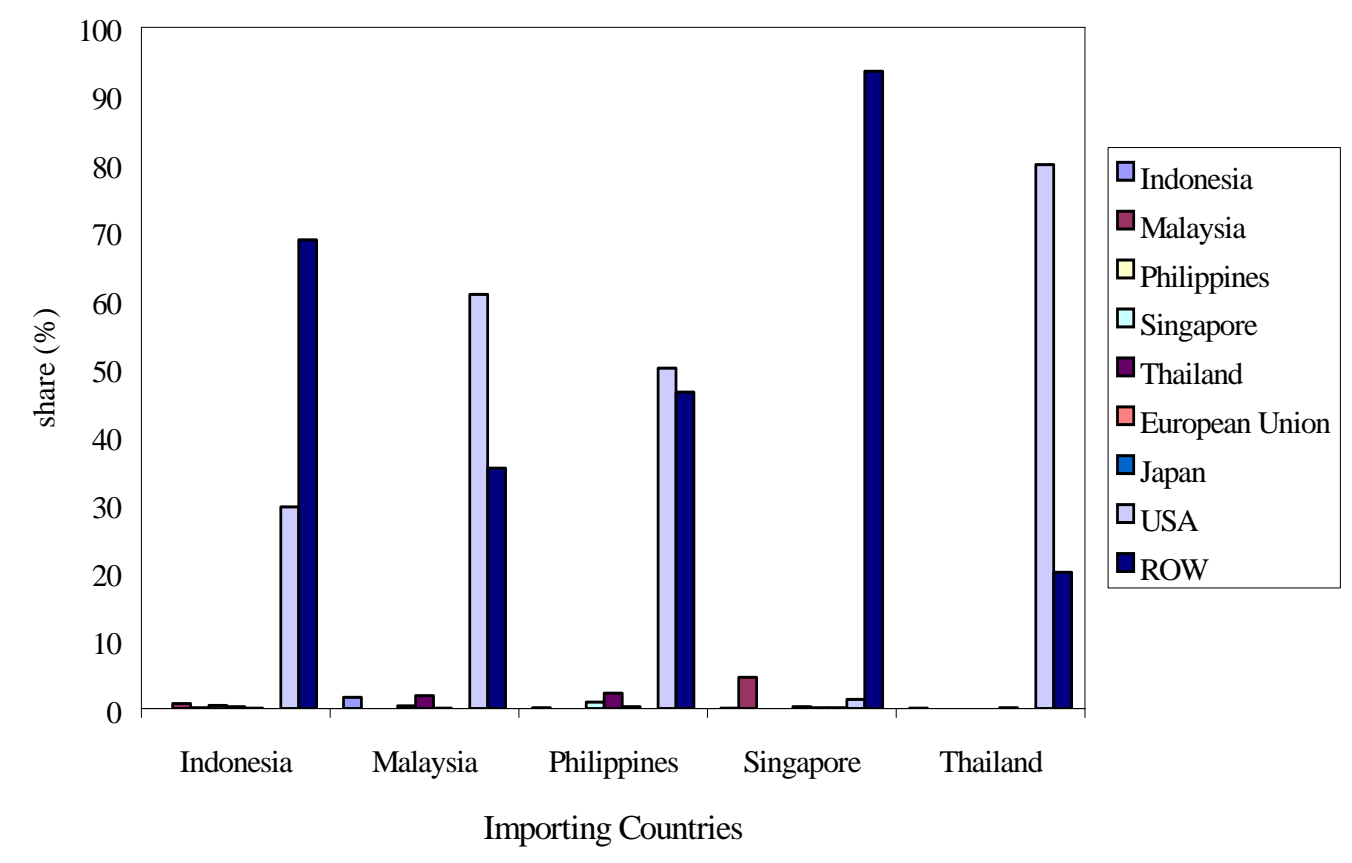

Source: GTAP Database Version 4 
Figure 2. 15 Source of Other Crops Import (\%)

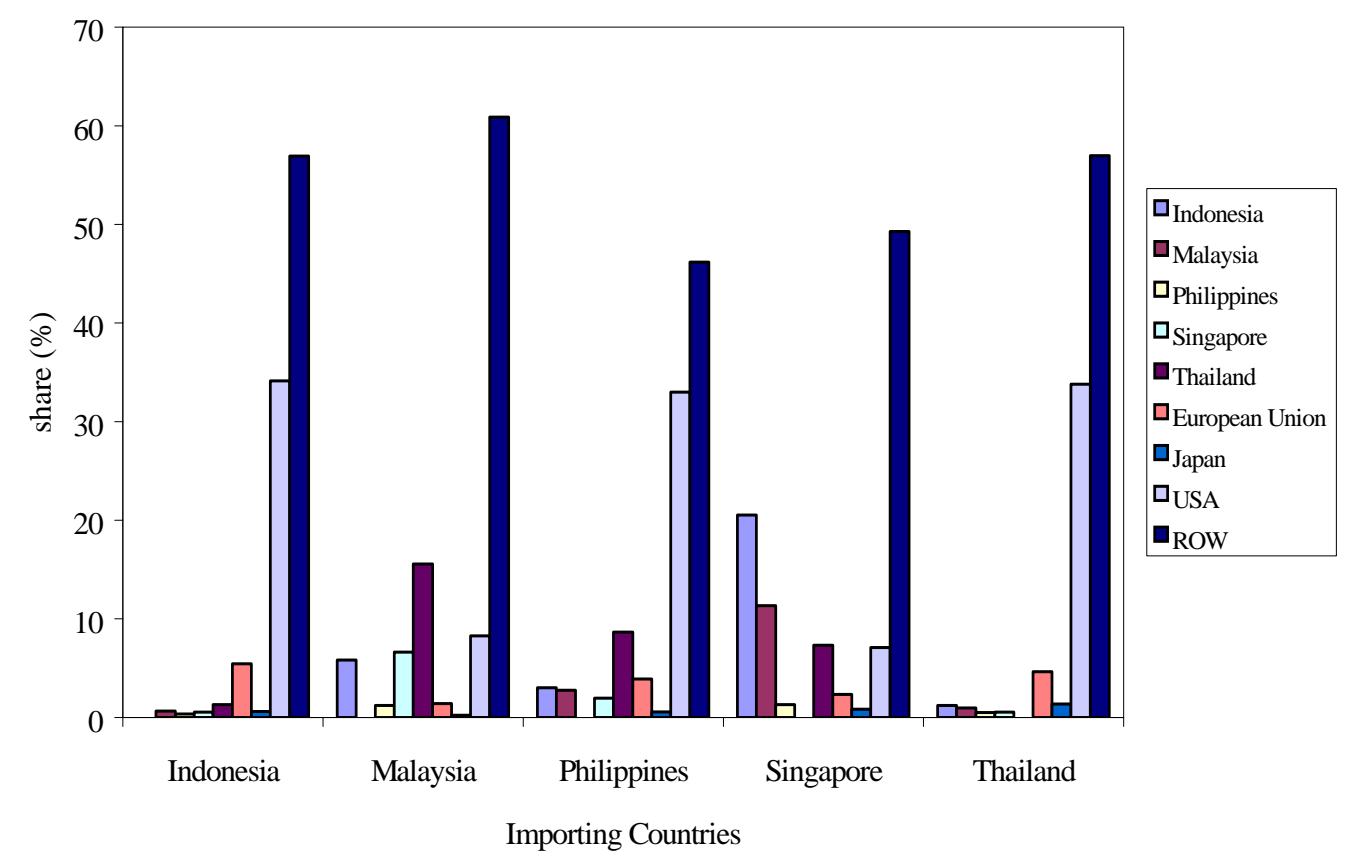

Source: GTAP Database Version 4

Figure 2. 16 Source of Livestock Import (\%)

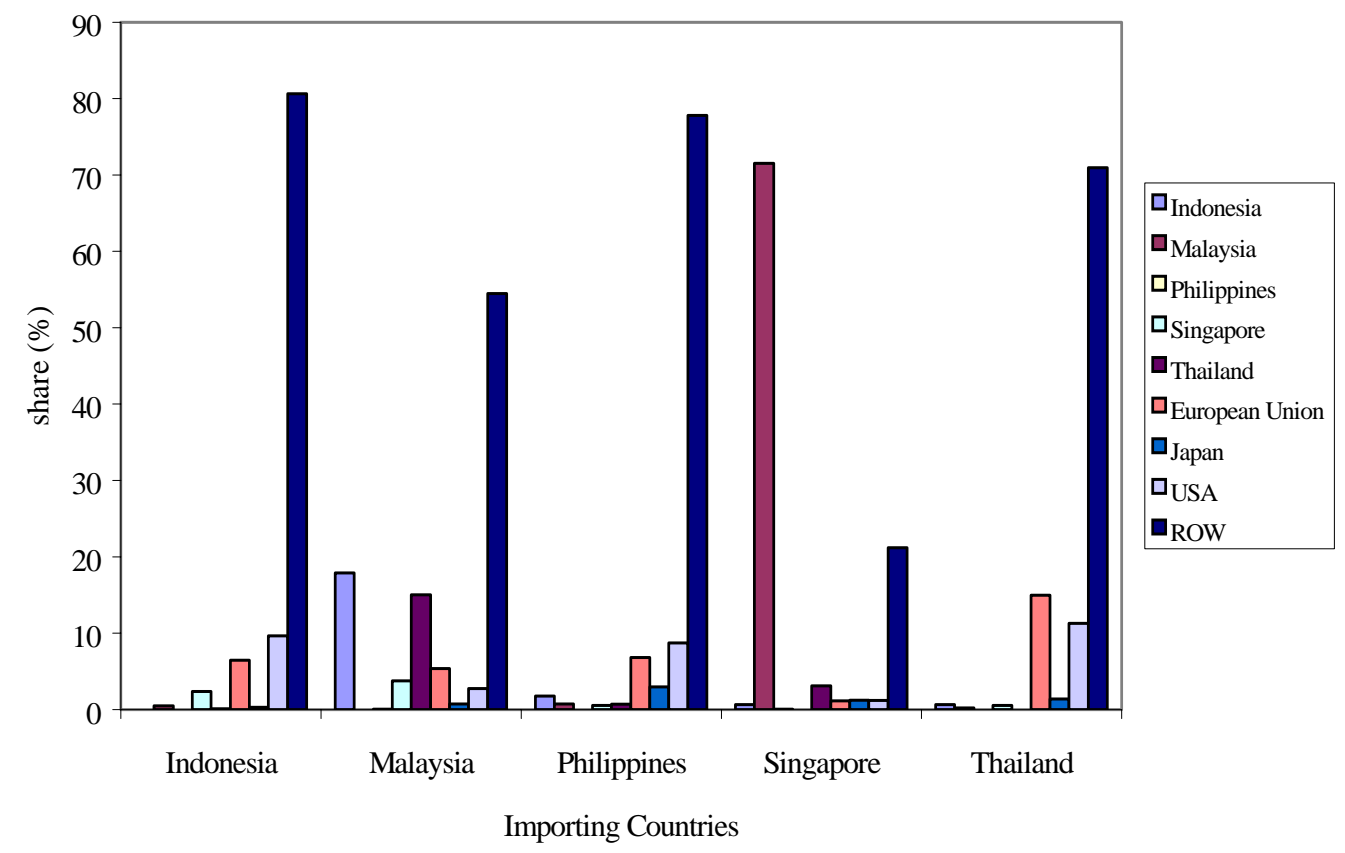

Source: GTAP Database Version 4 
Figure 2. 17 Source of Processed Other Crops Import (\%)

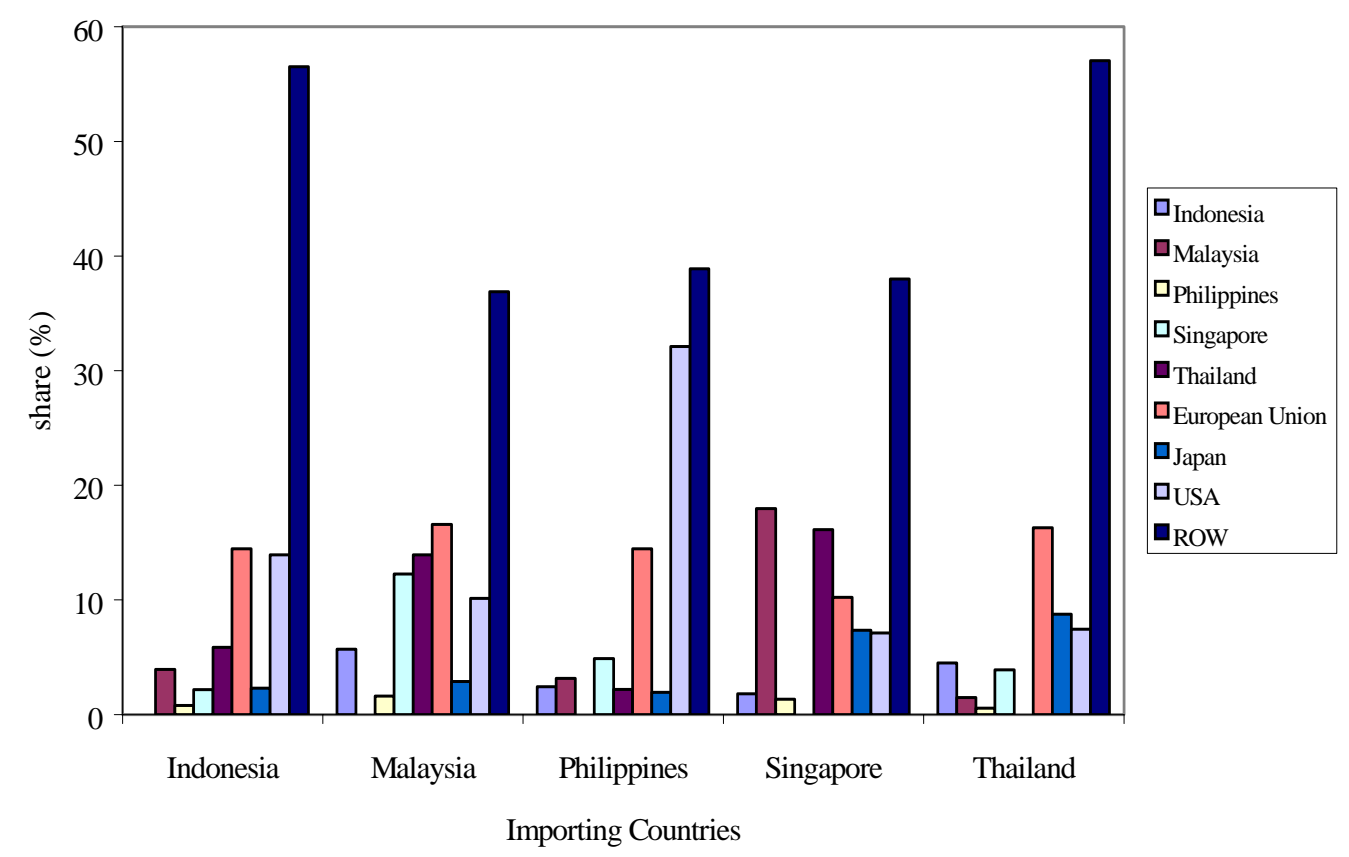

Source: GTAP Database Version 4

Figure 2. 18 Source of Processed Meat Import (\%)

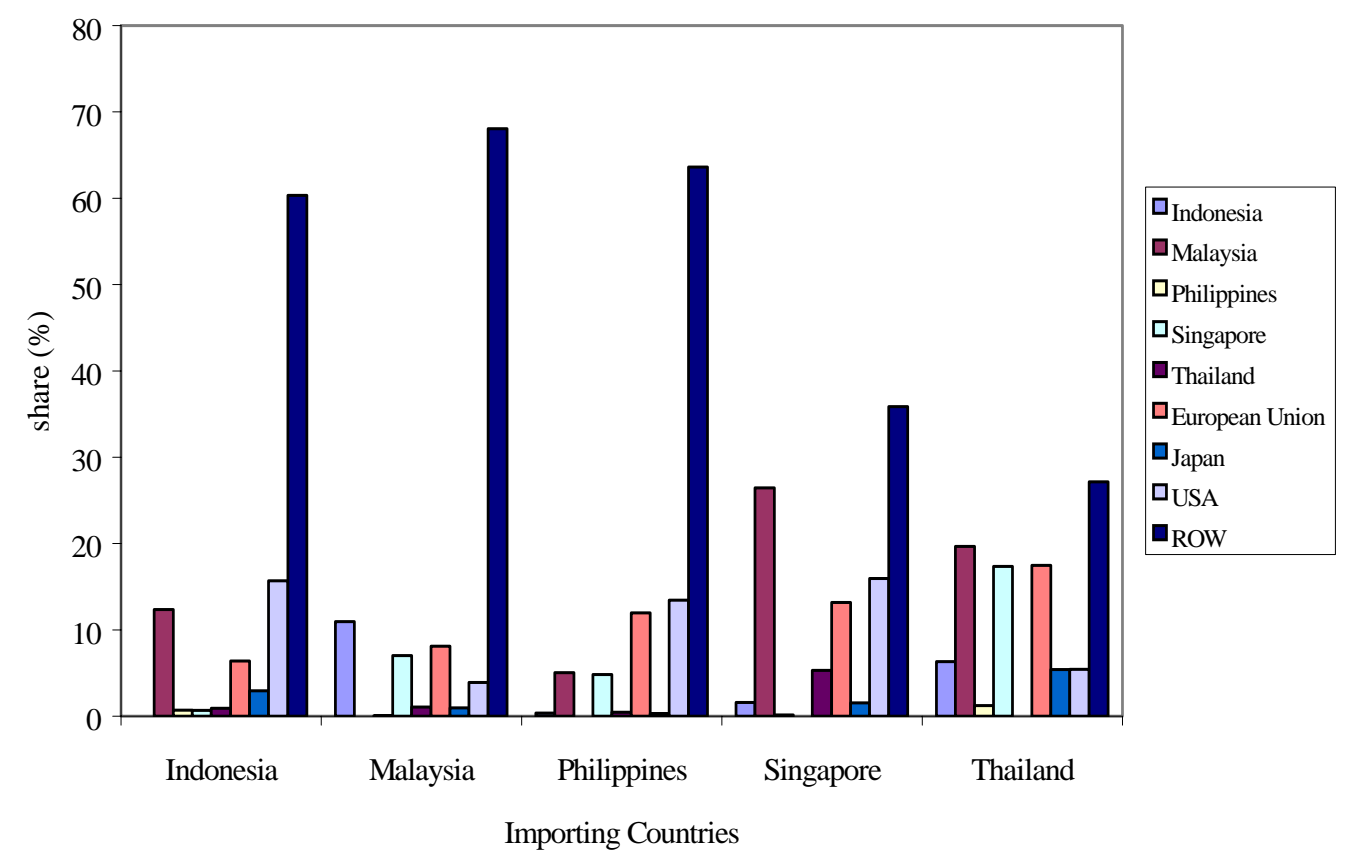

Source: GTAP Database Version 4 
Figure 2. 19 Source of Processed Milk Import (\%)

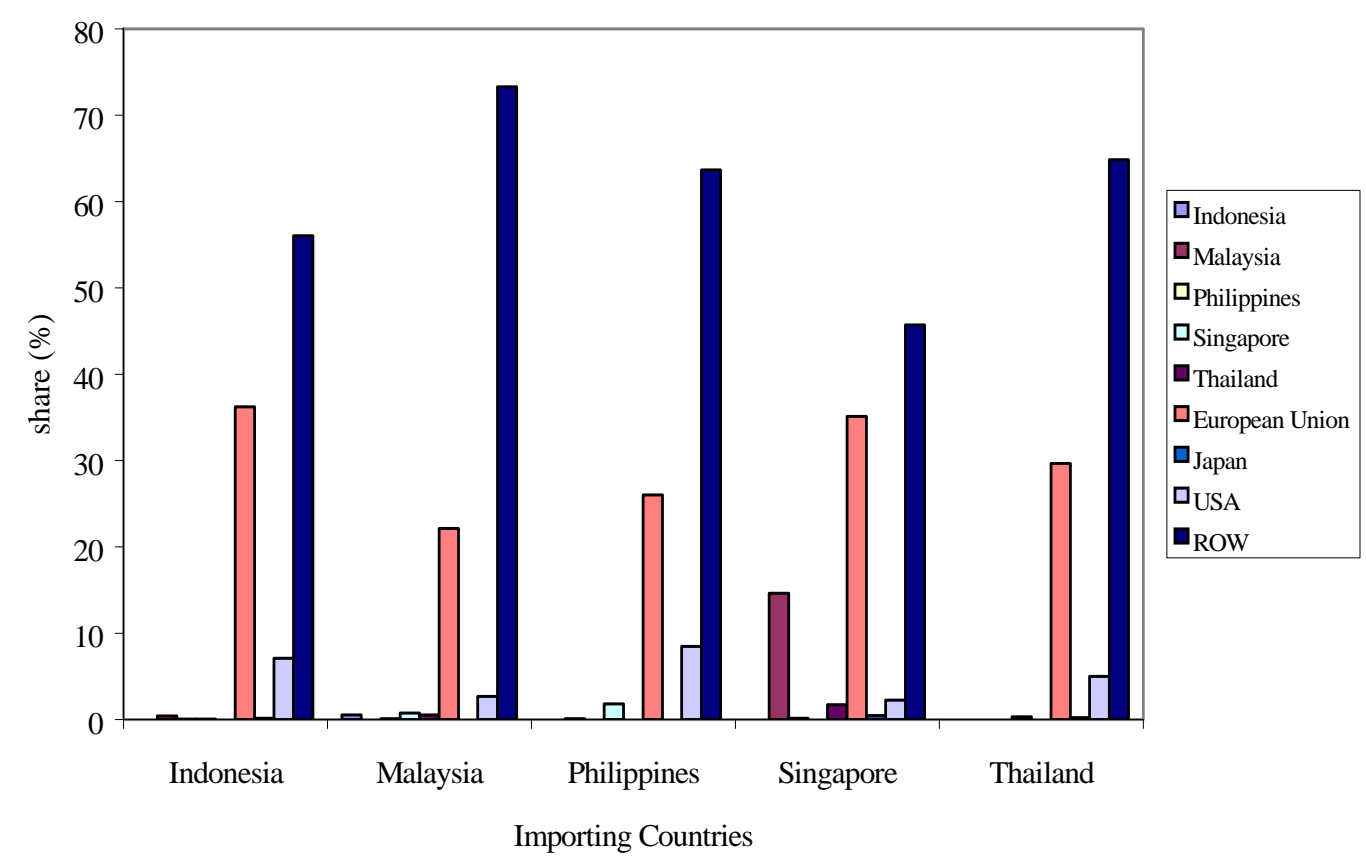

Source: GTAP Database Version 4

Figure 2. 20 Source of Vegetable Oil Import (\%)

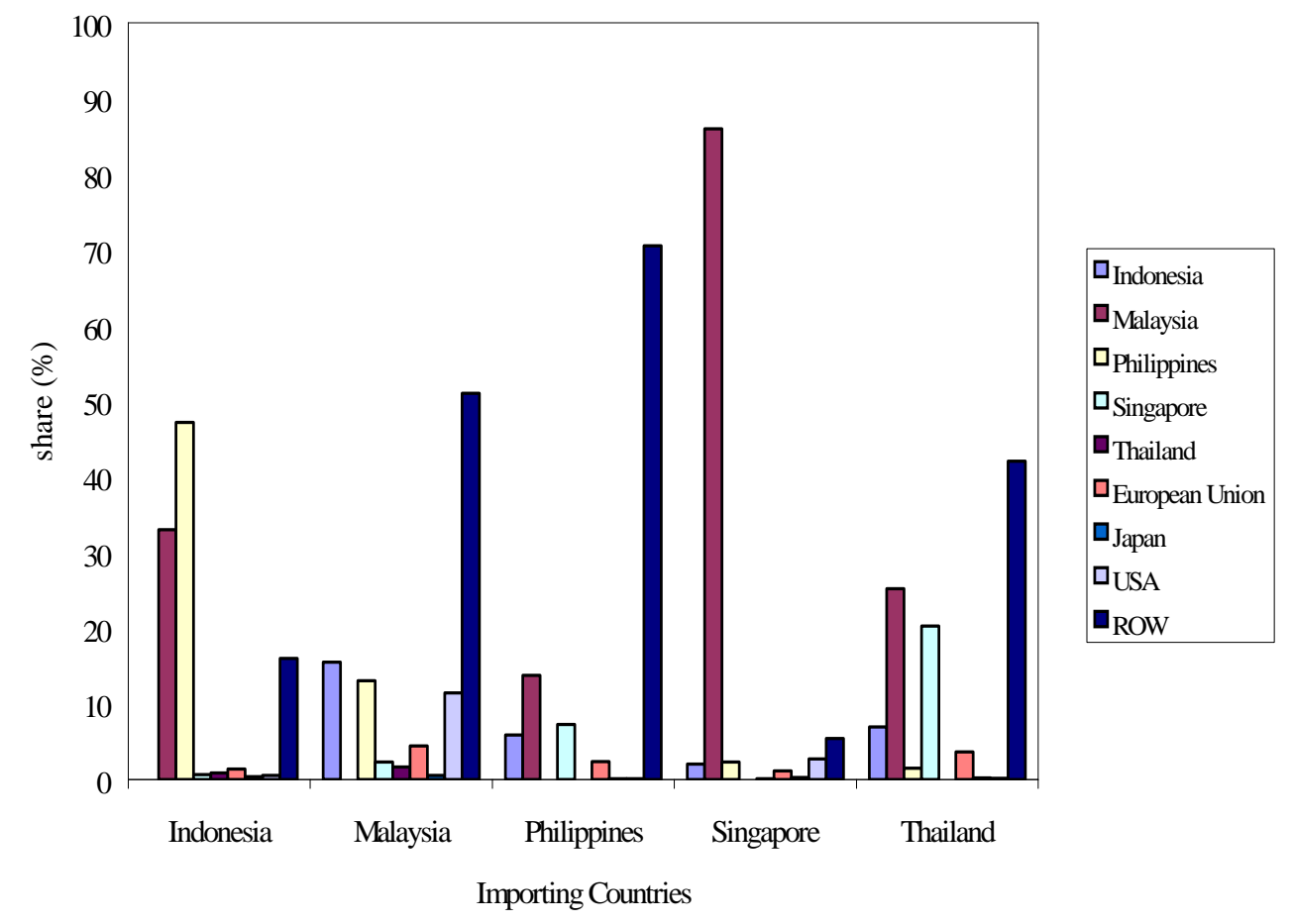

Source: GTAP Database Version 4 
Figure 2. 21 Source of Sugar Import (\%)

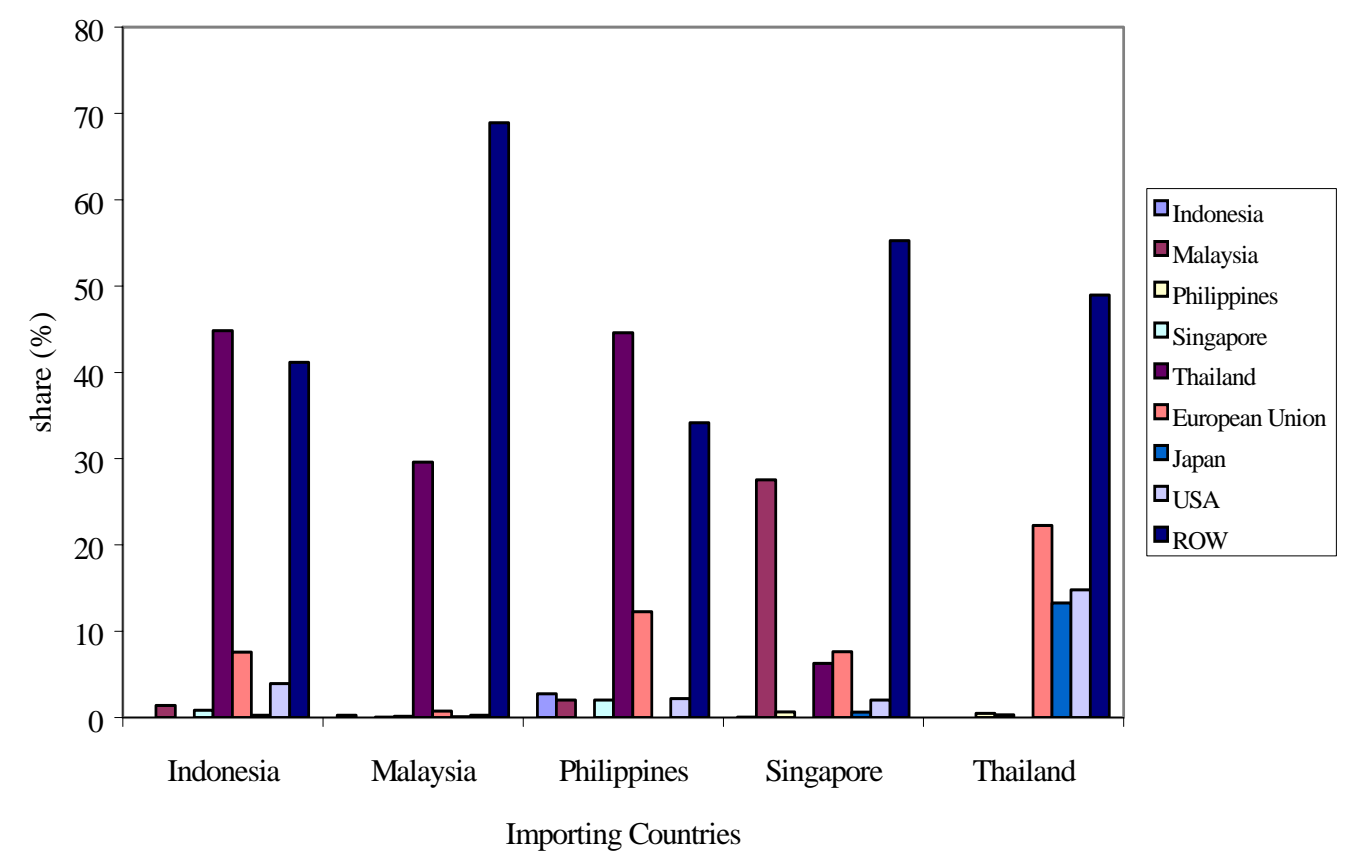

Source: GTAP Database Version 4

Figure 2. 22 Source of Beverages and Tobacco Import (\%)

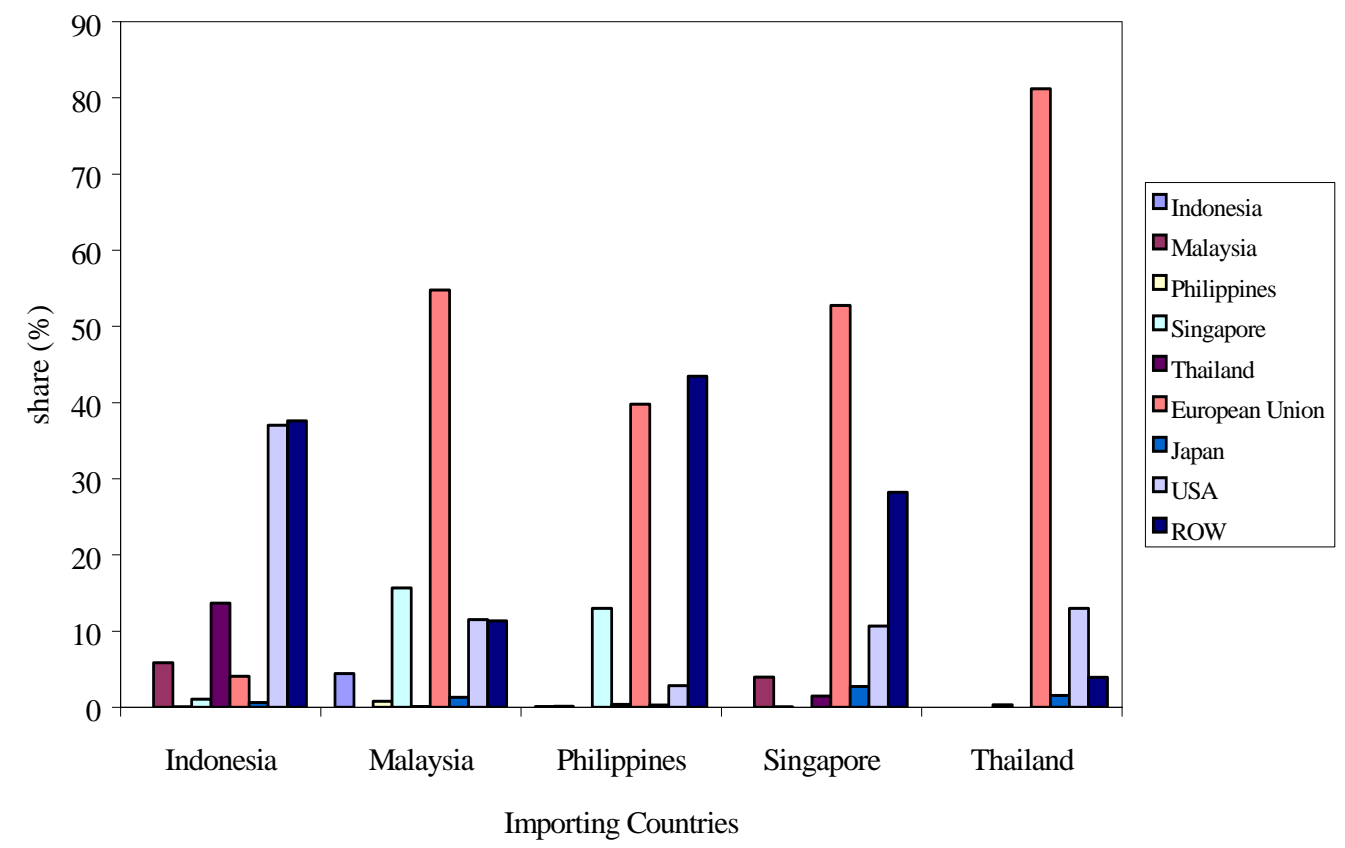

Source: GTAP Database Version 4 
Figure 5. 1 The Development of Rice Production (1995=100)

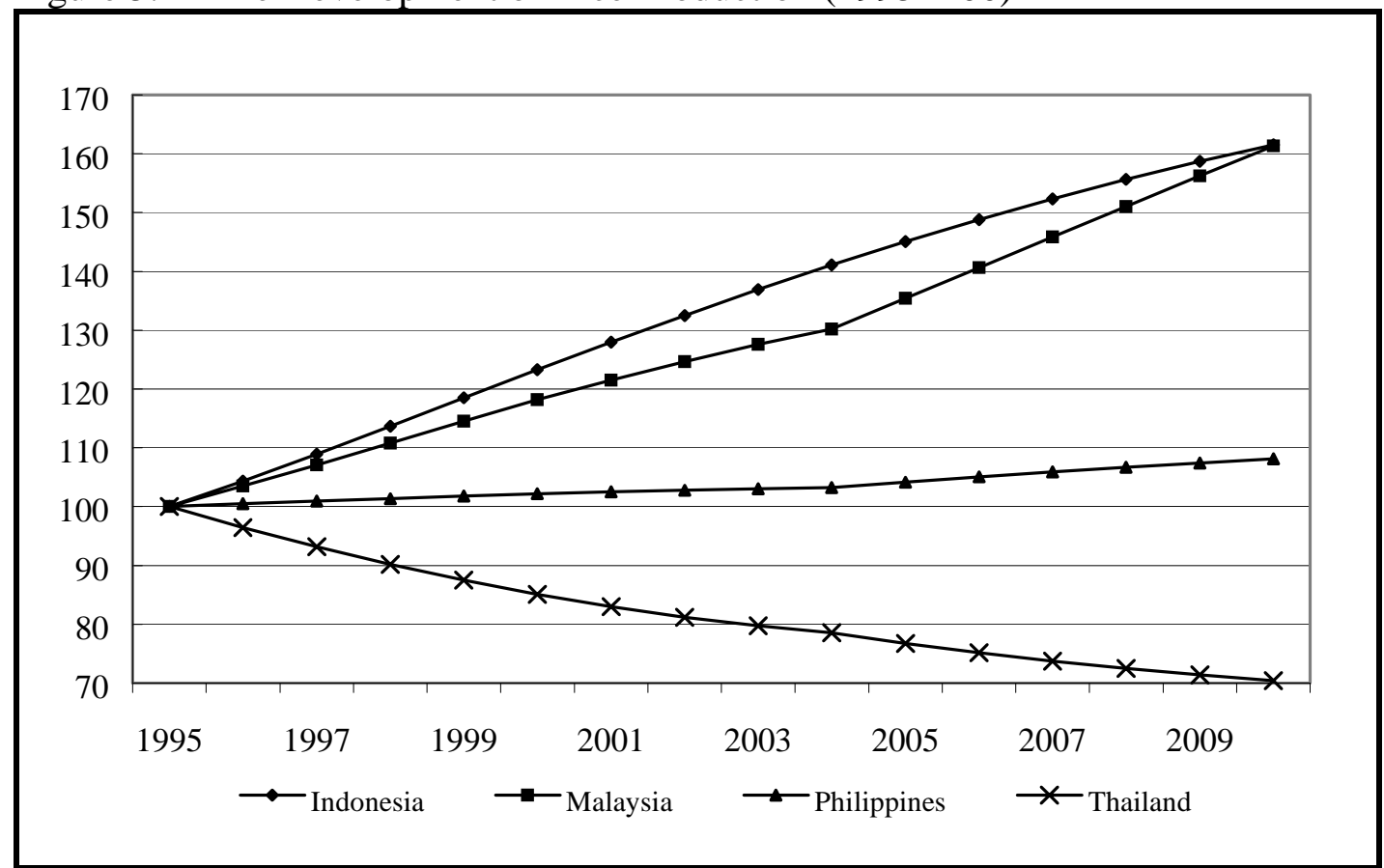

Source: Model Simulation

Figure 5.2 The Development of Cereal Production (1995)

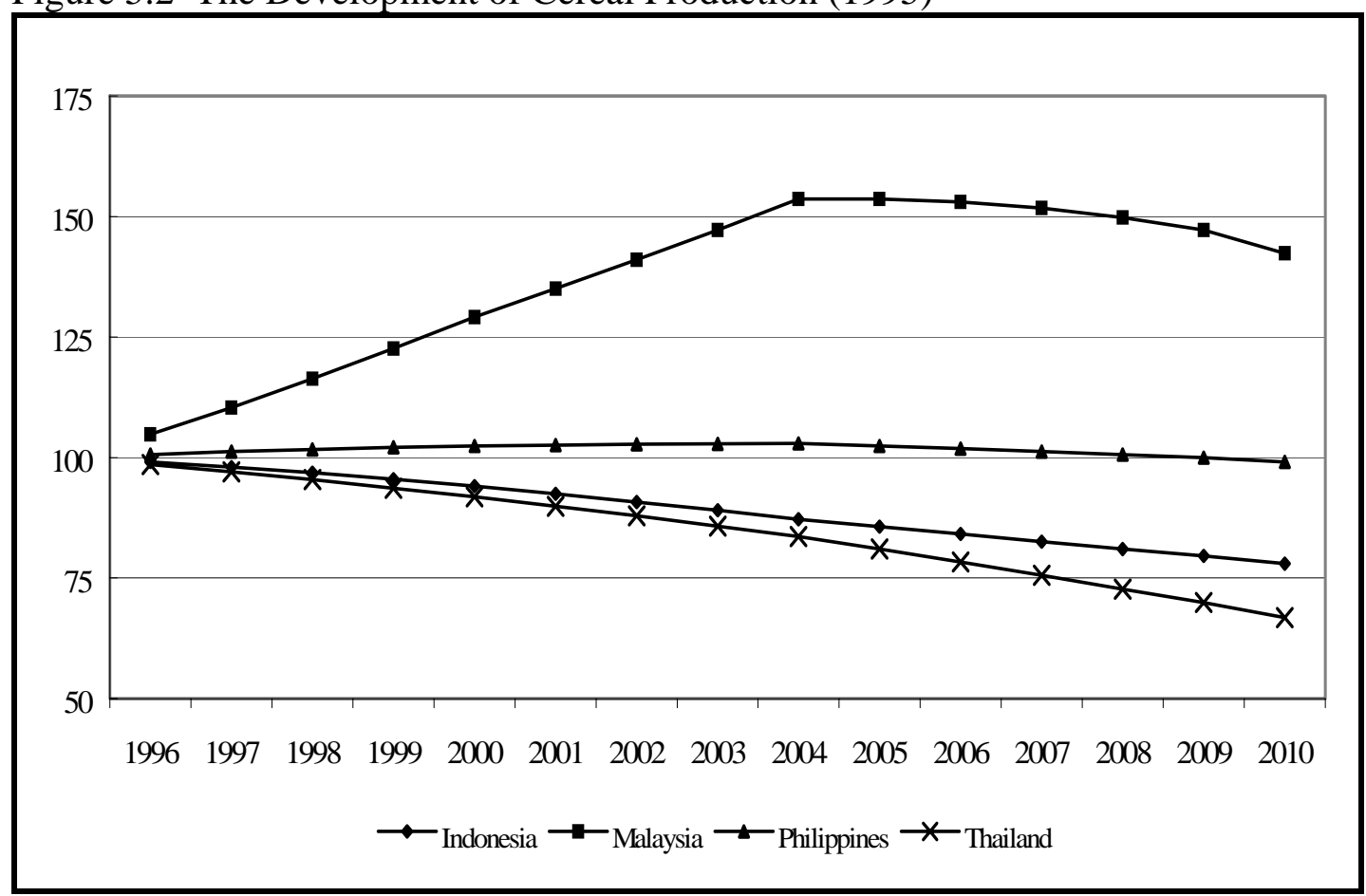

Source: Model Simulation 
Figure 5.3 The Development of Oil Seeds Production (1995=100)

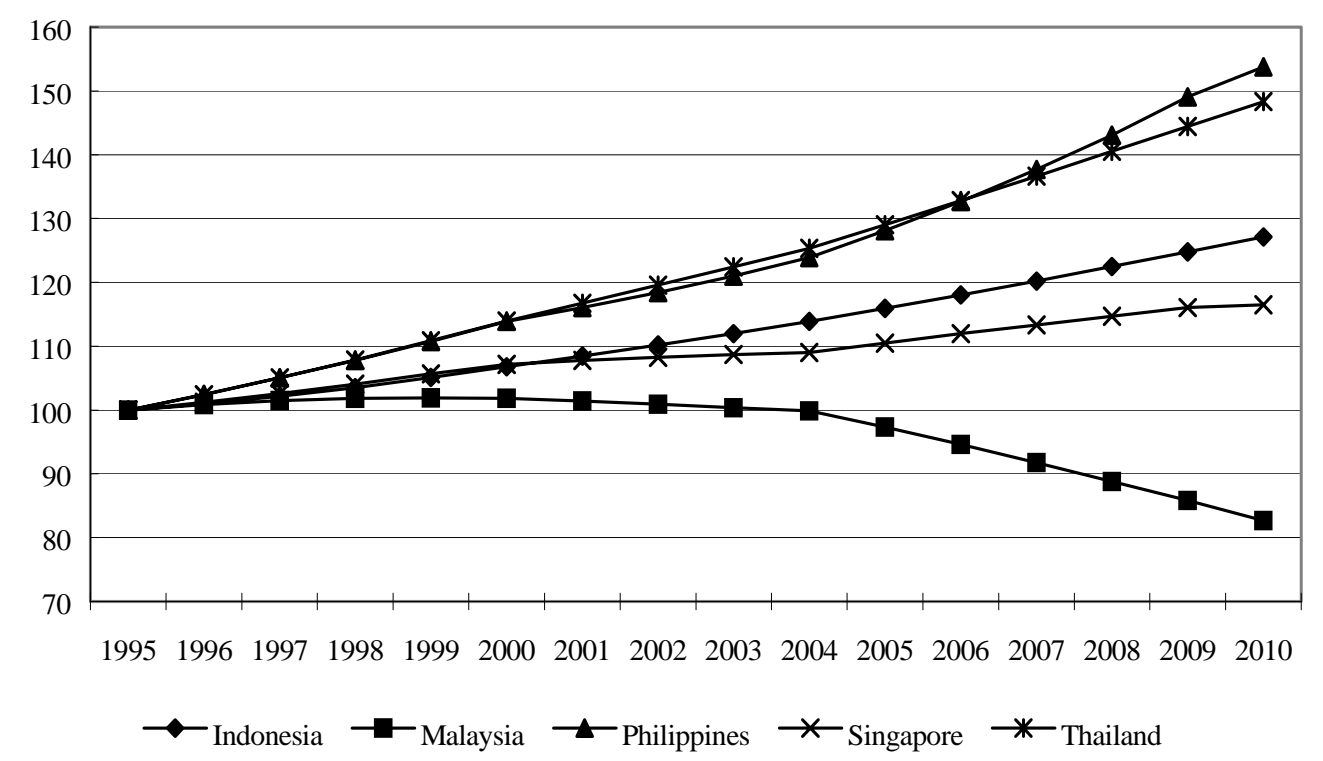

Source: Model Simulation.

Figure 5.4 The Development of Other Crop Production (1995=100)

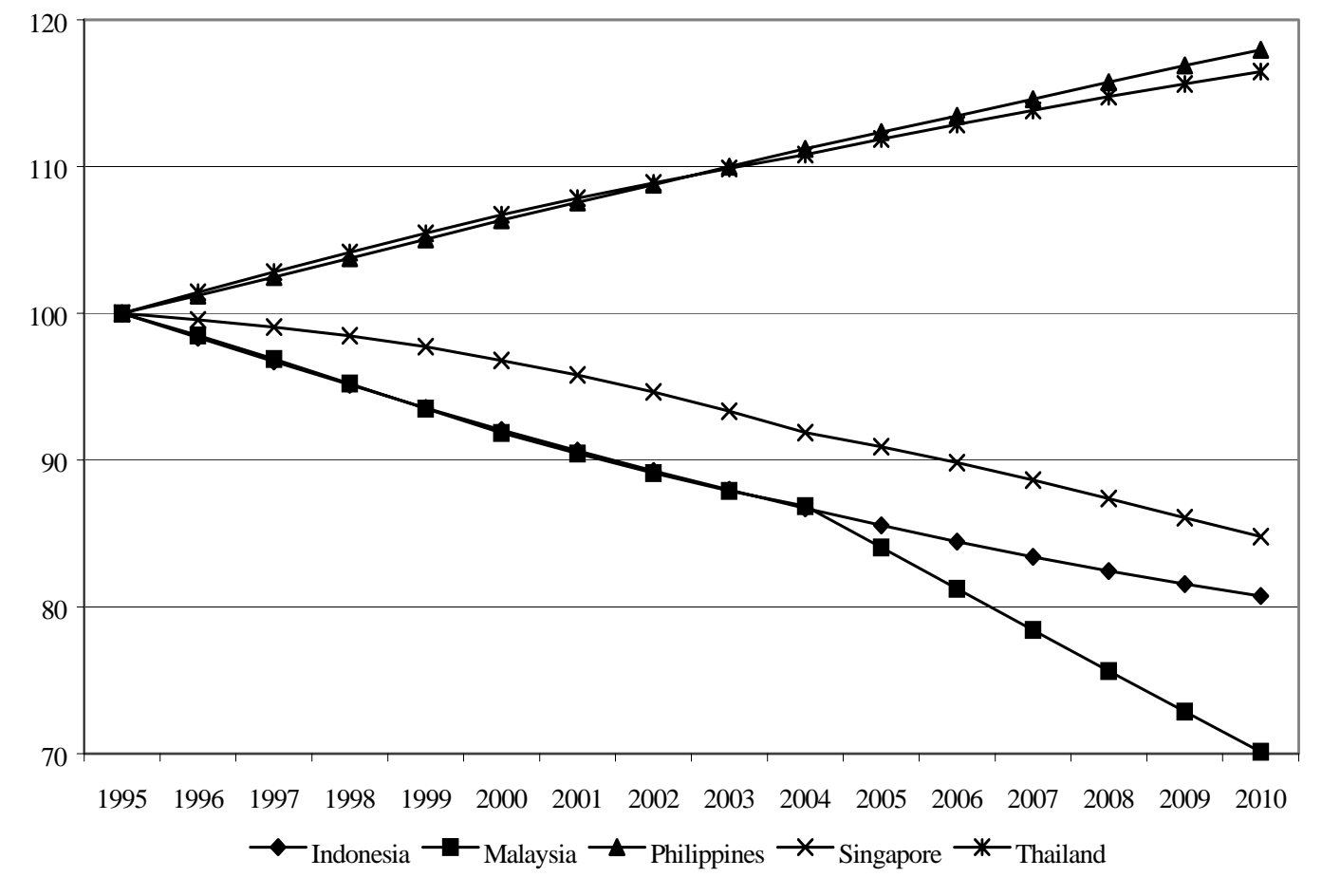

Source: Model Simulation. 
Figure 5.5 The Development of Livestock Production (1995=100)

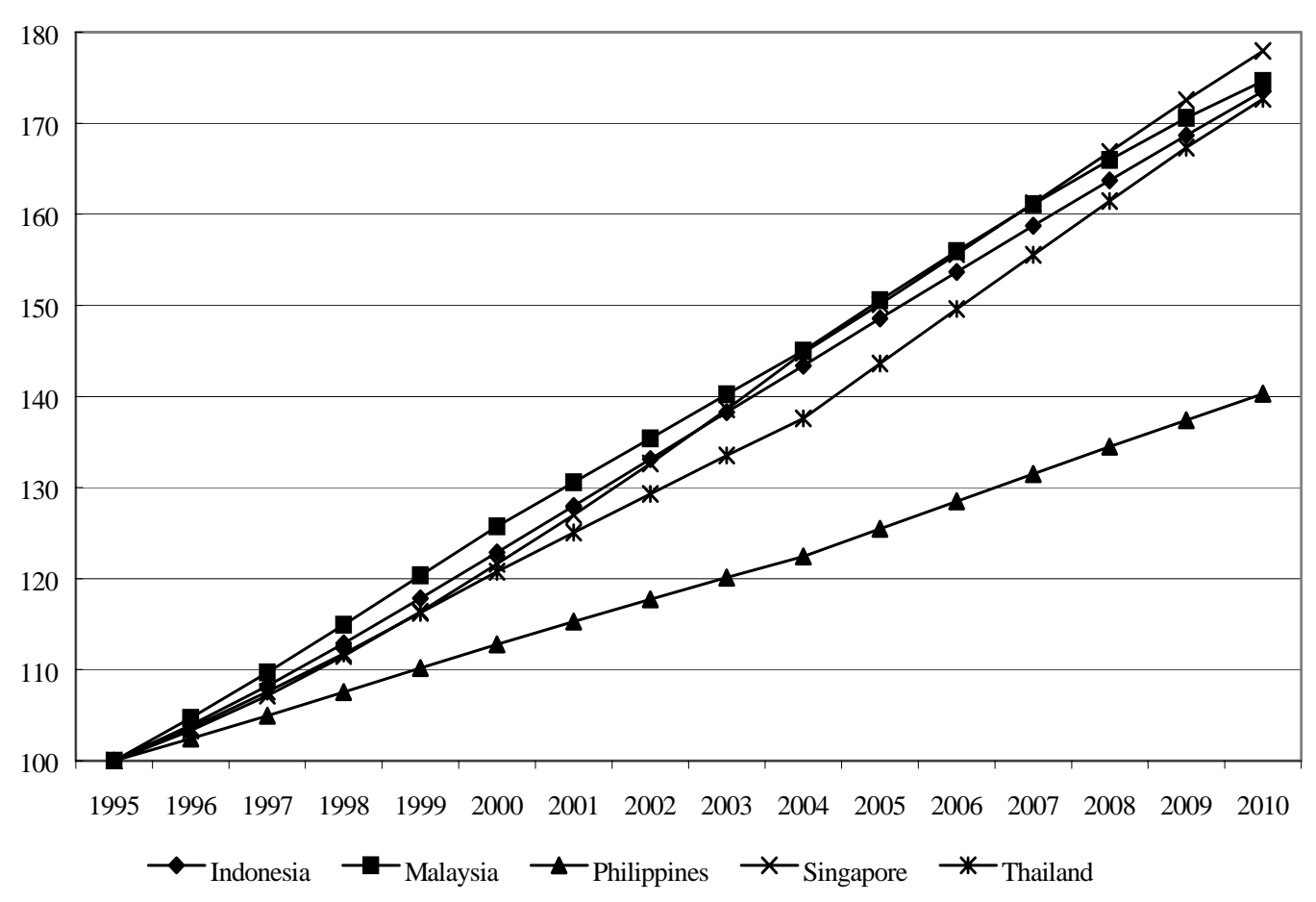

Source: GTAP Database Version 4.

Figure 5.6 The Development of Processed Other Crops Production (1995=100)

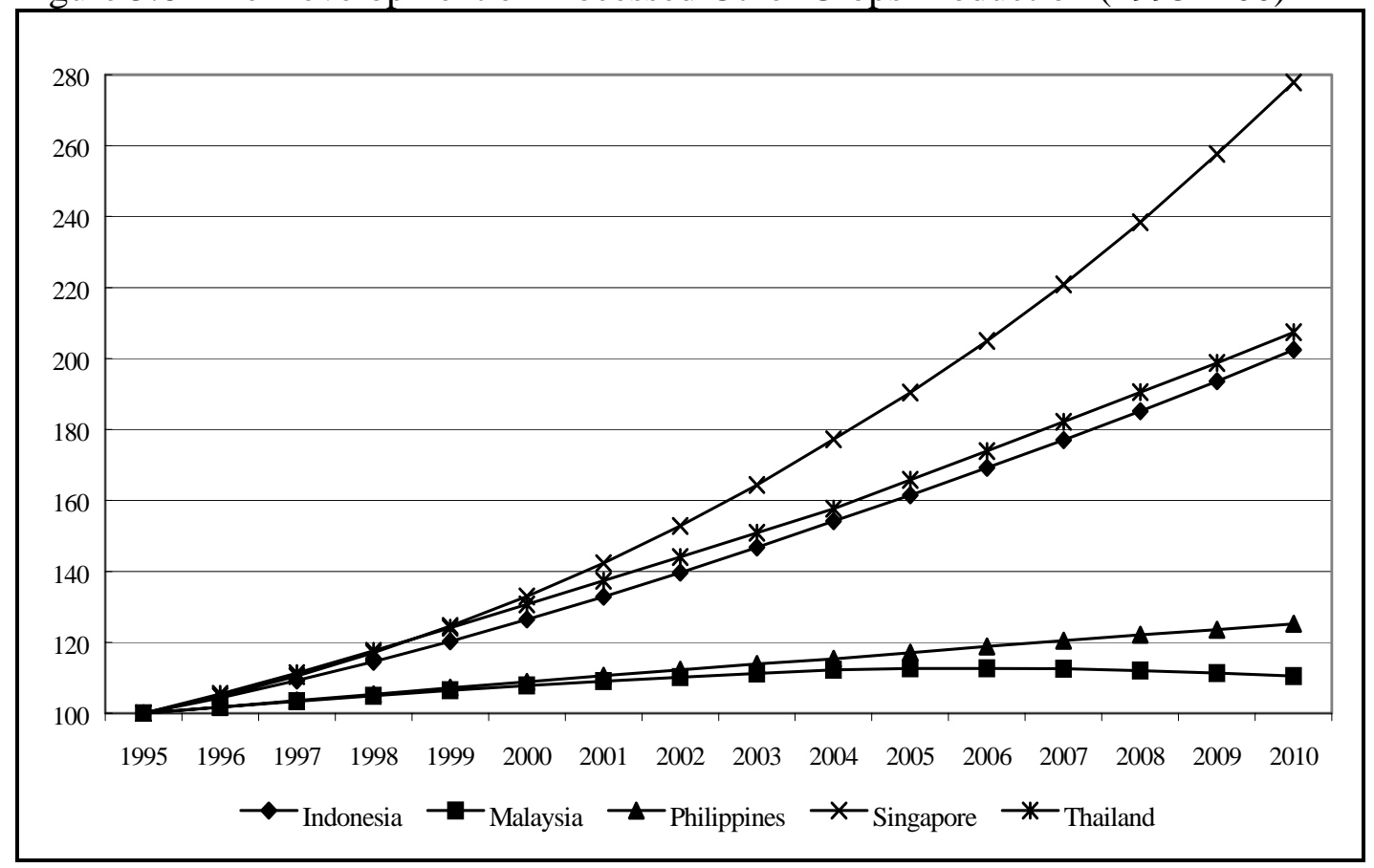

Source: Model Simulation. 
Figure 5.7 The Development of Processed Meat Production (1995=100)

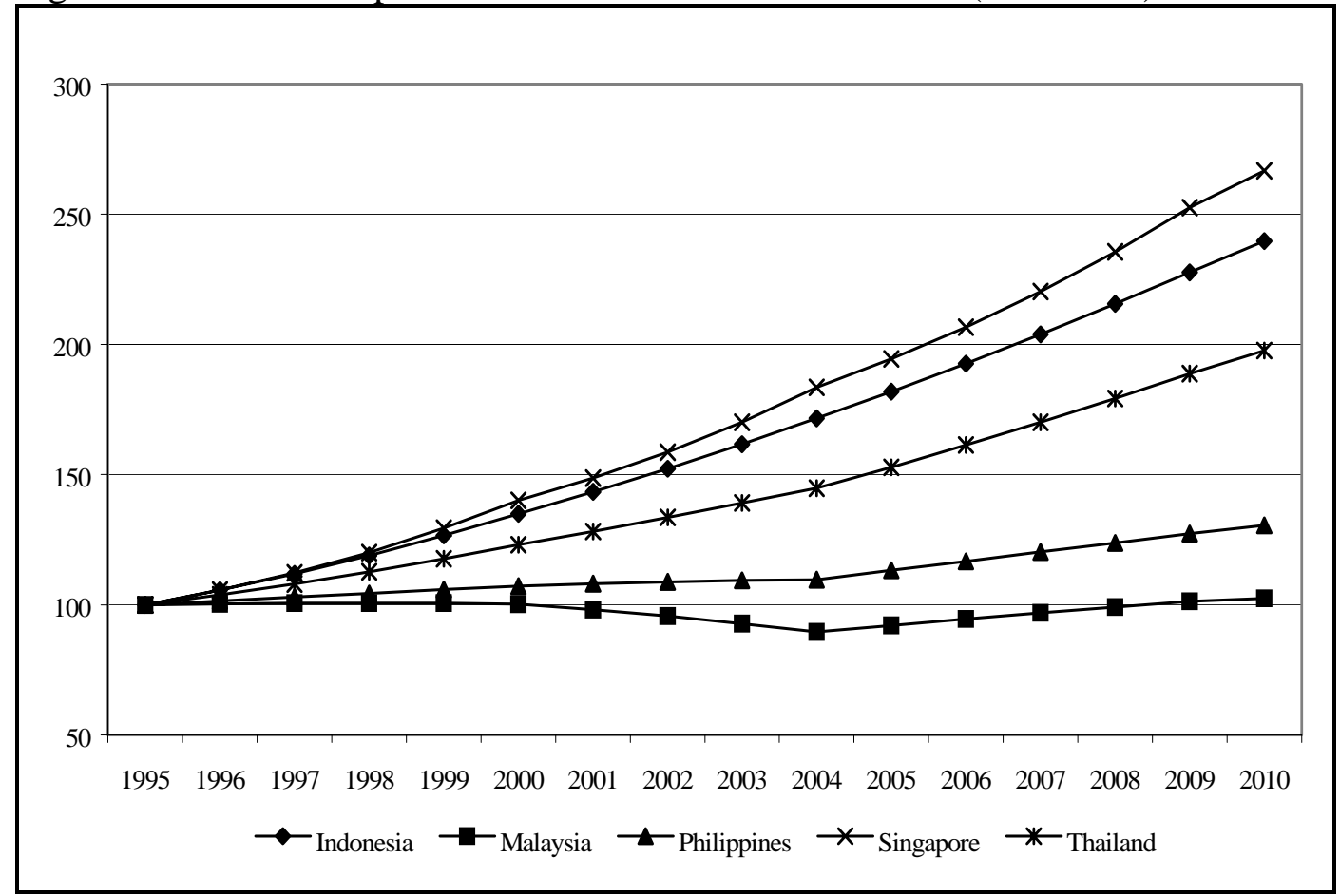

Source: Model Simulation.

Figure 5.8 The Development of Processed Milk Production (1995=100)

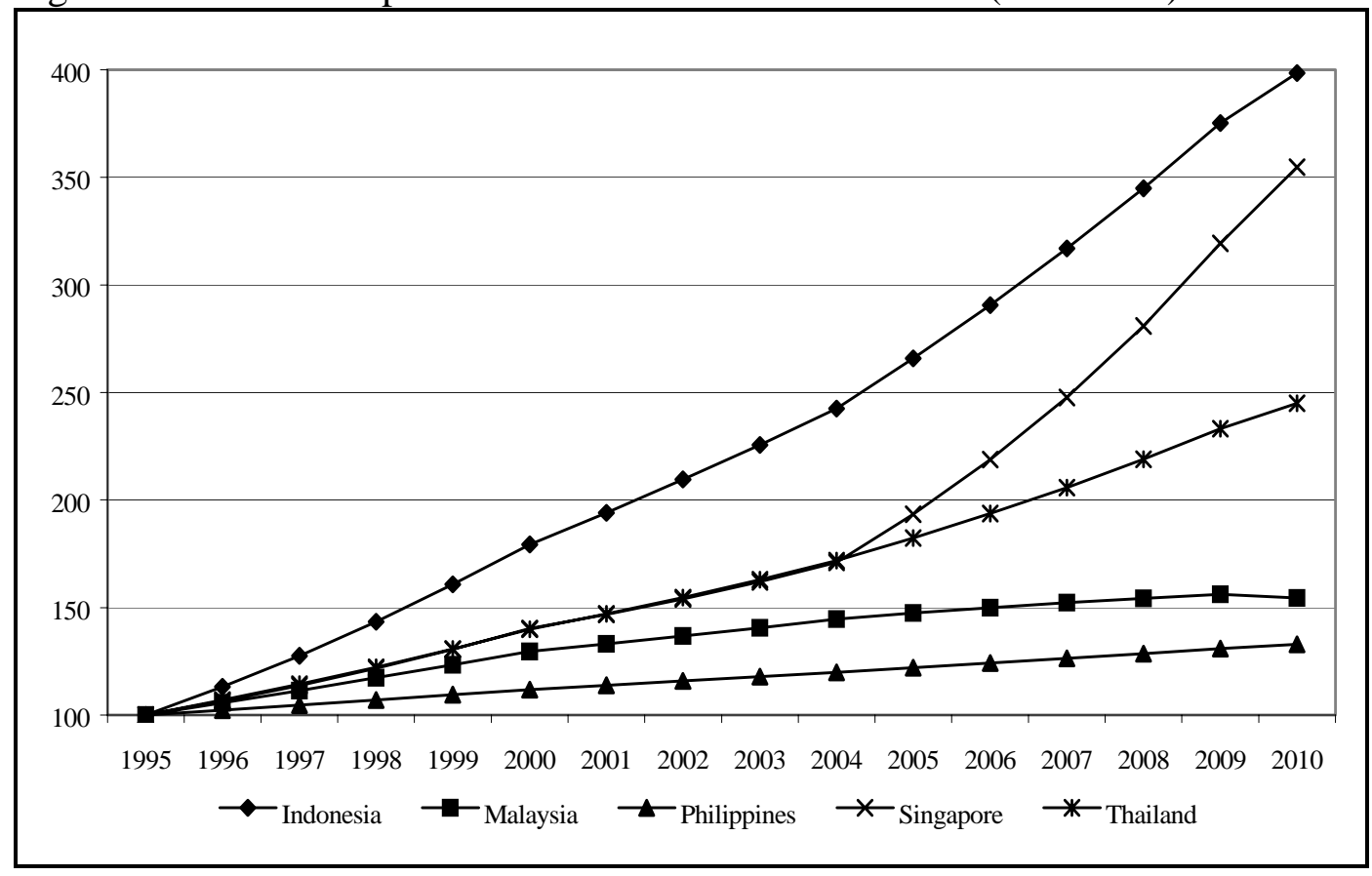

Source: Model Simulation. 
Figure 5.9 The Development of Vegetable Oil Production (1995=100)

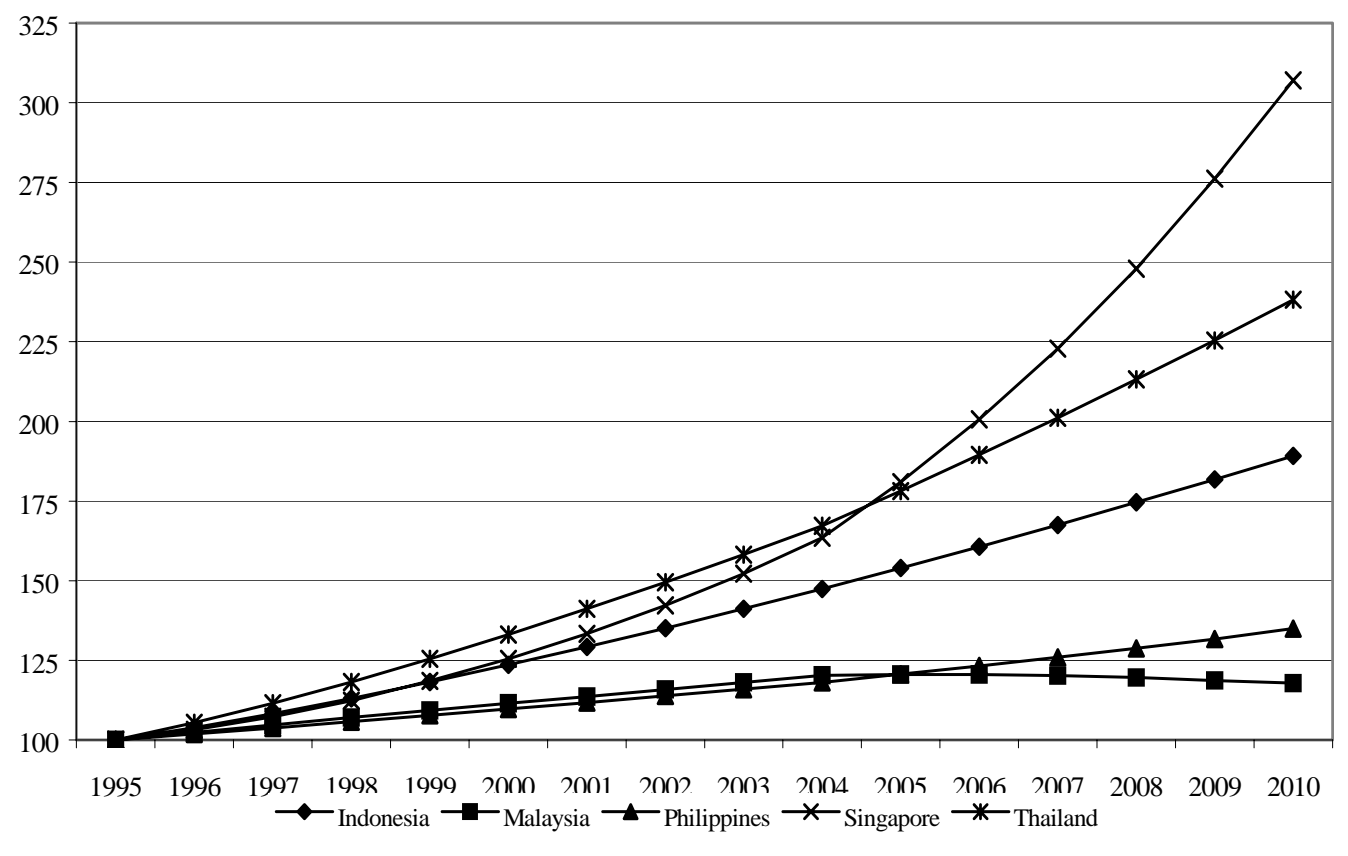

Source: Model Simulation.

Figure 5.10 The Development of Sugar Production (1995=100)

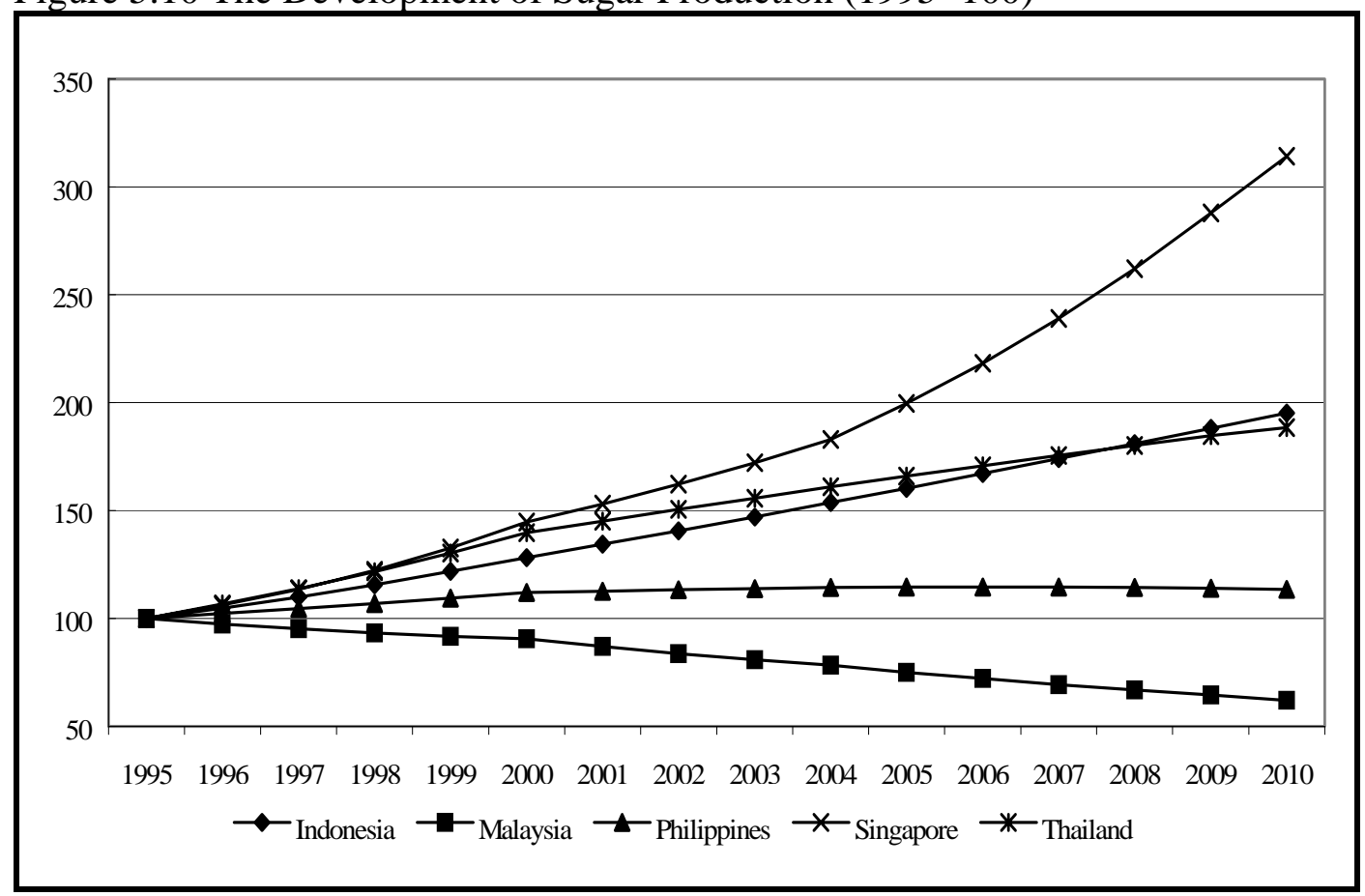

Source: Model Simulation. 
Figure 5.11 The Development of Beverages and Tobacco Production (1995=100)

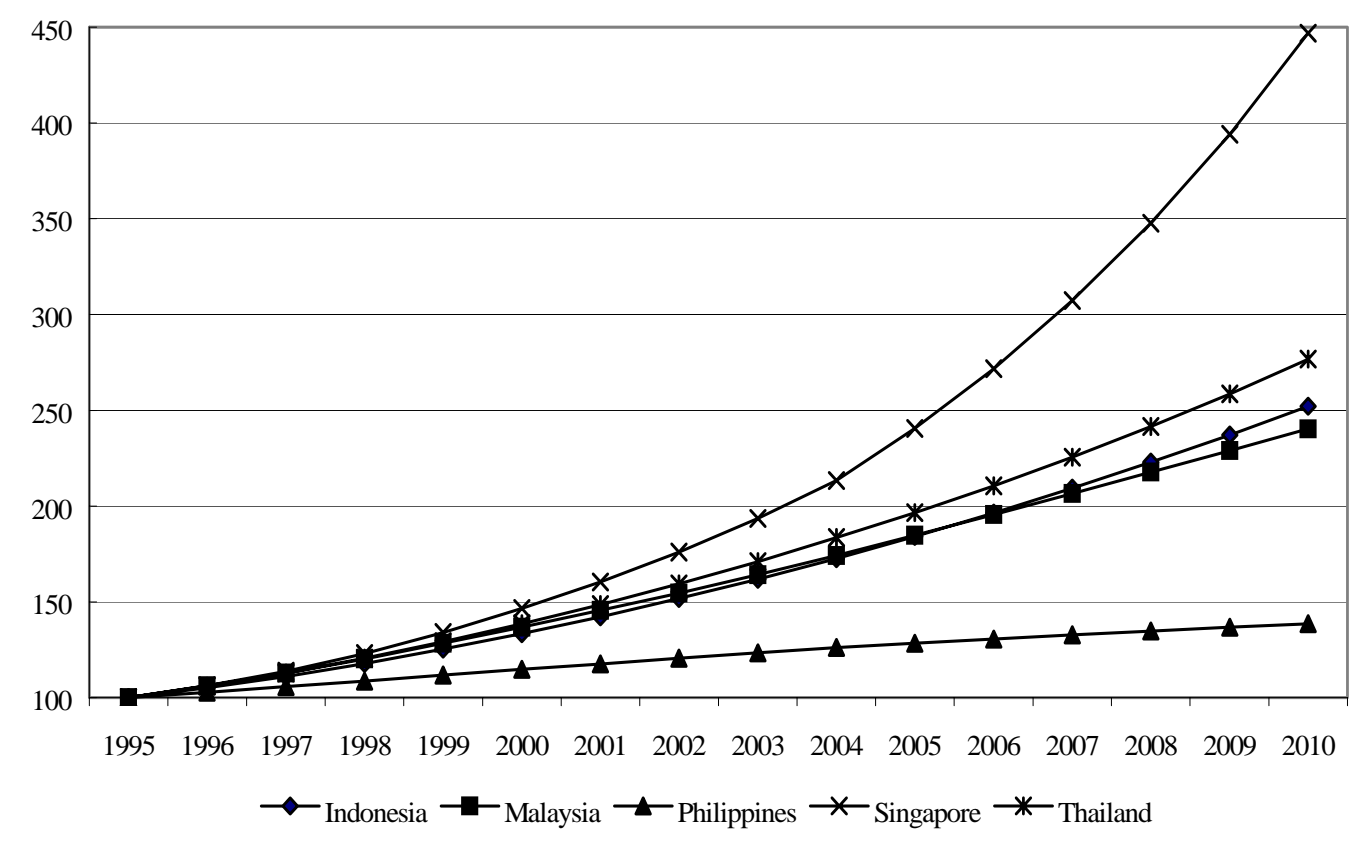

Source: Model Simulation.

Figure 5.12 The Development of Rice Export (1995=100)

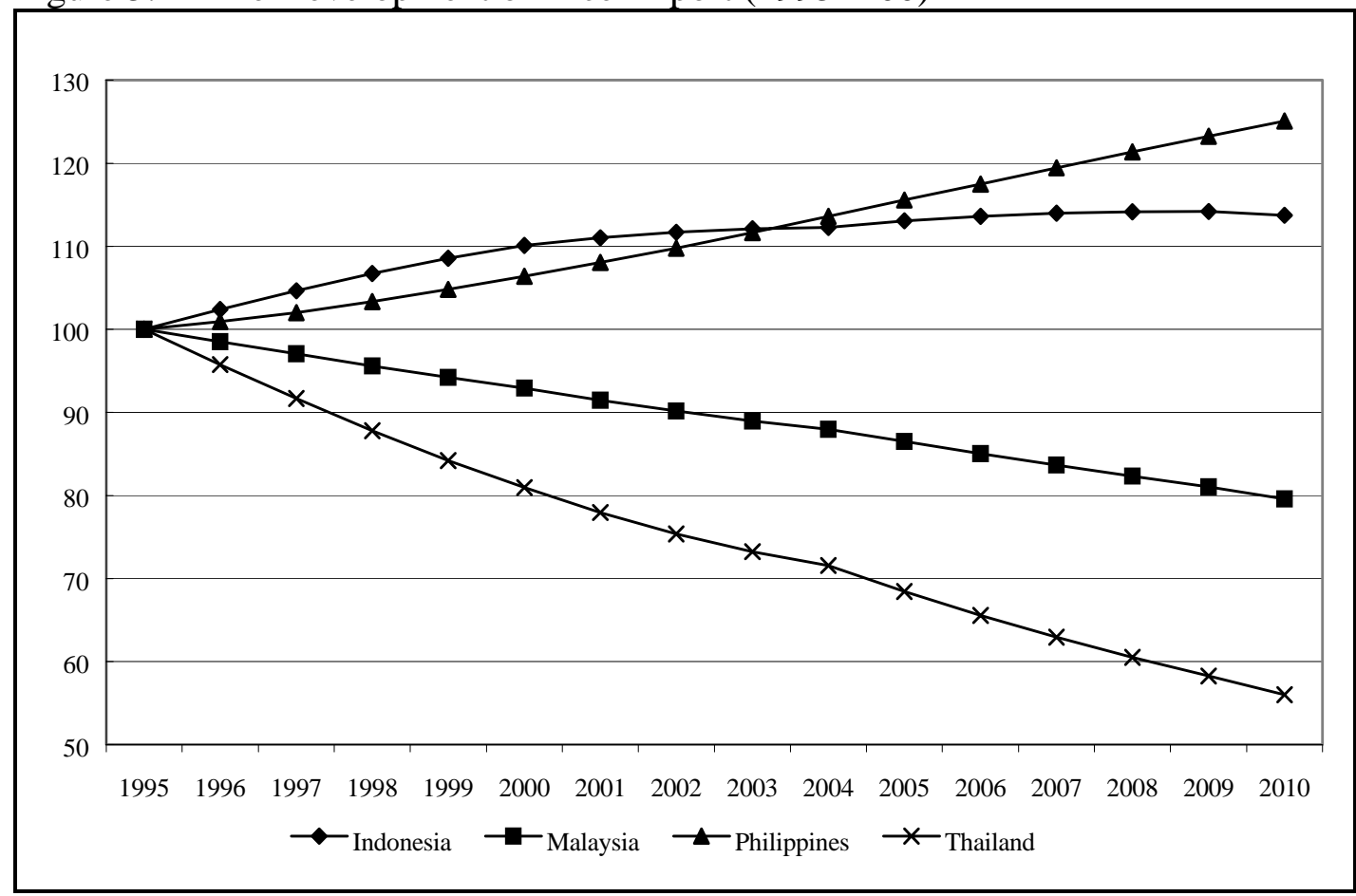

Source: Model Simulation. 
Figure 5.13 The Development of Cereal Export (1995=100)

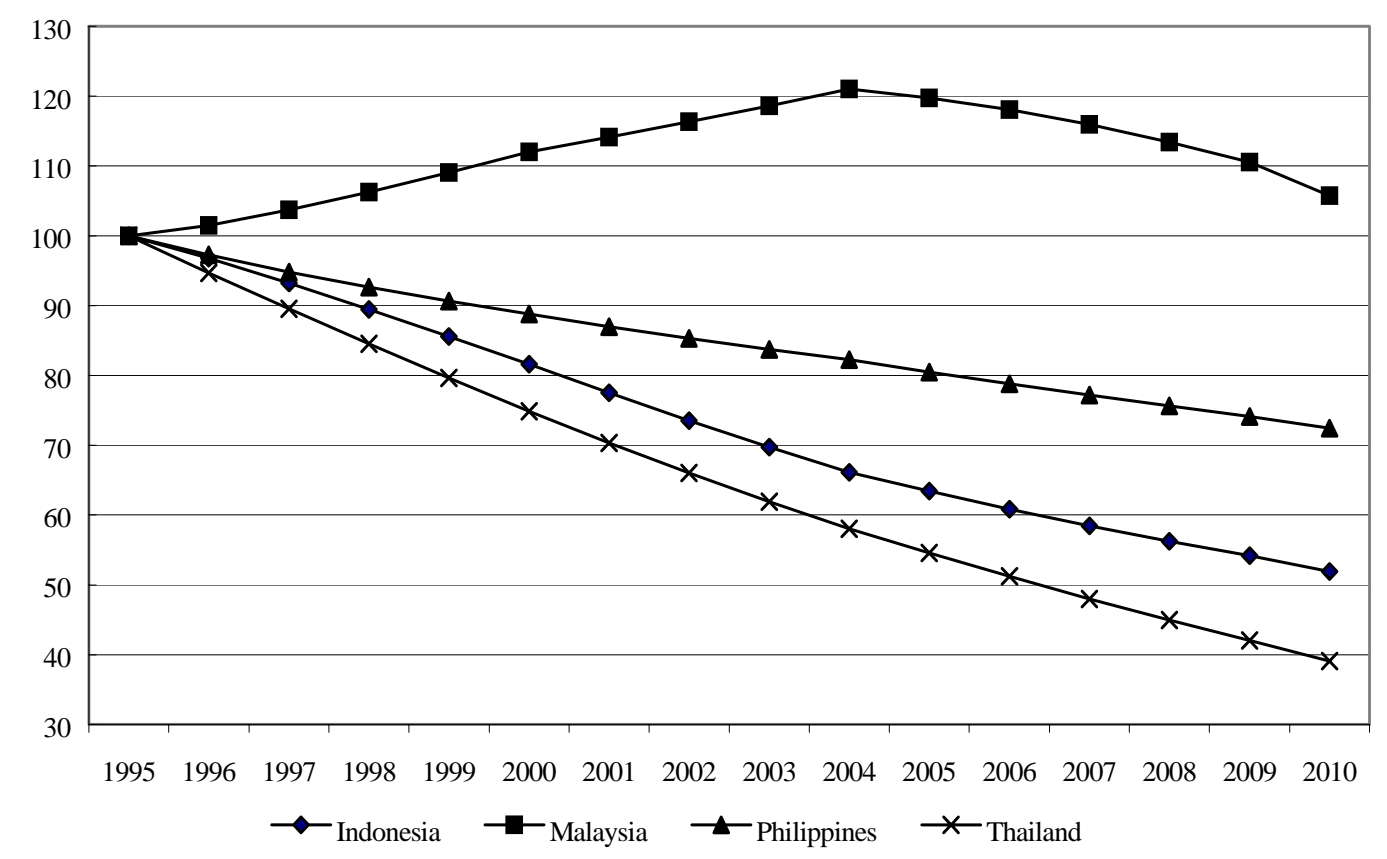

Source: Model Simulation.

Figure 5.14 The Development of Oil Seeds Export (1995=100)

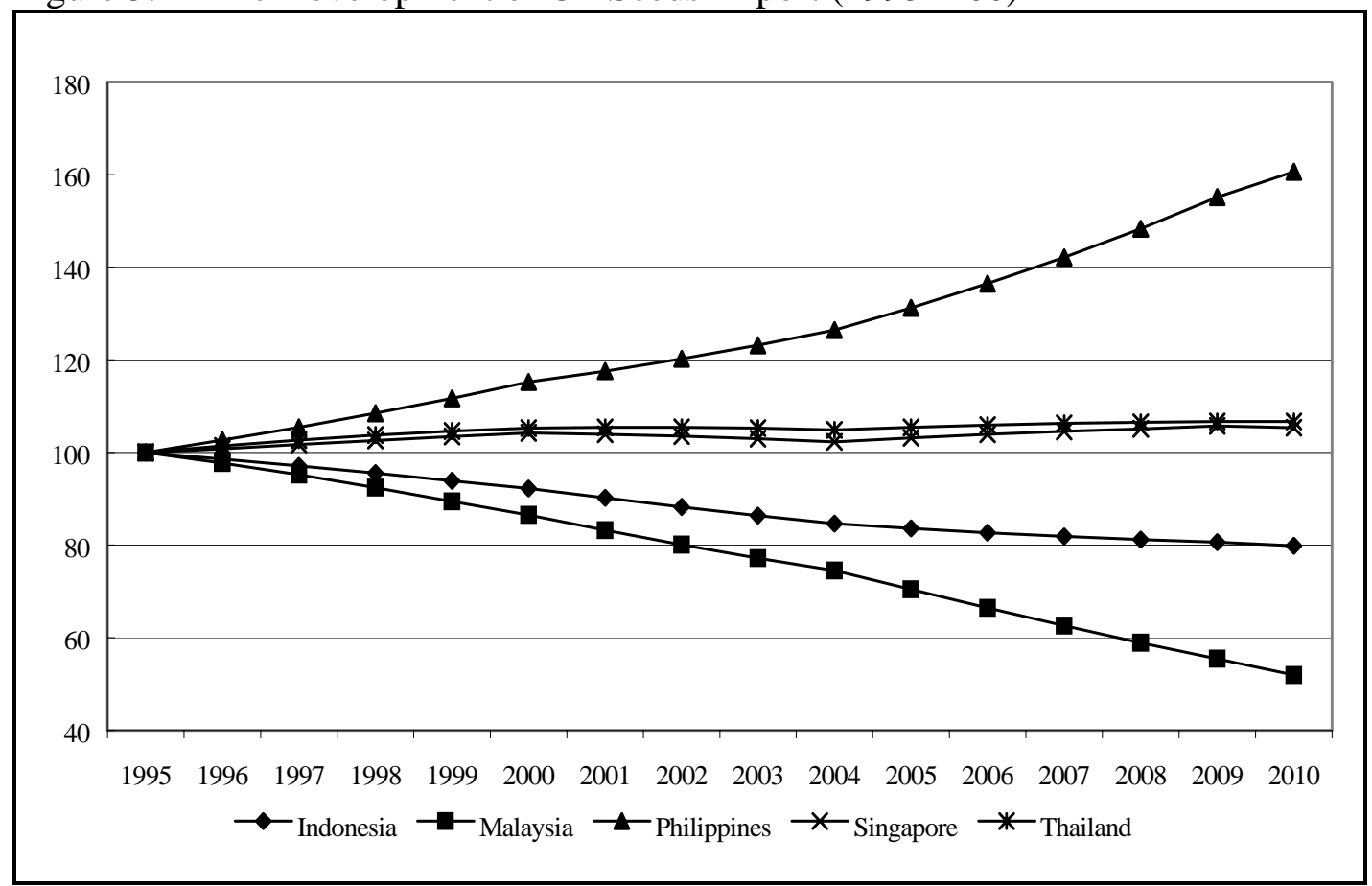

Source: Model Simulation. 
Figure 5.15 The Development of Other Crops Export (1995=100)

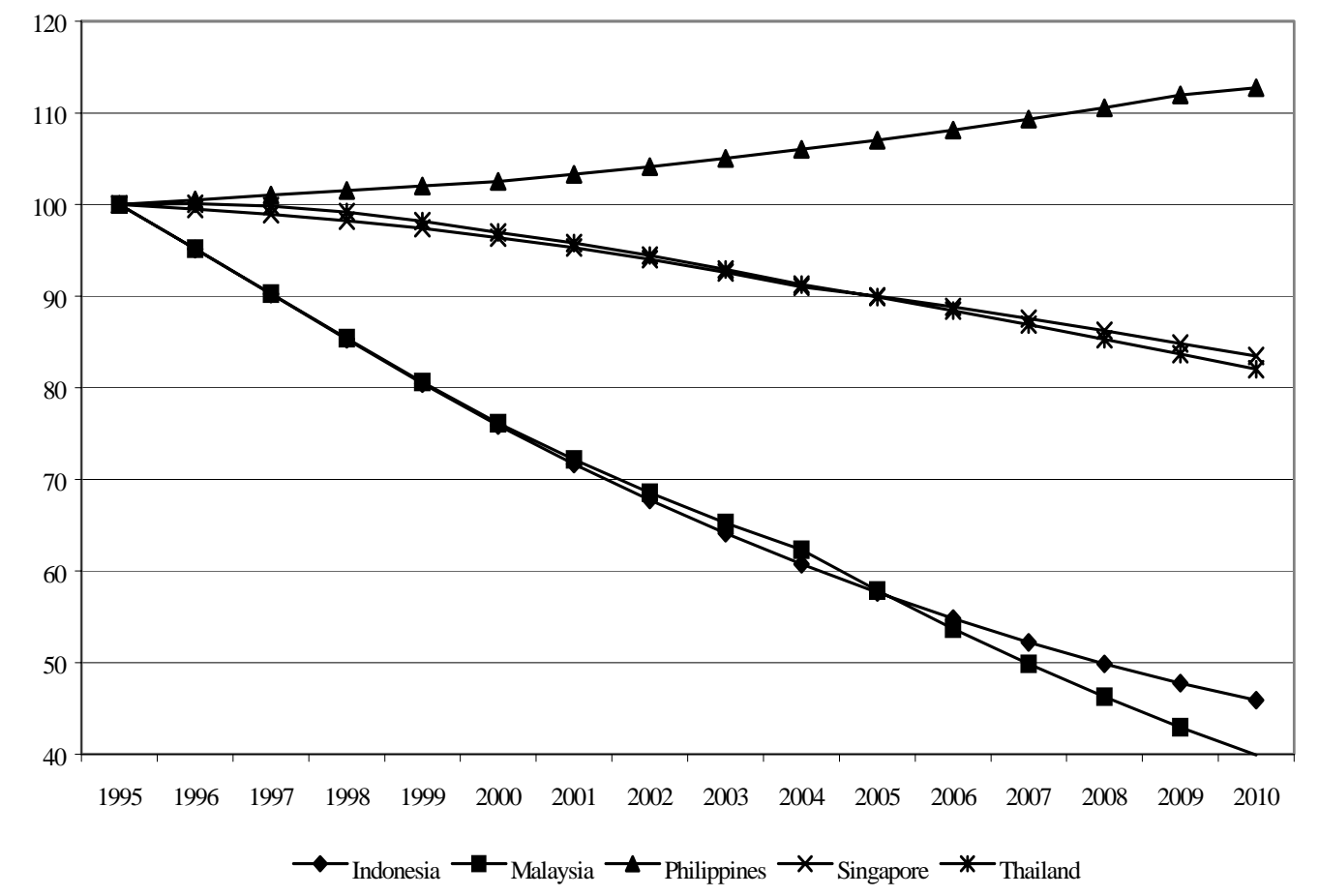

Source: Model Simulation.

Figure 5.16 The Development of Livestock Export (1995=100)

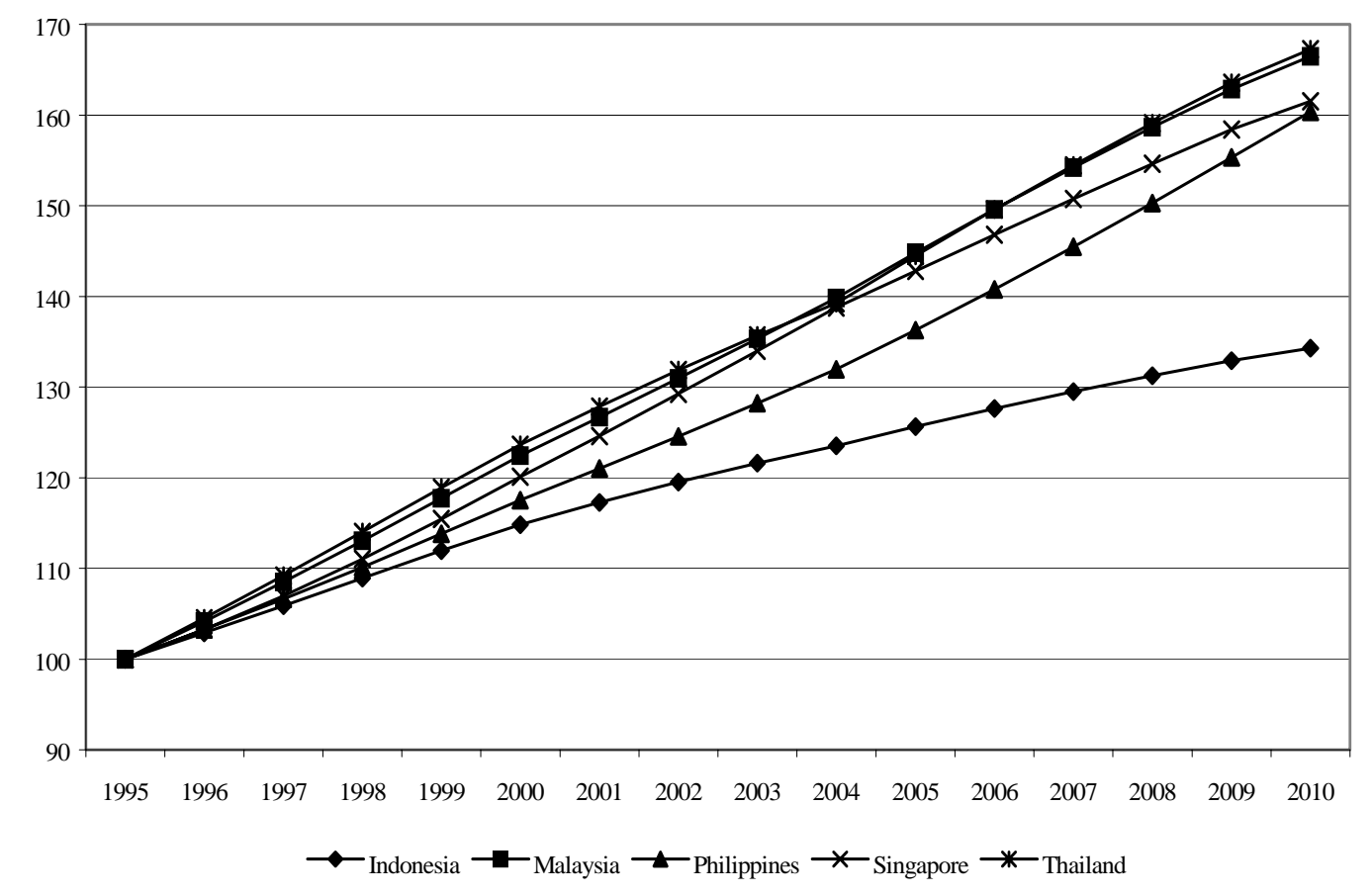

Source: Model Simulation. 
Figure 5.17 The Development of Processed Other Crops Export (1995=100)

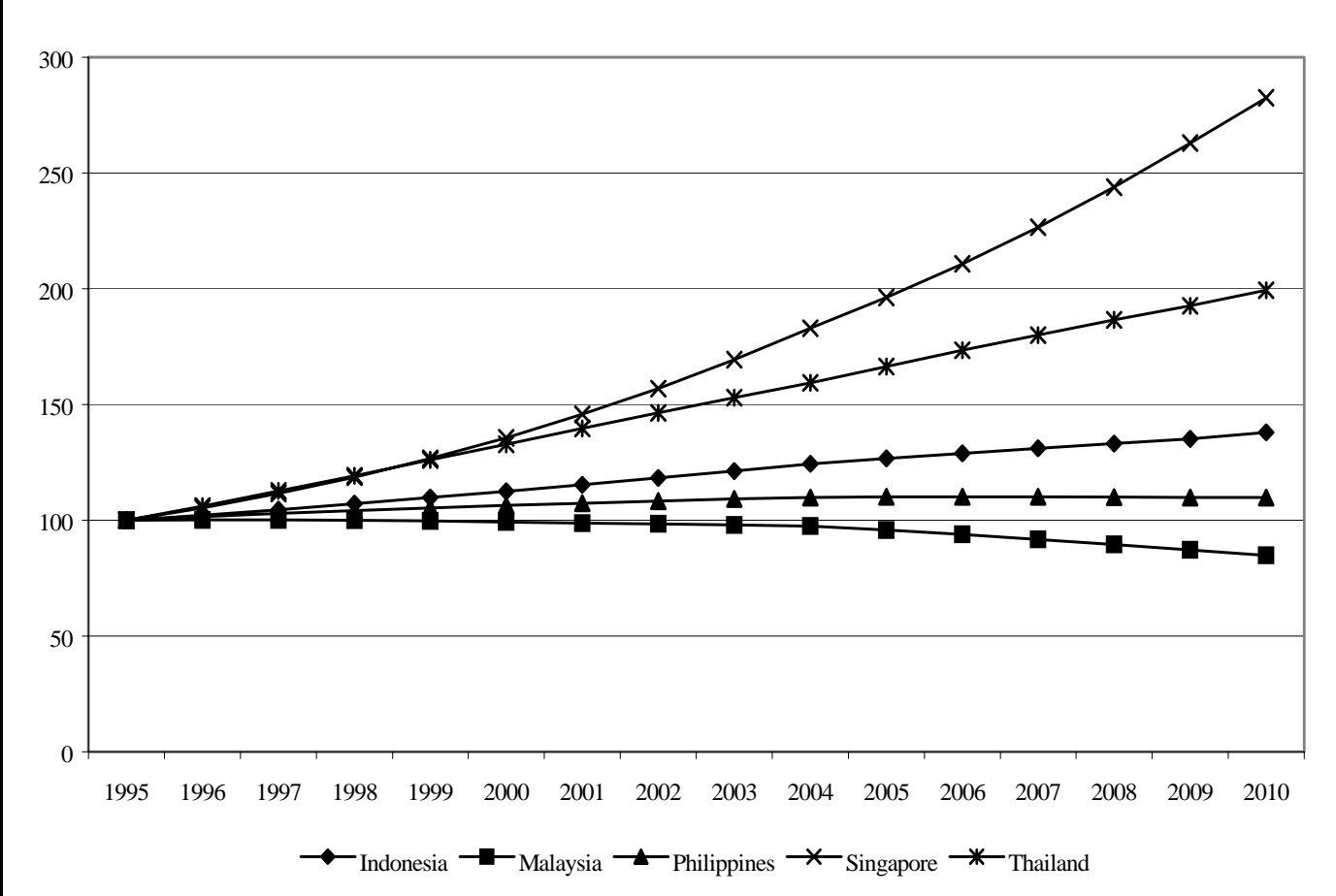

Source: Model Simulation.

Figure 5.18 The Development of Processed Meat Export (1995=100)

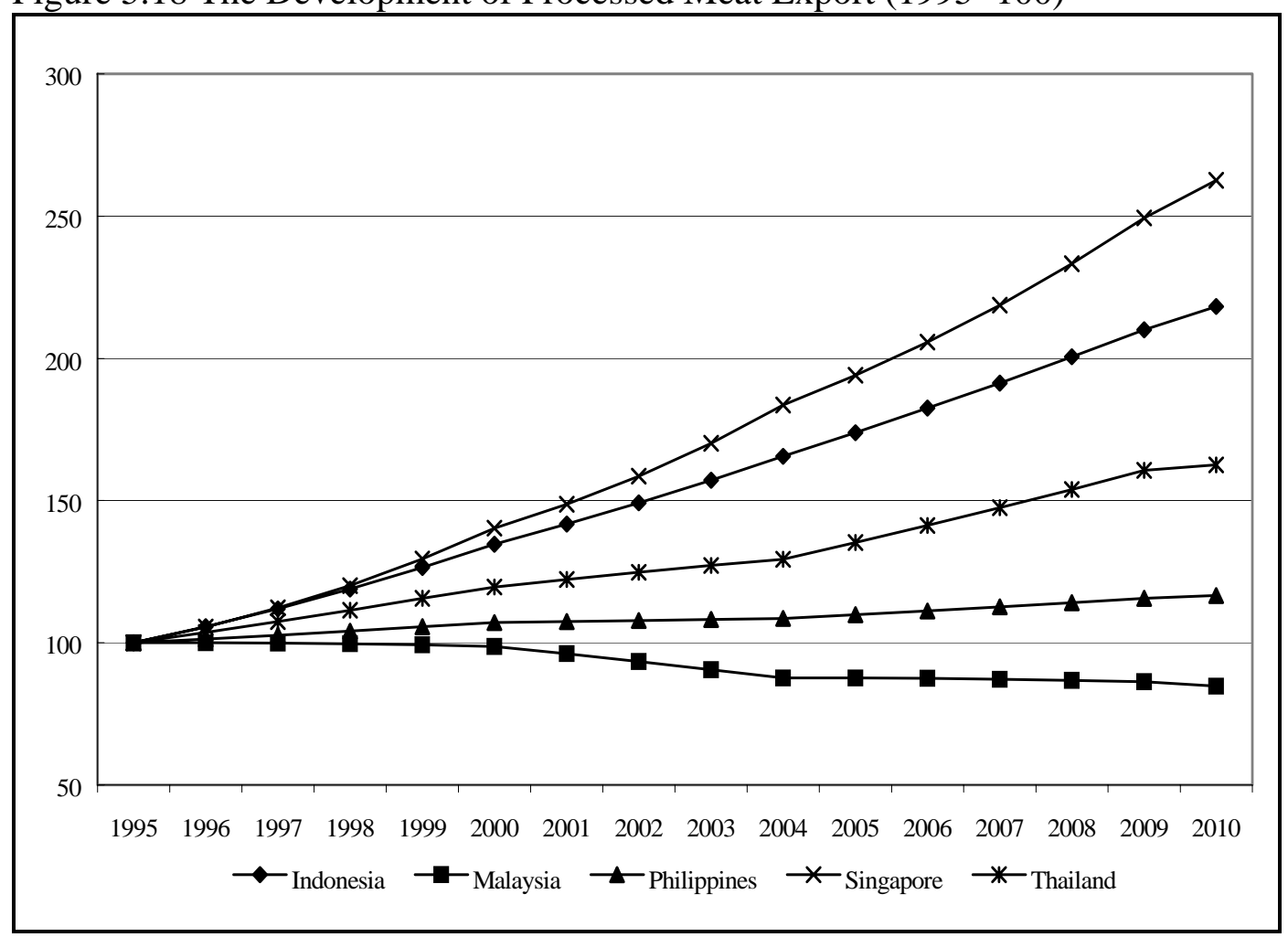

Source: Model Simulation. 
Figure 5.19 The Development of Processed Milk Export (1995=100)

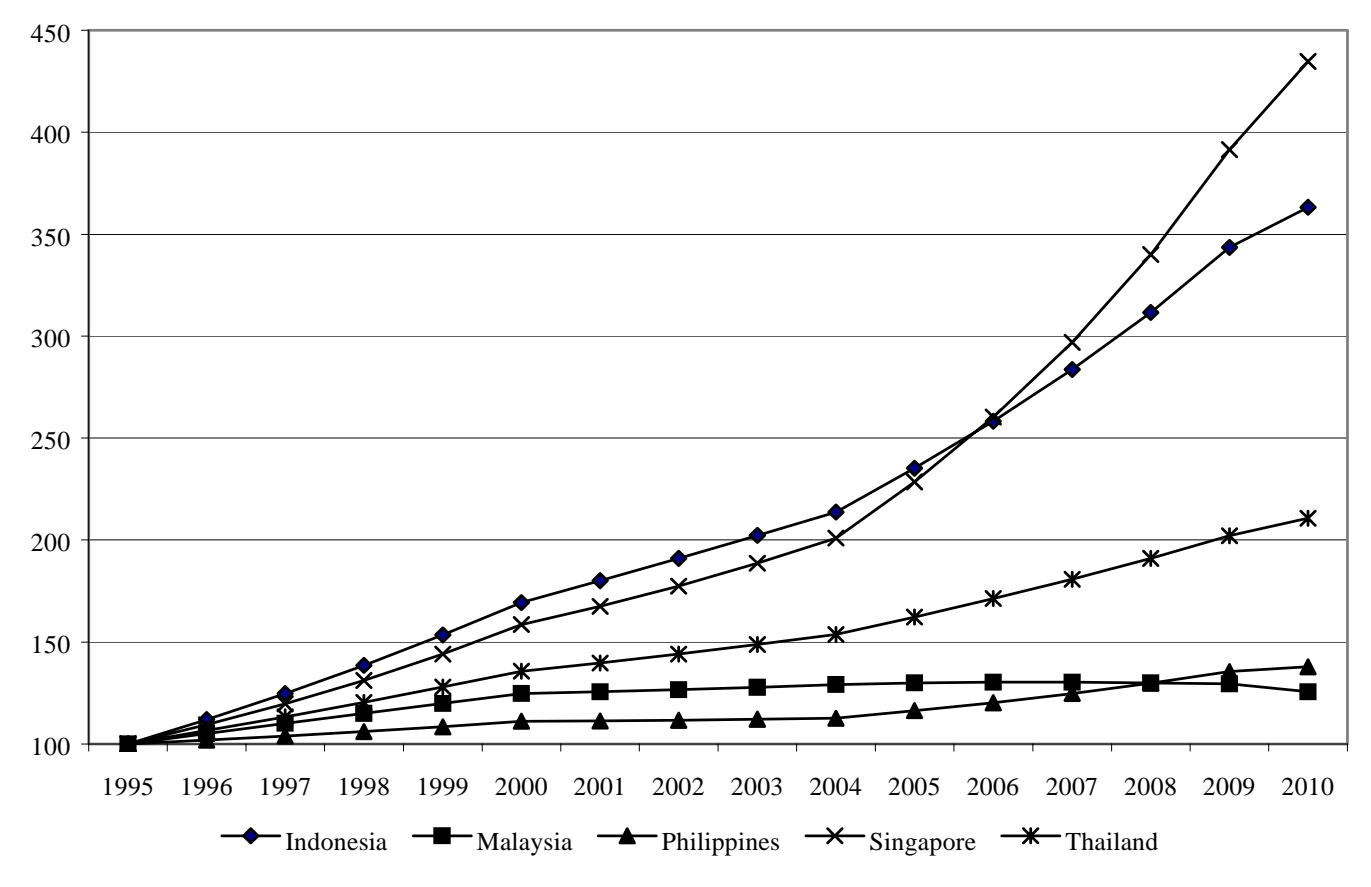

Source: Model Simulation.

Figure 5.20 The Development of Vegetable Oil Export (1995=100)

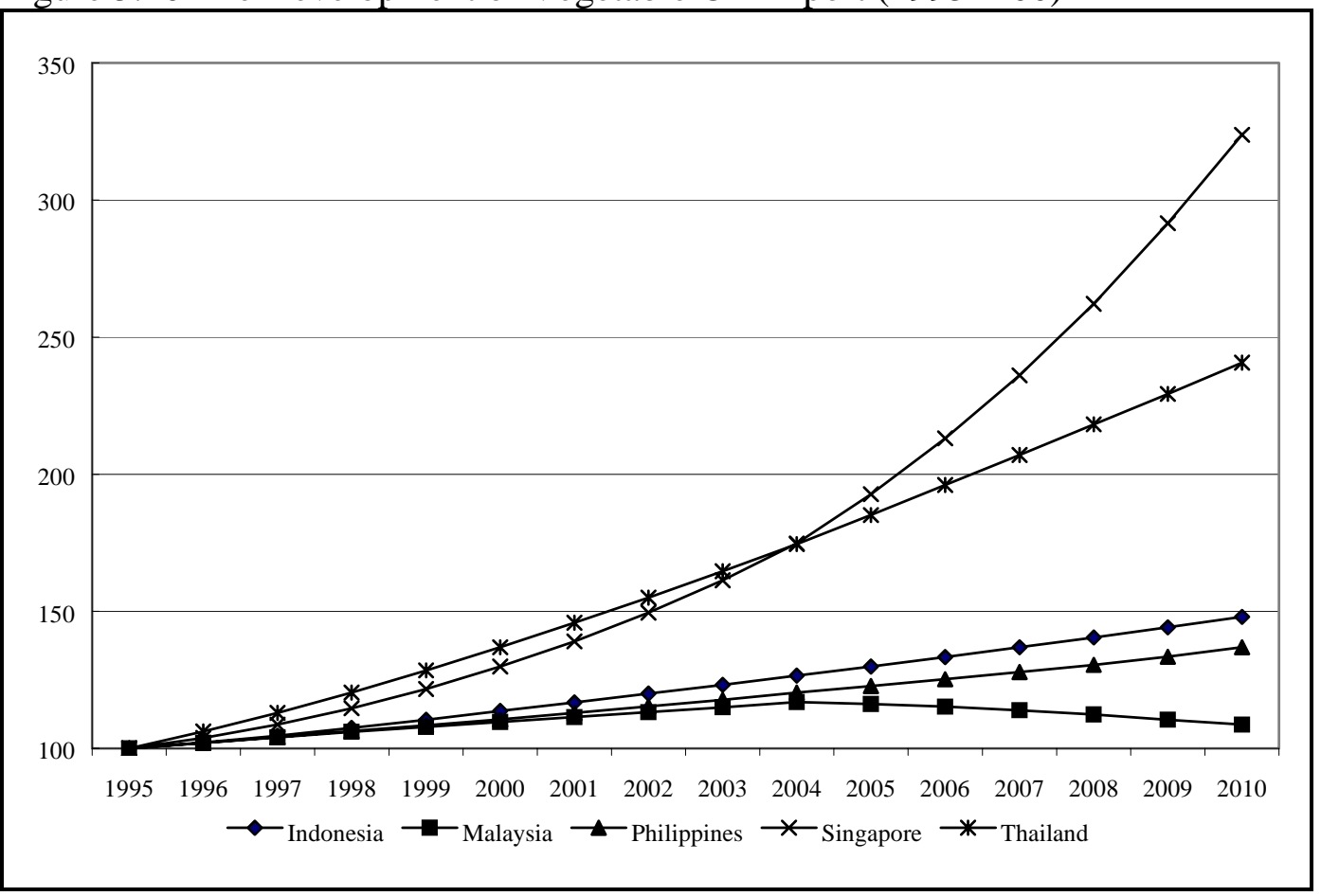

Source: Model Simulation. 
Figure 5.21 The Development of Sugar Export (1995=100)

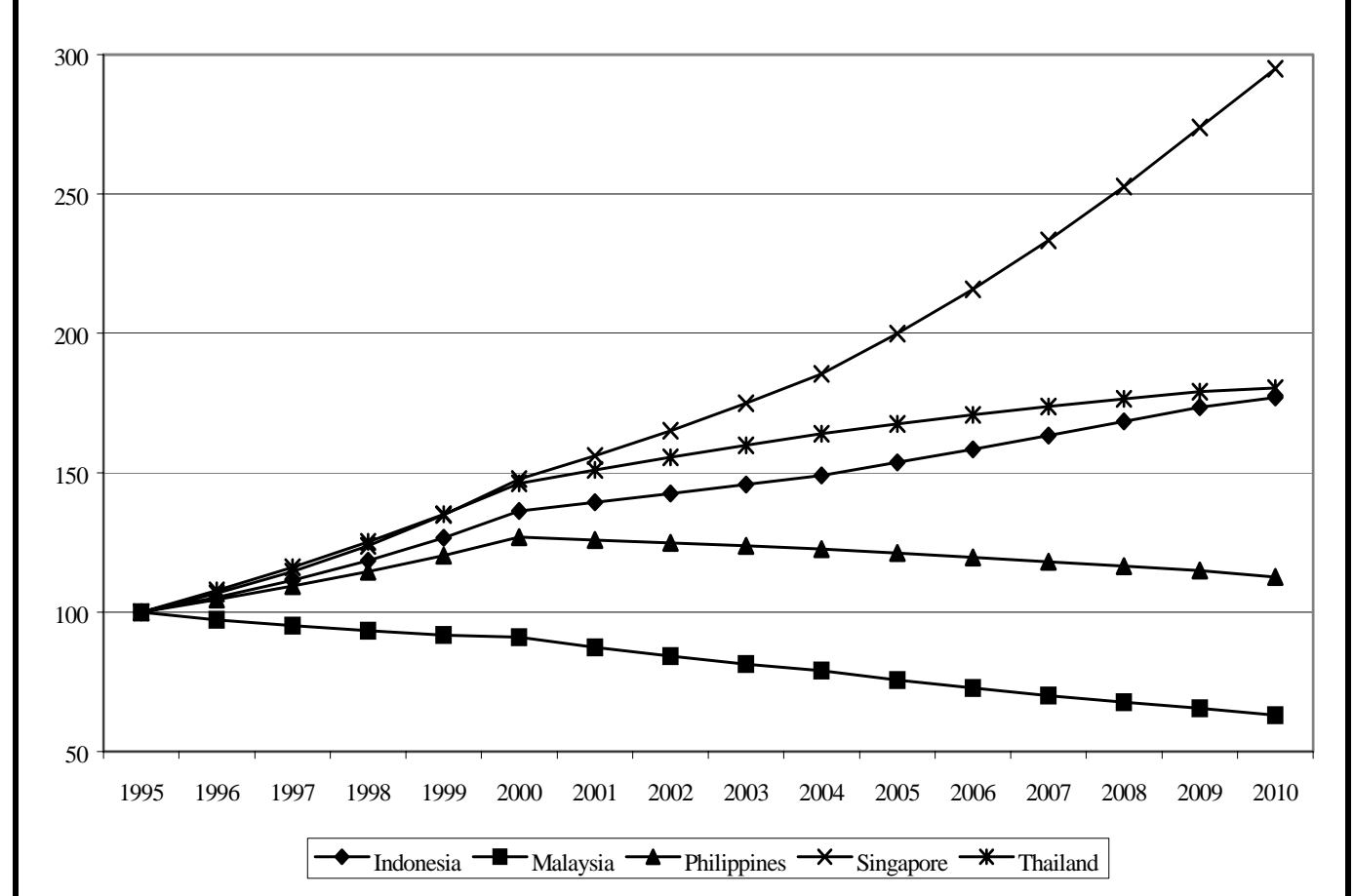

Source: Model Simulation.

Figure 5.22 The Development of Beverages and Tobacco Export (1995=100)

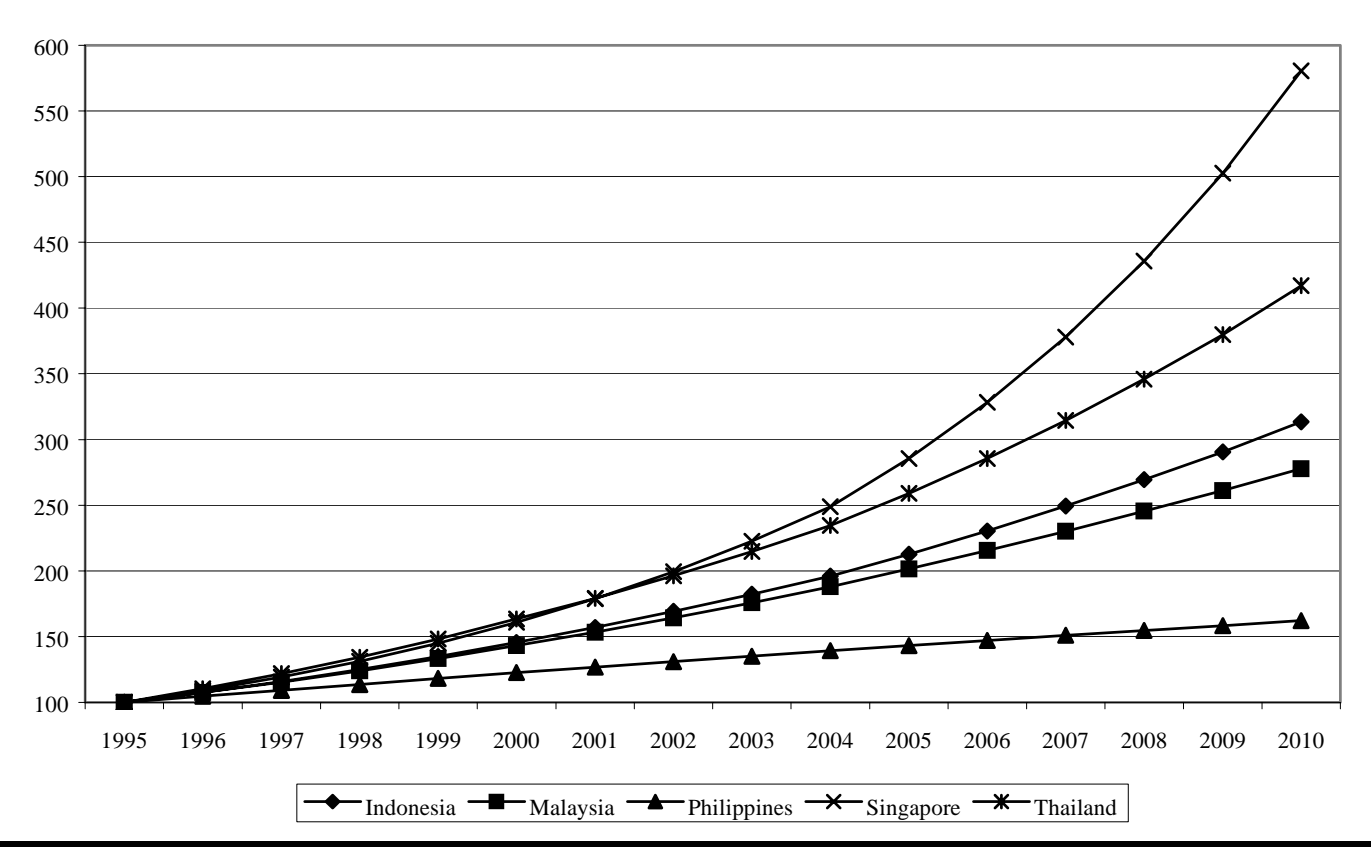

Source: Model Simulation. 
Figure 5.23 The Development of Rice Import (1995=100)

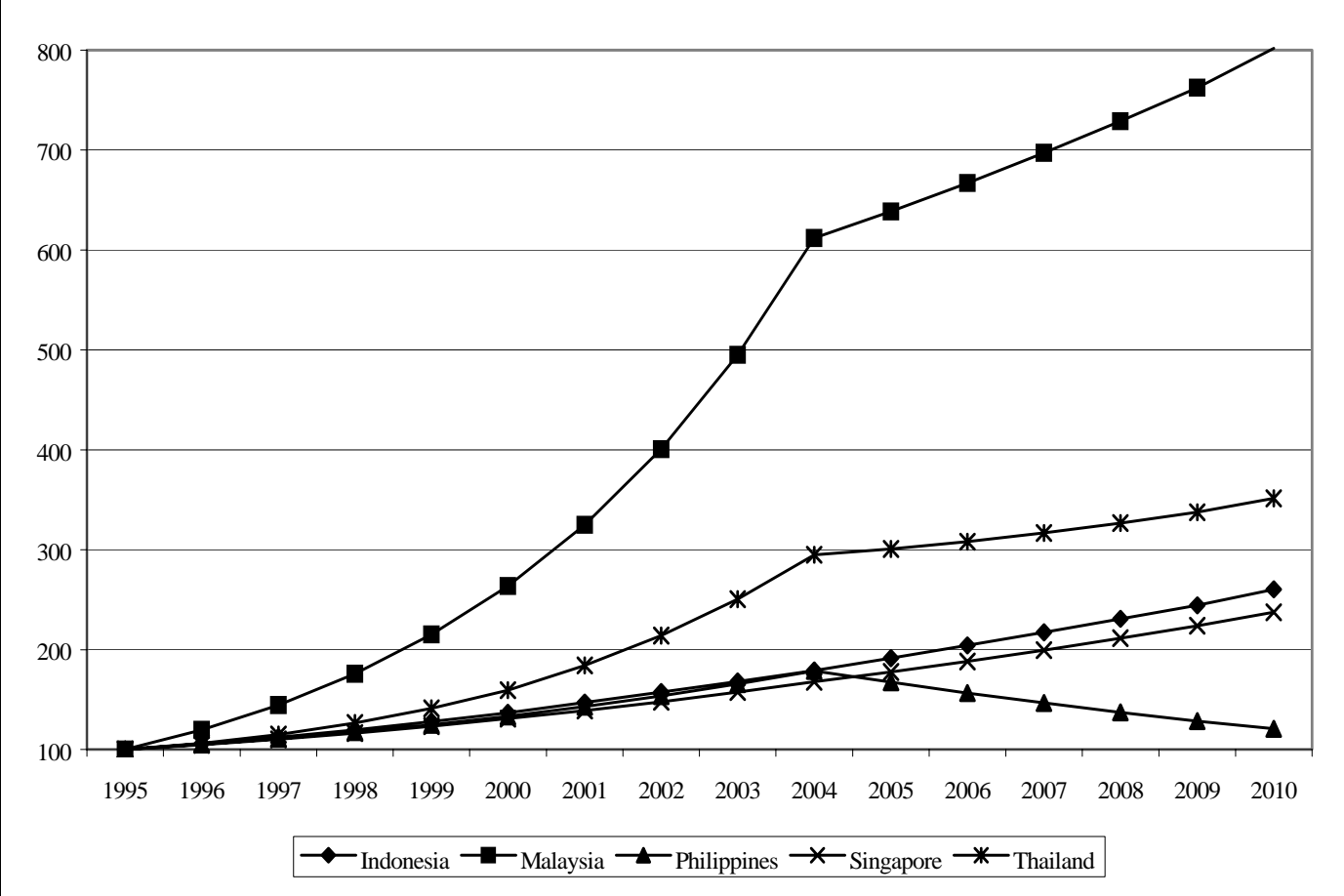

Source: Model Simulation.

Figure 5.24 The Development of Cereal Import (1995=100)

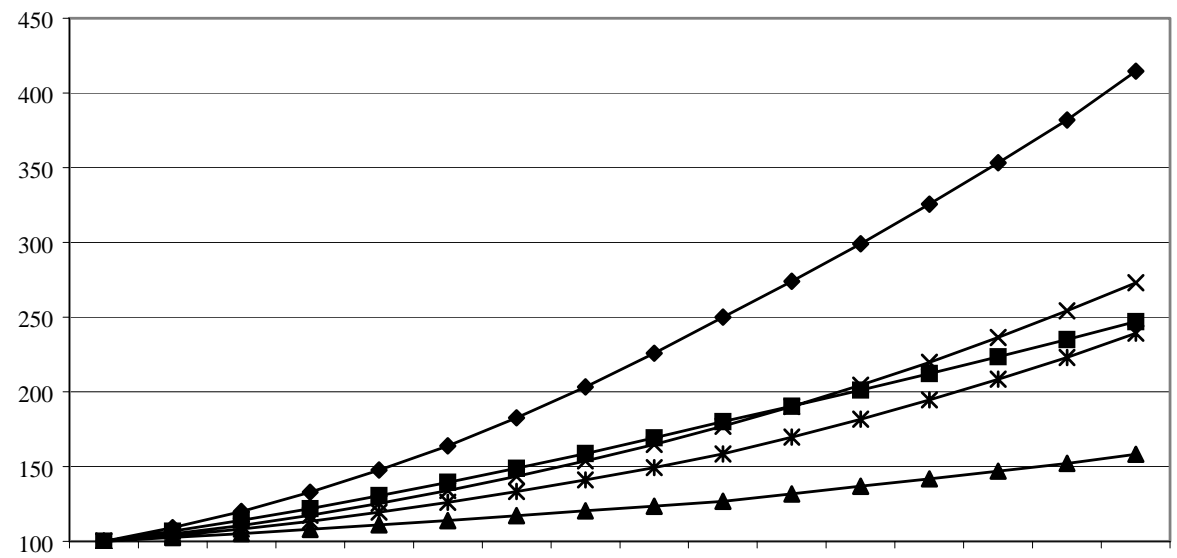

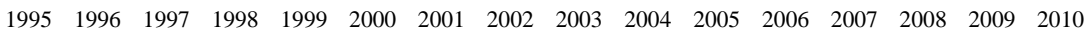

$\multimap$ Indonesia $\rightarrow$ Malaysia $\longrightarrow$ Philippines $\rightarrow$ Singapore $\rightarrow$ Thailand

Source: Model Simulation. 
Figure 5.25 The Development of Oil Seeds Import (1995=100)

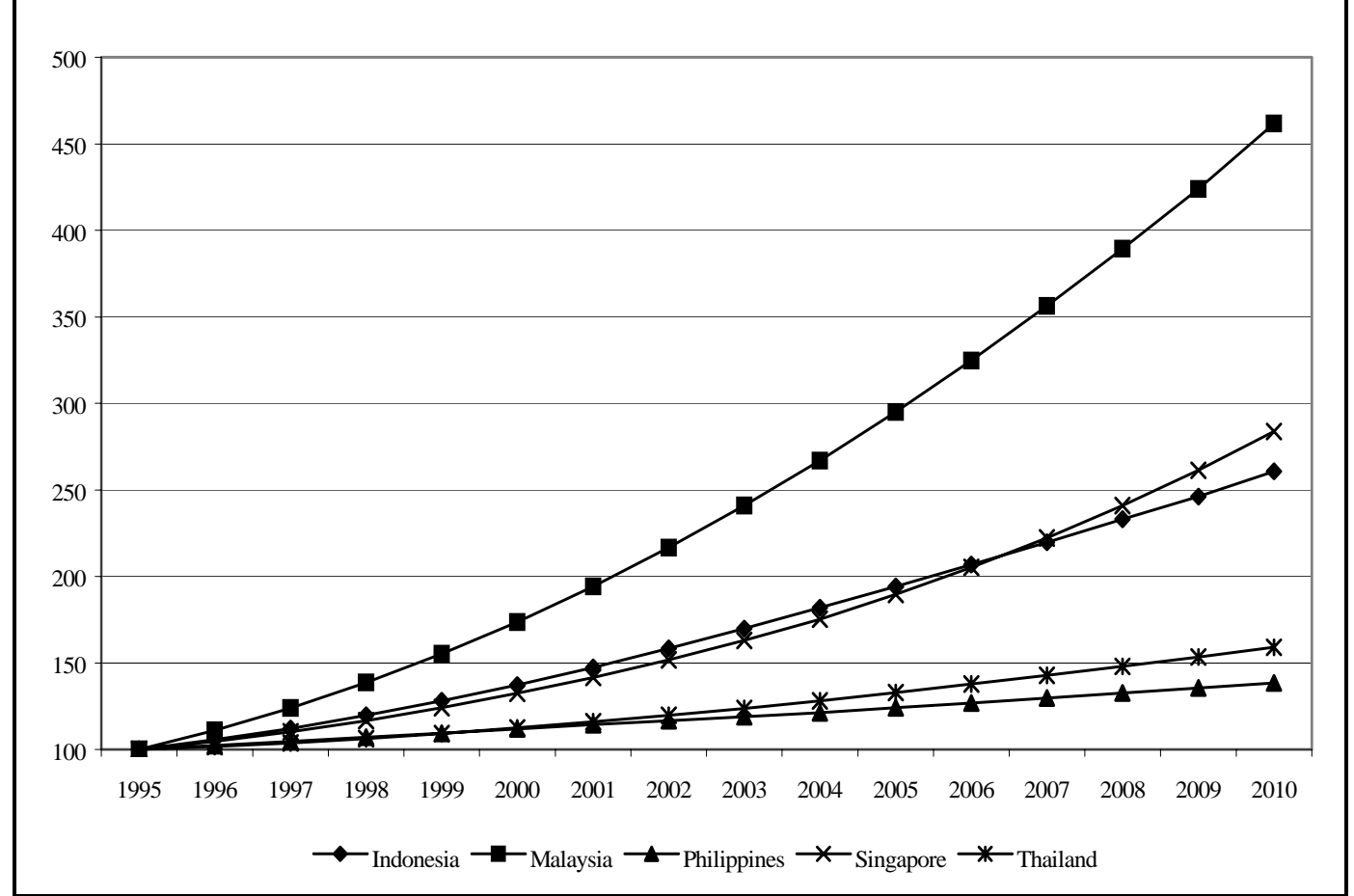

Source: Model Simulation.

Figure 5.26 The Development of Other Crop Import (1995=100)

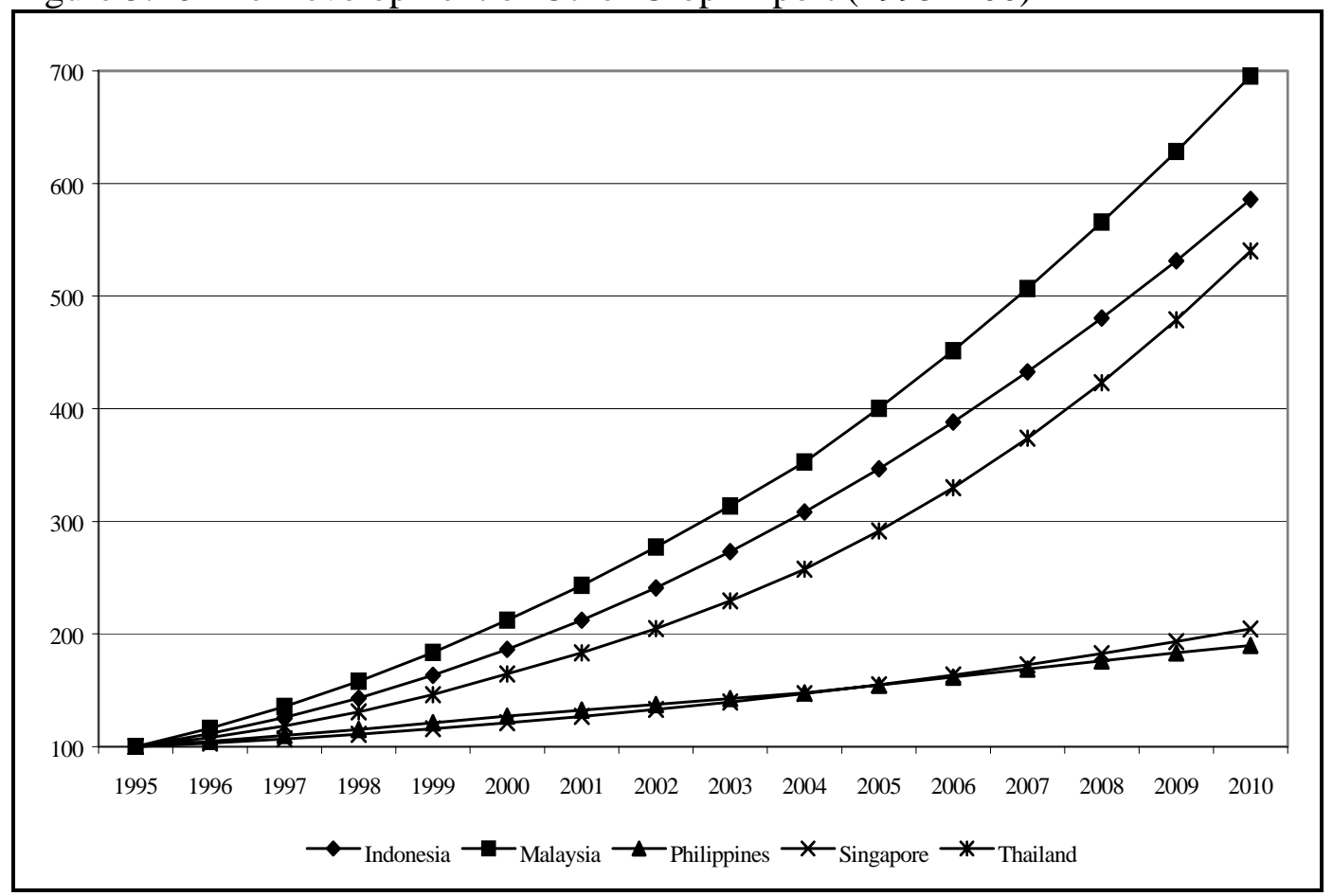

Source: Model Simulation. 
Figure 5.27 The Development of Livestock Import (1995=100)

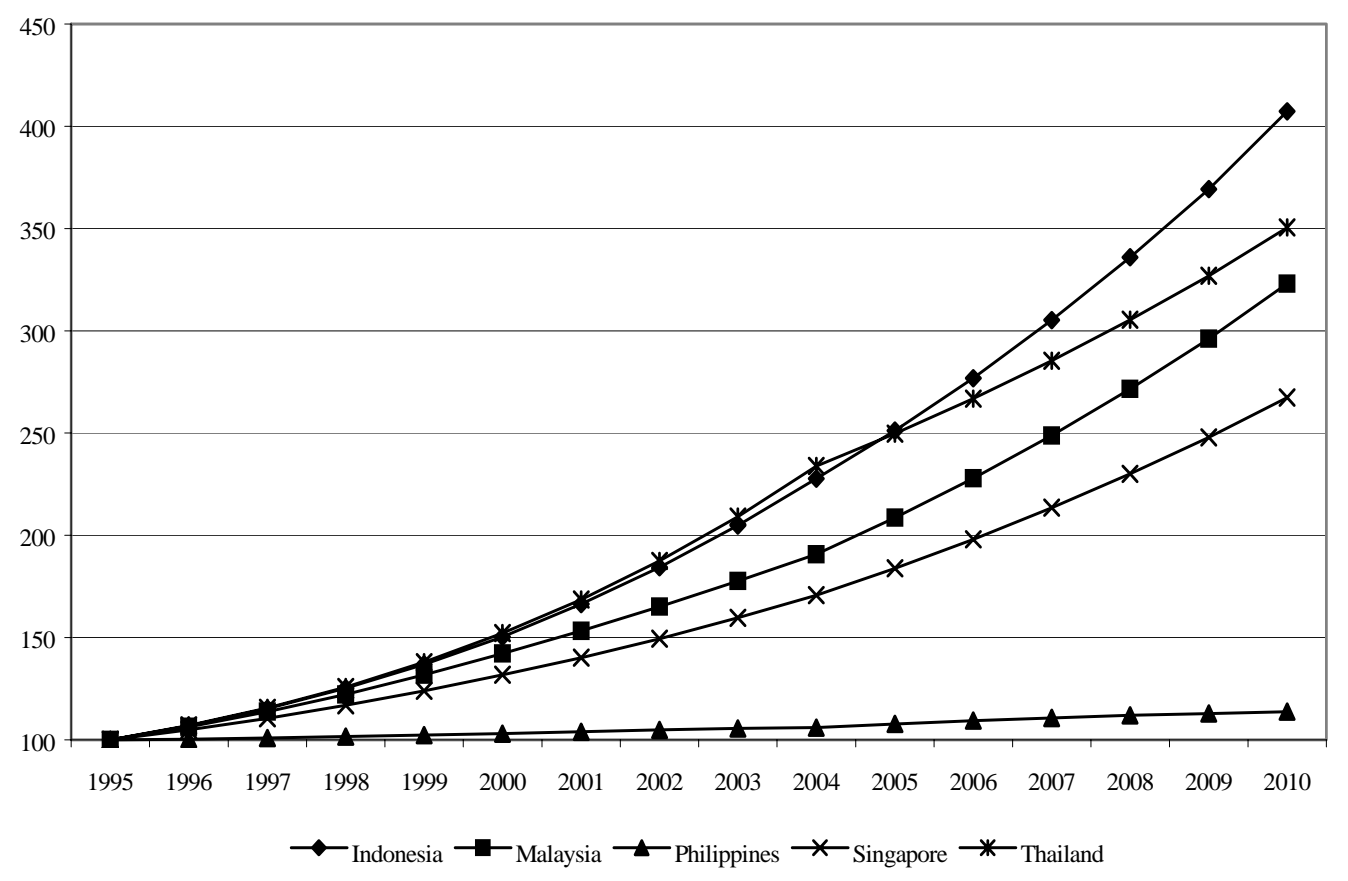

Source: Model Simulation.

Figure 5.28 The Development of Processed Other Crops Import (1995=100)

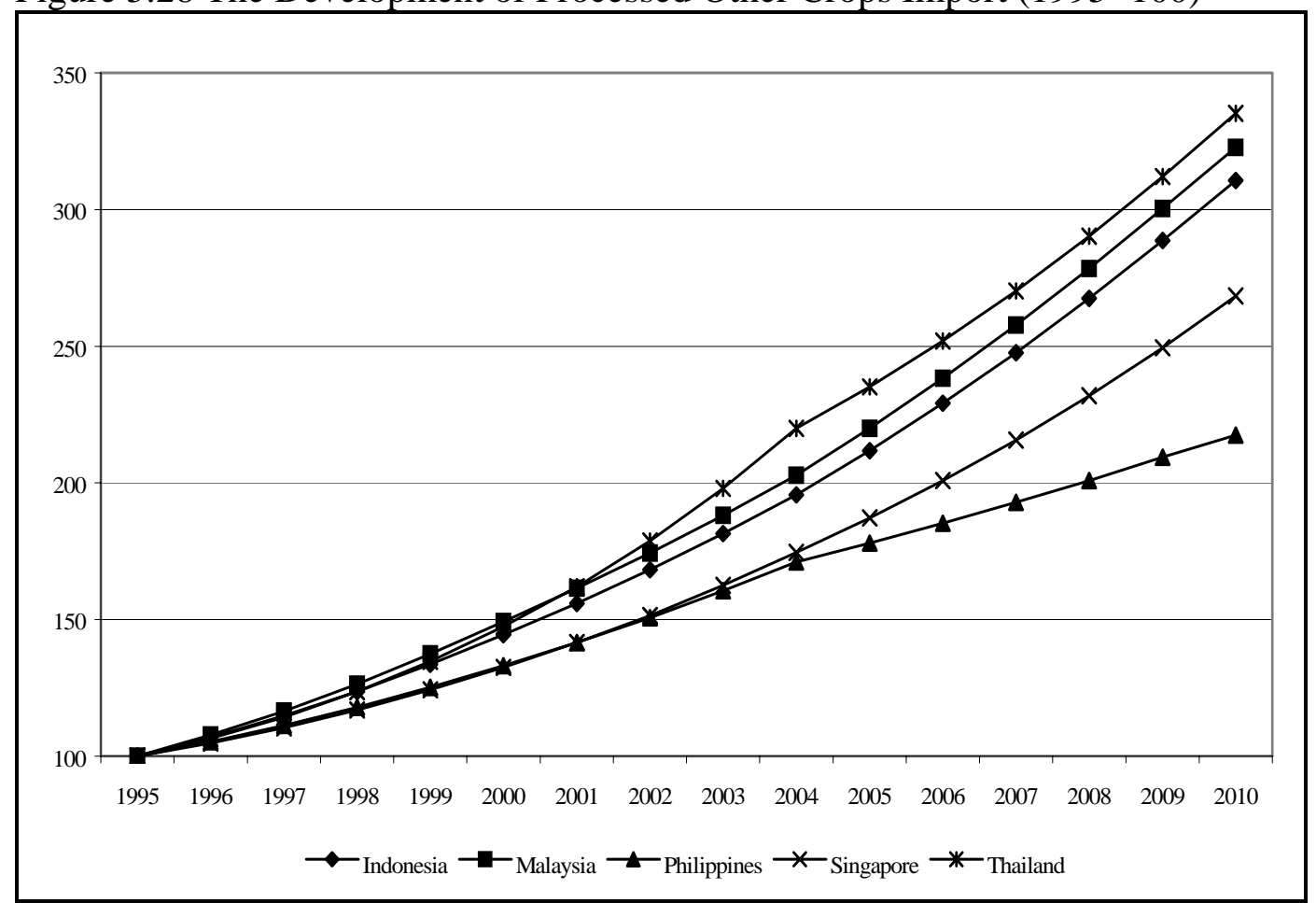

Source: Model Simulation. 
Figure 5.29 The Development of Processed Meat Import (1995=100)

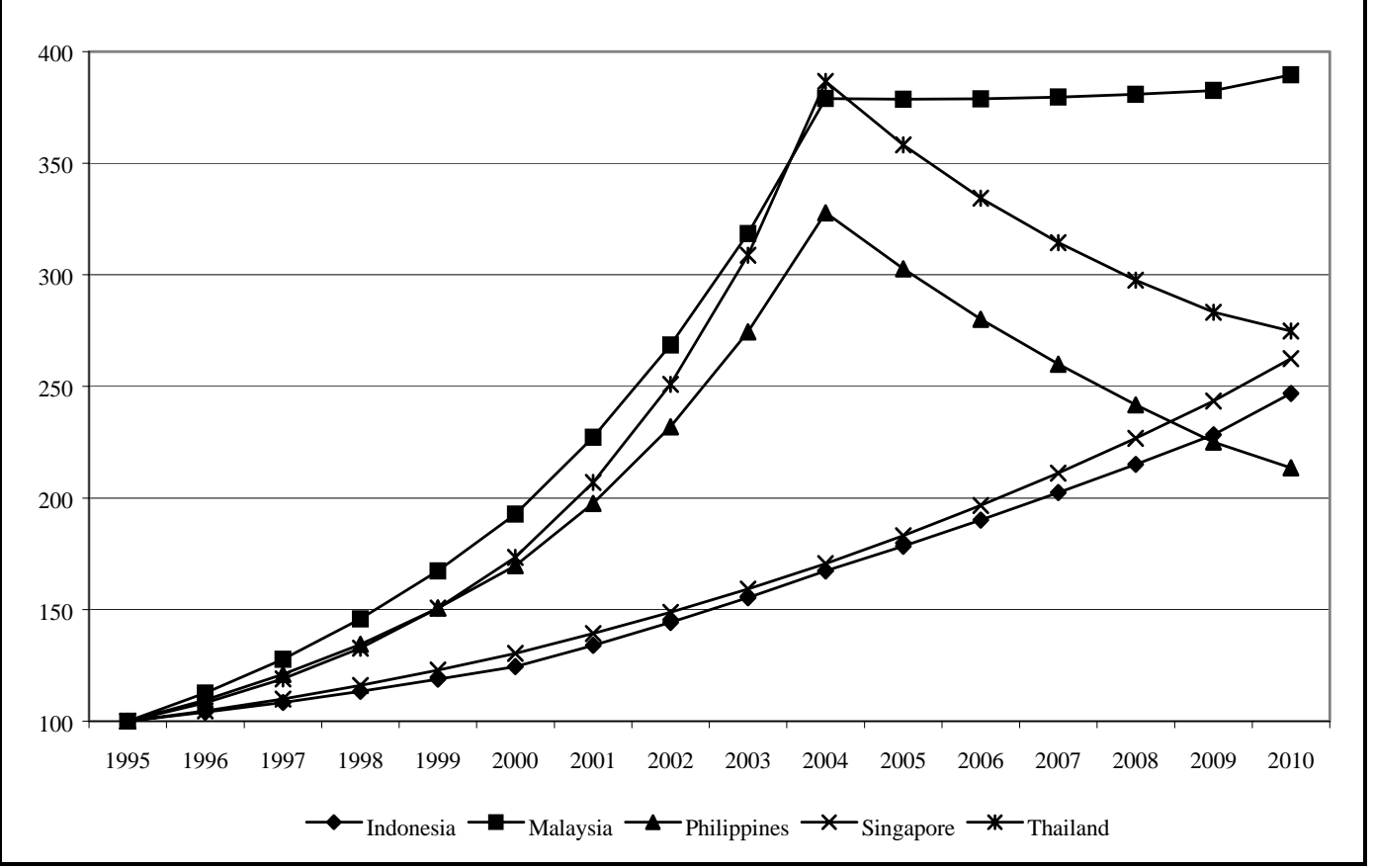

Source: Model Simulation.

Figure 5.30 The Development of Processed Milk Import (1995=100)

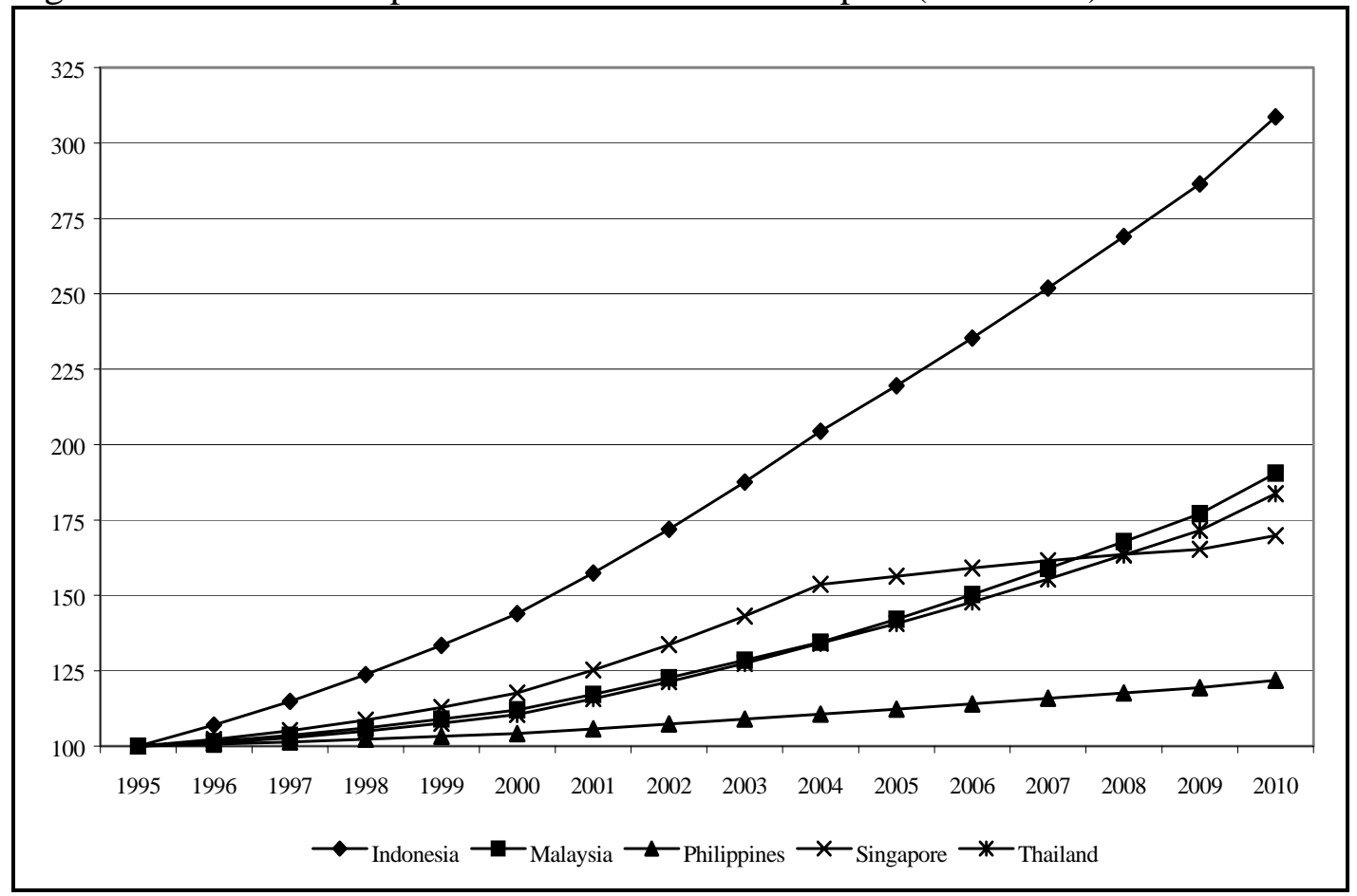

Source: Model Simulation. 
Figure 5.31 The Development of Vegetable Oil Import (1995=100)

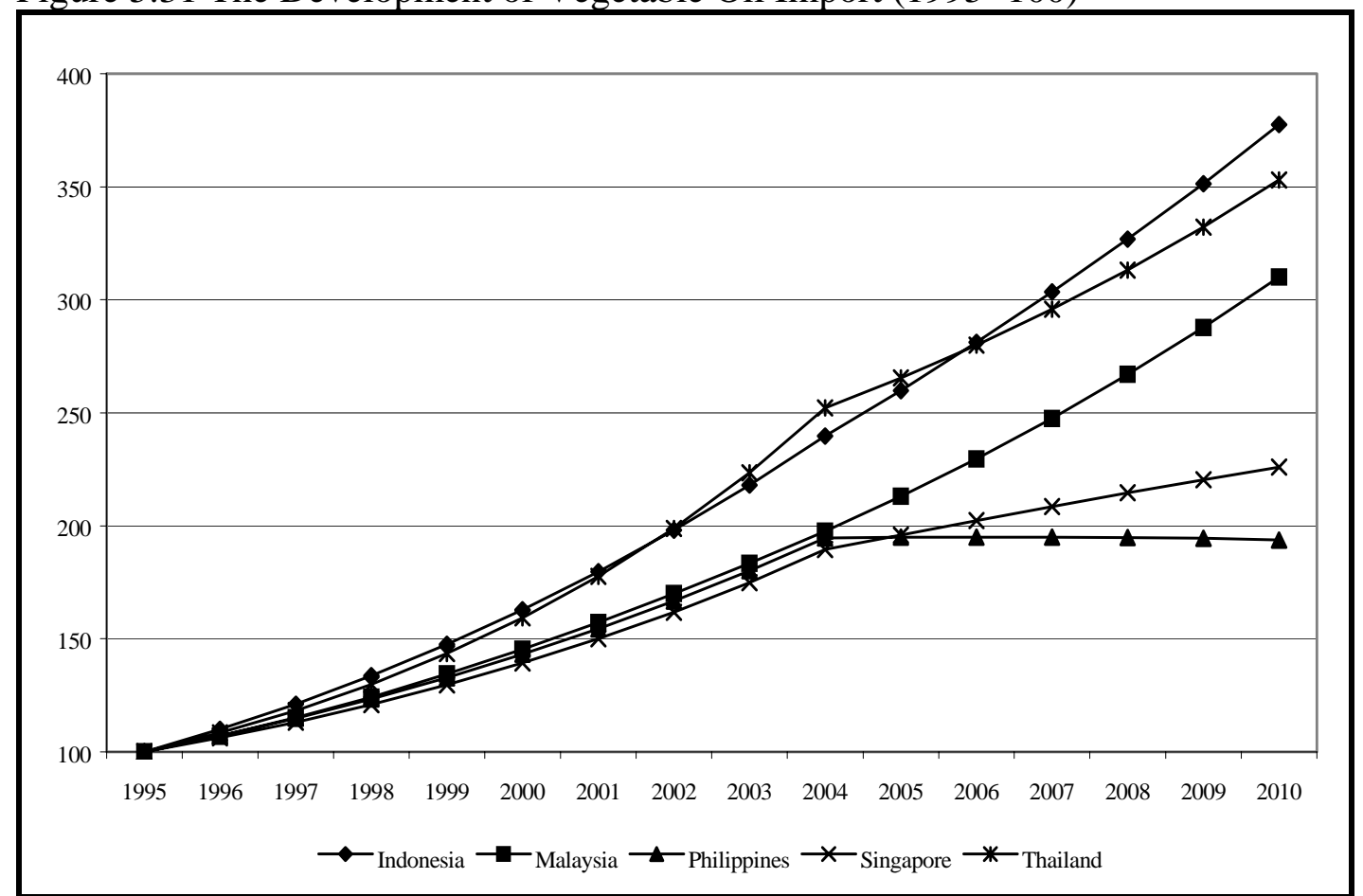

Source: Model Simulation.

Figure 5.32 The Development of Sugar Import (1995=100)

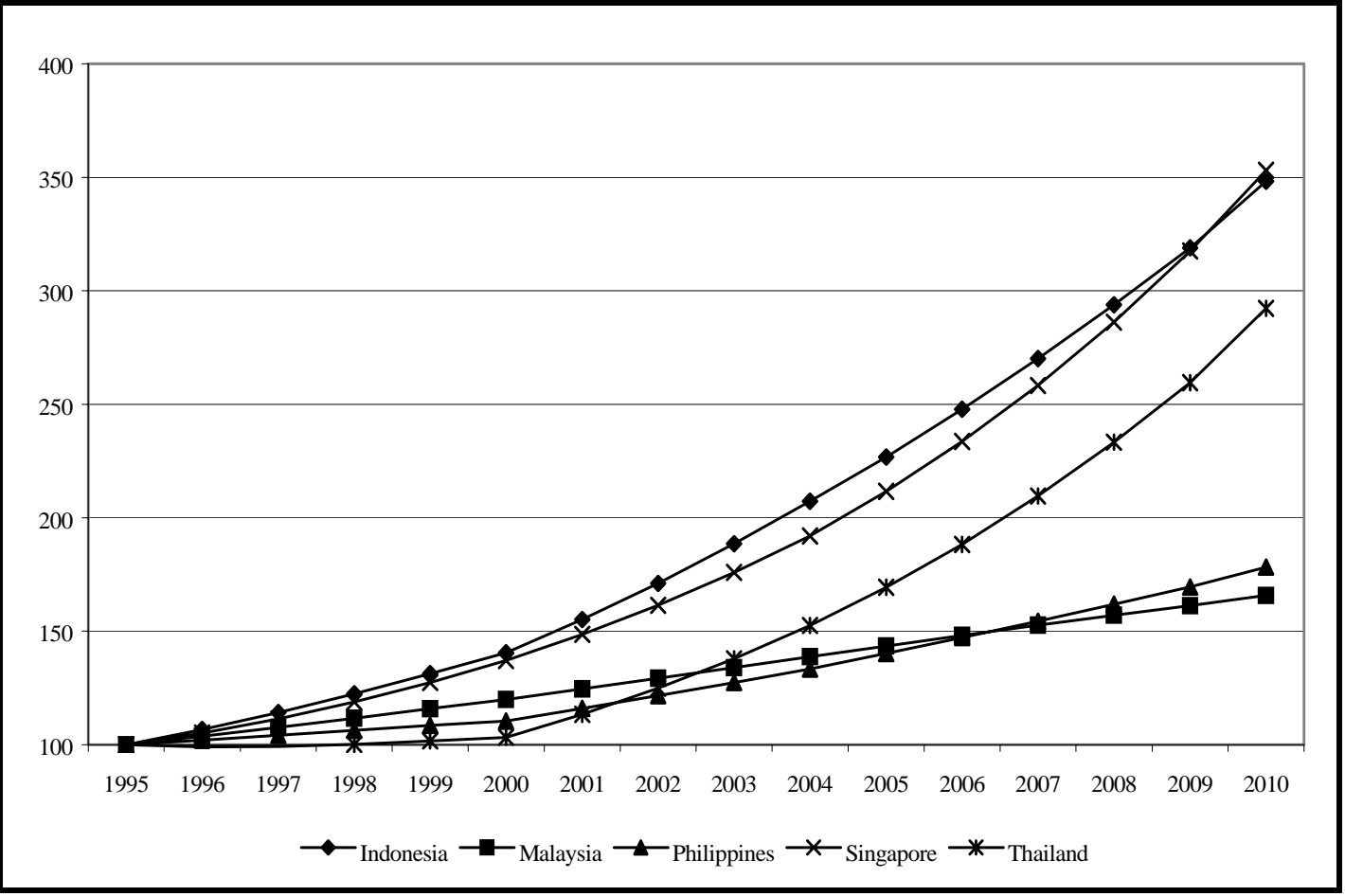

Source: Model Simulation. 
Figure 5.33 The Development of Beverages and Tobacco Import (1995=100)

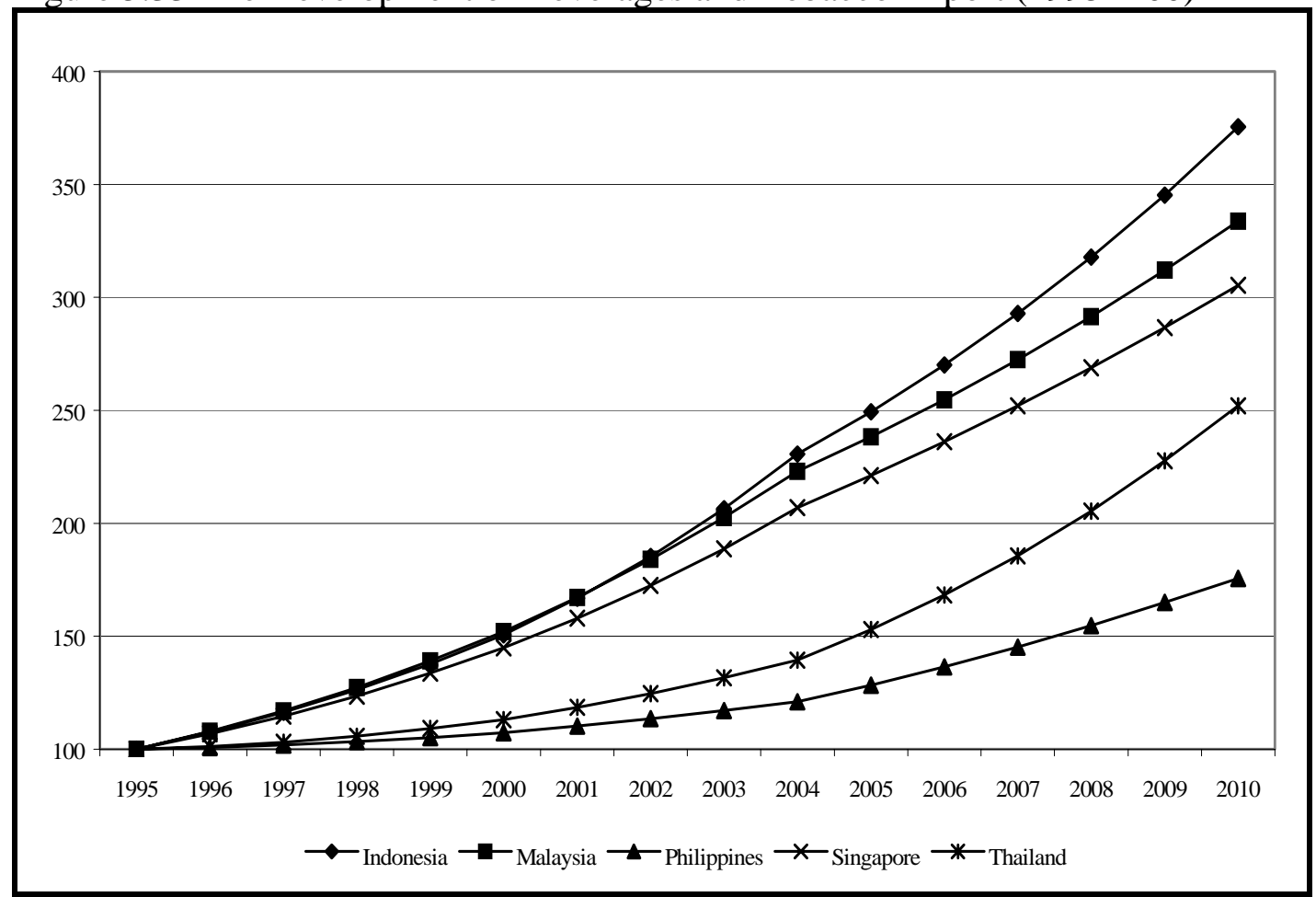

Source: Model Simulation.

Figure 5.34 The Development of Land Rent (1995=100)

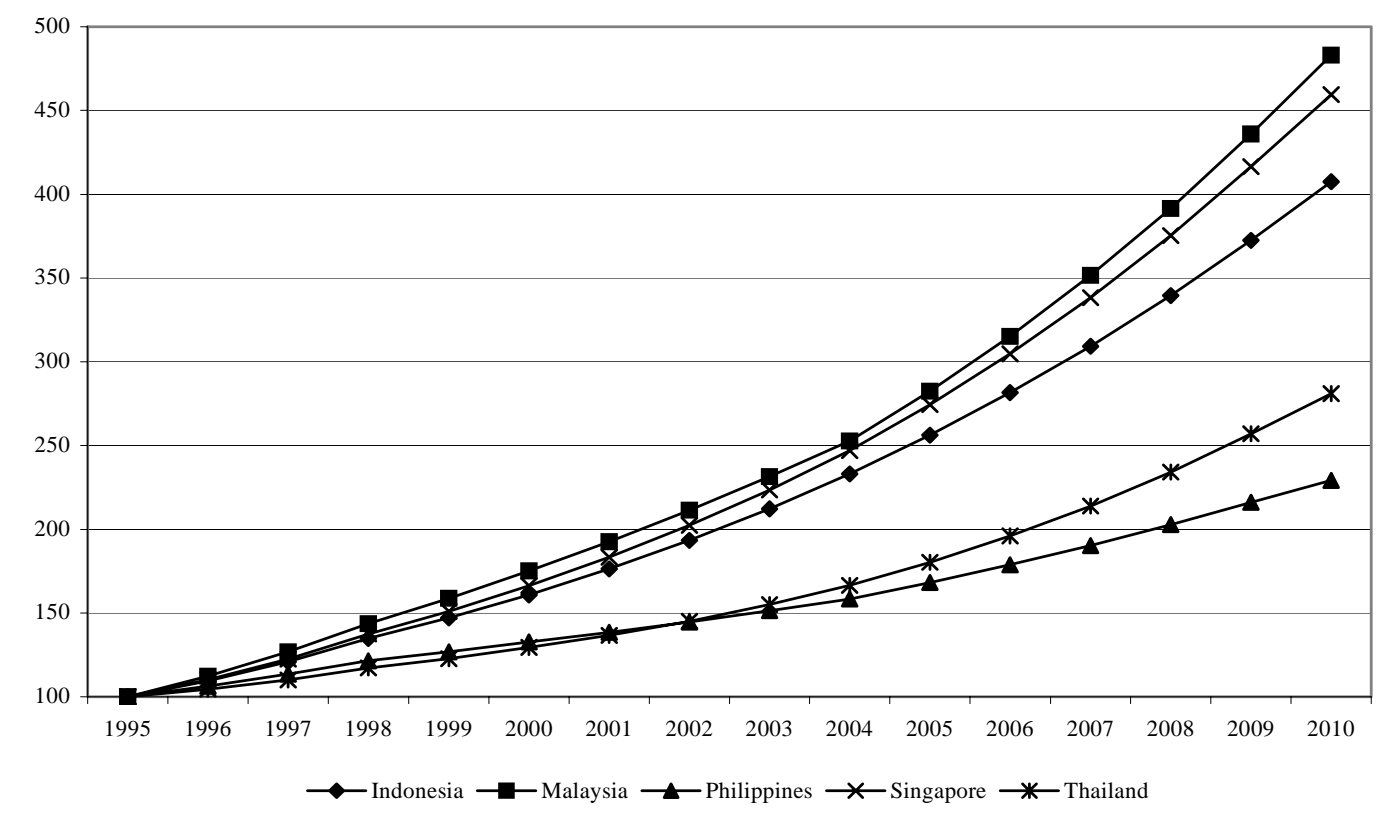

Source: Model Simulation 
Figure 5.35 The Development of Capital Rent (1995=100)

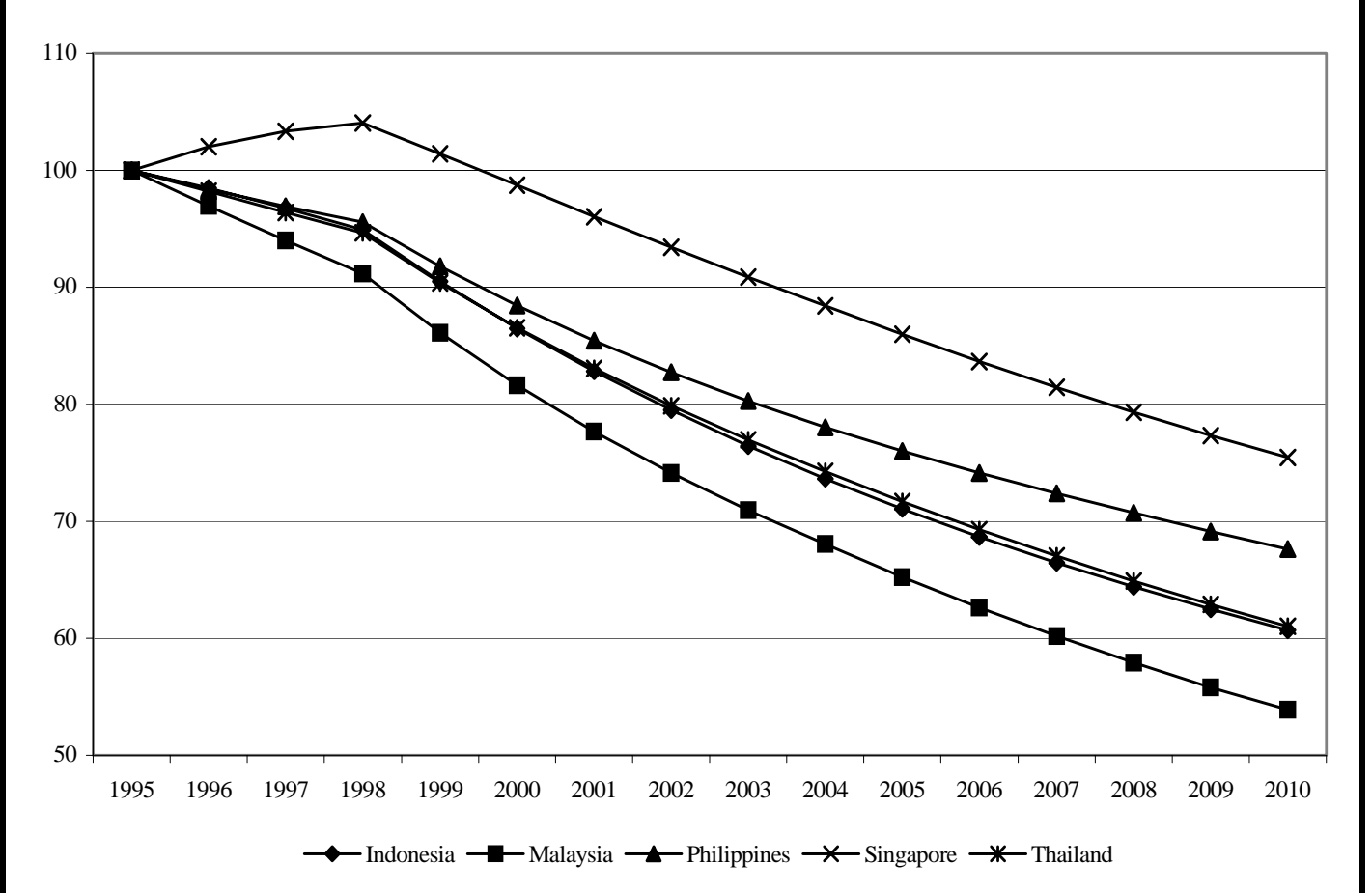

Source: Model Simulation 